\author{
UNIVERSIDADE DE SÃO PAULO \\ ESCOLA DE ENGENHARIA DE SÃO CARLOS \\ DEPARTAMENTO DE GEOTECNIA
}

\title{
ESTACAS DE COMPACTAÇÃO PARA MELHORIA DE SOLO
}

Dissertação de Mestrado apresentada à Escola de Engenharia de São Carlos da Universidade de São Paulo, como requisito para a obtenção do título de Mestre em Geotecnia

\section{AUTOR: WILSON CARTAXO SOARES}

ORIENTADOR: PROF. DR. JOSÉ CARLOS ÂNGELO CINTRA

São Carlos (SP), Novembro de 2002 
Candidato: Engenheiro WILSON CARTAXO SOARES

Dissertação defendida e julgada em 18-12-2002 perante a Comissão Julgadora:

Prof. Tit. JOSÉ CARLOS ÂNGELO CINTRA (Orientador)

(Escola de Engenharia de São Carlos/USP)

Prof. Dr. NELSON AOKI

(Escola de Engenharia de São Carlos/USP)

Prof. Dr. RAIMUNDO LEIDIMAR BEZERRA

(Universidade Federal da Paraíba/UFPB)

Prof. Assoc. LÁZARO VALENTIN ZUQUETTE

Coordenador do Programa de Pós-Graduação em Geotecnia

Profa. Assoc. MARIA DO CARMO CALIJURI

Presidente da Comissão de Pós-Graduação 
DEDICATÓRIA

Aos Meus Pais, Valdês e Vânia

e Meus Irmãos, Waldez e Wanessa 


\section{AGRADECIMENTOS}

A Deus que me fez errar para poder aprender.

A meu pai, meu primeiro professor, e minha mãe, meu porto seguro.

A meus irmãos e a toda minha família pelo apoio em todos os momentos difíceis.

Ao Prof. José Carlos A. Cintra, pela orientação deste trabalho e pela confiança e amizade.

Ao Prof. Nelson Aoki, pelos ensinamentos e orientações acadêmicas e profissionais.

A todos os amigos, colegas, professores e funcionários do Depto. de Geotecnia pelo apoio e companheirismo.

Aos funcionários da Concresolo \& Copesolo pela ajuda e amizade.

A CAPES pela bolsa de estudos.

A todos que de alguma forma contribuíram para a realização deste trabalho. 


\section{SUMÁRIO}

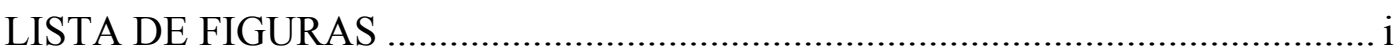

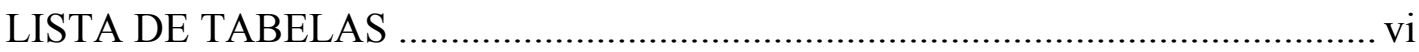

LISTA DE ABREVIATURAS E SIGLAS …........................................................ vii

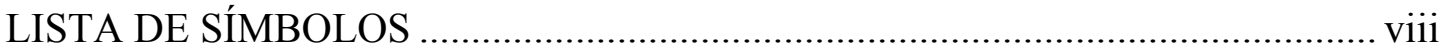

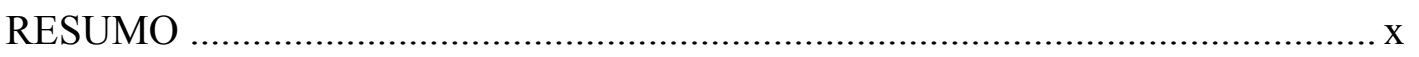

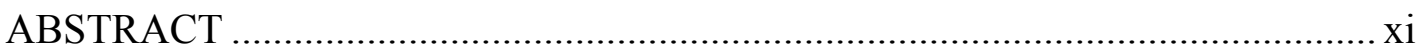

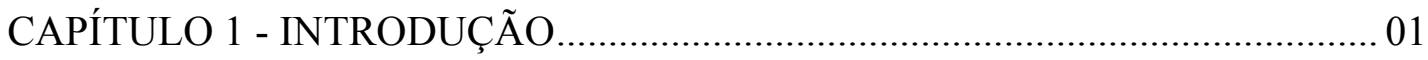

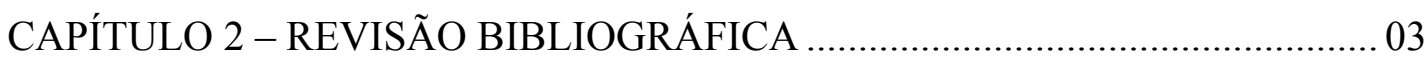

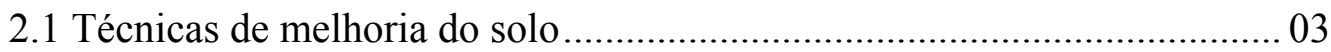

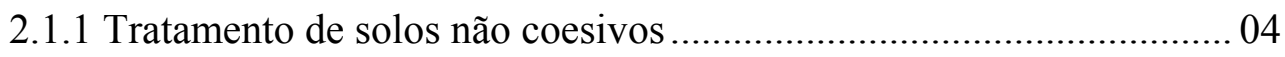

2.1.2 Tratamento de solos coesivos....................................................... 05

2.2 Melhoria do solo com estacas de compactação ........................................ 07

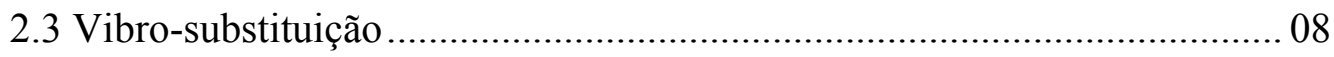

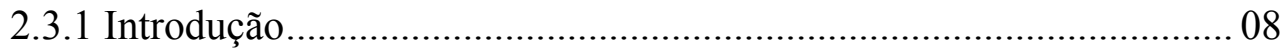

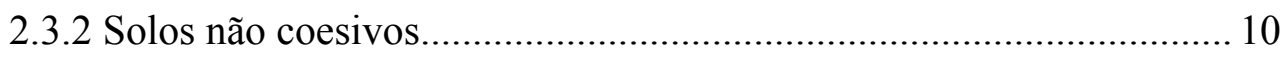

2.3.3 Solos coesivos ......................................................................... 12

2.3.4 Aspectos de projeto ................................................................ 14

2.3.5 Fatores influentes na densificação do solo ........................................ 20

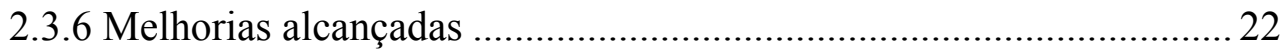

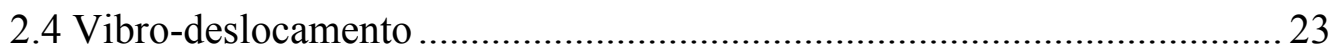

2.4.1 Generalidades ........................................................................... 23

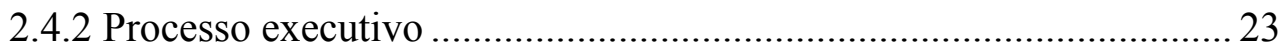


2.4.3 Equipamento

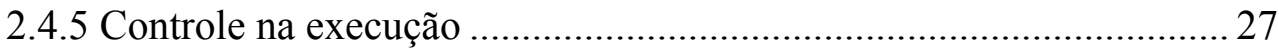

2.4.6 Solo adequado à melhoria _........................................................... 28

2.4.7 Estacas de compactação do solo em profundidade ........................... 29

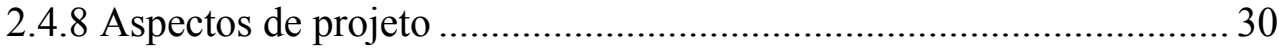

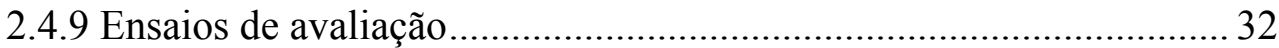

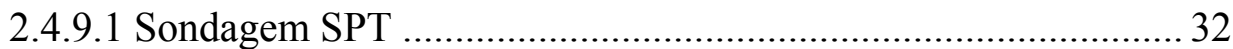

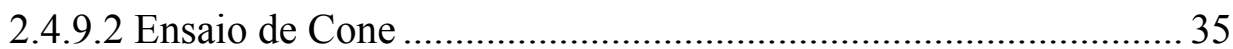

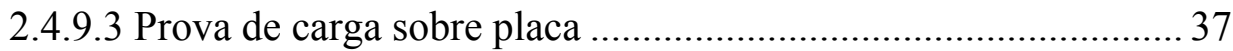

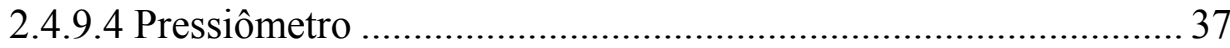

2.4.9.5 Ensaios de laboratório em amostras indeformadas.....................37

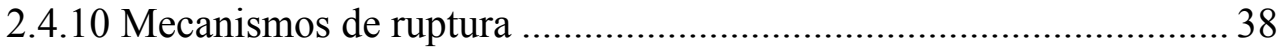

CAPÍTULO 3 - CAMPO EXPERIMENTAL DE FUNDAÇÕES ............................ 39

3.1 Caracterização geológica ....................................................................... 40

3.2 Caracterização geotécnica..................................................................... 42

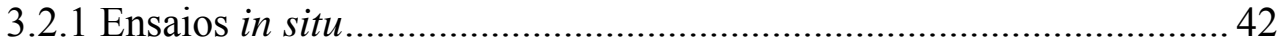

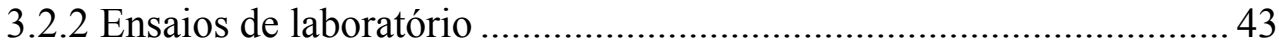

CAPÍTULO 4 - MATERIAIS E EQUIPAMENTOS ............................................ 45

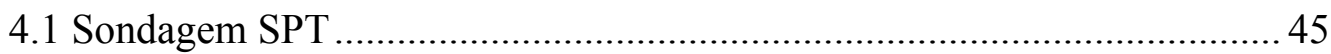

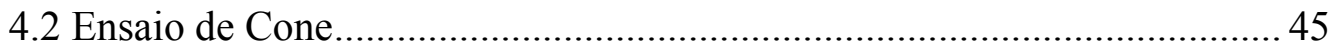

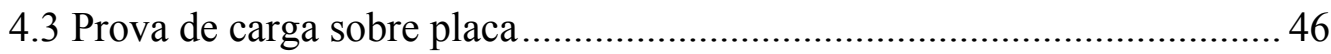

CAPÍTULO 5 - MÉTODOS E PROCEDIMENTOS ............................................. 51

5.1 Instalação das estacas de compactação .................................................... 51

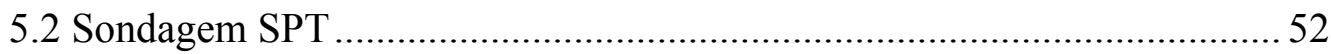

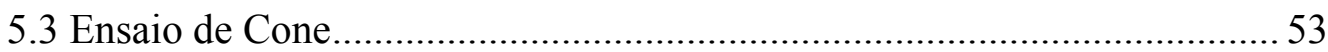


5.4 Prova de carga sobre placa.................................................................. 53

CAPÍTULO 6 - RESULTADOS OBTIDOS .......................................................... 54

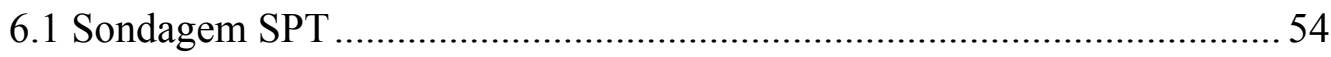

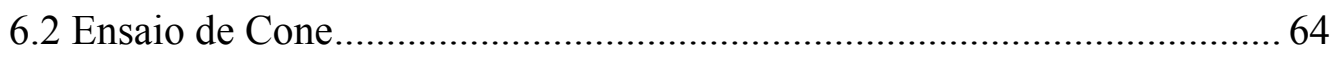

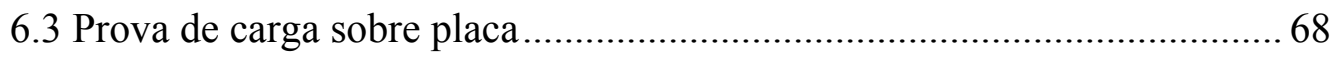

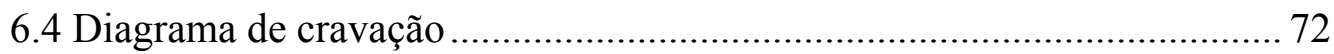

CAPÍTULO 7 - ANÁLISE DOS RESULTADOS ................................................. 74

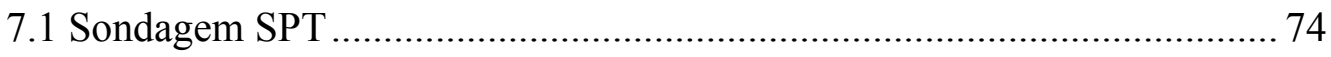

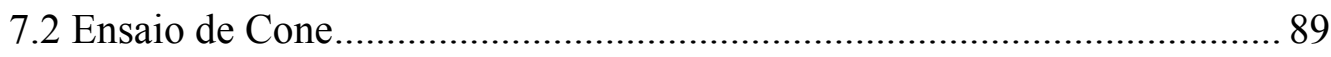

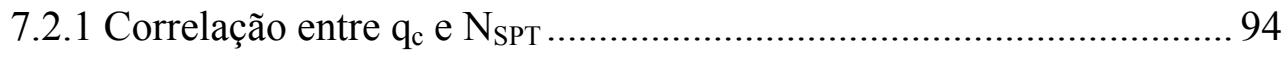

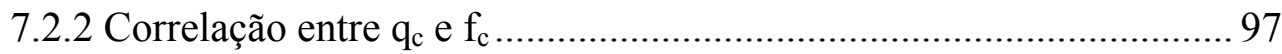

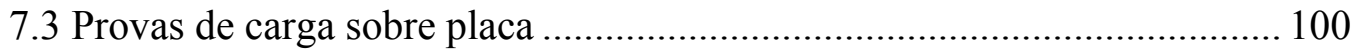

7.4 Diagrama de cravação das estacas ......................................................... 102

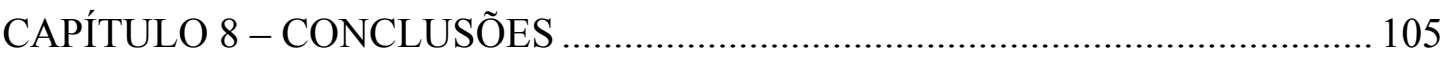

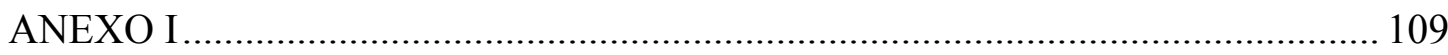

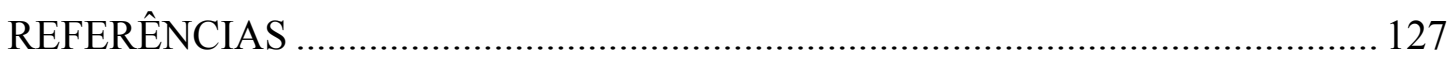

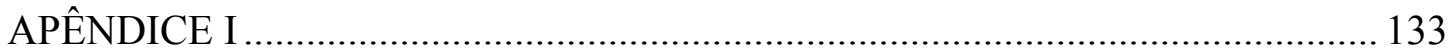




\section{LISTA DE FIGURAS}

FIGURA 01 - Técnicas de melhoria em função da granulometria

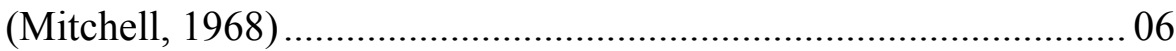

FIGURA 02 - Vibro-substituição (Atkinson, 1993) ................................................ 09

FIGURA 03 - Vibrador e seus componentes (Moseley \& Priebe, 1993) ................. 10

FIGURA 04 - Método de execução da estaca de areia compactada

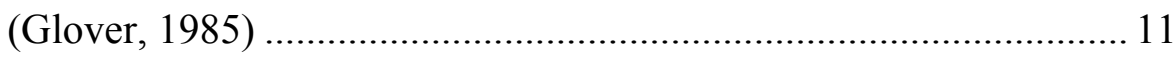

FIGURA 05 - Vibro-substituição em solos coesivos (Glover, 1985)....................... 13

FIGURA 06 - Fator de capacidade de carga Nc (Madhav \& Vitkar, 1978) .............. 16

FIGURA 07 - Fator de capacidade de carga Nq (Madhav \& Vitkar, 1978) ............. 17

FIGURA 08 - Fator de capacidade de carga N $\gamma$ (Madhav \& Vitkar, 1978) ............. 17

FIGURA 09 - Parâmetros A e B (Madhav \& Vitkar, 1978) ..................................... 18

FIGURA 10 - Distribuição da tensão vertical abaixo de uma sapata

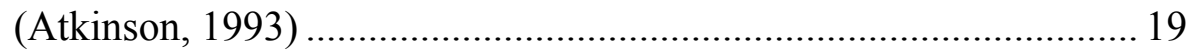

FIGURA 11 - Granulometria do solo adequado à melhoria (Glover, 1985) ............ 20

FIGURA 12 - Processo executivo das estacas de areia (Gusmão Filho, 1998) ........ 24

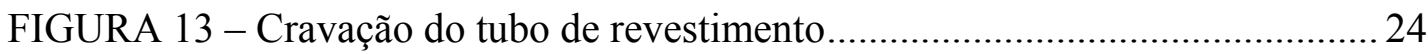

FIGURA 14 - Preparação da mistura de areia e cimento.......................................... 25

FIGURA 15 - Colocação do material dentro do tubo .............................................. 25

FIGURA 16 - Faixa de ocorrência em que a técnica é mais eficiente (adaptado de Gusmão Filho, 1998) .................................................. 28

FIGURA 17 - Processo executivo das estacas de areia em profundidade

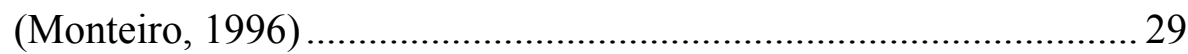

FIGURA 18 - Ábaco para previsão do $\mathrm{N}_{\text {SPT }}$ final (Alves; Lopes; Aragão, 2000) .... 30

FIGURA 19 - Fator de influência na deformação vertical ...................................... 32

FIGURA 20 - Sondagem antes e após tratamento ( Gusmão Filho, 2000b).............. 33

FIGURA 21 - Tensões admissíveis das areias em função do $\mathrm{N}_{\text {SPT }}$ para sapatas quadradas de lado B (Teixeira, 1996) ............................................... 35

FIGURA 22 - Mecanismos de ruptura (Madhav \& Vitkar, 1978)............................ 38

FIGURA 23 - Perfil geológico da cidade de João Pessoa (Gusmão, 1982) .............. 41

FIGURA 24 - Perfil estratigráfico do campo experimental.................................... 42 


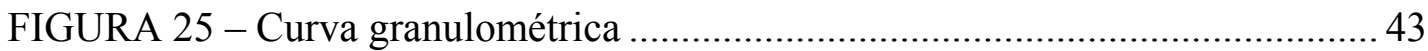

FIGURA 26 - Curva granulométrica do material de aterro das estacas ................... 44

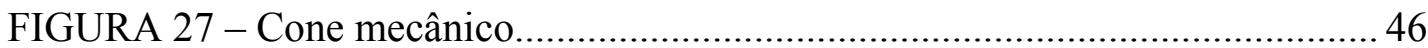

FIGURA 28 - Equipamentos da prova de carga ................................................ 48

FIGURA 29 - Esquema geral das provas de carga realizadas ................................ 49

FIGURA 30 - Vista lateral do ensaio de prova de carga ........................................ 50

FIGURA 31 - Posição dos ensaios numa malha de estacas...................................... 52

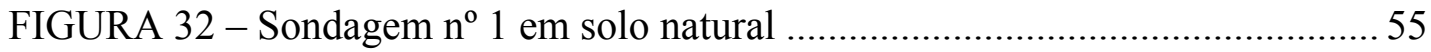

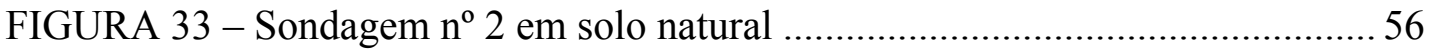

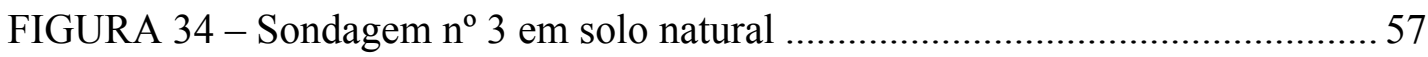

FIGURA 35 - Sondagem $n^{\circ} 4$ em malha de estacas com

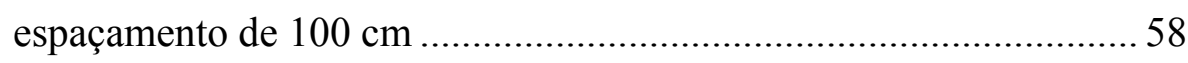

FIGURA 36 - Sondagem $n^{\circ} 5$ em malha de estacas com

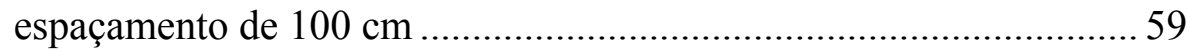

FIGURA 37 - Sondagem $n^{\circ} 6$ em malha de estacas com

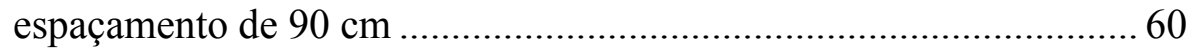

FIGURA 38 - Sondagem $n^{\circ} 7$ em malha de estacas com espaçamento de $90 \mathrm{~cm}$

FIGURA 39 - Sondagem $n^{\circ} 8$ em malha de estacas com espaçamento de $80 \mathrm{~cm}$

FIGURA 40 - Sondagem $n^{\circ} 9$ em malha de estacas com espaçamento de $80 \mathrm{~cm}$ 63

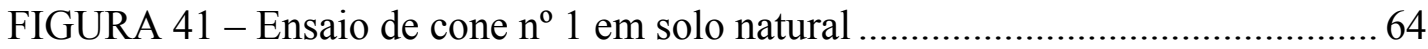

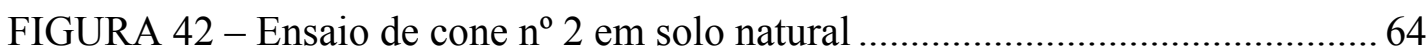

FIGURA 43 - Ensaio de cone $n^{\circ} 3$ em malha de estacas com espaçamento de $100 \mathrm{~cm}$

FIGURA 44 - Ensaio de cone $n^{\circ} 4$ em malha de estacas com espaçamento de $100 \mathrm{~cm}$ 65

FIGURA 45 - Ensaio de cone $n^{\circ} 5$ em malha de estacas com espaçamento de $90 \mathrm{~cm}$ 66

FIGURA 46 - Ensaio de cone $\mathrm{n}^{\circ} 6$ em malha de estacas com espaçamento de $90 \mathrm{~cm}$ 66

FIGURA 47 - Ensaio de cone $n^{\circ} 7$ em malha de estacas com espaçamento de $80 \mathrm{~cm}$ 
FIGURA 48 - Ensaio de cone $n^{\circ} 8$ em malha de estacas com

espaçamento de $80 \mathrm{~cm}$ 67

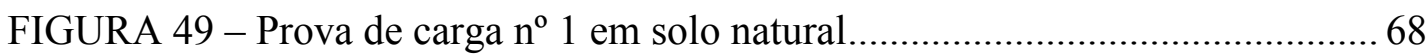

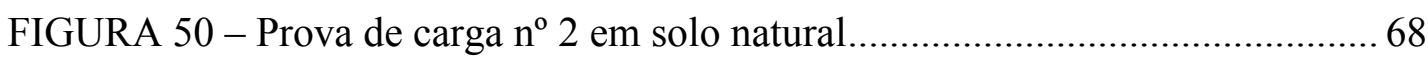

FIGURA 51 - Prova de carga $n^{\circ} 3$ em solo compactado (malha de estacas com

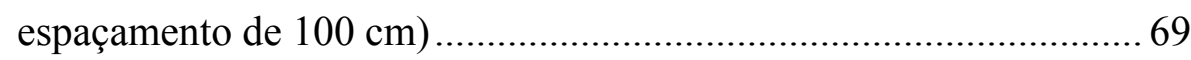

FIGURA 52 - Prova de carga $\mathrm{n}^{\mathrm{o}} 4$ em solo compactado (malha de estacas com espaçamento de $100 \mathrm{~cm}$ )

FIGURA 53 - Prova de carga ${ }^{\circ} 5$ em solo compactado (malha de estacas com espaçamento de $90 \mathrm{~cm}$ )

FIGURA 54 - Prova de carga ${ }^{\circ} 6$ em solo compactado (malha de estacas com espaçamento de $90 \mathrm{~cm})$

FIGURA 55 - Prova de carga $n^{\circ} 7$ em solo compactado (malha de estacas com espaçamento de $80 \mathrm{~cm}$ )

FIGURA 56 - Prova de carga $\mathrm{n}^{\circ} 8$ em solo compactado (malha de estacas com espaçamento de $80 \mathrm{~cm}$ ) 71

FIGURA 57 - Diagrama de cravação (malha de $100 \mathrm{~cm}$ ) ....................................... 72

FIGURA 58 - Diagrama de cravação (malha de $90 \mathrm{~cm}$ ) ......................................... 73

FIGURA 59 - Diagrama de cravação (malha de $80 \mathrm{~cm}$ ) ........................................ 73

FIGURA 60 - Sondagem com $\mathrm{N}_{\mathrm{SPT}}$ médios para o solo natural e compactado........ 75

FIGURA 61 - Gráfico teórico tensão admissível x $\mathrm{N}_{\mathrm{SPT}}$ natural para sapatas quadradas de lado $\mathrm{B}=1 \mathrm{~m}$ 78

FIGURA 62 - Gráfico experimental tensão admissível x $\mathrm{N}_{\text {SPT }}$ natural para sapatas quadradas de lado $\mathrm{B}=1 \mathrm{~m}$ 78

FIGURA 63 - Gráfico teórico tensão admissível x $\mathrm{N}_{\mathrm{SPT}}$ natural

para sapatas quadradas de lado $\mathrm{B}=1,5 \mathrm{~m}$

FIGURA 64 - Gráfico experimental tensão admissível x $\mathrm{N}_{\text {SPT }}$ natural para sapatas quadradas de lado $\mathrm{B}=1,5 \mathrm{~m}$

FIGURA 65 - Gráfico teórico tensão admissível x $\mathrm{N}_{\mathrm{SPT}}$ natural para sapatas quadradas de lado $\mathrm{B}=2 \mathrm{~m}$

FIGURA 66 - Gráfico experimental tensão admissível x $\mathrm{N}_{\mathrm{SPT}}$ natural para sapatas quadradas de lado $B=2 \mathrm{~m}$

FIGURA 67 - Gráfico teórico tensão admissível x N $\mathrm{SPT}_{\mathrm{SP}}$ natural para sapatas quadradas de lado $B=2,5 \mathrm{~m}$ 
FIGURA 68 - Gráfico experimental tensão admissível x N $\mathrm{SPT}_{\mathrm{SP}}$ natural para sapatas quadradas de lado $\mathrm{B}=2,5 \mathrm{~m}$ 81

FIGURA 69 - Gráfico teórico tensão admissível x N $\mathrm{N}_{\mathrm{SPT}}$ natural para sapatas quadradas de lado $\mathrm{B}=3 \mathrm{~m}$

FIGURA 70 - Gráfico experimental tensão admissível x $\mathrm{N}_{\mathrm{SPT}}$ natural

para sapatas quadradas de lado $B=3 \mathrm{~m}$ 82

FIGURA 71 - Gráfico tensão admissível x lado B da sapata .................................. 84

FIGURA 72 - Tensão admissível em solo natural .................................................. 85

FIGURA 73 - Tensão admissível em malha de estacas com espaçamento de $100 \mathrm{~cm}$

FIGURA 74 - Tensão admissível em malha de estacas com espaçamento de $90 \mathrm{~cm}$ 86

FIGURA 75 - Tensão admissível em malha de estacas com espaçamento de $80 \mathrm{~cm}$ 86

FIGURA 76 - Gráfico recalques x lado B da sapata quadrada 87

FIGURA 77 - Redução dos recalques em solo compactado 88

FIGURA 78 - Tensões admissíveis médias em solo natural e compactado 89

FIGURA 79 - Gráfico tensão admissível x lado B da sapata ................................... 90

FIGURA 80 - Tensão admissível em solo natural .................................................. 91

FIGURA 81 - Tensão admissível em malha de estacas com espaçamento de $100 \mathrm{~cm}$ 91

FIGURA 82 - Tensão admissível em malha de estacas com espaçamento de $90 \mathrm{~cm}$ 92

FIGURA 83 - Tensão admissível em malha de estacas com espaçamento de $80 \mathrm{~cm}$. 92

FIGURA 84 - Gráfico $\mathrm{q}_{\mathrm{c}} \mathrm{x} \mathrm{N}_{\mathrm{SPT}}$ para o terreno natural 94

FIGURA 85 - Gráfico $\mathrm{q}_{\mathrm{c}} \times \mathrm{N}_{\mathrm{SPT}}$ para malha de estacas com espaçamento de $100 \mathrm{~cm}$ 94

FIGURA 86 - Gráfico $\mathrm{q}_{\mathrm{c}} \times \mathrm{N}_{\mathrm{SPT}}$ para malha de estacas com espaçamento de $90 \mathrm{~cm}$. 95

FIGURA 87 - Gráfico q $\mathrm{q}_{\mathrm{c}} \mathrm{N}_{\mathrm{SPT}}$ para malha de estacas com espaçamento de $80 \mathrm{~cm}$. 95

FIGURA 88 - Gráfico $\mathrm{f}_{\mathrm{c}} \mathrm{x} \mathrm{q}_{\mathrm{c}}$ para o terreno natural .... 97 
FIGURA 89 - Gráfico $\mathrm{f}_{\mathrm{c}} \mathrm{x} \mathrm{q}_{\mathrm{c}}$ para malha de estacas com espaçamento de $100 \mathrm{~cm}$.

FIGURA 90 - Gráfico $f_{c} \times q_{c}$ para malha de estacas com espaçamento de $90 \mathrm{~cm}$ 98

FIGURA 91 - Gráfico $f_{c} \times q_{c}$ para malha de estacas com espaçamento de $80 \mathrm{~cm}$.............................................................. 98

FIGURA 92 - Gráficos tensão x recalque obtidos nas provas de carga.................... 100

FIGURA 93 - Tensão admissível em função do lado B para solo natural e compactado.

FIGURA 94 - Diagrama de cravação comparativo entre as malhas para a última estaca

FIGURA 95 - Diagrama de cravação comparado à sondagem na malha de $100 \mathrm{~cm}$

FIGURA 96 - Diagrama de cravação comparado à sondagem na malha de $90 \mathrm{~cm}$ 104

FIGURA 97 - Diagrama de cravação comparado à sondagem na malha de $80 \mathrm{~cm}$ 


\section{LISTA DE TABELAS}

TABELA 01 - Frações granulométricas constituintes do solo ................................. 43

TABELA 02 - Frações granulométricas constituintes do material de aterro ............ 44

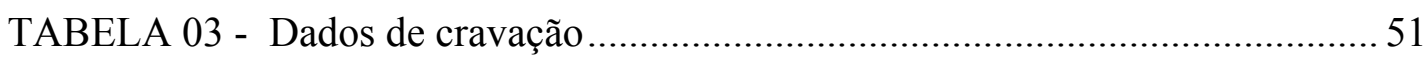

TABELA 04 - Aumento de resistência médio para cada malha de estacas ..............83 83

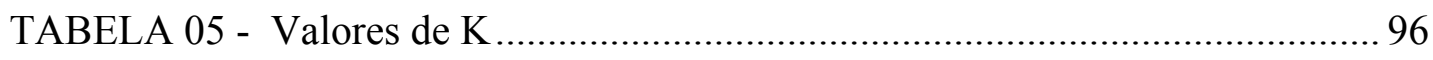

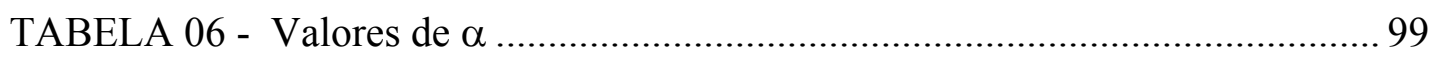

TABELA 07 - Valores equivalentes de recalques para placa de $40 \mathrm{~cm}$................... 101 


\section{LISTA DE ABREVIATURAS E SIGLAS}

ABNT ASSOCIAÇÃO BRASILEIRA DE NORMAS TÉCNICAS

CPT CONE PENETRATION TEST (ENSAIO DE PENETRAÇÃO DO CONE)

QML QUICK MANTEINED LOAD TEST (ENSAIO DO TIPO RÁPIDO)

SML SLOW MANTEINED LOAD TEST (ENSAIO DO TIPO LENTO)

SPT STANDARD PENETRATION TEST 


\section{LISTA DE SÍMBOLOS}

$\alpha \quad$ correlação entre $f_{c}$ e $q_{c}$

$\sigma^{*} \quad$ tensão líquida na fundação

$\sigma_{\mathrm{v}}$ tensão vertical efetiva

$\sigma_{\mathrm{a}}$ tensão admissível da fundação por sapata

$\Delta \mathrm{p} \quad$ tensão atuante na camada

$\sigma_{\mathrm{r}}$ tensão de ruptura ou capacidade de carga

B lado da sapata quadrada

c coesão

$c_{1}$ fator de correção do embutimento da fundação

$c_{2}$ fator de correção do tempo

d diâmetro das estacas

$\mathrm{d}_{\mathrm{h}} \quad$ espessura da camada

$\mathrm{D}_{\mathrm{r}} \quad$ compacidade relativa

$\mathrm{e}_{\text {máx }} \quad$ índice de vazios máximo

$\mathrm{e}_{\min } \quad$ índice de vazios mínimo

$\mathrm{E}_{\mathrm{S}} \quad$ módulo de deformabilidade

$\mathrm{f}_{\mathrm{c}} \quad$ resistência lateral do cone

$\mathrm{I}_{\mathrm{z}} \quad$ fator de influência na deformação

$\mathrm{K}$ correlação entre $\mathrm{q}_{\mathrm{c}}$ e $\mathrm{N}_{\mathrm{SPT}}$

$\mathrm{K}_{\mathrm{p}} \quad$ coeficiente de empuxo passivo

$\mathrm{m}_{\mathrm{v}} \quad$ coeficiente de deformação volumétrica

$\mathrm{N}_{\mathrm{SPT}} \quad$ índice de resistência à penetração

p sobrecarga

$\gamma \quad$ peso específico do solo

$\mathrm{q}_{\mathrm{c}} \quad$ resistência de ponta do cone

Qult tensão vertical última da estaca

$\mathrm{S}_{\mathrm{rl}} \quad$ tensão radial máxima

$\mathrm{S}_{\mathrm{ro}} \quad$ tensão efetiva vertical

$\mathrm{S}_{\mathrm{ro}} \quad$ tensão lateral in-situ

u sobrepressão neutra 
profundidade do assentamento das sapatas

$\rho \quad$ recalque 


\section{RESUMO}

SOARES, W. C. (2002). Estacas de Compactação para Melhoria de Solo. São Carlos, 2002. 133p. Dissertação de Mestrado - Escola de Engenharia de São Carlos, Universidade de São Paulo.

Este trabalho apresenta alguns parâmetros geotécnicos do solo arenoso na região litorânea de João Pessoa/PB, após a melhoria com estacas de compactação, instaladas pelo método denominado vibro-deslocamento. Esse procedimento é um método de melhoria de solos arenosos em que as estacas de areia e brita são introduzidas em solos de baixa resistência com o propósito de aumentar sua resistência e diminuir os recalques da fundação. Realizaram-se ensaios de cone, prova de carga em placa, sondagem SPT e anotação do diagrama de cravação das estacas, para se estudarem os efeitos da melhoria do solo arenoso por meio de estacas de compactação. São mostradas correlações entre o $\mathrm{N}_{\mathrm{SPT}}$, antes e após a compactação do solo, entre a resistência de ponta do cone e $\mathrm{N}_{\mathrm{SPT}}$, antes e após a compactação, bem como os resultados de provas de carga em placa, realizadas nos solos natural e compactado. Observou-se que a diminuição do espaçamento entre estacas aumenta a resistência do solo. Com base no $\mathrm{N}_{\mathrm{SPT}}$, é apresentada uma forma de previsão da capacidade de carga de fundações por sapata, instaladas em solo arenoso compactado com estacas de areia.

Palavras - chave: estaca de compactação, prova de carga estática, índice de resistência à penetração, diagrama de cravação. 


\section{ABSTRACT}

SOARES, W. C. (2002). Compaction Piles to Soil Improvement. São Carlos, 2002.

133 p. Dissertação de Mestrado - Escola de Engenharia de São Carlos, Universidade de São Paulo.

This work presents some geotechnical parameters in sandy soil improved by compaction piles installed by vibro-displacement on the cost of the city of João Pessoa in Northeastern Brazil. Significant increases on bearing capacity can be achieved with this ground improvement technique allowing the use of shallow foundation, even in the case of high buildings. Forty eight sand piles with diameter of $0,30 \mathrm{~m}$ and 3,5 $\mathrm{m}$ long were installed on three different groups varying distance between the piles. Standard Penetration Tests, Cone Penetration Tests and plate load tests were carried out before and after the installation of piles. The comparison between the tests allows quantify the benefit of soil improvement by compaction piles. Empirical relationships between $\mathrm{N}_{\mathrm{SPT}}$ before and after improvement, and relationships between $\mathrm{q}_{\mathrm{c}}$ and $\mathrm{N}_{\mathrm{SPT}}$ were established. These relations and results of plate load tests allowed an assessment of the influence of distance between the piles in the compacted soil. A prediction of bearing capacity of shallow foundations in sandy soil improved by sand piles, based on $\mathrm{N}_{\mathrm{SPT}}$ values is presented.

Keywords: compaction piles, plate load test, standard penetration test, drive diagram. 


\section{CAPÍTULO 1 - INTRODUÇÃO}

É prática corrente, em cidades do litoral nordestino, o uso de estacas de compactação, executadas pela técnica de vibro-deslocamento, como método de melhoria do terreno arenoso, no caso de fundações rasas por sapata. A execução das estacas de compactação aumenta a capacidade de carga do solo e diminui os recalques da fundação, de modo que a opção por fundações diretas seja viável técnica e economicamente.

Apesar de seu grande uso em obras de médio e grande porte, existem poucos trabalhos e estudos sobre o comportamento de solos melhorados com estacas de compactação. A maioria das obras executadas é calcada na experiência do engenheiro de fundações. Dessa forma, torna-se muito importante a realização de estudos geotécnicos nessa área.

Para o desenvolvimento desta dissertação de mestrado, realizaram-se ensaios de sondagem SPT, cone e provas de carga sobre placa no Campo Experimental de Fundações das empresas Concresolo \& Copesolo, localizadas na cidade de João Pessoa/PB. Os ensaios foram realizados em terreno natural e após a compactação, com estacas de areia instaladas pela técnica de vibro-deslocamento, com a anotação do diagrama de cravação. A fim de avaliar os efeitos do espaçamento entre as estacas na densificação do solo, foram executadas malhas de estacas com espaçamento, eixo a eixo, de 80, 90 e $100 \mathrm{~cm}$. Os ensaios pós-compactação foram realizados na área de solo densificada entre as estacas. Os capítulos seguintes apresentam todas as informações referentes à caracterização do solo melhorado com estacas de areia, dos métodos e 
procedimentos realizados e suas análises e conclusões, abordadas como melhoria do solo e não como fundação mista.

O Capítulo 2 apresenta uma revisão bibliográfica sobre o tema, mostrando a origem da técnica, seus diferentes processos de execução pelo mundo e as melhorias alcançadas no solo compactado com estacas de compactação.

No Capítulo 3, é feita a caracterização geológica e geotécnica do campo experimental onde foram realizados os ensaios.

O Capítulo 4 apresenta os materiais e equipamentos utilizados nos ensaios, e o Capítulo 5 mostra os métodos e procedimentos adotados para a realização deste trabalho.

No Capítulo 6, são mostrados os resultados obtidos pelos ensaios, e suas análises são apresentadas no Capítulo 7.

O Capítulo 8 mostra as conclusões obtidas do trabalho. 


\section{CAPÍTULO 2 - REVISÃO BIBLIOGRÁFICA}

\subsection{Técnicas de melhoria do solo}

Atualmente a melhoria do solo tem se tornado parte de muitos projetos de engenharia civil. Com o crescimento dos grandes centros urbanos, há a necessidade, cada vez maior, de se utilizarem solos de baixa resistência como suporte de fundações de grandes obras. Muitas técnicas de melhoria de solo permitem a execução de tais obras, garantindo o uso adequado do solo e satisfazendo critérios técnicos e econômicos.

As técnicas de melhoria do solo também são muito usadas após o término da construção, quando se precisa aumentar a resistência de solos, para garantir estabilidade, no caso de escavações adjacentes, construções de túneis ou aumento da resistência, no caso de carregamentos sísmicos.

MITCHELL (1970) cita que, independente da técnica, o propósito do tratamento é eliminar o perigo de recalques excessivos e, seguindo esse propósito, os vários métodos de melhoria do solo foram divididos em dois grandes grupos, conforme a sua aplicação em solos coesivos e não coesivos. 


\subsubsection{Tratamento de solos não coesivos}

\section{Vibroflotação}

Técnica de compactação do solo em que estacas de areia são introduzidas no terreno por vibração. O principal equipamento utilizado é composto de um vibrador com diâmetro entre 300 e $400 \mathrm{~mm}$ e comprimento em torno de 3 a $5 \mathrm{~m}$. A água é usada como fluido de desagregação e estabilização do solo.

\section{Estacas de compactação}

São estacas de areia e brita instaladas no solo por processos dinâmicos com o objetivo de densificá-lo e diminuir os recalques da fundação. São também conhecidas como estacas de areia ou estacas granulares.

\section{Explosivos}

Os explosivos são usados no tratamento de solos saturados não coesivos e de baixa resistência. Explosivos enterrados causam liquefação e expulsão da água intersticial, densificando o solo.

\section{Injeção de cimento}

Consiste na injeção de calda de cimento dentro do solo, para aumentar sua resistência e diminuir os recalques da fundação. Devido a seu alto custo, é geralmente limitado em zonas de pequeno volume e em problemas especiais que não podem ser resolvidos por outros métodos. 


\subsubsection{Tratamento de solos coesivos}

\section{Vibroflotação}

É um processo semelhante ao dos solos não coesivos, podendo-se usar o ar ou a água como fluido de desagregação e de estabilização dos furos. $\mathrm{O}$ material de aterro deve ter grãos de tamanhos maiores que os usados em solos não coesivos.

\section{Eletroosmose}

Fenômeno eletrocinético utilizado pela primeira vez por L. Casagrande, em 1939, na bem sucedida estabilização de uma escavação instável em um silte argiloso saturado. Desde então, a estabilização por eletrosmose tem encontrado maiores aplicações para a drenagem e tratamento de solos.

\section{Tratamento termal}

Tanto o congelamento quanto o aquecimento têm sido usados para o tratamento de solos de fundação. As técnicas são complexas e caras. $\mathrm{O}$ aquecimento dos grãos de solo em temperaturas moderadas maiores que $100^{\circ} \mathrm{C}$ pode causar secagem e aumento da resistência do solo, se a reumidificação for evitada. $\mathrm{O}$ aumento de temperaturas em torno de 600 a $1000^{\circ} \mathrm{C}$ pode produzir melhorias permanentes, incluindo diminuição da sensibilidade à água, inchamento, compressibilidade e aumento de resistência.

O congelamento artificial do solo tem aplicações temporárias no seu fortalecimento e suporte de escavações abertas, que é uma das suas aplicações mais importantes. 


\section{Aditivos}

Os aditivos são usados em conjunto com as técnicas de injeção, eletro-osmose e tratamentos termais. Os principais aditivos são: cimento, betume e produtos químicos, que são usados em profundidades rasas e no tratamento primário de solos expansivos, que serão usados como suporte de estruturas leves.

\section{Injeção de compactação}

Uma mistura de solo viscoso, cimento e água sob pressão é injetada em solos fracos com grandes índices de vazios, atuando como um macaco hidráulico que comprime o solo. É usada para corrigir recalques diferenciais e prover escoramento em escavações abertas.

A Figura 1 mostra um resumo da aplicabilidade dessas técnicas em função da granulometria dos solos apresentada por MITCHELL (1968).

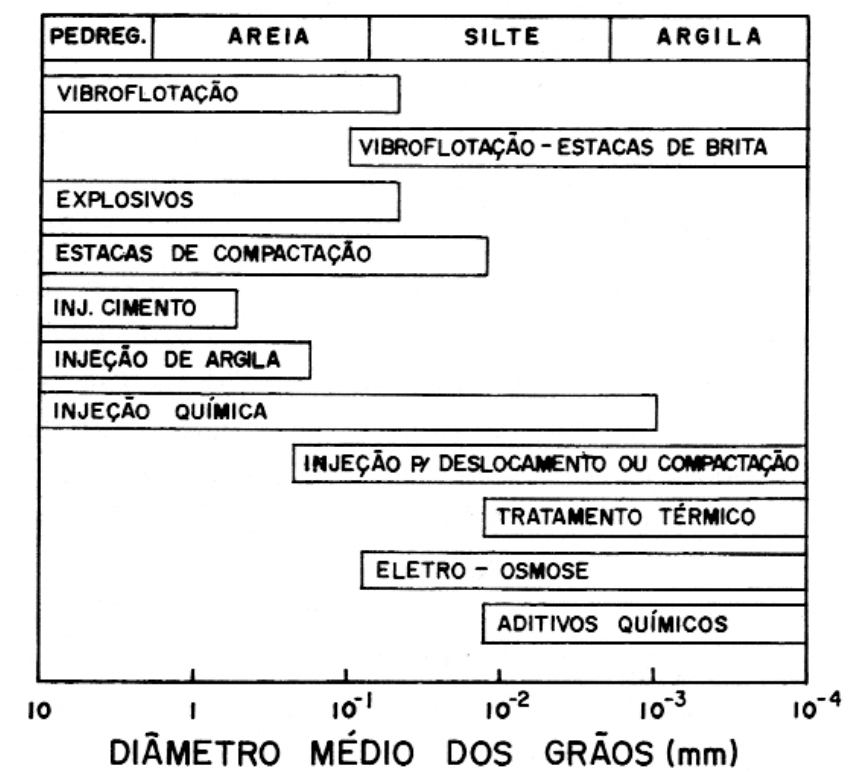

Figura 1. Técnicas de melhoria em função da granulometria (Mitchell, 1968). 


\subsection{Melhoria do solo com estacas de compactação}

A melhoria do solo com estacas de compactação se constitui em um processo em que estacas de areia e brita são introduzidas em solos de baixa resistência, melhorando suas propriedades geotécnicas através da aplicação de grandes energias de compactação por esforços dinâmicos ou vibração.

A reação dos solos durante o tratamento de compactação dinâmica varia com o tipo de solo e com a energia empregada. Existem diferenças entre a compactação de solos granulares e coesivos. Os efeitos da melhoria diminuem bastante quando há uma excessiva fração de finos no solo. No caso de solos preponderantemente coesivos, as estacas funcionam como drenos verticais de areia, em que o aumento da resistência é oriundo da aceleração do adensamento.

SABHAHIT et al. (1997) afirmam que a energia liberada, durante a instalação da estaca granular, causa um aumento na sobrepressão neutra do solo adjacente, e, desde que a estaca atue como dreno, a resistência e a rigidez do solo aumentam rapidamente.

Em solos granulares, SLOCOMBE (1993) afirma que o processo de compactação melhora as propriedades do solo através do deslocamento físico das partículas, que reduzem o volume de vazios do solo, aumentando a compacidade relativa e a capacidade de carga da fundação.

A exeqüibilidade do uso da melhoria com estacas de compactação depende de vários fatores, além das condições do solo, entre eles: tipo de estrutura, tolerância quanto aos recalques, condições ambientais, etc.

Existem duas técnicas para a execução de estacas de compactação: a vibrosubstituição e o vibro-deslocamento. A vibro-substituição é realizada em países desenvolvidos, sobretudo na Europa e nos Estados Unidos; também é conhecida como vibroflotação, e a compactação do solo se dá por vibração. O vibro-deslocamento é realizado em países de Terceiro Mundo como a Índia e o Brasil, e o processo de compactação do solo se dá por efeitos dinâmicos, sendo esta técnica o objeto de estudo deste trabalho. O processo evolutivo das duas técnicas, suas diferenças e características serão apresentadas a seguir. 


\subsection{Vibro-substituição}

\subsubsection{Introdução}

As primeiras estacas de areia foram, provavelmente, empregadas pelos engenheiros militares franceses no século XIX. Os métodos modernos começaram na década de 20, na Alemanha, por Sergei Steuermann e Wilhelm Degen. Eles verificaram que uma compactação efetiva só era possível quando um vibrador era colocado dentro do solo. Esse vibrador teria que estar permanentemente em contato com o solo arenoso, enquanto emitia forças vibratórias horizontais.

Entretanto, a difícil situação política da Alemanha no final da década de 30 forçou Steuermann a deixar o país e ir para os Estados Unidos. Degen permaneceu e produziu o primeiro vibrador de trabalho em 1936-37. Steuermann produziu sua própria máquina um pouco depois e continuou a expandir o processo na América do Norte.

Apesar de ser a forma mais comum de tratamento do solo na Inglaterra, atualmente, ainda não existe uma norma padrão (British Standard) para a melhoria do solo por vibração. Para sanar a deficiência de informações, tais como a natureza da técnica, suas limitações e benefícios, foi publicado um novo guia pela BRE, "Specifying vibro stone columns". O guia foi elaborado pelos melhores especialistas ingleses em melhoria do solo e fornece especificações técnicas para as estacas granulares executadas com vibração, bem como os elementos essenciais de projeto.

A vibro-substituição baseia-se na execução prévia de furos cilíndricos no interior do maciço de solo por meio da vibração de uma agulha, comumente denominada “torpedo". Emprega-se água ou ar sob pressão como fluido de desagregação do solo, agindo na extremidade dessa agulha. O material granular, lançado dentro do furo, é vibrado durante os movimentos ascendentes e descendentes do torpedo, constituindo-se um elemento mais resistente que o solo natural. A Figura 2 esquematiza este método, tradicionalmente conhecido pelo nome de vibroflotação. 


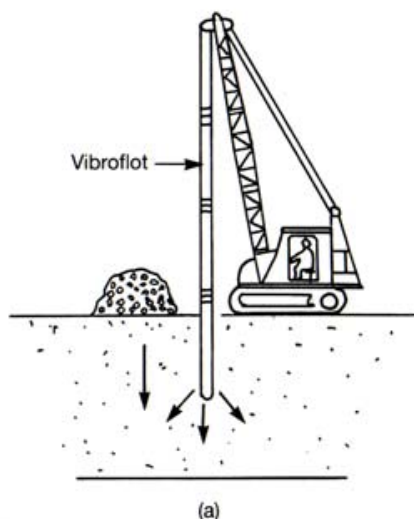

(a)

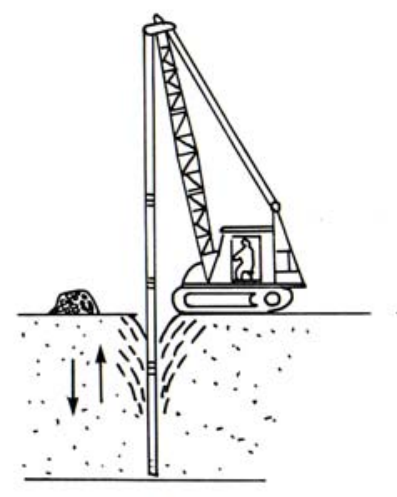

(b)

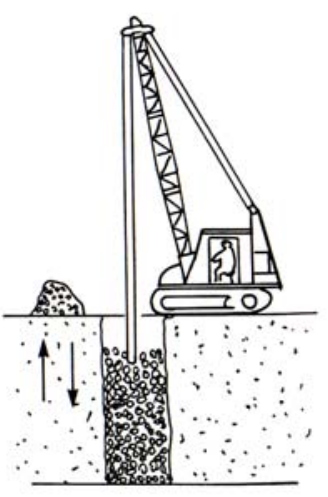

(c)

Figura 2. Vibro-substituição (Atkinson, 1993).

O equipamento desenvolvido para o procedimento de vibro-substituição é composto basicamente de quatro elementos:

- vibrador (torpedo), que é suspenso elasticamente por tubos de extensão com sistema de injeção de ar ou água;

- guindaste, que suporta o vibrador e os tubos de extensão;

- sistema de fornecimento de material;

- equipamentos de controle e verificação.

O principal equipamento utilizado para a compactação do terreno é o vibrador (Figura 3), que tem diâmetros de 300 a $460 \mathrm{~mm}$ e comprimento de 3 a 4,9 m. Segundo MOSELEY \& PRIEBE (1993), as vibrações são produzidas próximas à base do vibrador e são induzidas pela rotação de pesos excêntricos montados num fuste e acionados por um motor localizado na parte superior do vibrador. 


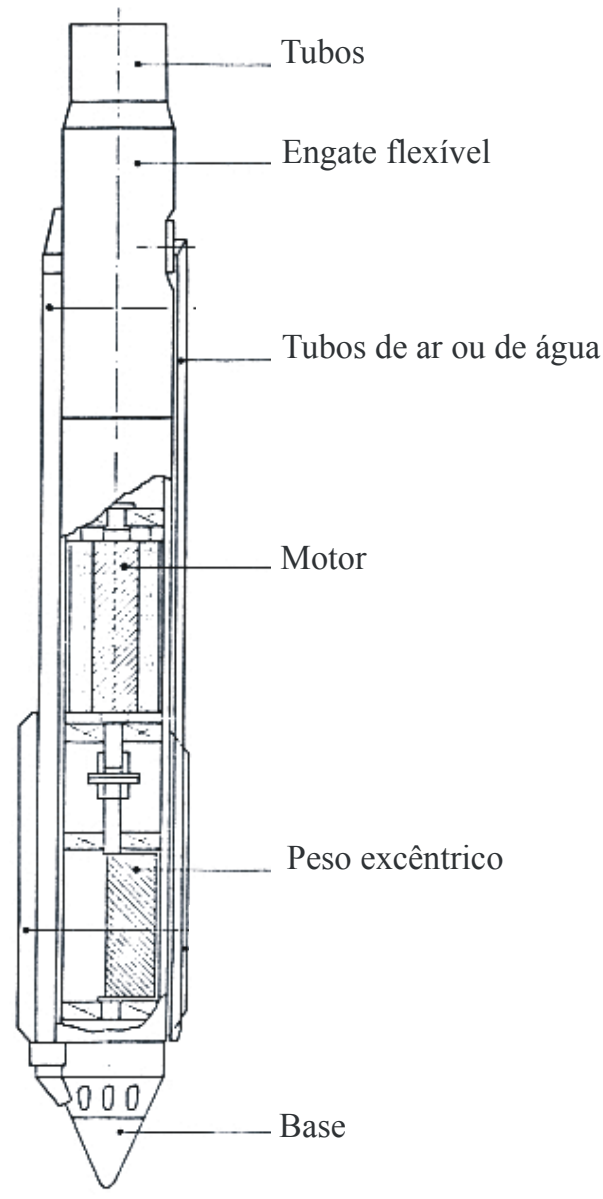

Figura 3. Vibrador e seus componentes (Moseley \& Priebe, 1993).

Com freqüências típicas de $30 \mathrm{~Hz}$ ou $50 \mathrm{~Hz}$, a profundidade usual do tratamento é em torno de $3 \mathrm{~m}$ a $6 \mathrm{~m}$, entretanto podem-se atingir profundidades de até $35 \mathrm{~m}$.

\subsubsection{Solos não coesivos}

O método de execução da vibro-substituição em solos não coesivos é ilustrado na Figura 4. 

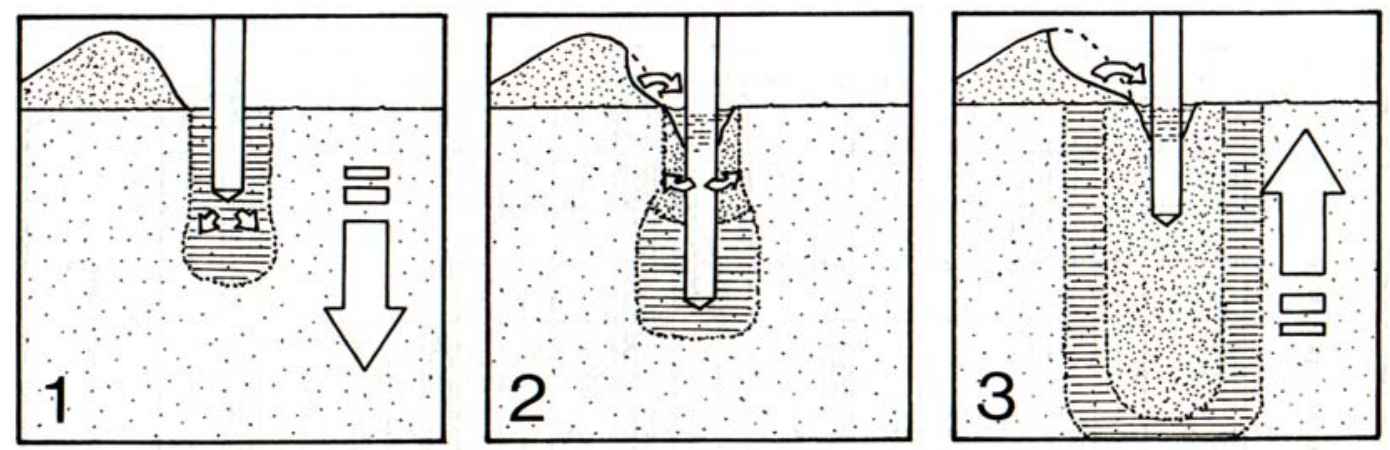

Figura 4. Método de execução da estaca de areia compactada (Glover, 1985).

1. Suspenso por um guindaste ou outro suporte, o torpedo é posicionado no ponto selecionado. Com a adição de jatos de água e com o peso próprio, o torpedo penetra até a profundidade desejada e os jatos de água são desligados.

2. Os jatos de água são lançados em sentido ascendente, e a compactação se inicia. A vibração reorganiza os grãos ao redor da cabeça do vibrador, aumentando a compacidade. O material adicional (areia ou pedregulho) é colocado no espaço entre o furo e o torpedo.

3. O torpedo é levantado lentamente, formando um cilindro de 2 a $4 \mathrm{~m}$ de diâmetro. Os pontos de compactação são dispostos de tal forma, que as áreas de influência se sobrepõem. Com isso é formada uma região melhorada com densidade uniforme.

THORBURN (1975) afirma que o objetivo dos jatos d'água é manter a estabilidade dos lados do furo formado pelo torpedo. O diâmetro da massa cilíndrica de solo influenciada pelas vibrações depende, entre outros fatores, da granulometria do terreno, do nível d'água e da amplitude e freqüência do vibrador. Em média, a compactação se mostra efetiva até uma distância de 2,5 m do centro de vibração.

Durante a execução, há alguns controles permanentes com o objetivo de se identificar alguma irregularidade inesperada no solo. Cada ponto de compactação é uma 
investigação destrutiva, e, quando o jato é usado, pode-se fazer uma inspeção das diferentes camadas do furo: siltes, areias, partículas orgânicas ou argilas.

BESANCON \& PERTUSIER (1985) sugerem que todas as observações feitas durante o tratamento devem ser registradas em um caderno de anotações, incluindo: profundidade de cada ponto de compactação, volume de material incorporado, energia consumida, alguma mudança no solo natural ao longo do processo, etc.

\subsubsection{Solos coesivos}

Em solos coesivos, o aumento do teor de finos reduz a transmissão de vibrações através do solo natural, reduzindo os efeitos da melhoria entre pontos de compactação. As vibrações são amortecidas dentro de um raio relativamente pequeno, a partir do centro de vibração. As forças intergranulares entre partículas impedem a reorganização do solo em maiores densidades.

O aumento de resistência de solos coesivos é conseguido através do uso de materiais de maior granulometria, pois os mesmos favorecem a drenagem do solo, acelerando os recalques. $\mathrm{O}$ aterro utilizado forma uma coluna densa, que aumenta a rigidez e reforça o solo coesivo, eliminando o risco de ruptura por cisalhamento, sob a ação das cargas de projeto, bem como reduzindo os recalques. De fato, BOUASSIDA \& HADHRI (1995) afirmam que, em solos moles, além do aumento da capacidade de carga, outras vantagens são obtidas como a redução de recalques e do tempo de adensamento primário.

A Figura 5 ilustra o método de vibro-substituição em solos coesivos. 

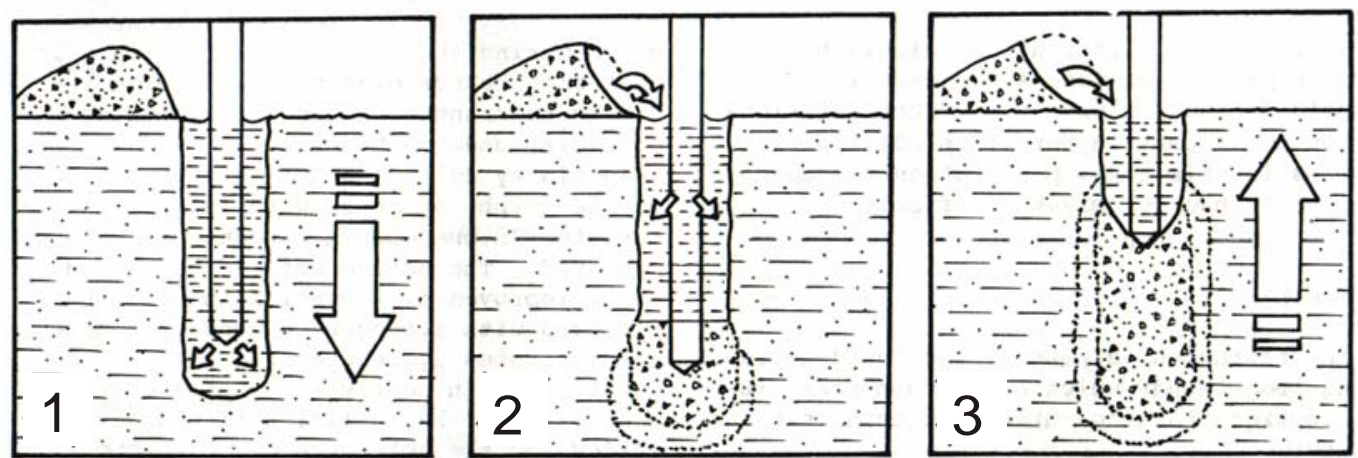

Figura 5. Vibro-substituição em solos coesivos (Glover, 1985).

1. O solo é penetrado até a profundidade requerida através dos efeitos combinados do peso do torpedo, vibração e ação de jatos de ar e/ou água.

2. O torpedo é, então, levantado. Areia grossa, pedra britada ou escória são despejados dentro do furo em incrementos de $500 \mathrm{~mm}$. O torpedo é recolocado, e a compactação se inicia. Forças radiais produzidas pelo vibrador forçam o material adicionado horizontalmente contra o solo natural.

3. Quando o grau de compactação requerido é atingido, o torpedo é retirado novamente. $\mathrm{O}$ ciclo de densificação e aterragem é repetido sucessivas vezes até a superfície. Com isso uma densa coluna de material granular é formada interagindo com o terreno natural, através da zona de tratamento.

Dependendo do fluido utilizado, ar ou água, o método de execução pode ser a seco ou molhado respectivamente. A água é utilizada em solos muito fracos, em que a retirada do torpedo causa seu desmoronamento, obstruindo o furo. Caso seja utilizado ar em solos fracos, pode ocorrer o estrangulamento, resultando uma estaca de areia contendo material fraco.

ATKINSON (1993) cita que o uso de estacas granulares em solos coesivos não aumenta a resistência do solo isoladamente, entretanto, a formação do sistema solo mais estacas produz um aumento de resistência igual a duas ou três vezes a resistência original. 
VAN IMPE (1989) afirma que uma compactação efetiva do solo, em tais casos, é virtualmente impossível. Entretanto, na prática, os parâmetros de resistência ao cisalhamento sofrem um pequeno aumento, devido ao adensamento acelerado ao redor da estaca.

DATYE (1985) conceitua as estacas granulares como sendo parte do sistema do solo reforçado, as quais interagem com o solo dividindo uma parte das cargas. A principal vantagem das estacas granulares é a propriedade de ajustar e redistribuir as cargas aplicadas onde ocorrem as concentrações de tensões. BERGADO et al. (1994) afirmam que a concentração de tensão ocorre na estaca granular, acompanhada de uma redução na tensão atuante no solo ao redor. Isso é explicado pelo fato de que, quando carregada, o recalque da estaca granular e do solo adjacente é aproximadamente o mesmo, causando a concentração de tensão na estaca, que é mais rígida que o solo ao seu redor.

\subsubsection{Aspectos de projeto}

\section{Capacidade de carga do elemento de fundação}

CINTRA \& AOKI (1999) conceituam elemento isolado de fundação como sendo o sistema formado pelo elemento estrutural e pelo maciço de solo que o envolve.

Para o sistema formado por uma estaca isolada, a capacidade de carga é governada pelo atrito lateral do solo ao redor da zona de empolamento da estaca.

Partindo da teoria da expansão da cavidade, ATKINSON (1993) desenvolve uma fórmula para capacidade de carga de uma estaca isolada:

$$
\mathrm{S}_{\mathrm{rl}}=\mathrm{S}_{\mathrm{ro}}+4 \mathrm{c}+\mathrm{u}
$$


Onde: $\mathrm{S}_{\mathrm{rl}}=$ tensão radial máxima; $\mathrm{S}_{\mathrm{ro}}=$ tensão lateral in-situ ao redor da estaca; $\mathrm{u}=$ sobrepressão neutra. Geralmente, o valor de u é zero, pois a sobrepressão neutra decresce rapidamente com a instalação da estaca. Dessa forma:

$\mathrm{S}_{\mathrm{rl}}=\mathrm{S}_{\mathrm{ro}}+4 \mathrm{c}$

Na seção de empolamento da estaca tem-se:

$\mathrm{S}_{\mathrm{v}}{ }^{\mathrm{i}}=\mathrm{K}_{\mathrm{p}} \mathrm{S}_{\mathrm{ro}}{ }^{\mathrm{i}}$

Onde: $\mathrm{K}_{\mathrm{p}}=$ coeficiente de empuxo passivo para o material usado na estaca

$$
\begin{aligned}
& \mathrm{K}_{\mathrm{p}}=(1+\operatorname{sen} \phi) /(1-\operatorname{sen} \phi) ; \\
& \mathrm{S}_{\mathrm{v}}{ }^{\mathrm{i}}=\text { tensão efetiva vertical; } \\
& \mathrm{S}_{\mathrm{ro}}{ }^{\mathrm{i}}=\text { tensão efetiva lateral. }
\end{aligned}
$$

Então:

$$
\begin{aligned}
& \mathrm{S}_{\mathrm{vi}}=\frac{(1+\operatorname{sen} \phi)}{(1-\operatorname{sen} \phi)} \cdot\left(\mathrm{S}_{\mathrm{ro}}+4 c\right) \\
& \mathrm{S}_{\mathrm{ro}}{ }^{\mathrm{i}}=\mathrm{K}(\gamma \mathrm{h}+\mathrm{p})
\end{aligned}
$$

Onde: $\mathrm{K}=$ coeficiente de empuxo de terra; $\mathrm{h}=$ profundidade crítica, $\mathrm{a}$ profundidade em que o empolamento ocorre (geralmente igual a um ou dois diâmetros 
da estaca medido logo abaixo do nível das sapatas); $\gamma=$ peso específico do solo ao redor da estaca; $\mathrm{p}=$ sobre carga imposta ao solo pelas fundações.

Os valores de $\mathrm{K}$ variam, dependendo das condições do terreno, mas geralmente o valor de $\mathrm{K}=1$ pode ser usado. Dessa forma, a tensão vertical última na estaca é dada por:

$$
\mathrm{q}_{\mathrm{ult}}=\frac{(1+\operatorname{sen} \phi)}{(1-\operatorname{sen} \phi)} \cdot(\gamma \mathrm{h}+4 \mathrm{c}+\mathrm{p})
$$

Já MADHAV \& VITKAR (1978) apresentam gráficos para se obterem os fatores de capacidade de carga da fórmula clássica de Terzaghi para cálculo da capacidade de carga de fundações por sapata:

$$
q_{u l t}=C_{2} N_{C}+\left(\gamma_{2} B / 2\right) N_{\gamma}+\gamma H N_{q}
$$

onde: $C_{2}$ e $\gamma_{2}$ são a coesão e o peso específico do solo, $C_{1}$ e $\gamma_{1}$ são a coesão e o peso específico do material da estaca, e $\mathrm{H}$ é a profundidade da fundação. Os fatores $\mathrm{Nc}, \mathrm{Nq}$ e $\mathrm{N} \gamma$ são obtidos dos gráficos nas Figuras 6, 7 e 8.
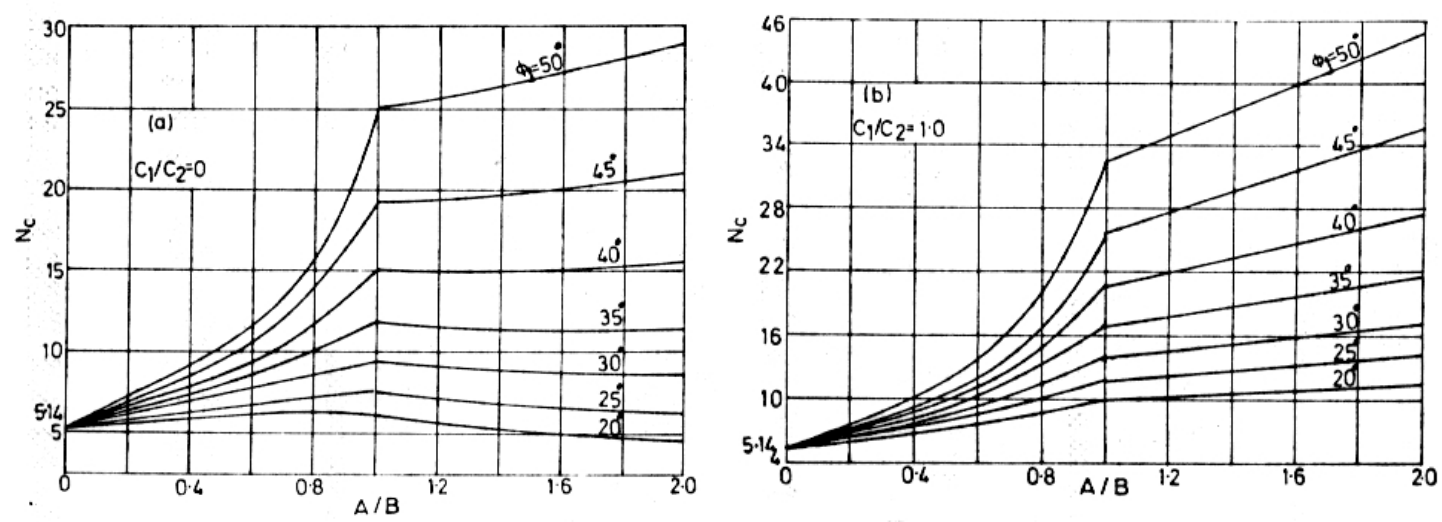

Figura 6. Fator de capacidade de carga Nc (Madhav \& Vitkar, 1978). 


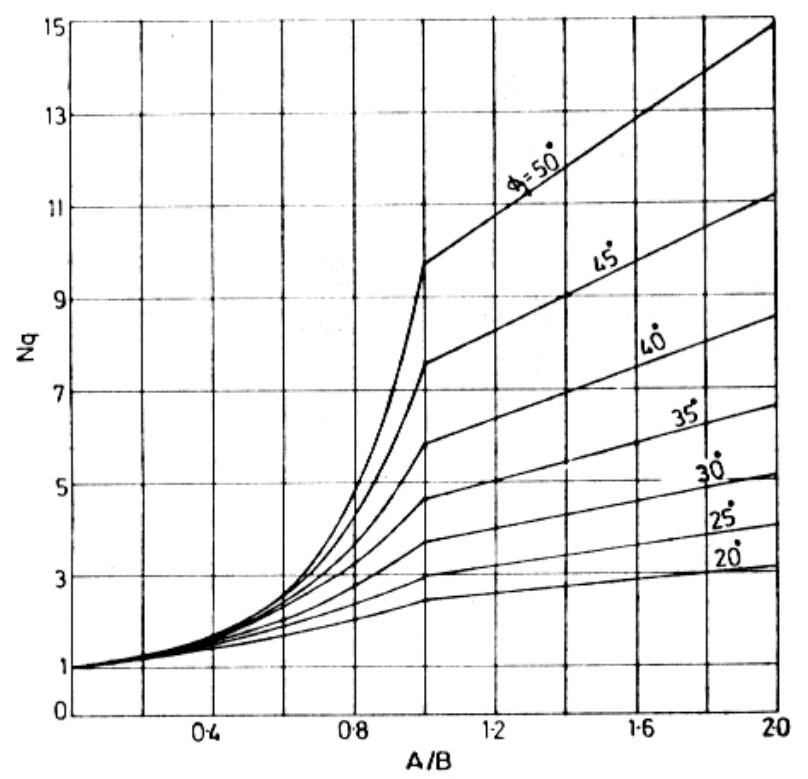

Figura 7. Fator de capacidade de carga Nq (Madhav \& Vitkar, 1978).

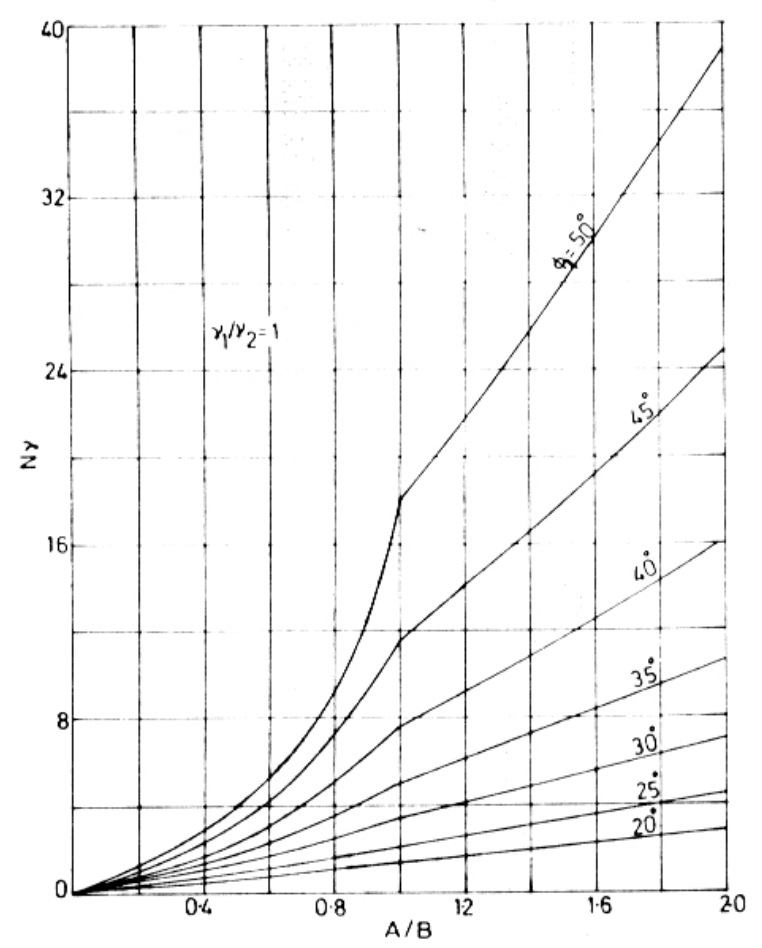

Figura 8. Fator de capacidade de carga N $\gamma$ (Madhav \& Vitkar, 1978). 
Os parâmetros A e B são o diâmetro da estaca e da sapata, respectivamente, conforme indicado na Figura 9.

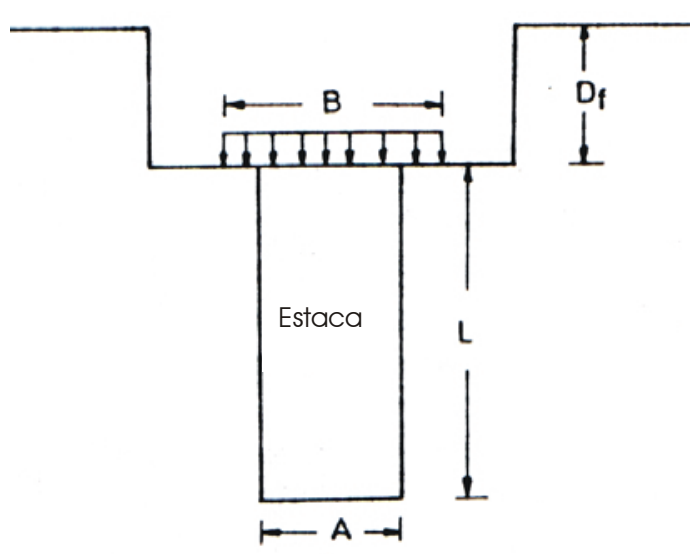

Figura 9. Parâmetros A e B (Madhav \& Vitkar, 1978).

\section{Recalques}

Os recalques de um sistema formado por solo melhorado com estacas de areia podem ser calculados pela fórmula (ATKINSON, 1993):

$$
\rho=\operatorname{dh} \cdot \mathrm{m}_{\mathrm{v}} \cdot \Delta \mathrm{p}
$$

Onde: $\mathrm{dh}=$ espessura de cada camada; $\mathrm{m}_{\mathrm{v}}=$ coeficiente de deformação volumétrica; $\Delta \mathrm{p}=$ pressão atuante na camada obtida pelo gráfico a seguir: 


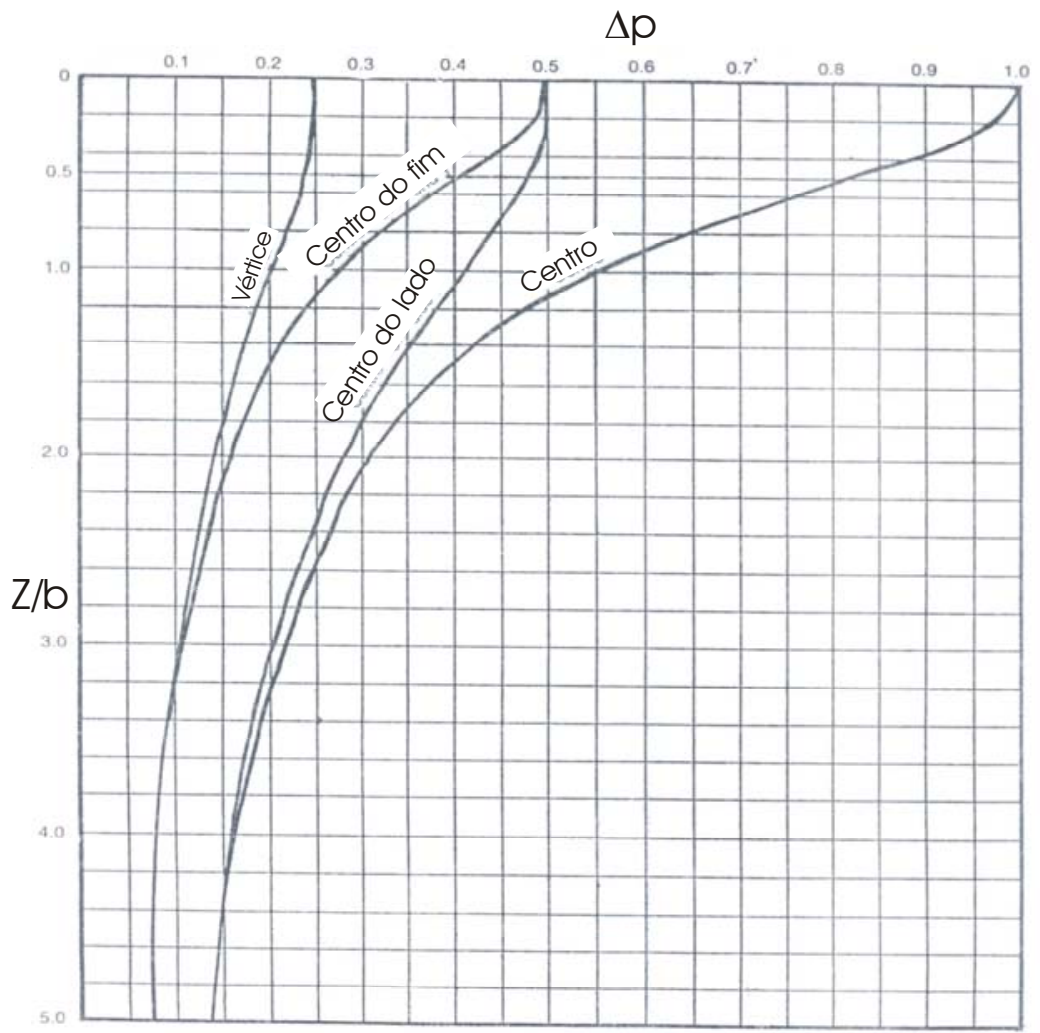

Figura 10. Distribuição da tensão vertical abaixo de uma sapata (ATKINSON, 1993).

Onde: $\Delta \mathrm{p}=$ tensão atuante na camada; $\mathrm{z}=$ profundidade de assentamento das sapatas; B = largura da sapata. 


\subsubsection{Fatores influentes na densificação do solo}

\section{Granulometria do solo in situ}

A vibro-substituição pode ser empregada para tratar diversos tipos de solo. Como qualquer sistema de compactação, as características do solo in situ influenciam significantemente a capacidade de densificação da vibro-substituição. A Figura 11 ilustra a variação de solos adequados à técnica.

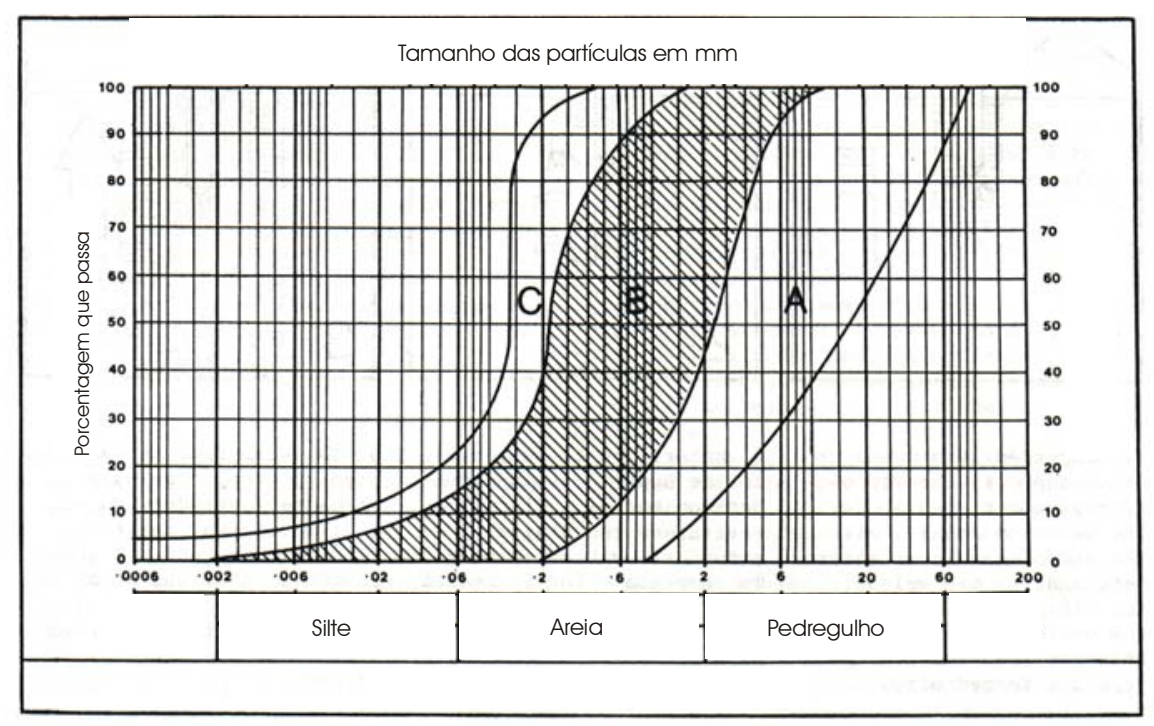

Figura 11. Granulometria do solo adequado à melhoria (Glover, 1985).

Os solos com granulometria dentro da zona A são excelentes para a densificação por vibro-substituição. Quando o solo contém mais de 20\% de areia grossa nessa zona, a penetração em profundidades maiores que $10 \mathrm{~m}$ pode ser dificultada.

A vibro-substituição é mais bem adaptada para densificar areias fofas, que possuem distribuição dos grãos situados inteiramente na zona B.

GLOVER (1985) afirma que a presença de silte e/ou camadas de argila, excesso de finos e material orgânico no solo requer um avaliação especial. Em geral, solos com granulometria situada preponderantemente na zona $\mathrm{C}$ necessitam de material de aterro especial, procedimentos de compactação modificados e espaçamento reduzido. 
SLOCOMBE \& BELL (1985) ressaltam que outros fatores, além do teor de silte, são responsáveis pela adequação do solo à técnica. A experiência tem mostrado que mesmo areias bem graduadas, com mais de $20 \%$ de teores de siltes, podem ser densificadas. Outro fator de igual importância é a relação entre os tamanhos dos grãos, pois materiais uniformes são mais difíceis de tratar.

De início, a técnica de compactação foi aplicada para a densificação de solos predominantemente granulares, visto que materiais finos possuem coesão suficiente para suprimir a transmissão da vibração, diminuindo, dessa forma, a eficiência do sistema.

Além da granulometria do solo, uma série de fatores influencia o resultado final da densificação do solo, sendo eles descritos a seguir:

\section{Tipo de equipamento}

A potência do vibrador tem grande influência na densidade alcançada do terreno, porque equipamentos com maior potência dão melhores resultados na melhoria, atingindo maiores densidades.

\section{Espaçamento entre pontos de compactação}

A distância entre os pontos é um fator importante na densidade alcançada, visto que a densidade diminui com um aumento da distância entre os pontos. Malhas quadradas ou retangulares são geralmente usadas, para compactar solos em sapatas isoladas. $\mathrm{O}$ uso de malhas quadradas requer de 5 a $8 \%$ a mais de pontos, para se alcançar a mesma densidade de uma malha em forma triangular.

\section{Retirada do torpedo}

Para se obter um equilíbrio entre produção e compacidade, a taxa de retirada do torpedo deve coincidir com a taxa de colocação do aterro. Dessa forma, há um equilíbrio entre uma boa produção e uma boa compacidade alcançada. 
Se a retirada do torpedo for lenta, serão alcançadas maiores compacidade, entretanto, o torpedo poderá ficar preso no solo, causando atrasos e uso excessivo do equipamento. Já se a retirada do torpedo for rápida, serão obtidas altas produções, mas o solo não será adequadamente compactado.

HARDER et al. (1984) relatam que, se a quantidade de aterro adicionado for grande, pode haver dificuldades na retirada do torpedo.

\section{Material do aterro}

Para se alcançar a compactação desejada, é necessário adicionar material de aterro suficiente, para que as vibrações do torpedo sejam transmitidas ao solo natural e também, para preencher os vazios deixados pela sua retirada.

Areias grossas dão melhor densificação que as finas, pois o material mais grosso transmite melhor as vibrações.

\subsubsection{Melhorias alcançadas}

Por meio do tratamento com vibração, são melhoradas algumas propriedades geotécnicas do solo, tais como: compacidade in situ, ângulo de atrito interno, módulo de deformabilidade, aumento da capacidade de carga e redução de recalques, além do aumento da resistência ao cisalhamento e da resistência à liquefação.

Em alguns países, sujeitos a terremotos, a melhoria do solo com estacas de compactação se constitui em uma forma de aumentar a resistência à liquefação do terreno, fenômeno comum em áreas submetidas a carregamentos cíclicos provenientes de abalos sísmicos.

Segundo ABELEV (1975), as estacas de compactação também são muito usadas na Rússia, para a melhoria de solos colapsíveis. De fato, com o uso dessa técnica desde 1948, cerca de 4,5 milhões de metros cúbicos de loess foi compactado dessa maneira. O loess russo é um solo colapsível, que, ao ser inundado, entra em colapso apenas pelo peso próprio da camada, isto é, sem carregamento externo (CINTRA, 1998). 


\subsection{Vibro-deslocamento}

\subsubsection{Generalidades}

Em países desenvolvidos, as estacas de areia são geralmente formadas por mecanismos de vibro-substituição. Em países subdesenvolvidos, sobretudo na Índia, foi desenvolvida uma técnica em que as estacas de areia são executadas com equipamentos de cravação de estacas. Essa técnica é denominada vibro-deslocamento e é uma extensão da vibro-substituição, pois foi modificada, para se adequar às condições de países em desenvolvimento. No Brasil, os primeiros trabalhos publicados sobre a técnica foram de autoria do Professor Costa Nunes. No Nordeste, a técnica é utilizada desde a década de 50, apresentando resultados bastante satisfatórios, de acordo com GUSMÃO (2000a).

GUSMÃO FILHO (1998) afirma que o principal objetivo da compactação de camadas de areias com baixa compacidade é a sua densificação, que é conseguida mediante a introdução no terreno das estacas de areia e brita. A melhoria permite elevar a tensão admissível do terreno para valores de até 600 kPa (GUSMÃO, 2000a).

\subsubsection{Processo executivo}

A execução da estaca de areia é iniciada pelo posicionamento do tubo de revestimento e pela formação do plugue de solo em sua base (bucha). O tubo de revestimento é cravado dinamicamente por impactos repetidos de golpes de pilão na bucha até a profundidade especificada de projeto. Em seguida, o tubo é preso na torre do bate-estaca por meio de cabos de aço, e a bucha é expulsa. O passo seguinte é a colocação do material granular, que pode ser areia e brita, areia e cimento ou uma mistura desses materiais, dentro do tubo, o qual será compactado pela queda livre do pilão. Simultaneamente à introdução do material, é feita a retirada do tubo, alcançando uma densificação máxima e finalizando a execução da estaca. As Figuras 12 a 15 mostram o processo executivo das estacas de compactação. 


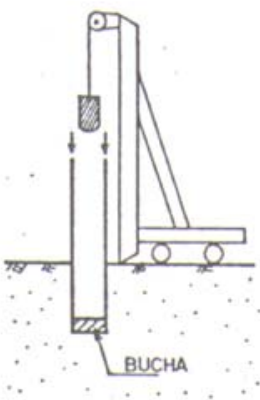

(A)

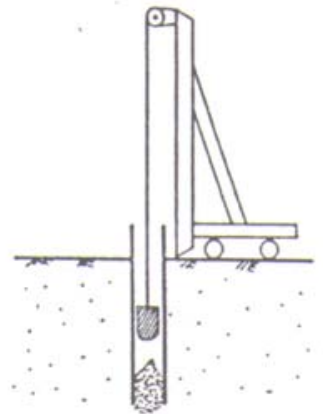

(B)

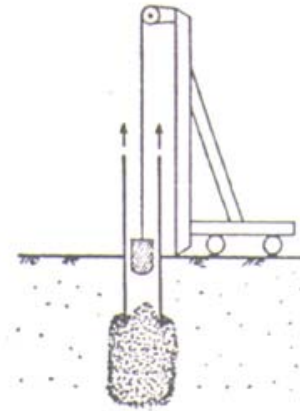

(C)

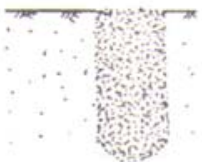

(D)

Figura 12. Processo executivo das estacas de areia (Gusmão Filho, 1998).

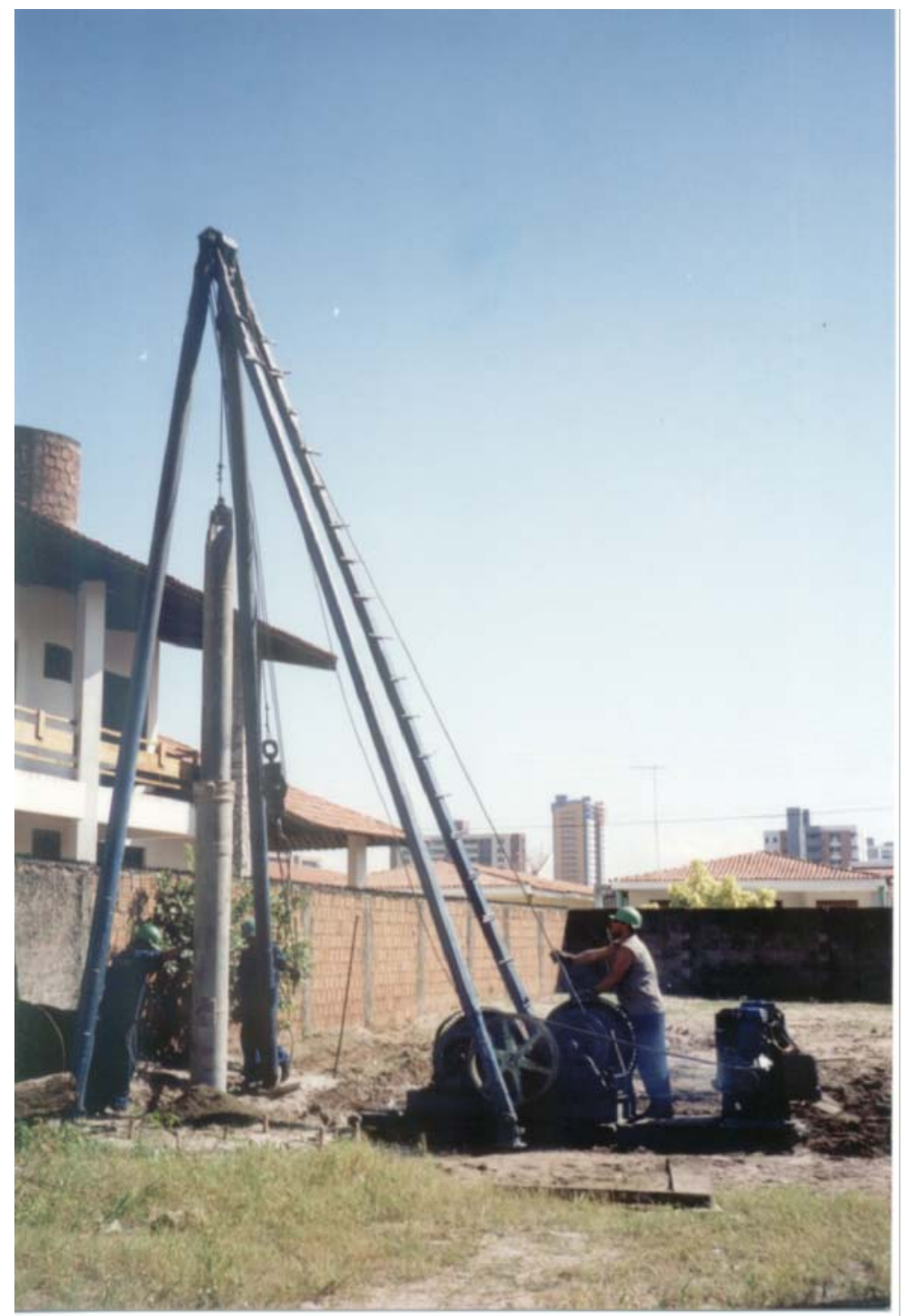

Figura 13. Cravação do tubo de revestimento 


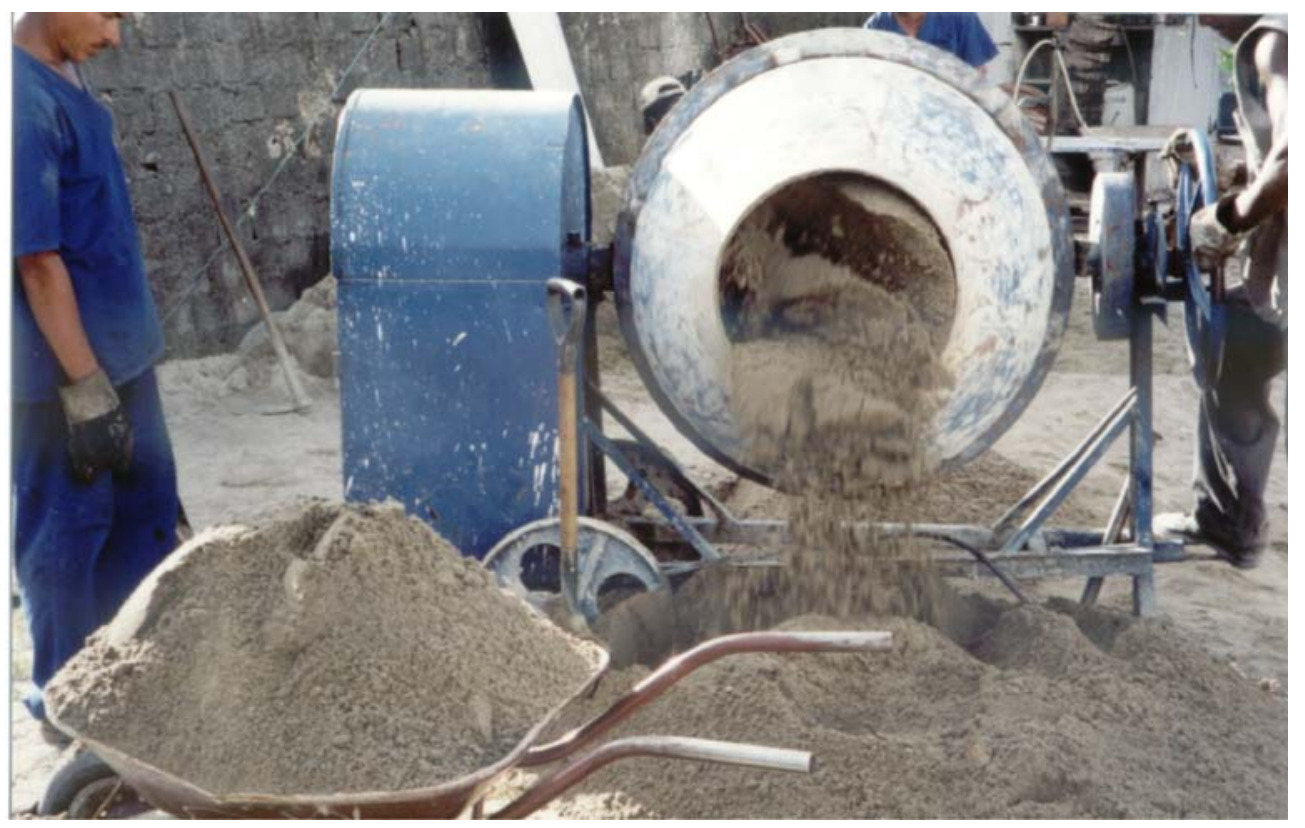

Figura 14. Preparação da mistura de areia e cimento

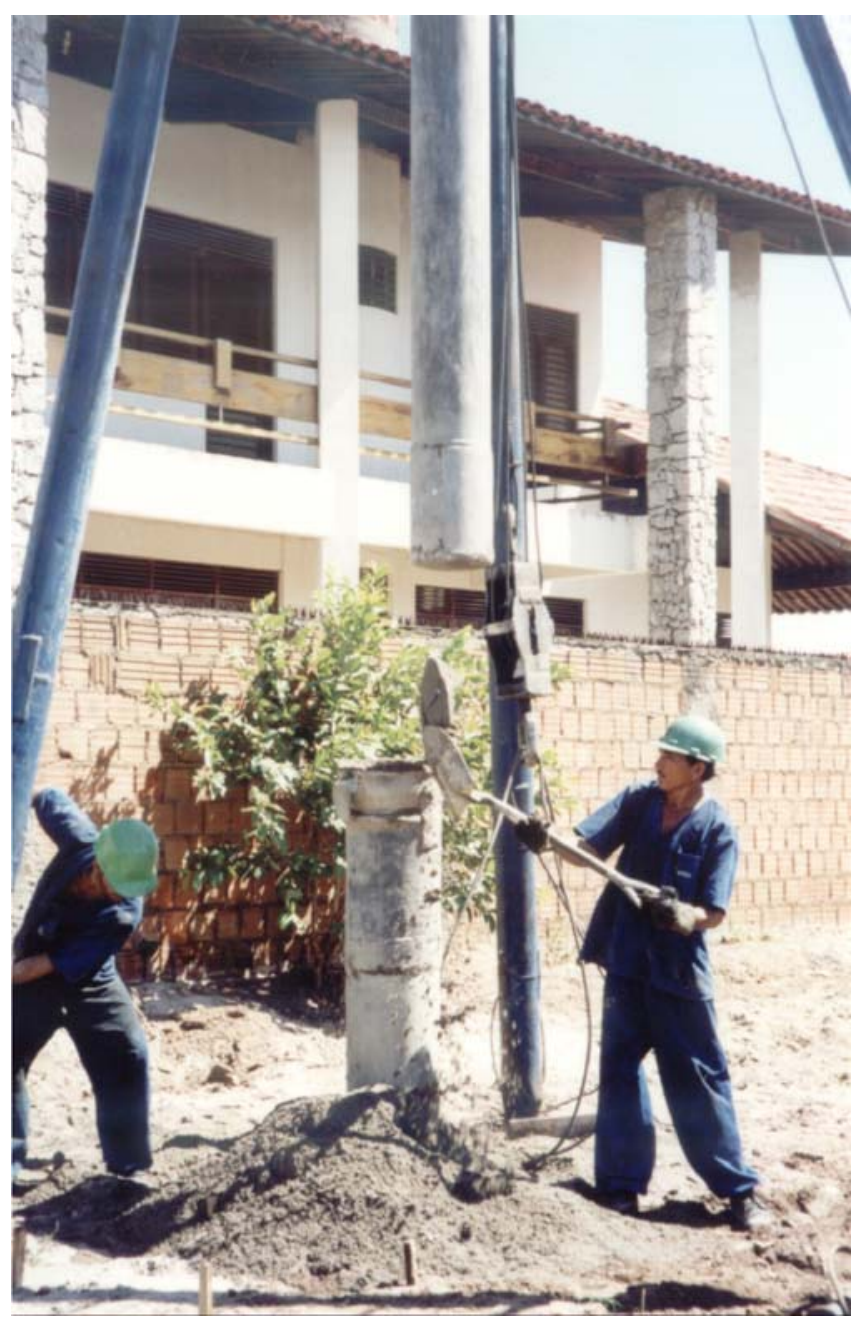

Figura 15. Colocação do material dentro do tubo 
GUSMÃO FILHO (1998) cita que a densificação da camada é conseguida por meio de três efeitos: o deslocamento de material no terreno igual ao volume da estaca; introdução de material adicional compactado no terreno, e efeitos de vibração decorrente do processo executivo.

Já BELL (1993) afirma que, em solos granulares, a densificação é alcançada através da vibração e do deslocamento das partículas de solo, causada pela introdução das estacas.

As estacas são geralmente executadas em malhas quadradas ou triangulares, com espaçamento em torno de 2 a 3 vezes seu diâmetro. SOARES (2000) cita que o projeto das estacas obedece a uma malha que pode ser total (abrangendo toda a área de projeção do prédio), ou pode ser parcial (abrangendo apenas as regiões das sapatas). Segundo GUSMÃO FILHO (1998), a execução de uma estaca de areia promove a compactação do solo circundante em um raio de influência de 2 a 2,5 vezes seu diâmetro.

SLOCOMBE (1993) afirma que o sucesso da melhoria do terreno depende do correto entendimento do comportamento do solo, associado com a experiência da técnica. O tratamento deve assegurar estabilidade à fundação e evitar recalques que possam trazer danos à estrutura. 


\subsubsection{Equipamento}

O equipamento utilizado na execução de estacas de areia é basicamente um bateestaca do tipo "Strauss", constituído de tripé, motor, guincho e mecanismo de movimentação, além do pilão e tubo de revestimento.

O potencial de execução de um bate-estacas é definido pelas características desses elementos (altura da torre, potência do motor, capacidade de guinchos e agilidade do mecanismo de movimentação).

O peso do pilão é cerca de $13 \mathrm{kN}$, caindo de uma altura de $3 \mathrm{~m}$. O diâmetro usual do tubo de revestimento é de $300 \mathrm{~mm}$.

\subsubsection{Controle na execução}

Durante o processo de execução, devem ser feitos controles sobre os dados de cravação, como: profundidade atingida, equipamento e energia utilizados, quantidade de material injetado na base e fuste, etc. DATYE \& NAGARAJU (1981) citam que um importante fator na avaliação da performance das estacas granulares é o seu consumo de material, que pode ser uma mistura de areia e pedra britada. Com uma proporção de 1: 0,2 - 0,5 em volume, pode-se esperar uma massa bem compactada, com a areia preenchendo os vazios da pedra britada.

WALLAYS (1985) cita três métodos, para se verificar a densidade: a medida da compacidade relativa, o índice de resistência à penetração $N_{S P T}$ e a medida de resistência do cone. 


\subsubsection{Solo adequado à melhoria}

Segundo MITCHELL (1970), a eficiência da técnica de vibro-substituição é limitada a solos que apresentam uma quantidade de finos em torno de $20 \%$. Já para as estacas de areia executadas por vibro-deslocamento, o autor afirma que pode se obter sucesso em solos contendo uma percentagem maior de finos.

A quantidade de finos é um dos principais fatores a influenciar o sucesso da técnica, pois, em solos coesivos, as estacas funcionam como drenos verticais, em que o aumento da resistência é oriundo da aceleração do adensamento. A Figura 16 mostra a faixa de ocorrência granulométrica, de terrenos naturais, em que a compactação do solo com estacas de areia é mais eficiente.

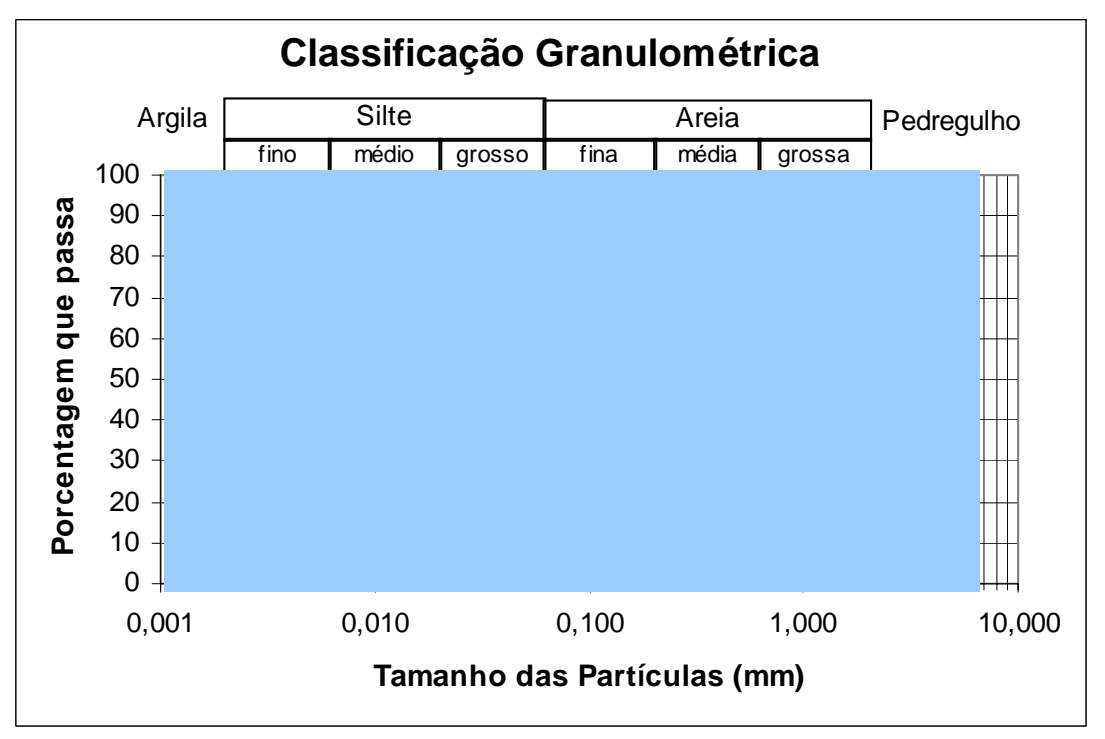

Figura 16. Faixa de ocorrência em que a técnica é mais eficiente (adaptado de GUSMÃO FILHO, 1998).

A compacidade inicial da camada arenosa é outro fator a influenciar o resultado da compactação do solo. Para camadas mais compactas, com $\mathrm{N}_{\mathrm{SPT}}$ superior a 20, por exemplo, diminui-se o efeito da melhoria. Para pequenas profundidades, de até 1,5 m, por exemplo, o efeito da melhoria é desprezível. O não aumento da resistência do solo nessa profundidade deve-se à falta de confinamento próximo à superfície do terreno, ocorrendo refluxo do solo ou levantamento das camadas mais superficiais com a compactação (GUSMÃO FILHO, 1998). O efeito da melhoria é mais significativo para camadas com $\mathrm{N}_{\mathrm{SPT}}$ inicial entre 5 e 10 e para profundidades entre 2 e $3 \mathrm{~m}$. 


\subsubsection{Estacas de compactação do solo em profundidade}

As estacas de compactação também são usadas em camadas arenosas profundas, quando se deseja a associação da técnica com outras soluções em fundações profundas. A melhoria permite diminuir a profundidade e a quantidade das fundações. A Figura 17 mostra o processo executivo das estacas de areia em camadas profundas, que é o mesmo das camadas superficiais, em associação com estacas Franki.

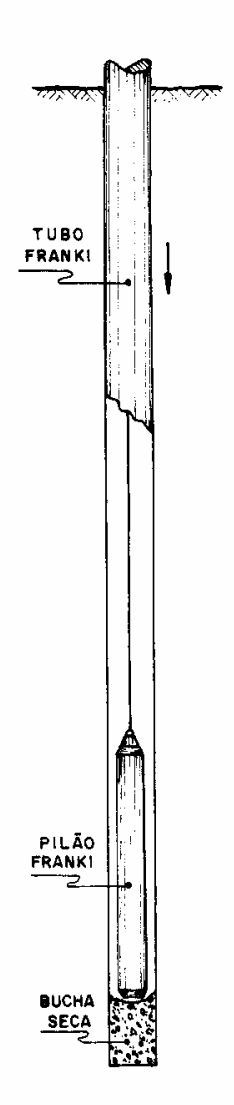

(1)

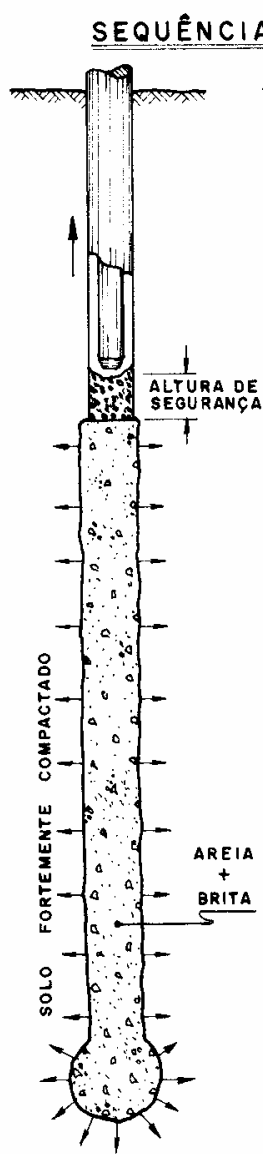

(2)

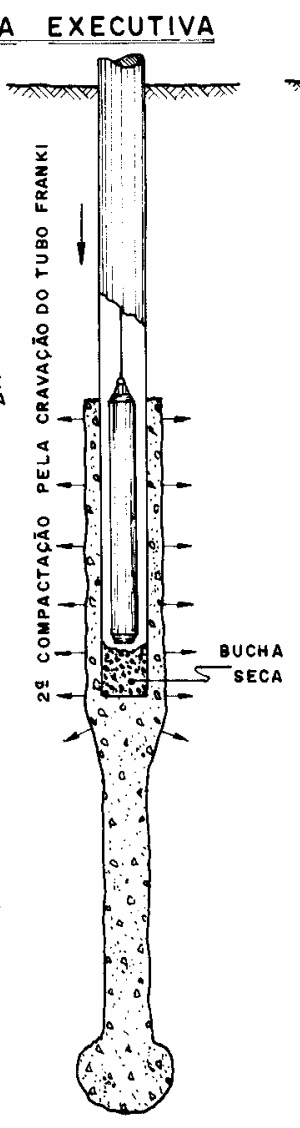

(3)

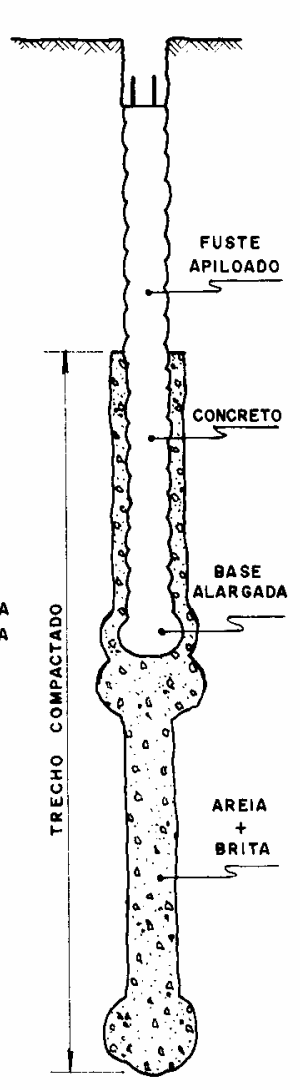

(4)

\footnotetext{
I - cravacão do tugo franki até a PRofundidade de PROJETO;

2 - ABRIR A BASE E COMPACTAR ENERGICAMENTE COM PEDRA (50\%) E AREIA $(50 \%)$

- TUBO FRANKI VAI SENDO EXTRAIDO LENTAMENTE 'A MEDIDA QUE SE

PROCESSA A COMPACTACĀO. DEVERA' SER DEIXADO DENTRO DO TUBO UMA

QUANTIDADE DE MATERIAL - ALTURA DE SEGURANÇA;

3 - RECRAVAÇÁO DO TUBO FRANKI;

4- EXECUCAO NORMAL DA ESTACA DE CONCRETO COM FUSTE APILOAdO.
}

Figura 17. Processo executivo das estacas de areia em profundidade associadas com estacas Franki (MONTEIRO, 1996). 
MONTEIRO (1996) afirma que a compactação do solo em profundidade tem por finalidade:

- o aumento de sua resistência ao cisalhamento com conseqüente diminuição do índice de vazios;

- o aumento da capacidade de carga do solo no trecho compactado;

- limitação de recalques com a redução dos níveis de recalques diferenciais;

- redução do comprimento concretado da estaca, propiciando uma economia no custo da obra.

\subsubsection{Aspectos de projeto}

\section{Capacidade de carga do elemento de fundação}

ALVES et al. (2000) apresentam um ábaco (Figura 18) para a previsão do $\mathrm{N}_{\mathrm{SPT}}$, após melhoria do solo com estacas de compactação. Por meio de métodos semiempíricos, pode-se estimar a capacidade de carga da fundação por sapata a partir do $\mathrm{N}_{\text {SPT }}$.

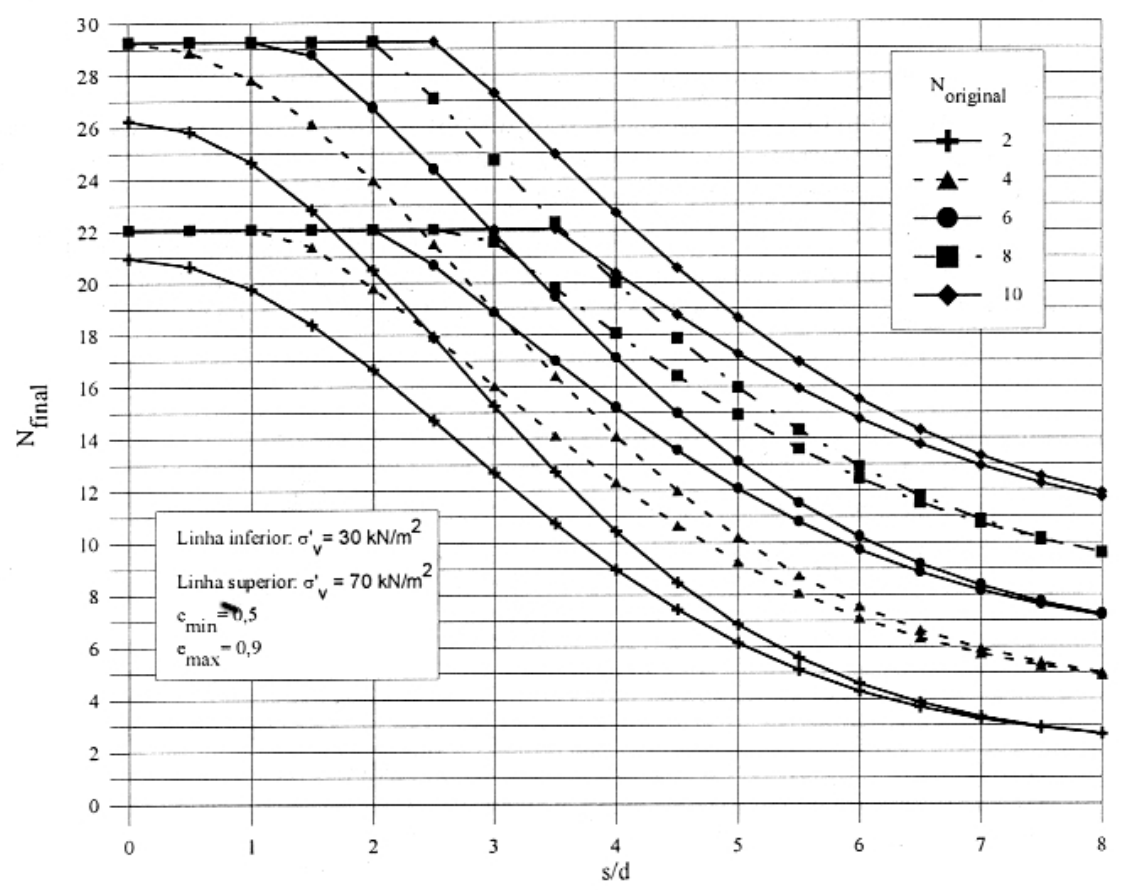

Figura 18. Ábaco para previsão do $\mathrm{N}_{\mathrm{SPT}}$ final (ALVES et al., 2000). 
O ábaco admite, como índices de vazios máximo e mínimo, os valores de 0,9 e 0,5 respectivamente, sendo $s$ o espaçamento entre estacas de eixo a eixo, e $d$, o diâmetro das mesmas.

\section{Recalques}

A previsão de recalques em solos não coesivos pode ser feita pelo método proposto por Schmertmann (1970), em que o recalque é obtido pela seguinte equação:

$\rho=C_{1} \cdot C_{2} \cdot \sigma^{*} \cdot \sum_{i=1}^{n}\left(\frac{I z}{E s}\right) \cdot \Delta z_{i}$

onde:

$\mathrm{C}_{1}=$ fator de correção que leva em conta o embutimento da fundação, dado pela seguinte expressão:

$C_{1}=1-0,5\left(\frac{q}{\sigma^{*}}\right) \geq 0,5$

$q$ = tensão efetiva na cota de apoio da fundação.

$\mathrm{C}_{2}=$ fator de correção que considera o aumento do recalque com o tempo:

$C_{2}=1+0,2 \log \left(\frac{t}{0,1}\right)$

$\mathrm{t}=$ tempo em anos.

$\sigma^{*}=$ tensão líquida aplicada pela fundação.

Es $=$ módulo de deformabilidade da i-ésima camada de espessura $\Delta \mathrm{z}_{\mathrm{i}}$. No caso de fundação por sapatas, Aoki \& Cintra (2002) utilizam a expressão: Es $=3 . \mathrm{K}_{\mathrm{AOKI}-\text { VELLOSO }} \cdot \mathrm{N}_{\mathrm{SPT}}$. 
Iz = fator de influência na deformação. É encontrado pelo seguinte gráfico:

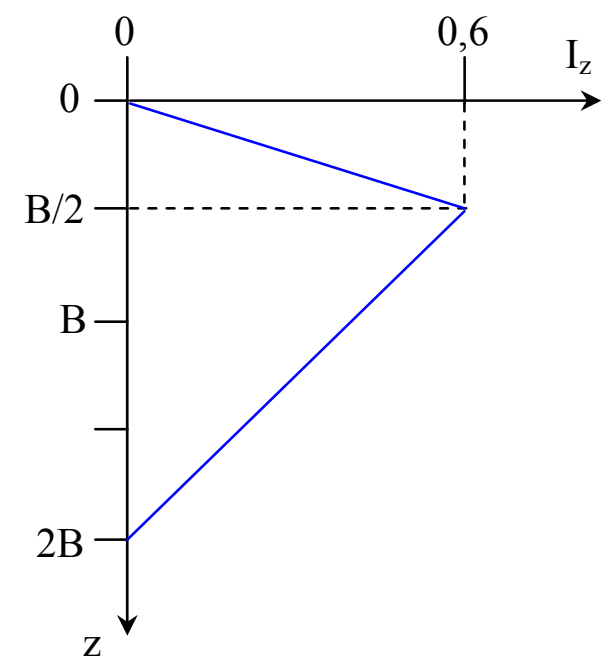

Figura 19. Fator de influência na deformação vertical (SCHMERTMANN, 1970).

Esse método foi aperfeiçoado em 1978 para destacar o caso de sapatas retangulares. Para sapatas quadradas a modificação não foi significativa. Por simplicidade de cálculo, será utilizado o método original de 1970.

\subsubsection{Ensaios de avaliação}

Após a execução da melhoria, alguns ensaios podem ser realizados com o intuito de se verificar a eficiência do tratamento. Os principais ensaios realizados são: Sondagens SPT, ensaios de Cone, Provas de Carga, Pressiômetro e retirada de amostras indeformadas, para verificação da densidade.

\subsubsection{Sondagem SPT}

MOH et al. (1981) afirmam que o Standard Penetration Test é o meio mais conveniente para se avaliar as condições de compactação de solos arenosos in situ. De fato, o SPT se constitui no ensaio mais utilizado como forma de verificação da eficiência da melhoria do solo. São usuais as comparações feitas com ensaios realizados antes e após o tratamento da fundação (Figura 20). 


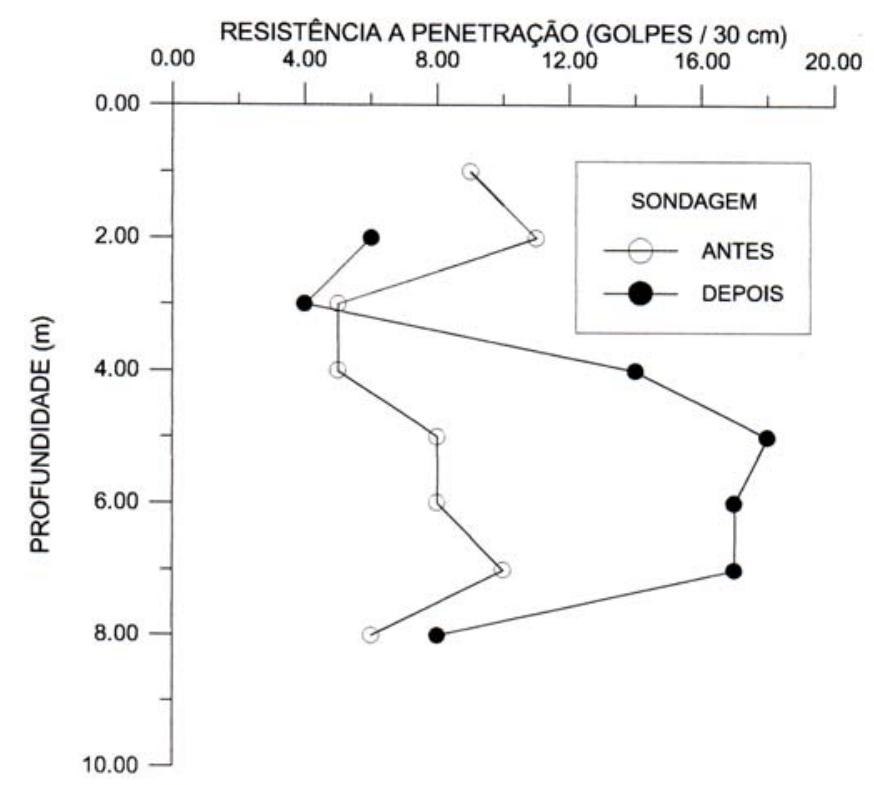

Figura 20. Sondagem antes e após tratamento (GUSMÃO, 2000b).

Através de métodos semi-empíricos, pode-se estimar a capacidade de carga bem como a compacidade relativa do solo, antes e após compactação.

\section{Capacidade de carga de fundações por sapata}

Segundo a NBR 6122/1996 Projeto e Execução de Fundações, os métodos semiempíricos são aqueles em que as propriedades dos materiais são estimadas com base em correlações e usadas em teorias de Mecânica dos Solos, adaptadas, para incluir a natureza semi-empírica do método. A estimativa de parâmetros de resistência e compressibilidade seria feita com base no índice de resistência à penetração $\mathrm{N}_{\mathrm{SPT}}$.

TERZAGHI \& PECK (1948) foram os primeiros a recomendar correlações entre $\mathrm{o}$ valor da resistência à penetração $\mathrm{N}_{\mathrm{SPT}} \mathrm{e}$ o valor da tensão admissível.

No Brasil, Leme, em 1953, foi o primeiro a correlacionar resultados de provas de carga sobre placa com a resistência à penetração medida com o amostrador e técnica de sondagem do IPT de São Paulo. TEIXEIRA (1966) também estabeleceu correlação entre provas de carga em placa e a resistência à penetração, medida com o amostrador Mohr-Geotécnica.

No campo do projeto de fundações tem ocorrido um contínuo aperfeiçoamento 
na estimativa da capacidade de carga das fundações em função dos índices de resistência à penetração $\mathrm{N}_{\mathrm{SPT}}$, medidos nas sondagens de simples reconhecimento, uma vez que outros processos de investigações geotécnicas, considerados mais completos, não têm tido uso mais generalizado no Brasil.

TEIXEIRA (1996) demonstrou fórmulas para a estimativa da tensão admissível de solos argilosos e arenosos, em função do índice de resistência à penetração $\left(\mathrm{N}_{\mathrm{SPT}}\right)$ :

- Solos argilosos: Partindo-se da fórmula de SKEMPTON (1951), para capacidade de carga de fundações por sapata: $\sigma_{\mathrm{r}}=\mathrm{S}_{\mathrm{u}} \mathrm{N}_{\mathrm{c}}=6 \mathrm{~S}_{\mathrm{u}}$. Considerando-se a correlação entre a resistência ao cisalhamento não-drenado e o $\mathrm{N}_{\mathrm{SPT}}$ : $\mathrm{Su}=10 \mathrm{~N}_{\mathrm{SPT}}(\mathrm{kPa})$ e o coeficiente de segurança em relação à ruptura de 3 resulta a tensão admissível de:

$$
\sigma_{a}=\frac{N_{S P T}}{50} \quad(M P a)
$$

Recomenda-se utilizar esta correlação para o intervalo de $5<\mathrm{N}_{\mathrm{SPT}}<25$

- Solos arenosos: Partindo-se da fórmula clássica de Terzaghi para capacidade de carga de fundações por sapata quadrada apoiadas em areia:

$$
\sigma_{r}=\gamma \cdot H \cdot N_{q}+0,4 \cdot \gamma \cdot B \cdot N_{\gamma}
$$

Considerando-se a correlação entre ângulo de atrito interno das areias com o $\mathrm{N}_{\mathrm{SPT}}: \phi=\sqrt{20 \cdot N}+15$ e para $\mathrm{H}=1,5 \mathrm{~m}, \gamma=18 \mathrm{kN} / \mathrm{m}^{3}$ e coeficiente de segurança em relação à ruptura de 3, resulta a tensão admissível:

$$
\sigma_{\mathrm{a}}=50+(10+4 \mathrm{~B}) \mathrm{N}_{\mathrm{SPT}}
$$

(B em metros e $\sigma_{\mathrm{a}}$ em $\mathrm{kPa}$ )

Onde: $\mathrm{B}=$ lado da sapata; $\mathrm{N}_{\mathrm{SPT}}=$ índice de resistência à penetração $\left(5<\mathrm{N}_{\mathrm{SPT}}<25\right)$

TEIXEIRA (1996) cita que tais valores são compatíveis com os resultados da experiência de execução de fundações diretas rasas apoiadas nas areias médias argilosas da bacia terciária de São Paulo, conforme relatado por VARGAS (1955), e apresentado na Figura 21. 


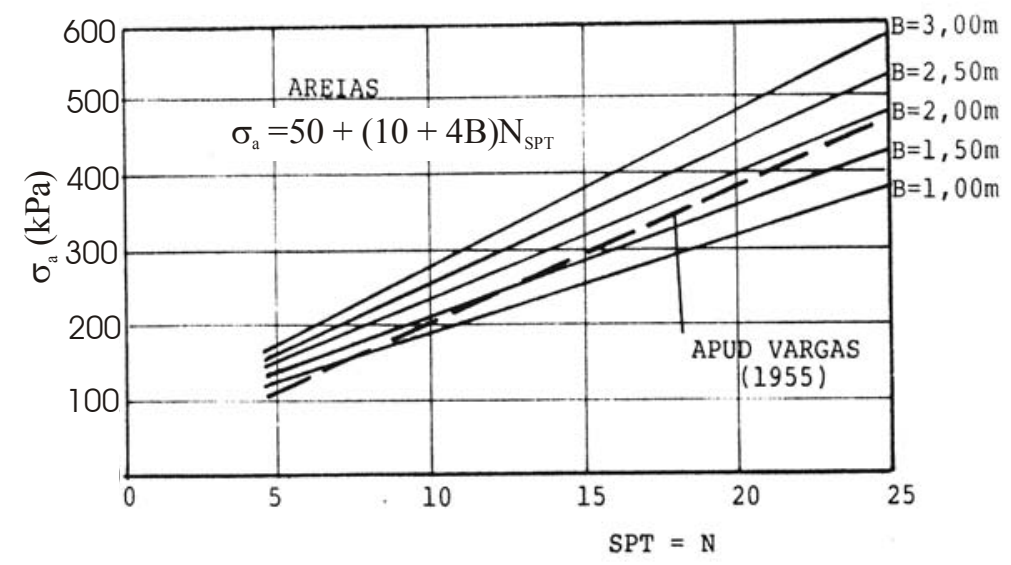

Figura 21. Tensões admissíveis das areias em função do $\mathrm{N}_{\text {SPT }}$ para sapatas quadradas de lado B (Teixeira, 1996).

\section{Compacidade relativa}

Para solos granulares, existem algumas correlações entre o $\mathrm{N}_{\mathrm{SPT}}$ e a compacidade relativa $D_{\mathrm{r}}$. As proposições de GIBBS \& HOLTZ (1957) e SKEMPTON (1986) são, respectivamente:

$\mathrm{D}_{\mathrm{r}}=\left(\frac{N}{0,23 \sigma^{\prime}{ }_{\mathrm{vo}}+16}\right)^{\frac{1}{2}}$

$\mathrm{D}_{\mathrm{r}}=\left(\frac{N}{0,28 \sigma_{{ }_{v o}}^{\prime}+27}\right)^{\frac{1}{2}}$

\subsubsection{Ensaio de Cone}

Este ensaio fornece resultados mais confiáveis na avaliação da compacidade de solos não coesivos. Da mesma forma que no caso do SPT, é necessário obter uma correlação para encontrar a compacidade relativa.

As principais vantagens do ensaio são o registro contínuo da resistência à penetração, fornecendo uma descrição detalhada da estratigrafia do subsolo, e a eliminação de qualquer influência do operador nas medidas de ensaio. 
Sua aparelhagem, procedimentos de execução do ensaio e resultados são normatizados pela MB-3406 Solo - Ensaio de Penetração de Cone In Situ (CPT).

\section{Capacidade de carga de fundações por sapata}

O U.S. DEPARTMENT OF TRANSPORTATION (1978) apresenta valores para os fatores de capacidade de carga $\mathrm{N} \gamma$ e $\mathrm{N}_{\mathrm{q}}$, em função da resistência de ponta $\left(\mathrm{q}_{\mathrm{c}}\right)$ :

$0,08 \mathrm{~N}_{\gamma}=0,08 \mathrm{~N}_{\mathrm{q}} \cong \mathrm{q}_{\mathrm{c}} \quad(\mathrm{MPa})$

para uso na fórmula geral de Terzaghi, para determinação da capacidade de carga do elemento de fundação por sapata. Os valores são válidos para $\mathrm{H} / \mathrm{B}<1,5$ :

$\sigma_{r}=\gamma \frac{B}{2} N_{\gamma}+\gamma H N_{q}+c N_{c}$

Onde: $\sigma_{\mathrm{r}}=$ a tensão de ruptura, $\gamma=$ peso específico do solo, $\mathrm{B}=$ largura da sapata, $\mathrm{H}=$ profundidade, $\mathrm{c}=$ coesão, e $\mathrm{N}_{\mathrm{c}}, \mathrm{N}_{\gamma}$ e $\mathrm{N}_{\mathrm{q}}$ são os fatores de capacidade de carga.

A tensão admissível também pode ser estimada com base nos valores de resistência de ponta $\mathrm{q}_{\mathrm{c}}$, por meio do seguinte método empírico (TEIXEIRA \& GODOY, 1996):

- Sapatas apoiadas sobre argilas:

$$
\sigma_{\mathrm{a}}=\mathrm{q}_{\mathrm{c}} / 10(\mathrm{MPa})
$$

- Sapatas apoiadas sobre areias:

$$
\sigma_{\mathrm{a}}=\mathrm{q}_{\mathrm{c}} / 15(\mathrm{MPa})
$$

Onde $\mathrm{q}_{\mathrm{c}}$ é a média dos valores dentro do bulbo de tensões. 


\section{Compacidade relativa}

Segundo SCHNAID (2000), a compacidade relativa pode ser determinada pela seguinte relação:

$\mathrm{D}_{\mathrm{r}}=-98+66 \log _{10} \frac{q_{c}}{\left(\sigma_{\text {vo }}^{\prime}\right)^{0,5}}$

\subsubsection{Prova de carga sobre placa}

A prova de carga sobre placa consiste no ensaio de um modelo reduzido do elemento isolado de fundação. Essa técnica procura reproduzir o comportamento da solicitação de uma fundação e sua execução é regulamentada pela NBR-6489 Prova de Carga Direta Sobre Terreno de Fundação.

\subsubsection{Pressiômetro}

O módulo de deformabilidade determinado neste ensaio fornece uma medida direta da compressibilidade do solo. Esse é o parâmetro de maior interesse geotécnico na realização de ensaios pressiométricos, já que são reconhecidas as dificuldades em determiná-lo através de outros ensaios de campo e laboratório. Não é um ensaio usual na área de melhoria do terreno.

\subsubsection{Ensaios de laboratório em amostras indeformadas}

Mediante a determinação do peso específico e o teor de umidade do solo removido de uma amostra cilíndrica de volume conhecido, pode-se quantificar a melhoria em termos de compacidade. 


\subsubsection{Mecanismos de ruptura}

As estacas de compactação apresentam três tipos de ruptura. O primeiro tipo é a por cisalhamento, mostrada na Figura 22a. É considerada a mais apropriada nas teorias convencionais e ocorre quando o comprimento das estacas é três vezes maior que o comprimento da área carregada.

O segundo tipo de ruptura é o empolamento, mostrado na Figura 22b, o qual tem sido observado em estacas de areia instaladas em solos moles por HUGHES \& WITHERS (1974). Já nas estacas instaladas em materiais menos compressíveis, GOUGHNOUR (1988) observa que o fenômeno do empolamento geralmente é insignificante, e são usuais as análises baseadas na teoria da elasticidade. Segundo SHAHU et al. (1975), o empolamento e a conseqüente ruptura da estaca de areia ocorrem, principalmente, devido à alta concentração de tensão perto do topo da estaca, em uma profundidade de um a dois diâmetros.

O terceiro modo de ruptura, mostrado na Figura 22c, é similar à ação de uma estaca rígida, em que é esperada a ocorrência de pequenos deslocamentos laterais no material da estaca.

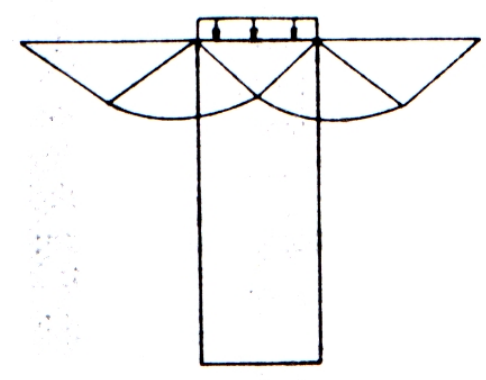

a) Ruptura por cisalhamento

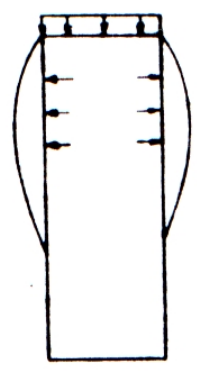

b) Empolamento

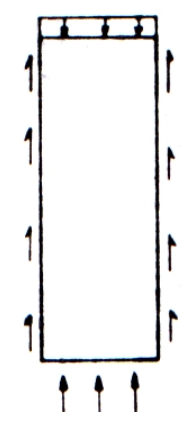

c) Estaca rígida

Figura 22. Mecanismos de ruptura (Madhav \& Vitkar, 1978). 


\section{CAPÍTULO 3 - CAMPO EXPERIMENTAL DE FUNDAÇÕES}

Para a elaboração desta pesquisa, foram realizados ensaios no Campo Experimental de Fundações das empresas Concresolo - Consultoria em Concreto e Solos Ltda. e Copesolo - Estacas e Fundações Ltda. O campo experimental localiza-se na região litorânea da cidade de João Pessoa / PB e apresenta as dimensões de $30 \times 50 \mathrm{~m}^{2}$.

O campo experimental foi implantado para pesquisas da empresa e para projetos em parceria com universidades. Os primeiros ensaios foram realizados com equipamentos de execução de estacas escavadas no ano de 1997. Em seguida, realizaram-se ensaios de CPT elétrico, em uma pesquisa em parceria com a UFCG Universidade Federal de Campina Grande. No ano de 2001, foram instaladas estacas de compactação, para a realização desta pesquisa, visando, principalmente, a analisar o comportamento de fundações rasas, apoiadas em solo melhorado com estacas de compactação. Recentemente, o Campo Experimental passou a abrigar pesquisas com equipamentos de execução de estacas ômega.

O maciço de solo foi caracterizado geotecnicamente por meio da realização de ensaios in situ, como SPT e CPT, e ensaios de laboratório, como granulometria. Alguns dos resultados obtidos são apresentados neste capítulo.

A região do Campo Experimental encontra-se no Litoral Norte de João Pessoa, em uma área com perfil geológico-geotécnico considerado representativo de toda região litorânea da cidade. A prática de fundações nessa área é constituída, em sua grande maioria, por estacas de compactação, visto que seu subsolo arenoso favorece o uso de tal técnica. Outros tipos de fundação comuns na área são as estacas tipo Franki, 
utilizadas quando a solução de fundação por sapata, em solo compactado, não é aprovada, por ultrapassar os limites toleráveis de recalques diferenciais e distorcionais. Menos comuns são as fundações por estacas pré-moldadas e metálicas, estas geralmente apoiadas na rocha calcária, localizada a aproximadamente $24 \mathrm{~m}$ de profundidade.

A parte alta da cidade apresenta um subsolo mais coesivo, com predominância de siltes-argilosos e ausência de nível d'água superficial. Nessa área, os tipos de fundações mais comuns são as estacas escavadas e tubulões.

\subsection{Caracterização geológica}

De acordo com GUSMÃO FILHO (1982), João Pessoa situa-se sobre a formação sedimentar Barreiras, com sotoposição de calcários e arenitos, para chegar ao cristalino que aflora ocasionalmente.

Segundo CONCIANI et al. (1999), a região litorânea de João Pessoa apresenta um subsolo arenoso composto por sedimentos marinhos do período holoceno (era quaternária), os quais são constituídos por areias sobrepostas em camadas de diferentes graus de compacidade. Tal estratificação pode ter sua origem nos movimentos de transgressão e regressão do mar ocorridos em eras passadas.

Em alguns pontos, a linha costeira é cortada por afloramento de rochas que permanecem resistentes à ação erosiva, formando cabos e pontas. $\mathrm{O}$ solo superficial é predominantemente granular, sendo constituído de areias e siltes geralmente fofos $\left(\mathrm{N}_{\mathrm{SPT}}<5\right)$. 


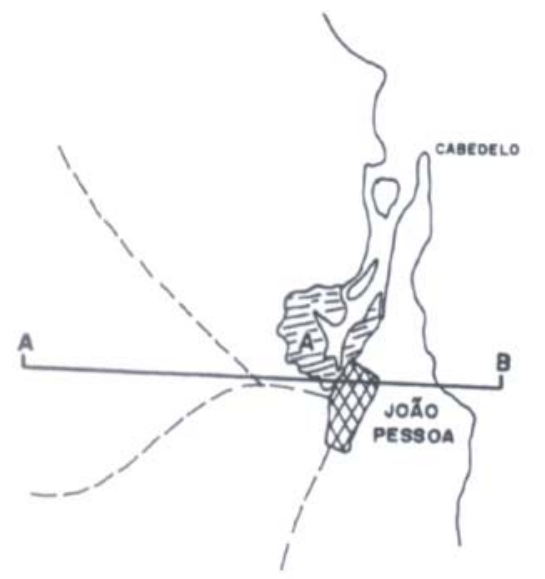

$$
\stackrel{N}{N}
$$

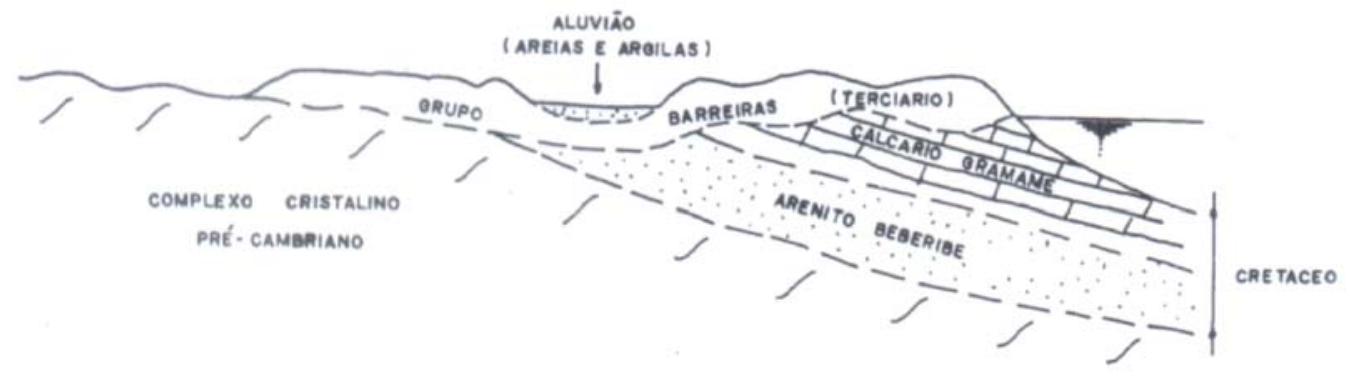

A

8

Figura 23. Perfil geológico da cidade de João Pessoa (GUSMÃO FILHO, 1982) 


\subsection{Caracterização geotécnica}

\subsubsection{Ensaios in situ}

No total, foram realizados 17 ensaios penetrométricos in situ, sendo nove sondagens à percussão (SPT) e oito ensaios de penetração estática (CPT). A disposição dos furos encontra-se no Apêndice I.

A Figura 24 mostra o perfil estratigráfico do Campo Experimental obtido mediante três furos de Sondagem SPT. Observa-se uma camada superficial de areia fina, cor cinza, com cerca de 2,50 m de espessura. Abaixo dessa, há camadas de areia fina com uma porção siltosa, com cores marrons e cinza até a profundidade de, aproximadamente, 11,0 m, onde aparece uma camada de areia fina silto-argilosa de cor variegada. O nível d'água encontra-se à profundidade de $1,80 \mathrm{~m}$.

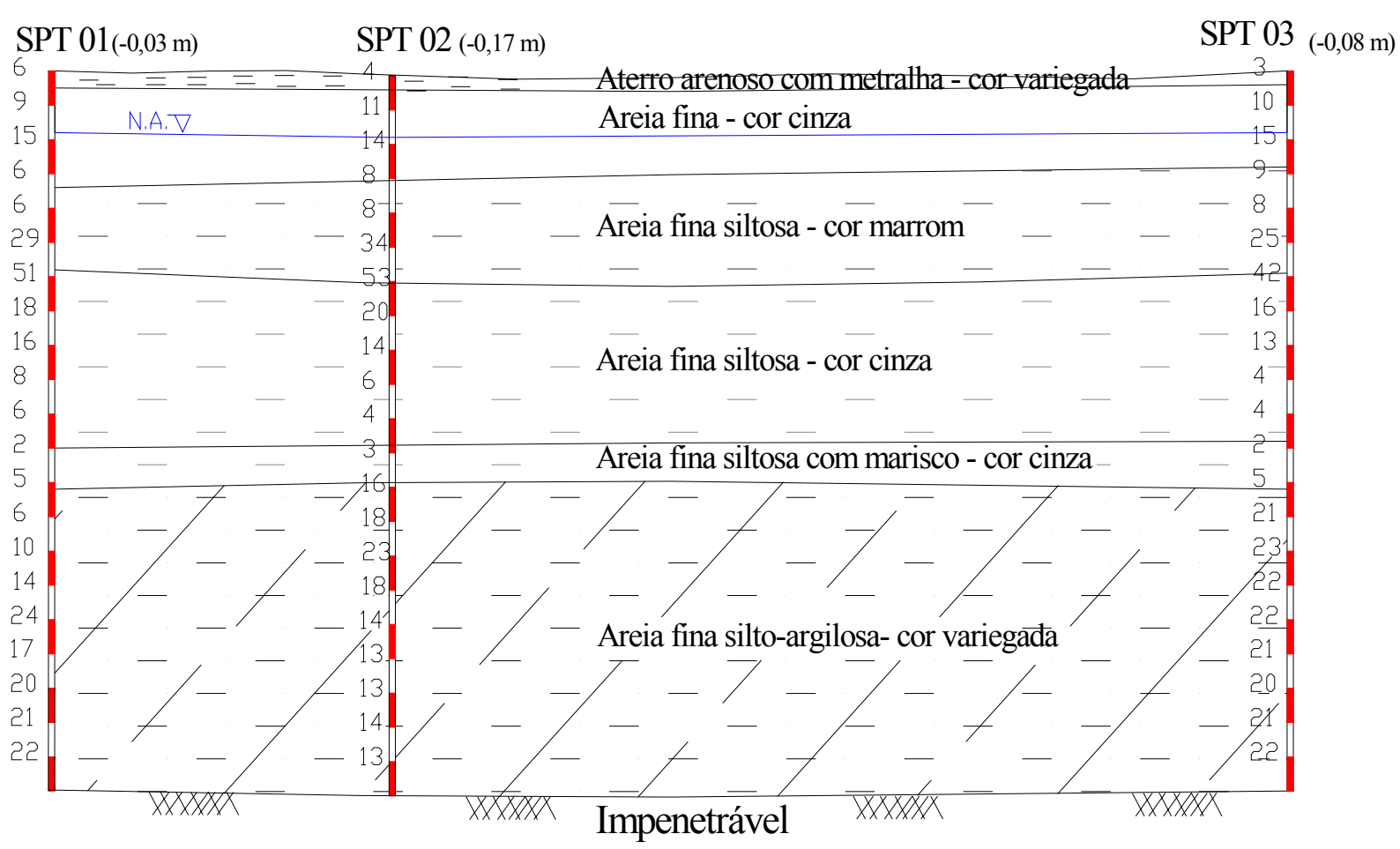

Figura 24. Perfil estratigráfico do Campo Experimental. 


\subsubsection{Ensaios de laboratório}

Realizou-se, no laboratório, o ensaio de peneiramento da camada de areia fina situada até $3 \mathrm{~m}$ de profundidade, obtendo-se a curva granulométrica apresentada na Figura 25. Observa-se que essa curva se encontra dentro da faixa de ocorrência de solos em que a técnica de estacas de areia é mais eficiente.

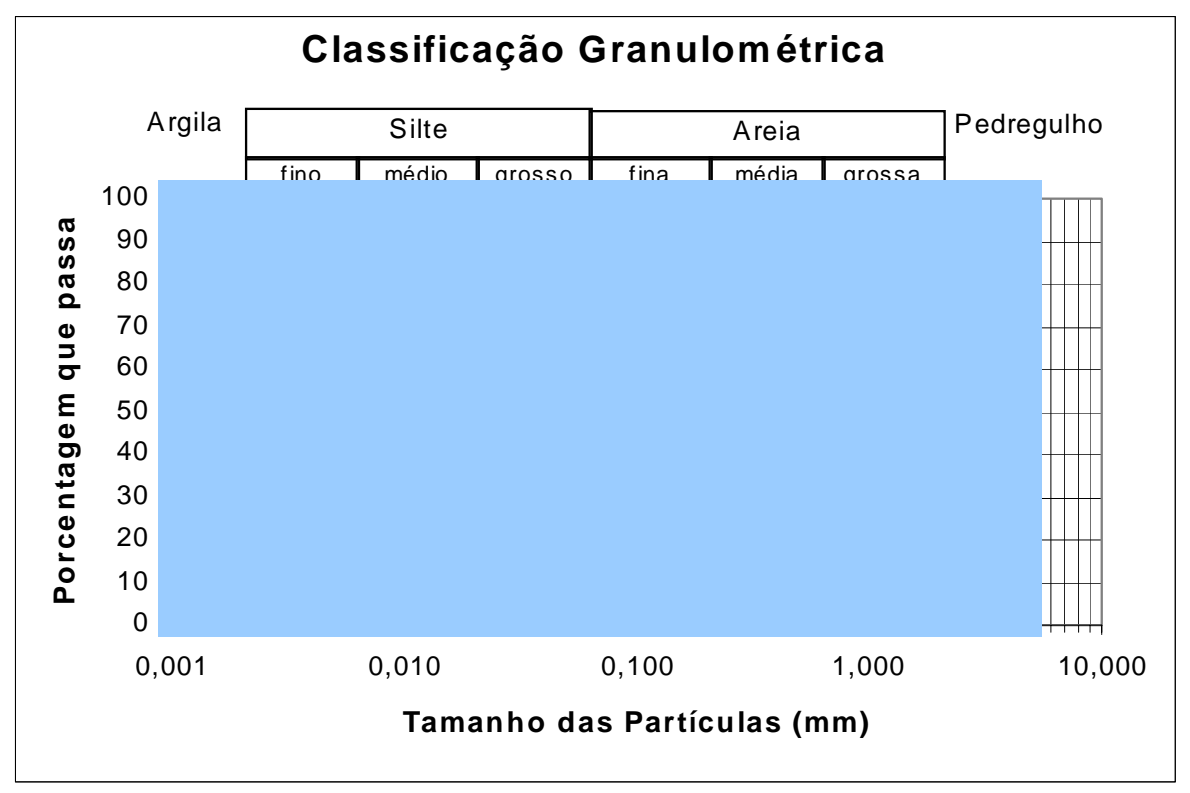

Figura 25. Curva granulométrica.

As características granulométricas representativas do maciço de solo do Campo Experimental são apresentadas na Tabela 1.

Tabela 1. Frações granulométricas constituintes do solo.

\begin{tabular}{c|ccc}
\hline \multirow{2}{*}{ Profundidade (m) } & \multicolumn{3}{|c}{ Areia } \\
\cline { 2 - 4 } $0-3 \mathrm{~m}$ & Fina (\%) & Média (\%) & Grossa (\%) \\
& 20,0 & 29,0 & 51,0 \\
\hline
\end{tabular}

Coeficiente de não uniformidade $\mathrm{Cu}=4,67$

Coeficiente de curvatura $\mathrm{Cc}=0,85$ 
A curva granulométrica do material de aterro usado nas estacas é apresentada na Figura 26.

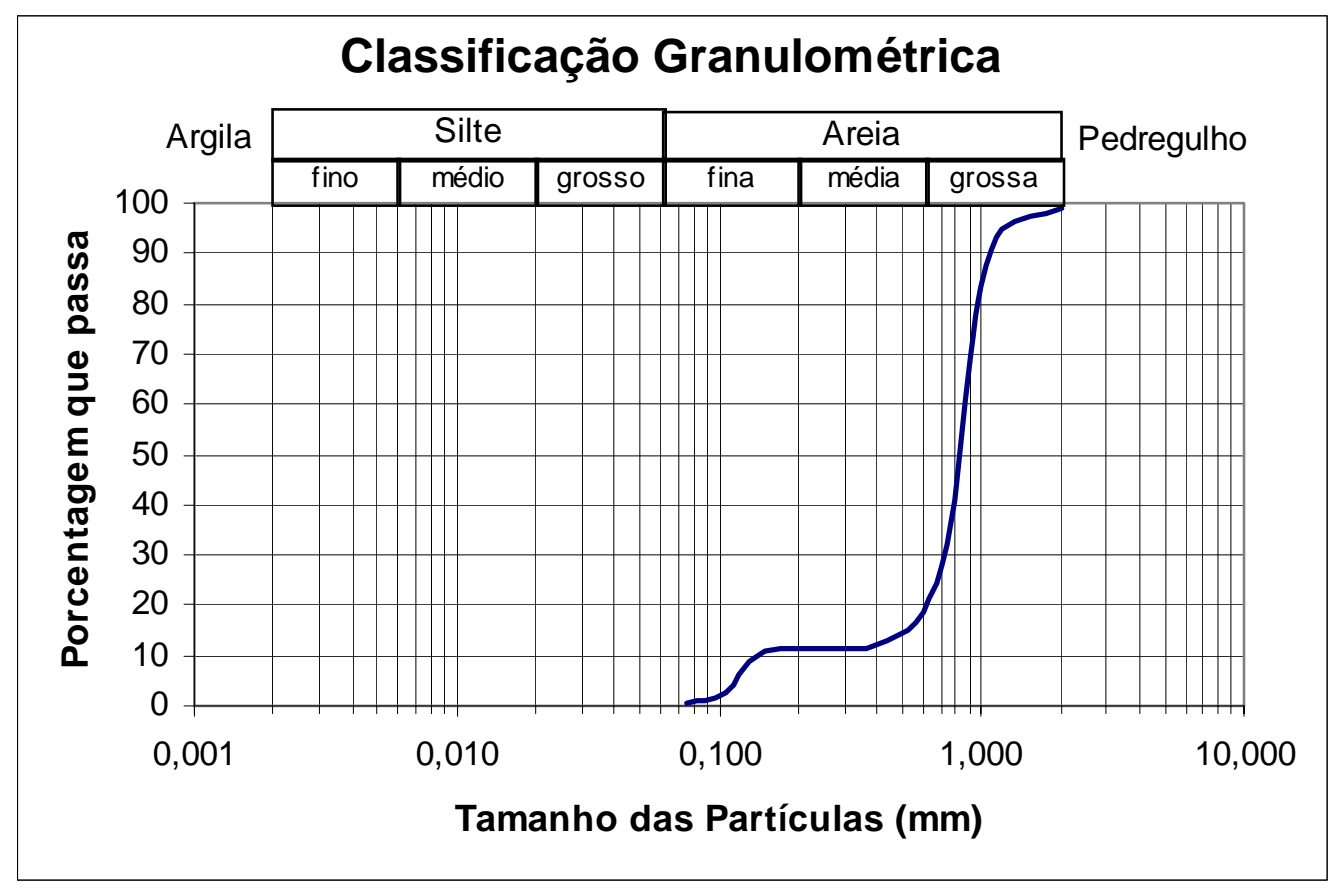

Figura 26. Curva granulométrica do material de aterro das estacas

A tabela 2 apresenta as características granulométricas do material de aterro das estacas.

Tabela 2. Frações granulométricas constituintes do material de aterro.

\begin{tabular}{c|ccc}
\hline \multirow{2}{*}{ Profundidade (m) } & \multicolumn{3}{|c}{ Areia } \\
\cline { 2 - 4 } $0-3 \mathrm{~m}$ & Fina (\%) & Média (\%) & Grossa (\%) \\
& 11,0 & 8,0 & 81,0 \\
\hline
\end{tabular}

Coeficiente de não uniformidade $\mathrm{Cu}=4,25$

Coeficiente de curvatura $\mathrm{Cc}=2,88$ 


\section{CAPÍTULO 4 - MATERIAIS E EQUIPAMENTOS}

\subsection{Sondagem SPT}

O equipamento utilizado na execução da campanha de Sondagens SPT é o equipamento padrão, segundo a NBR 6484/2001 Solo -Sondagens de simples reconhecimento com SPT.

\subsection{Ensaio de Cone}

O equipamento utilizado na realização dos ensaios e penetração estáticos é um CPT do tipo mecânico com uma carga limite de trabalho de $90 \mathrm{kN}$, que corresponde a $40 \mathrm{MPa}$ de leitura no manômetro (Figura 27). Algumas características do equipamento são dadas a seguir:

Capacidade nominal de carga da prensa $100 \mathrm{kN}$

Sistema de ancoragem .... 04 tirantes

Tirantes: Profundidade $2,0 \mathrm{~m}$

Diâmetro Externo $152 \mathrm{~mm}$

Diâmetro da barra $20 \mathrm{~mm}$

Ponteira leituras total e de ponta

Hastes de penetração:

Comprimento 1,0 metro/tubo

Diâmetro externo $36 \mathrm{~mm}$ 


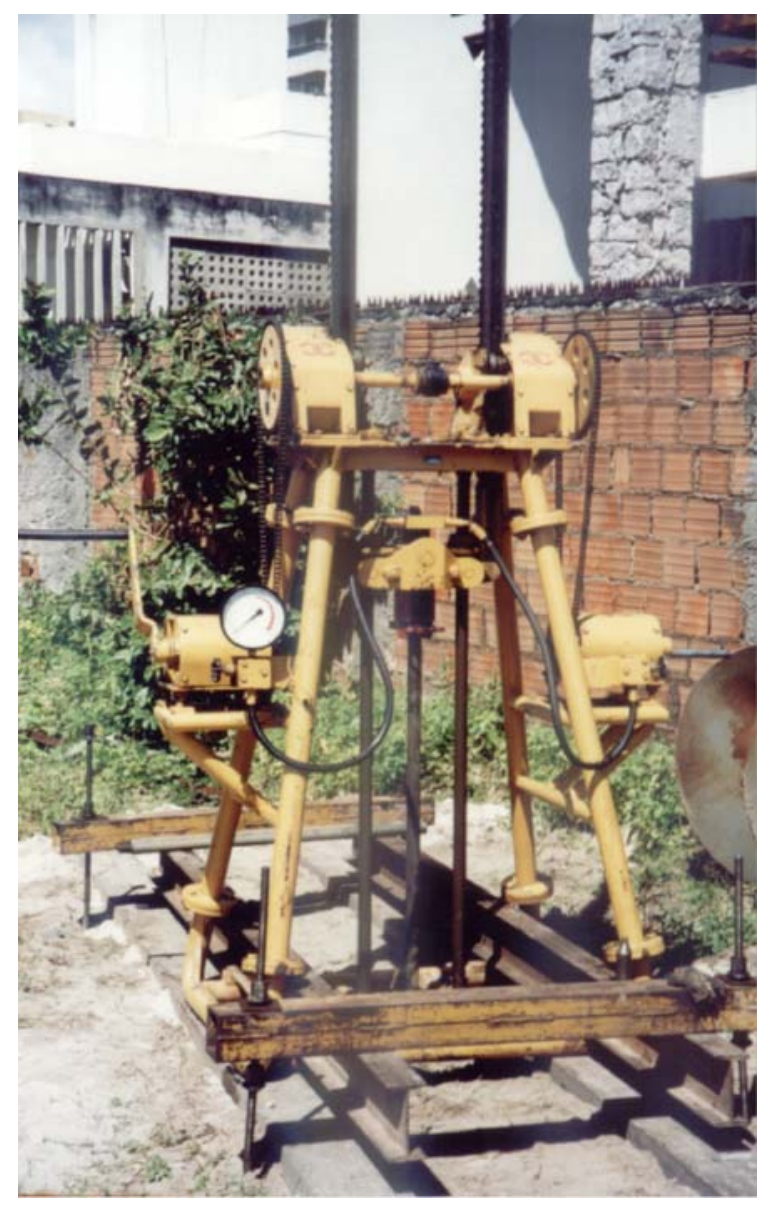

Figura 27. Cone mecânico.

\subsection{Prova de carga sobre placa}

A seguir, são apresentados os equipamentos utilizados nas provas de carga sobre placa.

\section{Macaco hidráulico}

O macaco hidráulico utilizado possui forma cilíndrica com curso máximo de 0,15 m (Figura 28). Sua capacidade de aplicação de carga é de até $250 \mathrm{kN}$, sendo seu acionamento efetuado por bomba manual. 


\section{Bomba manual}

A bomba usada foi do tipo hidráulica manual, com mangueira de alta pressão e capacidade máxima de $70 \mathrm{MPa}$.

\section{Célula de carga}

Utilizou-se uma célula de carga tipo disco modelo LPX 50000, marca PT, com capacidade de realizar leituras até $500 \mathrm{kN}$. A Figura 28 apresenta a célula de carga utilizada.

\section{Indicador de carga}

Empregou-se um indicador digital para a célula de carga, com indicação de pico superior, inferior e função de tara.

\section{Extensômetros mecânicos}

Os deslocamentos verticais, na placa, foram medidos com quatro extensômetros da marca Mitutoyo, com escala máxima de 50,0 mm e resolução de $0,01 \mathrm{~mm}$.

Como os ensaios deveriam ser realizados na profundidade de $1,5 \mathrm{~m}$, foram utilizadas barras de aço de $12 \mathrm{~mm}$ de diâmetro como elemento de ligação entre a placa, no fundo da cava, e os extensômetros na superfície.

Os extensômetros foram instalados em dois pares, diametralmente opostos e apoiados em pequenas placas quadradas de azulejo, coladas nas barras de aço (Figura 28). Usaram-se, como suporte, bases magnéticas articuláveis.

\section{Rótula}

A fim de manter a verticalidade do carregamento, usou-se uma rótula maciça de aço, posicionada entre a célula de carga e a viga de reação, com diâmetro de base de $0,20 \mathrm{~m}$ e altura de $0,15 \mathrm{~m}$. 


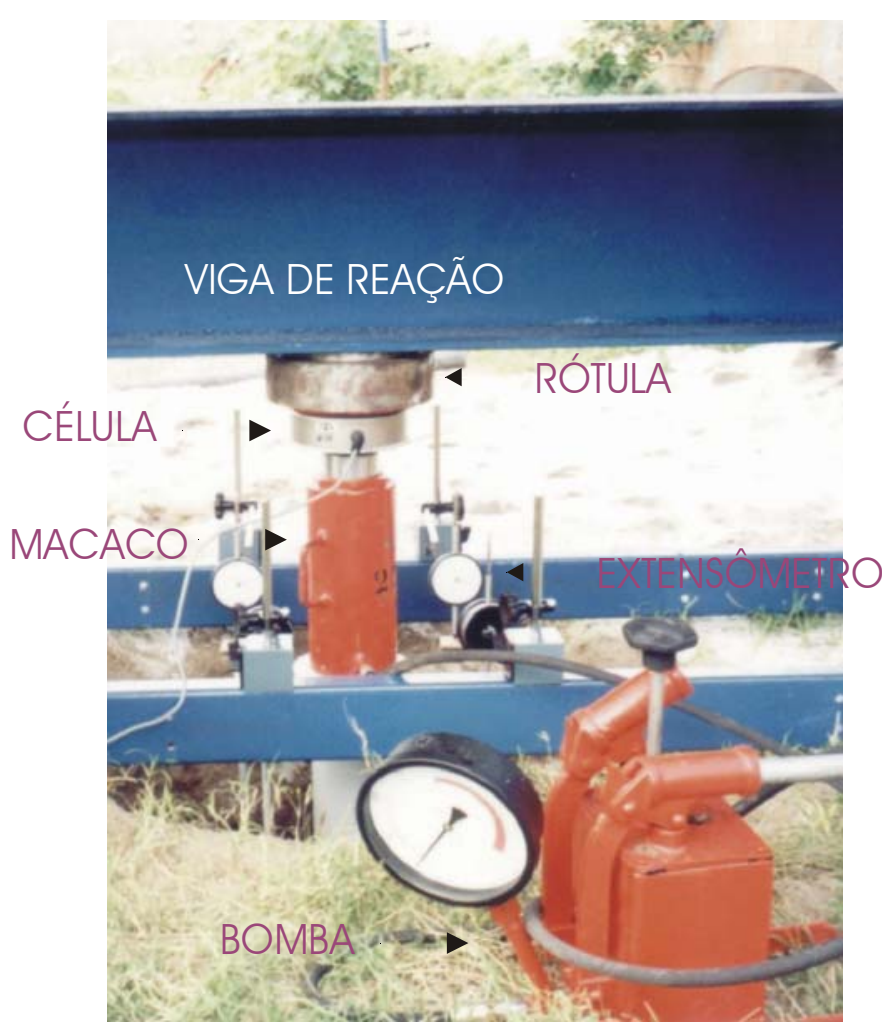

Figura 28. Equipamentos da prova de carga.

\section{Torre de transferência de carga}

Para transferir a carga aplicada pelo macaco hidráulico até a placa, apoiada a 1,5 $\mathrm{m}$ de profundidade, foi utilizada uma torre de aço cilíndrica de 1,60 $\mathrm{m}$ de comprimento, $0,17 \mathrm{~m}$ de diâmetro externo e parede de $10 \mathrm{~mm}$ de espessura.

\section{Elementos de referência}

Como sistema de referência, para medição dos deslocamentos, foram usadas duas vigas de aço de 3,3 $\mathrm{m}$ de comprimento e com perfil $\mathrm{U}$, em que eram dispostas as bases magnéticas dos extensômetros. As vigas foram presas a pontaletes metálicos cravados no solo. 


\section{Sistema de reação}

Utilizou-se um sistema de reação misto, com uma viga metálica presa em quatro estacas de reação mais uma sobrecarga ("cargueira"). A viga metálica principal possui seção transversal em I com $200 \times 320 \mathrm{~mm}$ e comprimento de $3,30 \mathrm{~m}$ e as duas vigas metálicas secundárias possuem seção circular com $20 \mathrm{~cm}$ de diâmetro e espessura de $15 \mathrm{~mm}$.

As estacas de reação eram metálicas, perfil I 80 × $50 \mathrm{~mm}$ e comprimento de 5,0 m. A "cargueira" era formada por estacas pré-moldadas de concreto armado, com o peso total de $48 \mathrm{kN}$. O esquema geral das provas de carga e seu sistema de reação são mostrados nas Figuras 29 e 30.

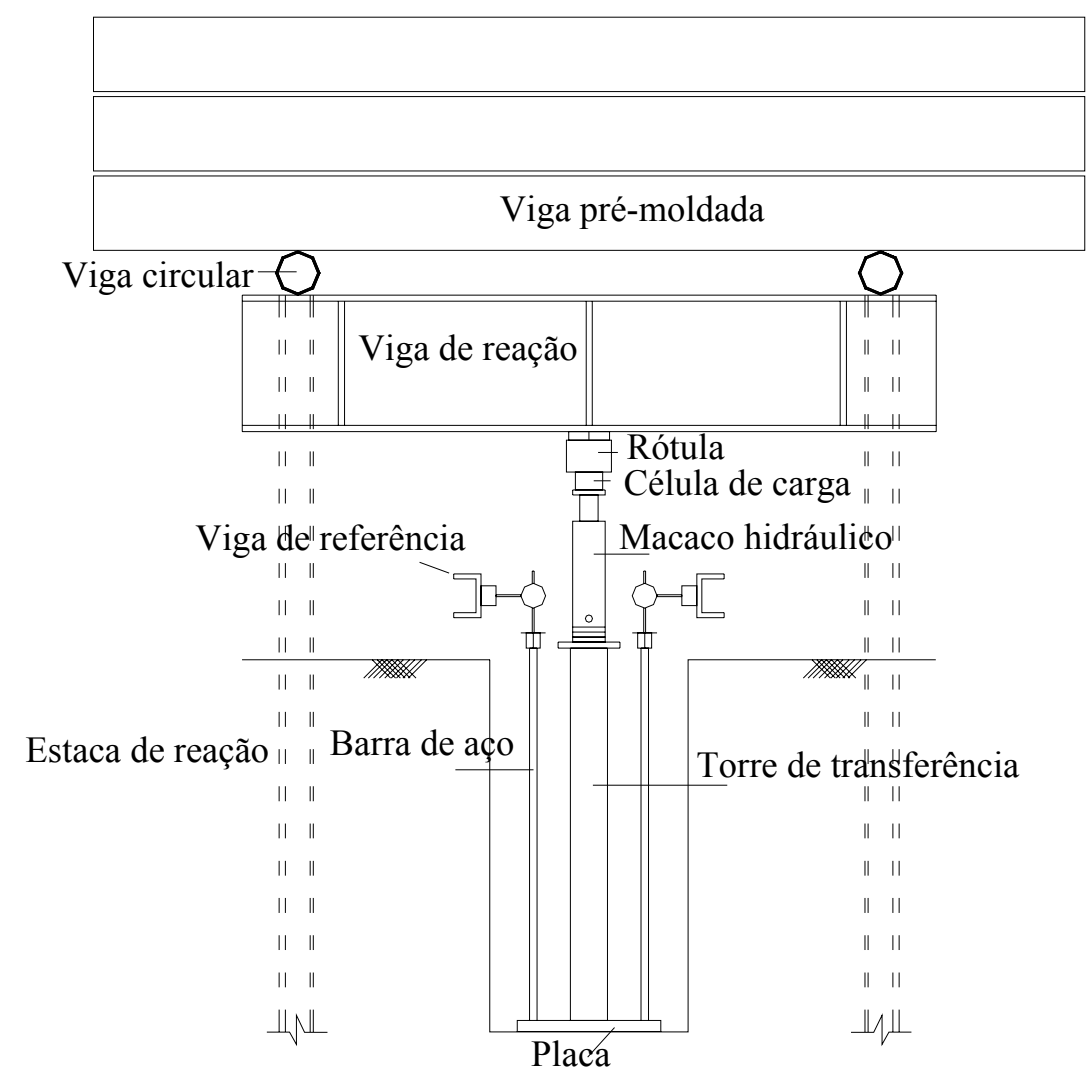

Figura 29. Esquema geral da prova de carga. 


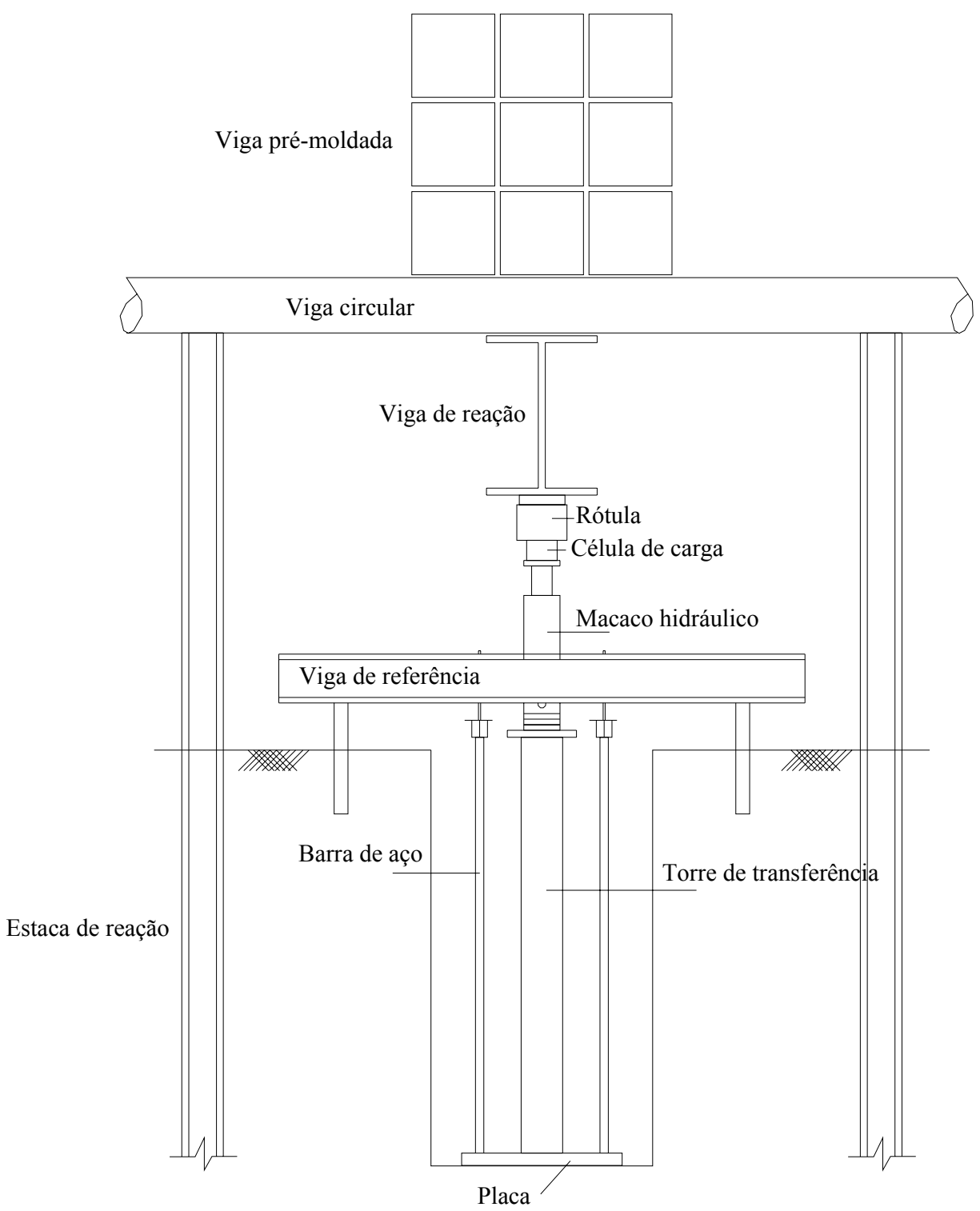

Figura 30. Vista lateral do sistema de reação.

\section{Barraca}

Todo o sistema de reação e equipamentos das provas de carga eram protegidos por uma barraca fabricada em estrutura metálica e lona. 


\section{CAPÍTULO 5 - MÉTODOS E PROCEDIMENTOS}

\subsection{Instalação das estacas de compactação}

O campo experimental foi dividido em quatro áreas: uma referente ao solo no estado natural, e as outras três referentes ao solo no estado compactado. Em terreno natural, realizaram-se três ensaios de Sondagem SPT, dois ensaios de Cone e duas provas de carga sobre placa.

Em cada área compactada, foi executada uma malha de estacas de areia e cimento, no traço de 1:15 em volume. As estacas foram executadas pelo método do vibro-deslocamento, com diâmetro de $30 \mathrm{~cm}$ e profundidade de $3,5 \mathrm{~m}$. Cada malha possui 16 estacas, formando um quadrado ( $4 \times 4$ ), com espaçamento entre eixos de estacas de 80, 90 e $100 \mathrm{~cm}$, respectivamente. O Apêndice I mostra a locação do campo experimental, e a Tabela 3 apresenta os dados de execução das estacas.

Tabela 3. Dados de cravação.

\begin{tabular}{c|c} 
Peso do pilão & $13 \mathrm{kN}$ \\
Altura de queda do pilão & $3,30 \mathrm{~m}$ \\
Comprimento do tubo & $3,50 \mathrm{~m}$ \\
Número de golpes/min & 15
\end{tabular}


Em cada malha de estacas, foram realizados dois ensaios de Sondagem SPT, dois de Cone e duas provas de carga sobre placa, além da anotação do diagrama de cravação das estacas, visando a analisar o comportamento do solo no estado compactado. Cada ensaio foi realizado na região de solo localizada entre as estacas, mais precisamente no ponto situado no meio da distância entre estacas, teoricamente o ponto de menor resistência. Um ensaio foi realizado no centro geométrico da malha, e outro, em uma posição periférica. As estacas não foram ensaiadas, pois esse trabalho tem como objetivo analisá-las como método de melhoria do maciço de solo, e não como elemento isolado de fundação. A Figura 31 ilustra o posicionamento dos ensaios em uma malha de estacas.
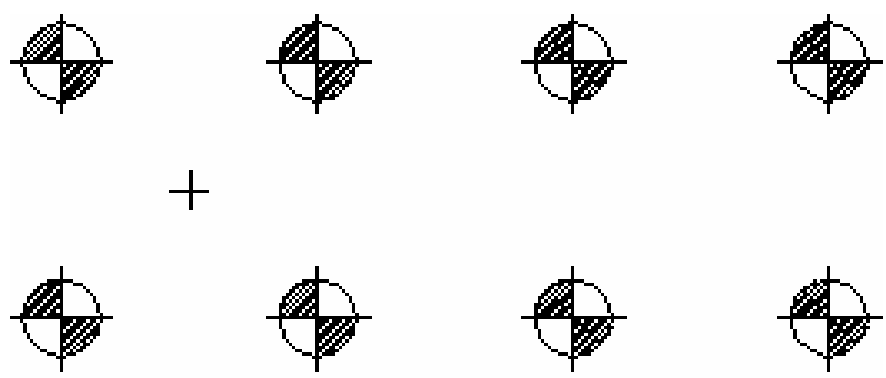

$+$
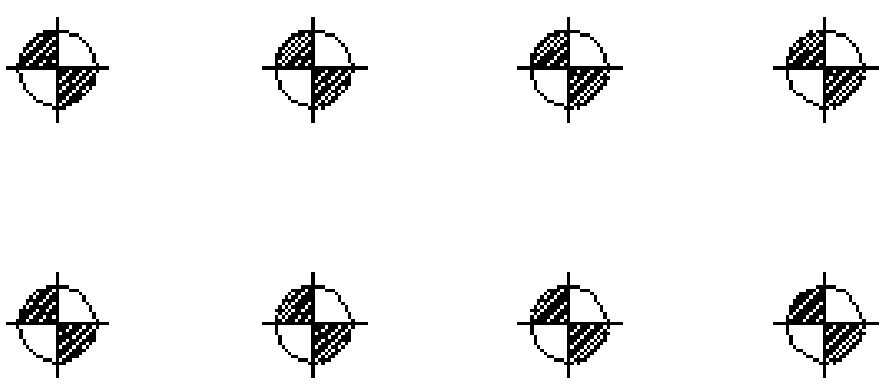

Figura 31. Posição dos ensaios em uma malha de estacas.

\section{2 - Sondagem SPT}

Os ensaios de SPT foram realizados segundo as recomendações da NBR 6484 Execução de Sondagens de Simples Reconhecimento dos Solos. No solo compactado, atingiram a profundidade de $12 \mathrm{~m}$, visto que, a partir dos $5 \mathrm{~m}$ de profundidade, os 
efeitos da compactação são pouco notados. A locação dos furos é mostrada no Apêndice I.

\subsection{Ensaio de Cone}

Os ensaios de penetração estática foram executados segundo os preceitos da $\mathrm{MB}$ 3406 Solo - Ensaio de Penetração de Cone in situ (CPT). A profundidade alcançada em cada ensaio foi bastante influenciada pela resistência apresentada pela camada de solo superficial, submetido ao processo de compactação, que permitiu que a tensão mobilizada na cravação atingisse a tensão limite de trabalho da prensa em profundidades inferiores a oito metros. O Apêndice I apresenta a locação dos ensaios no campo experimental.

\subsection{Prova de carga sobre placa}

As provas de carga foram executadas em uma placa de $40 \mathrm{~cm}$ de diâmetro, instalada a uma profundidade de $1,5 \mathrm{~m}$. A escolha da placa de $40 \mathrm{~cm}$ se dá pela limitação do sistema de reação. Da mesma forma, a escolha da profundidade de $1,5 \mathrm{~m}$ deve-se ao fato de que em profundidades menores, os efeitos da compactação são pouco notados. No total, foram realizadas oito provas de carga, sendo duas em terreno natural e duas em cada malha de estacas.

Os ensaios foram do tipo "mistos", ou seja, iniciados com aplicações de carregamento do tipo lento (SML), até atingir-se a tensão admissível prevista, e depois utilizando carregamentos do tipo rápido (QML) até o término da prova de carga.

Os ensaios SML foram realizados segundo as prescrições da norma da ABNT NBR 6489/84 - Prova de Carga Direta Sobre Terreno de Fundação.

Nos ensaios do tipo rápido (QML), os intervalos de aplicação dos incrementos de carga foram mantidos por 15 minutos em cada estágio, segundo a proposição de FELLENIUS (1975), sendo as leituras dos recalques feitas nos tempos 0, 1, 2, 3, 6, 9, 12 e 15 min. O descarregamento foi realizado em quatro estágios e a locação das provas de carga é mostrada no Apêndice I. 


\section{CAPÍTULO 6 - RESULTADOS OBTIDOS}

\subsection{Sondagem SPT}

A seguir, são apresentados os relatórios de sondagem (Figuras 32 a 40) com os valores do índice de resistência à penetração $\mathrm{N}_{\mathrm{SPT}}$, obtidos em solo natural e nas malhas de estacas com espaçamento de 80,90 e $100 \mathrm{~cm}$. 


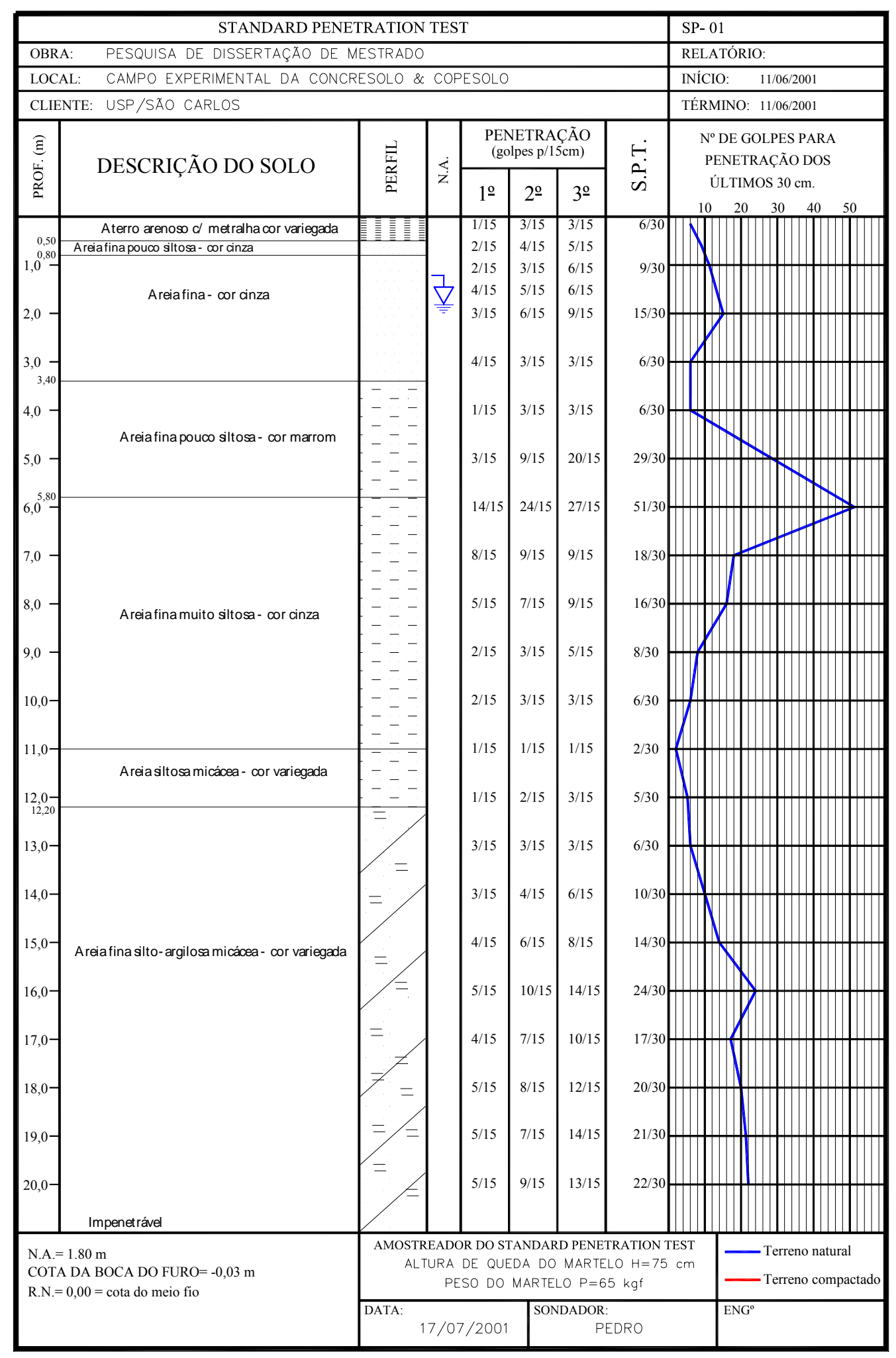

Figura 32. Sondagem $n^{\circ} 1$ em solo natural. 


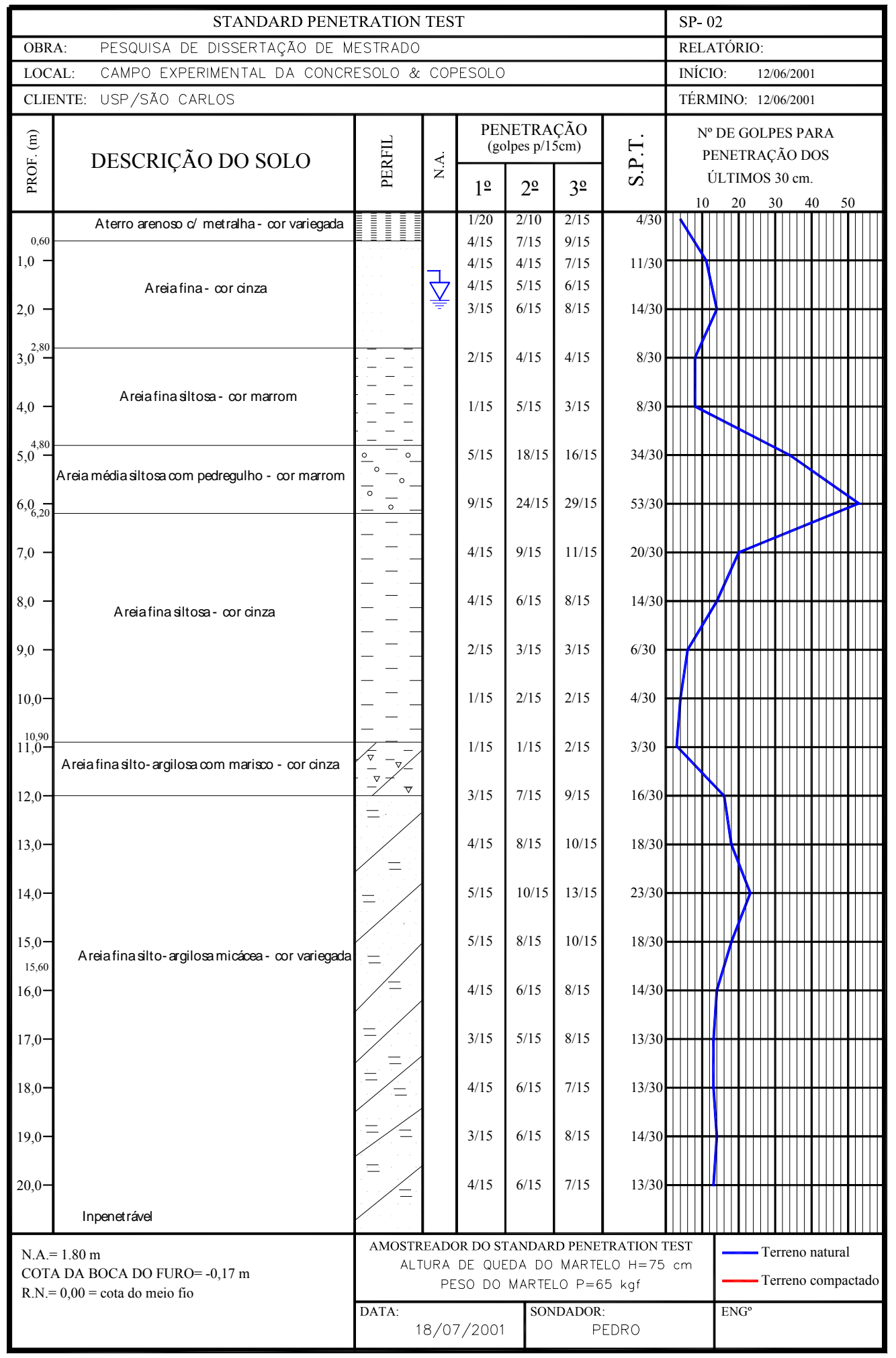

Figura 33. Sondagem $n^{\circ} 2$ em solo natural. 


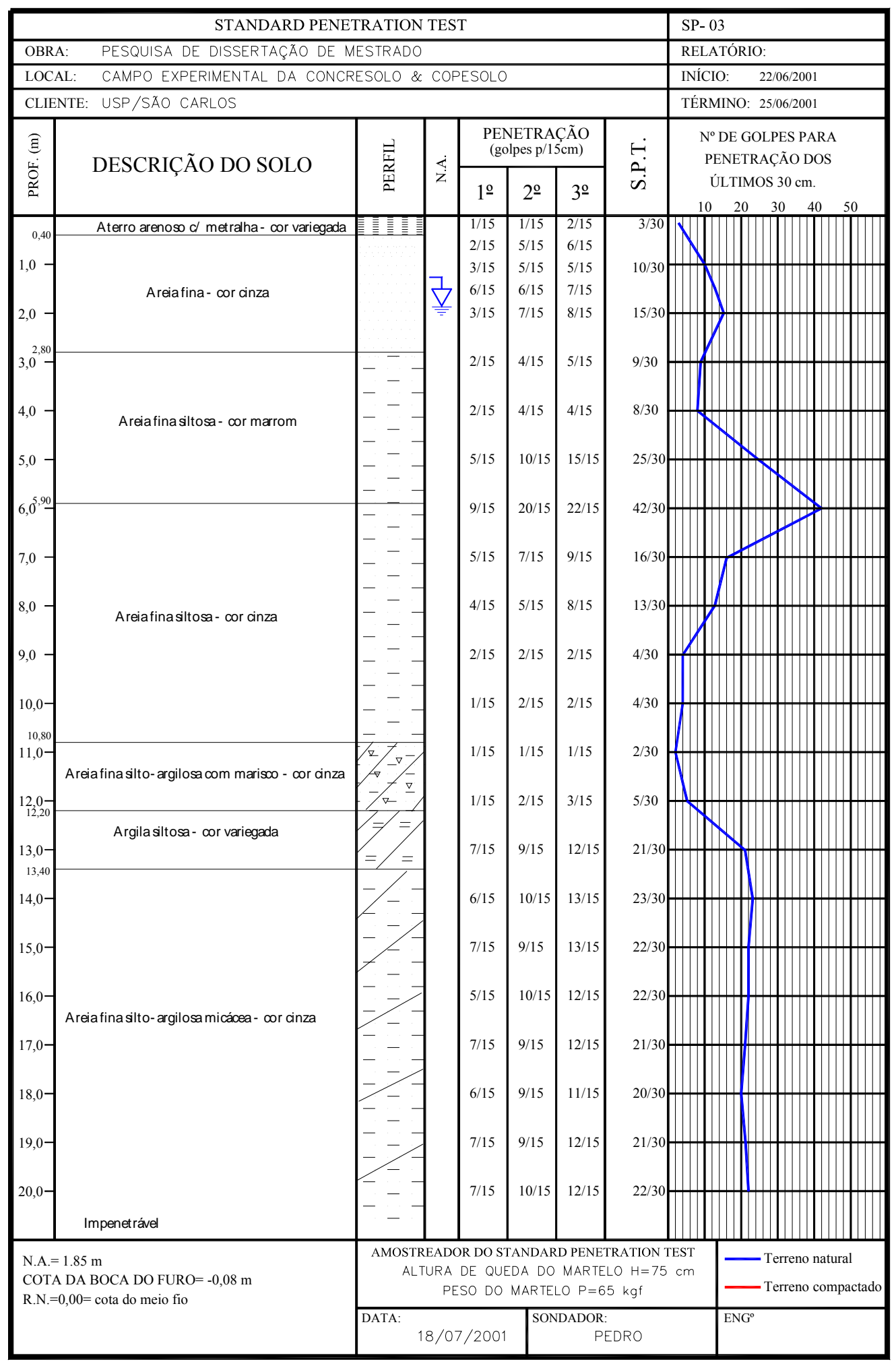

Figura 34 . Sondagem $n^{0} 3$ em solo natural. 


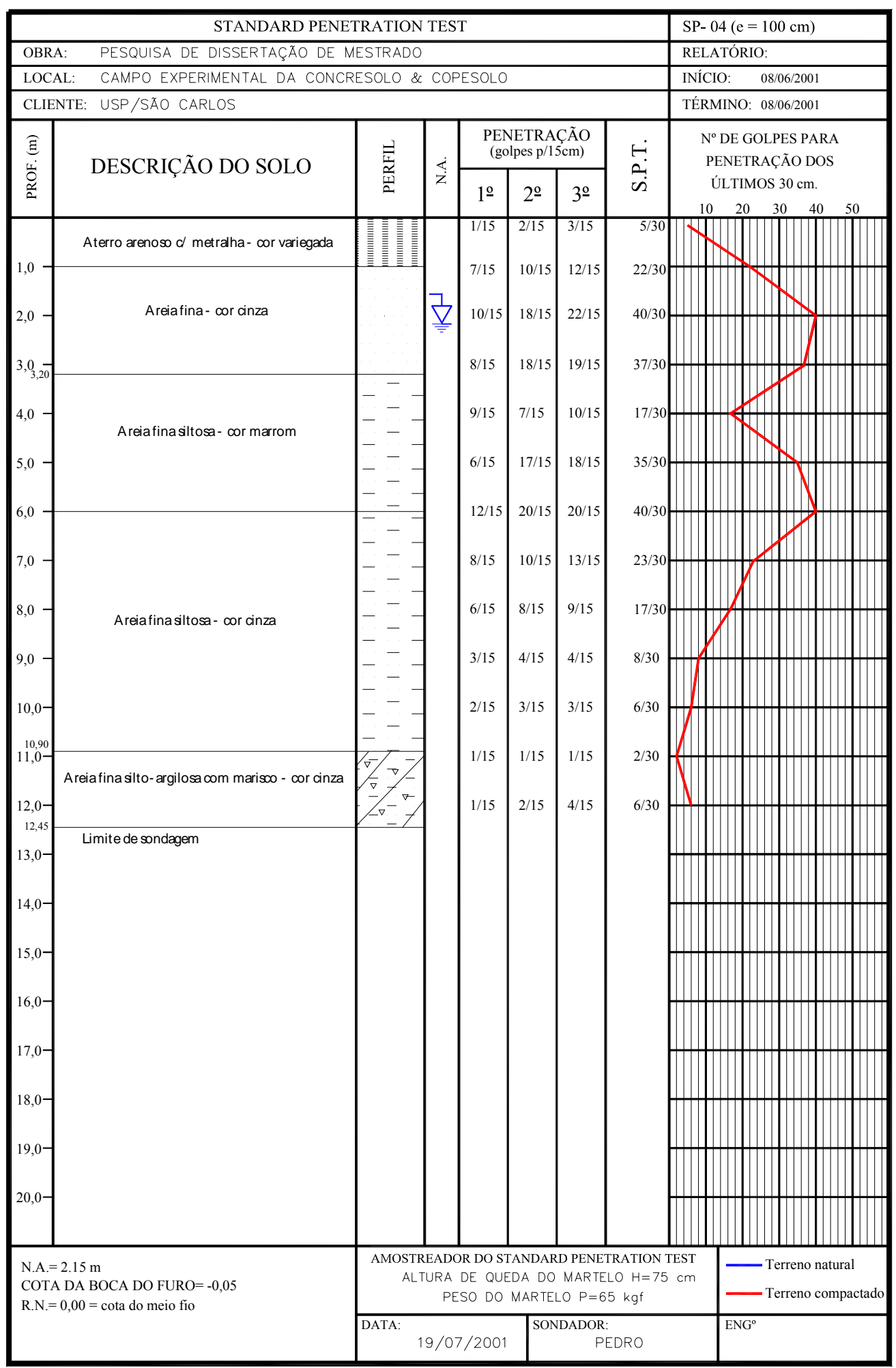

Figura 35. Sondagem $\mathrm{n}^{\circ} 4$ em malha de estacas com espaçamento de $100 \mathrm{~cm}$. 


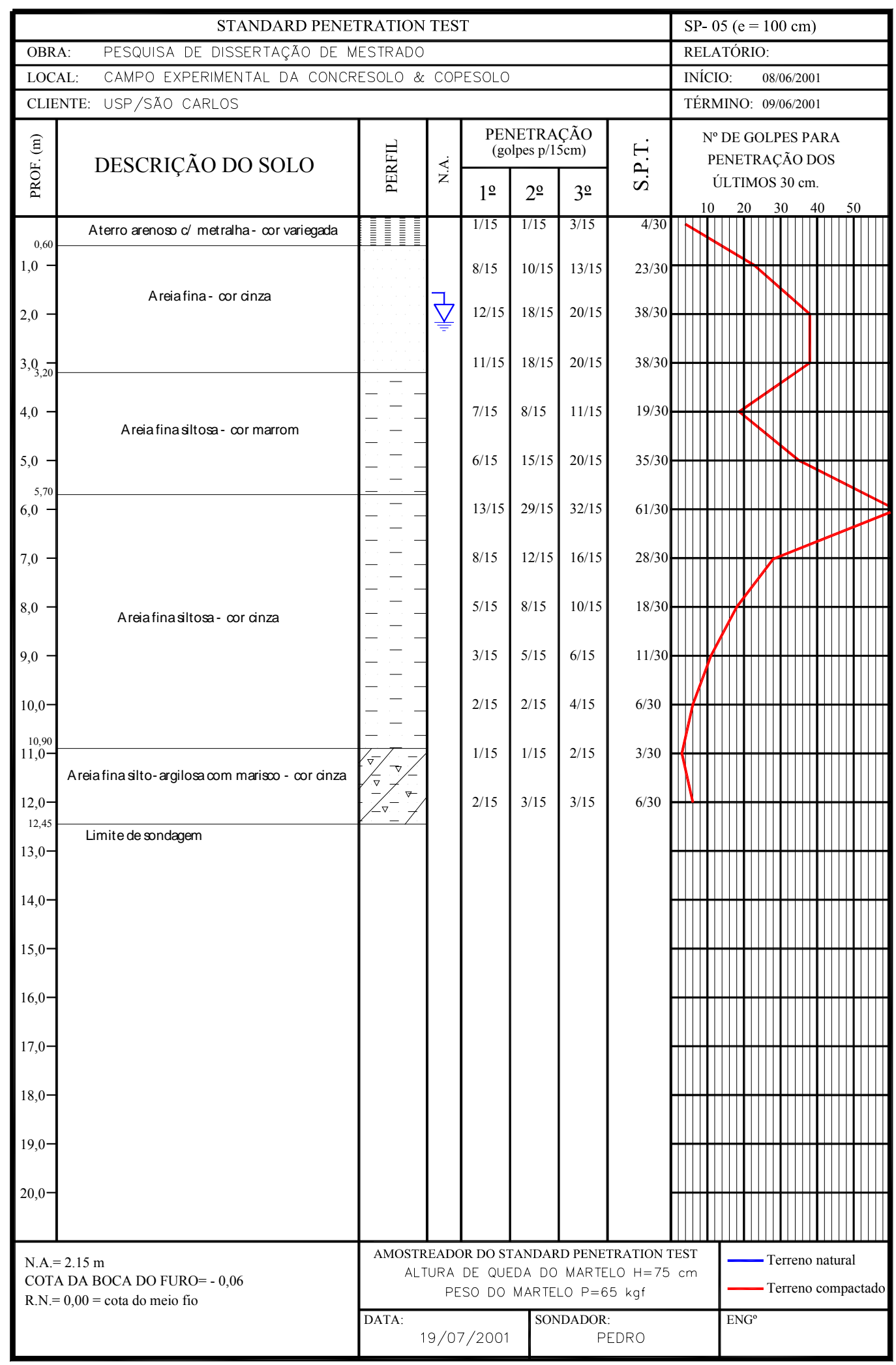

Figura 36. Sondagem $\mathrm{n}^{\mathrm{o}} 5$ em malha de estacas com espaçamento de $100 \mathrm{~cm}$ 


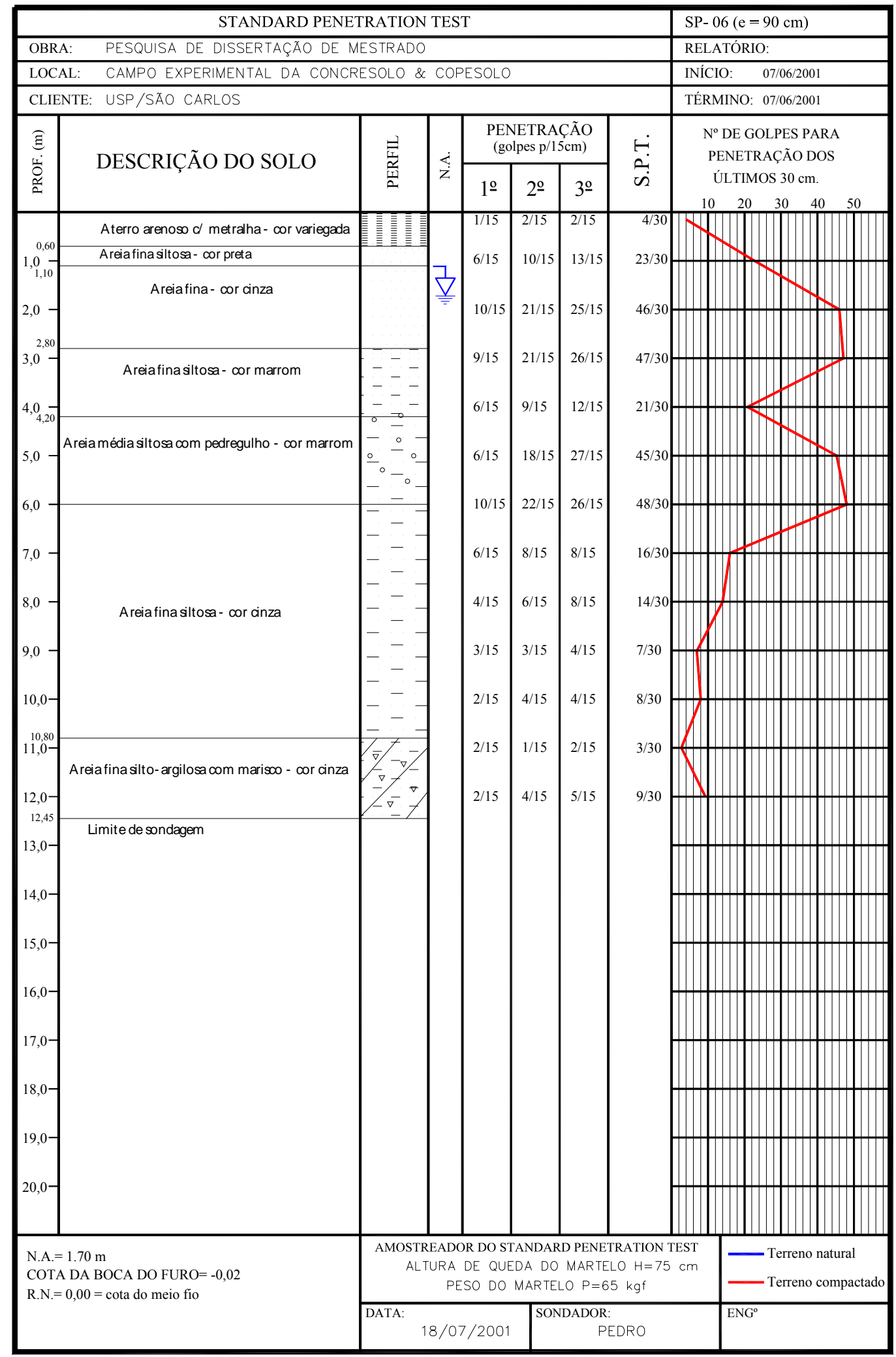

Figura 37. Sondagem $\mathrm{n}^{\circ} 6 \mathrm{em}$ malha de estacas com espaçamento de $90 \mathrm{~cm}$. 


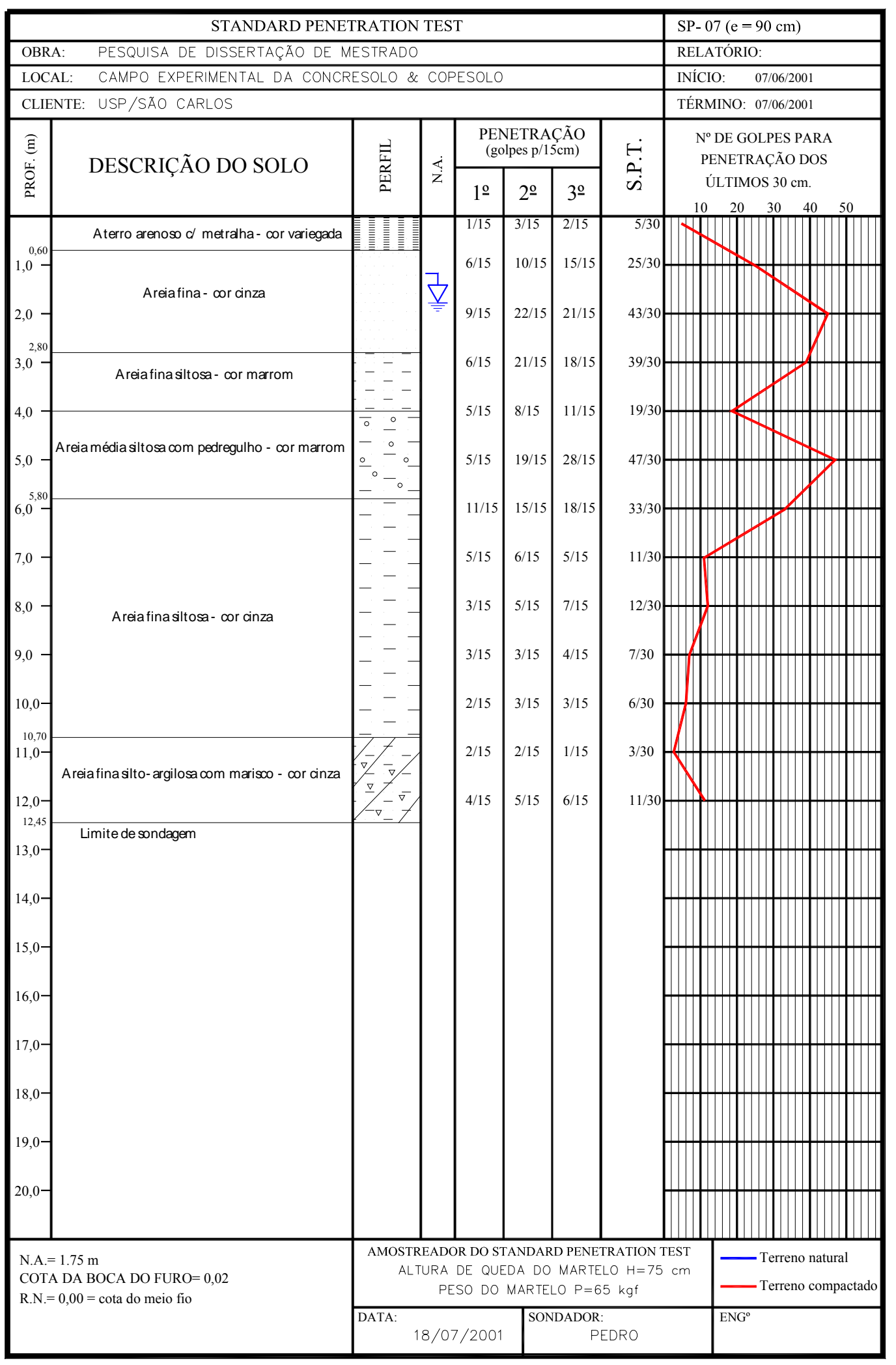

Figura 38. Sondagem $\mathrm{n}^{\circ} 7$ em malha de estacas com espaçamento de $90 \mathrm{~cm}$. 


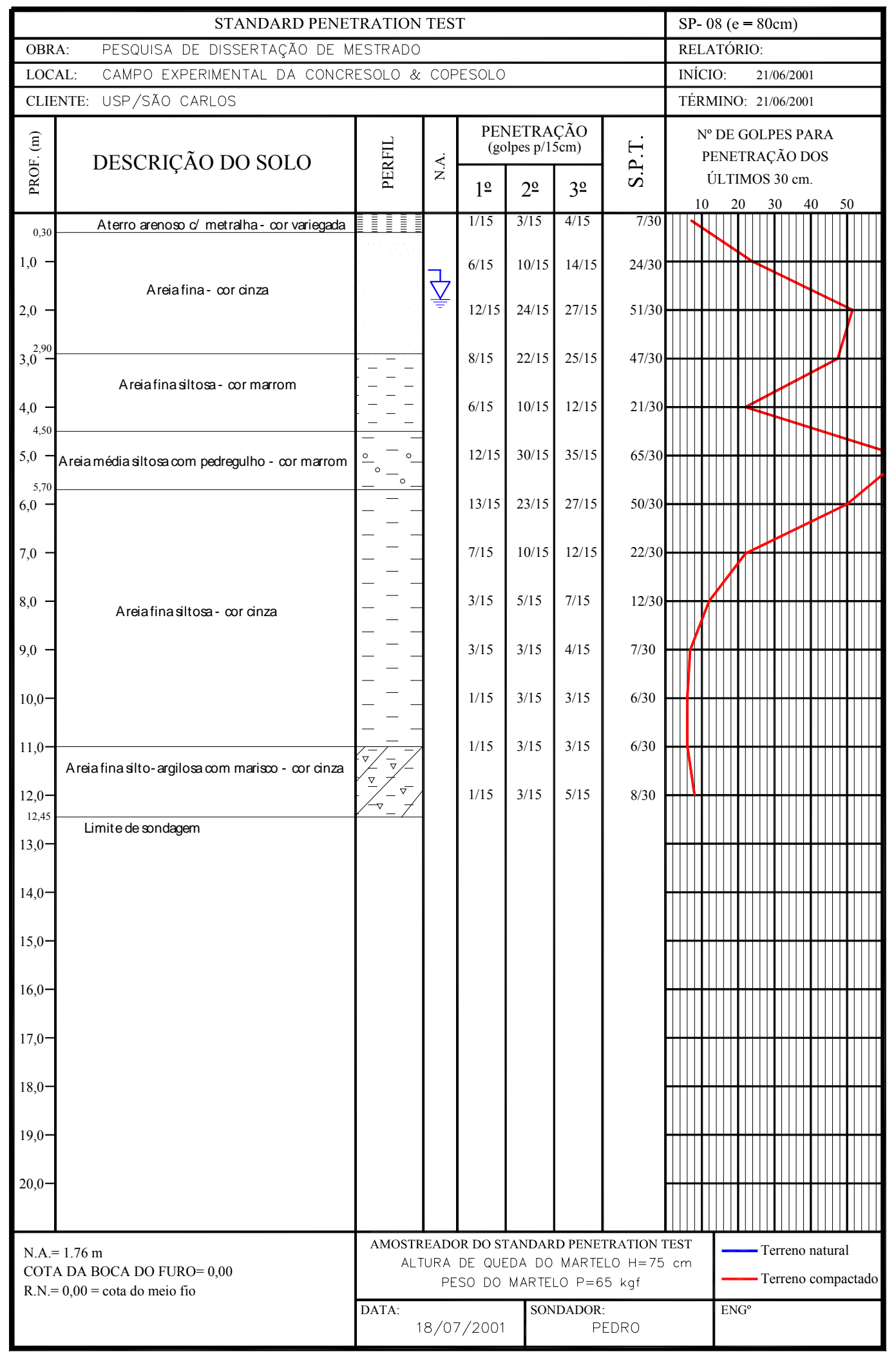

Figura 39. Sondagem $\mathrm{n}^{\circ} 8 \mathrm{em}$ malha de estacas com espaçamento de $80 \mathrm{~cm}$. 


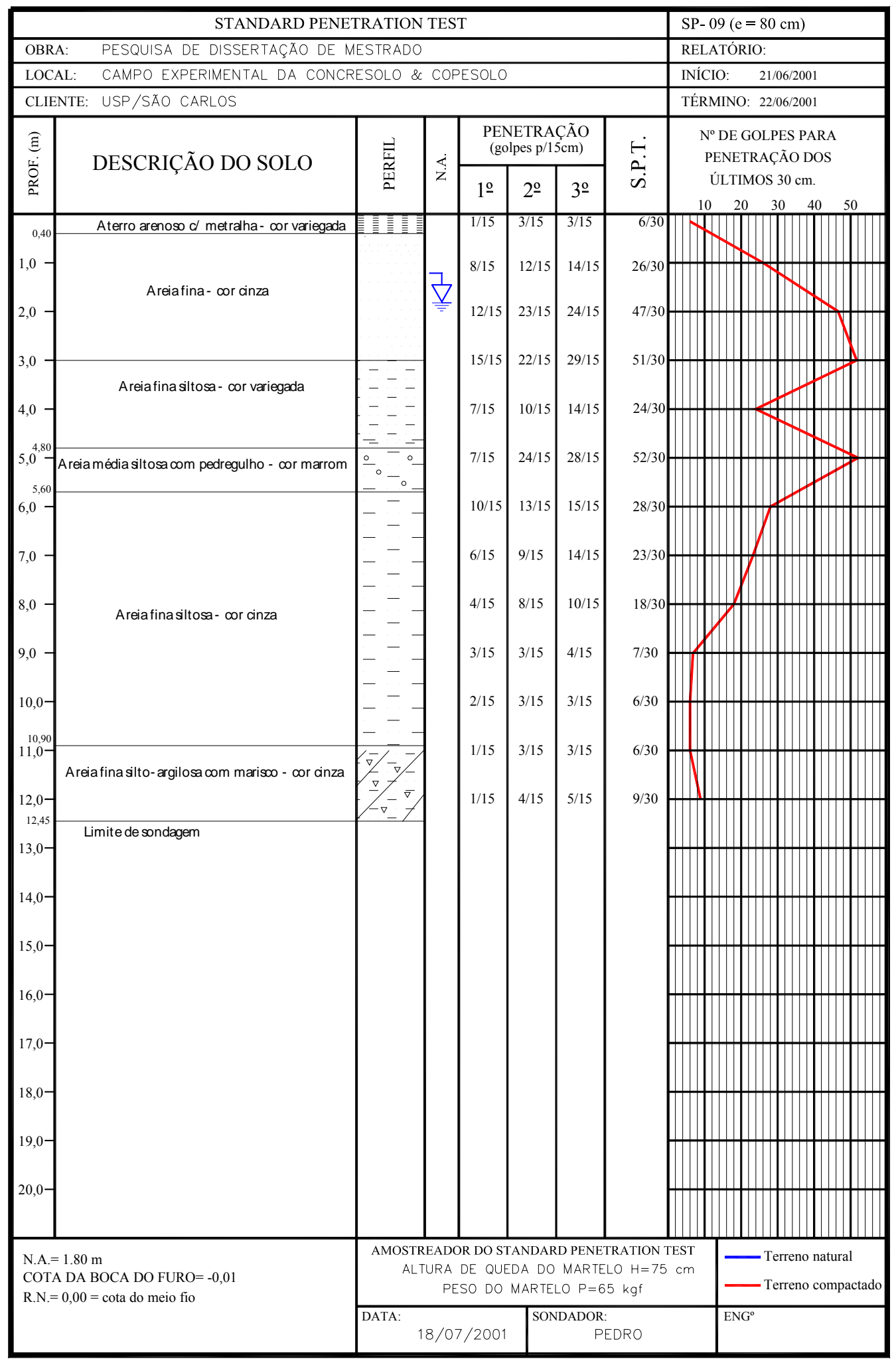

Figura 40. Sondagem $\mathrm{n}^{\circ} 9$ em malha de estacas com espaçamento de $80 \mathrm{~cm}$. 


\subsection{Ensaio de Cone}

A seguir são apresentados os gráficos de resistência de ponta $\mathrm{x}$ profundidade $\mathrm{e}$ atrito lateral x profundidade (Figuras 41 a 48), para o solo natural e compactado.
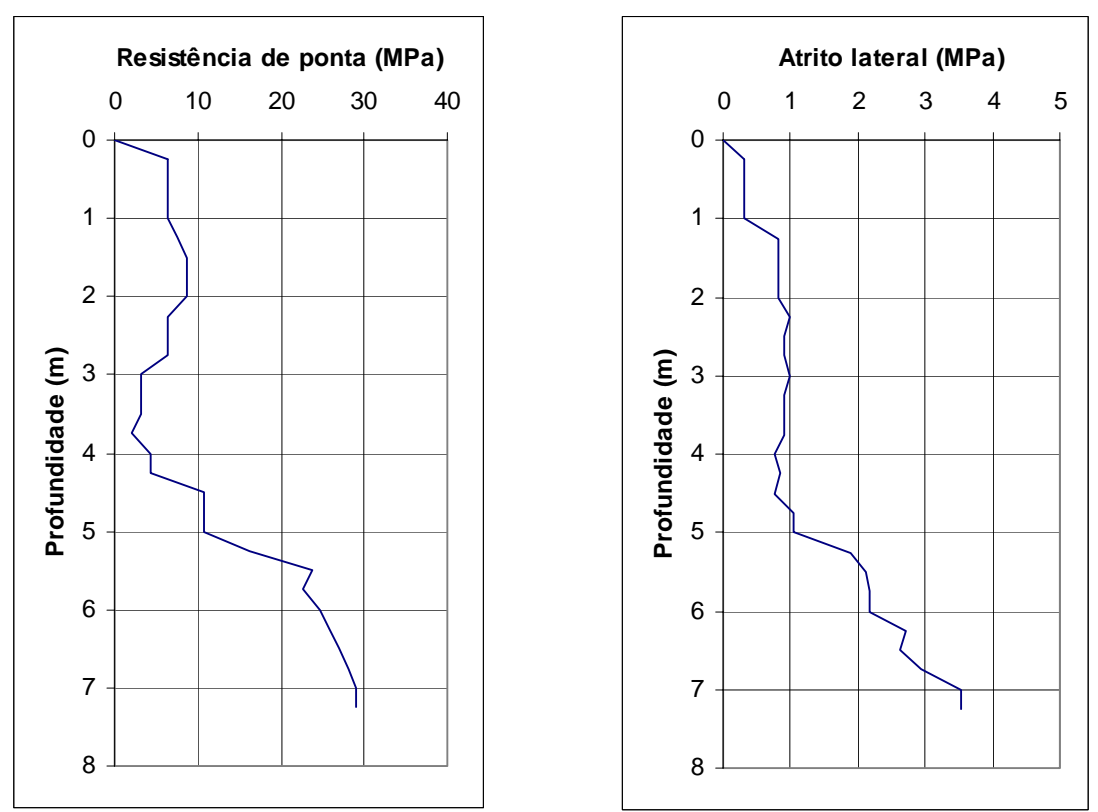

Figura 41. Ensaio de cone n ${ }^{\circ} 1$ em solo natural.
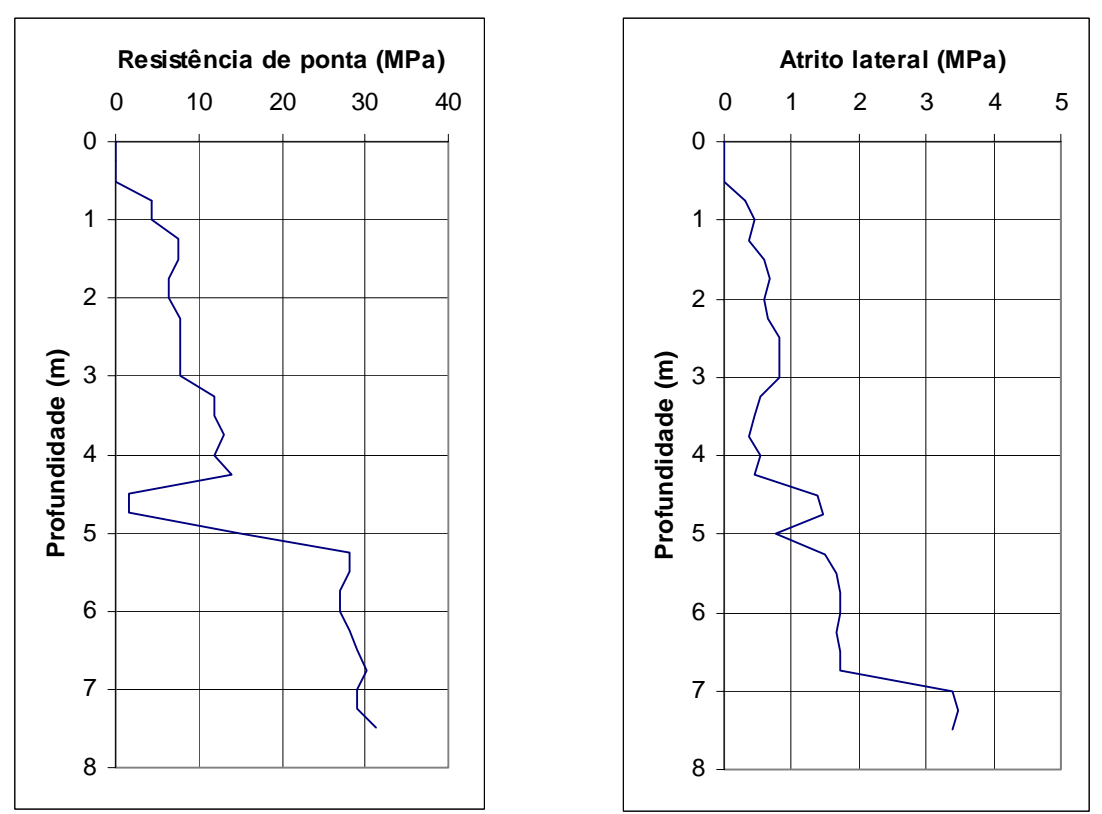

Figura 42. Ensaio de cone n ${ }^{\circ} 2$ em solo natural. 

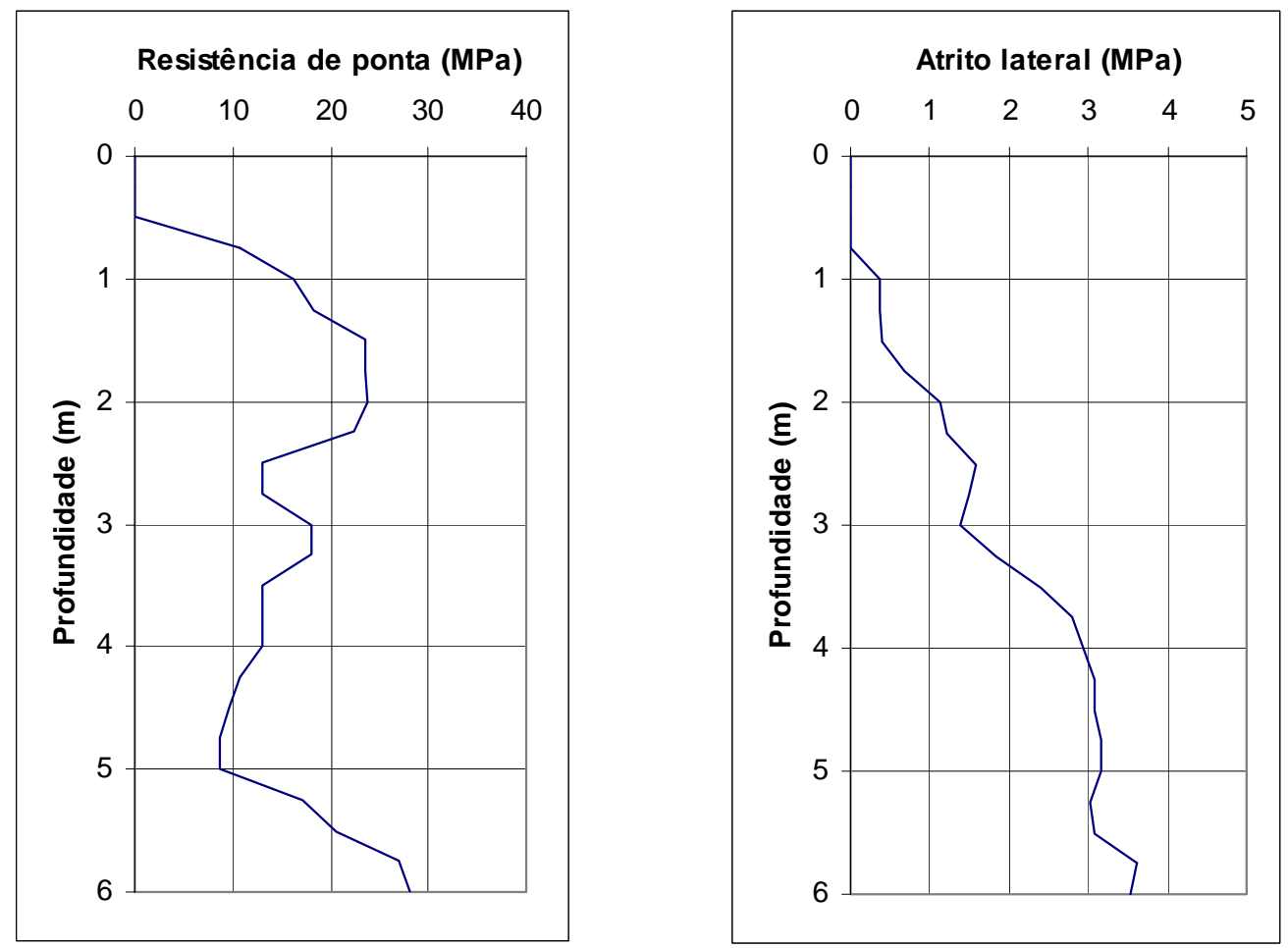

Figura 43. Ensaio de cone $\mathrm{n}^{\mathrm{o}} 3 \mathrm{em}$ malha de estacas com espaçamento de $100 \mathrm{~cm}$.
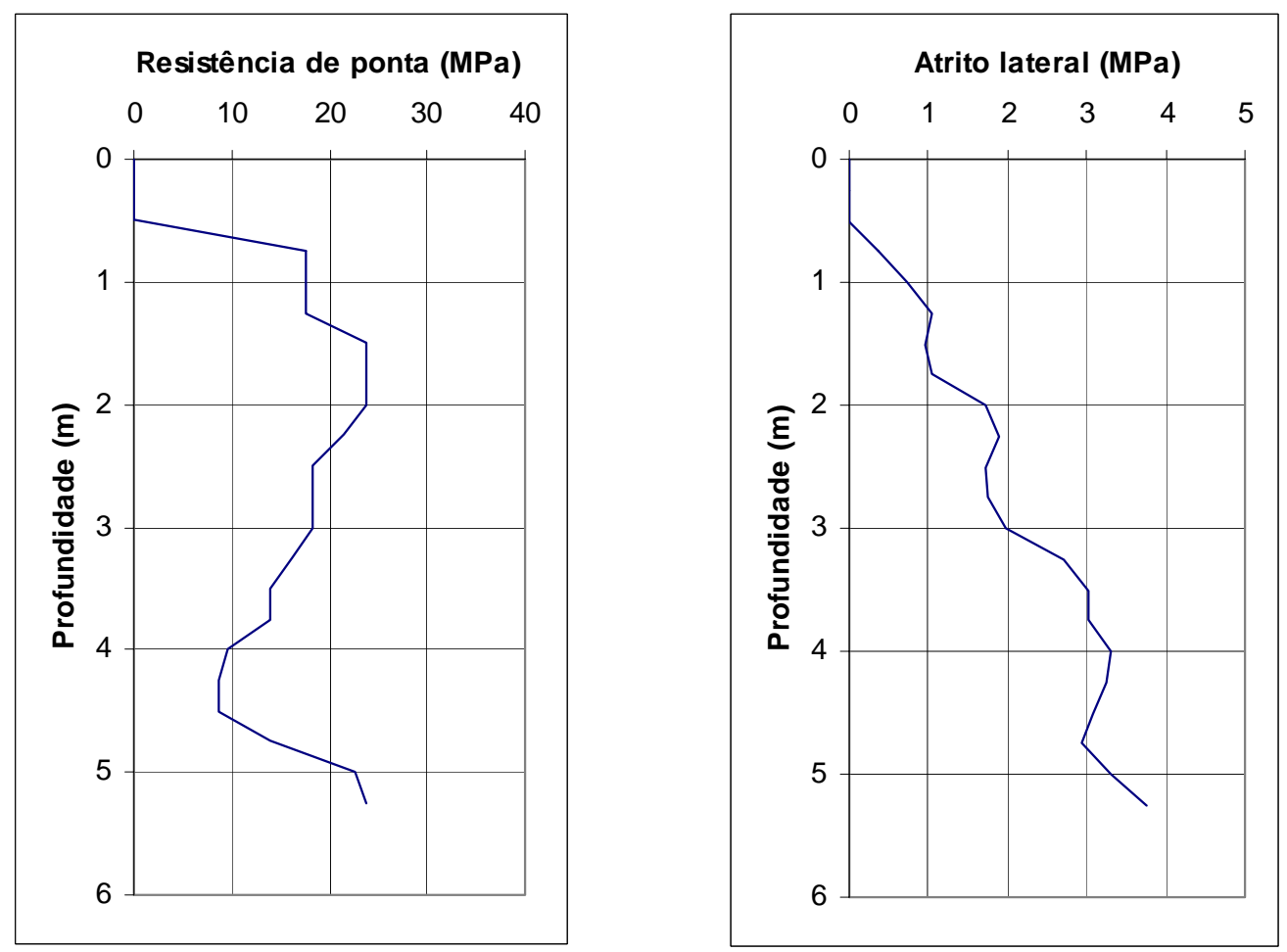

Figura 44. Ensaio de cone $\mathrm{n}^{\mathrm{o}} 4 \mathrm{em}$ malha de estacas com espaçamento de $100 \mathrm{~cm}$. 

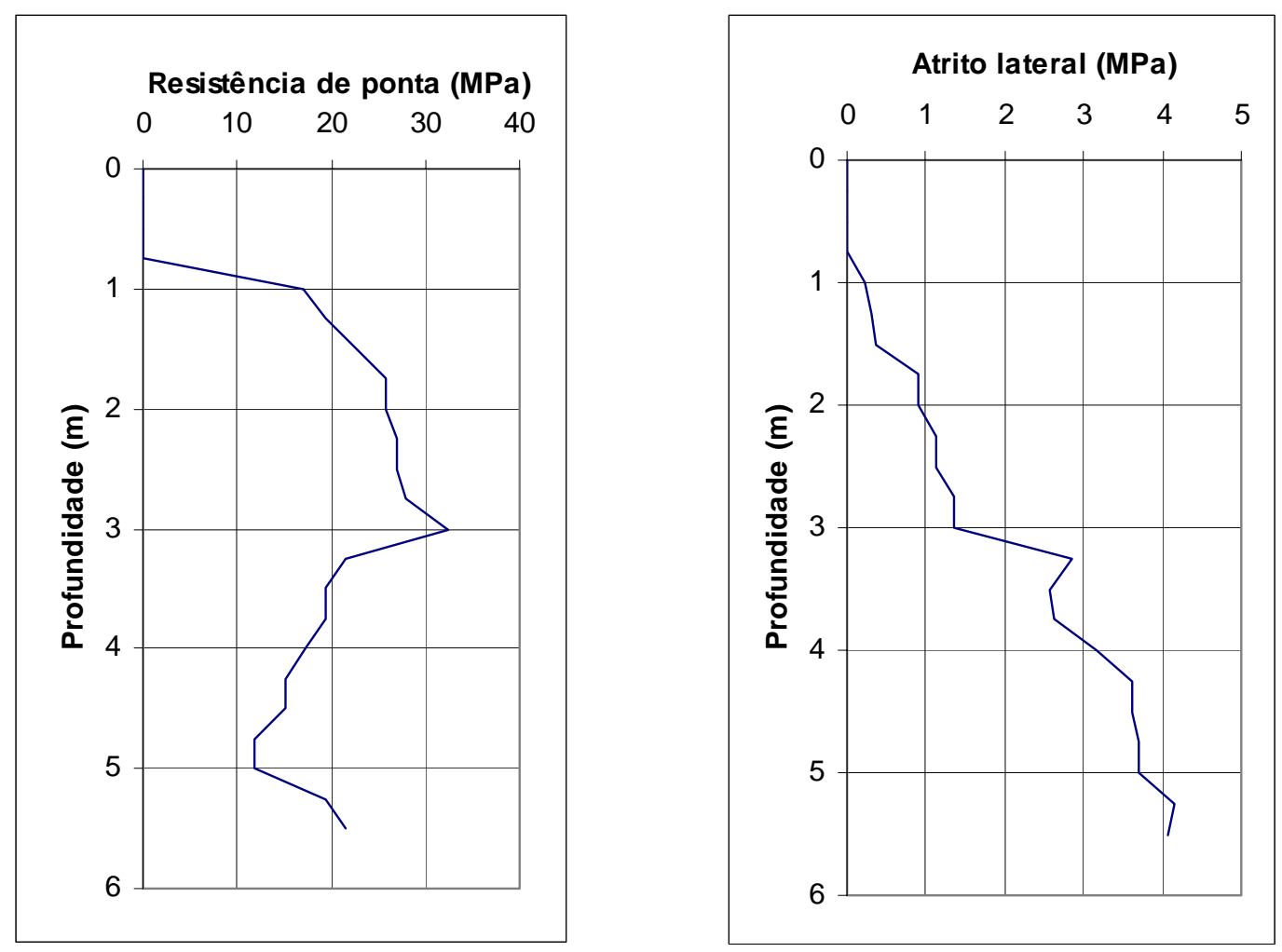

Figura 45. Ensaio de cone $\mathrm{n}^{\mathrm{o}} 5 \mathrm{em}$ malha de estacas com espaçamento de $90 \mathrm{~cm}$.
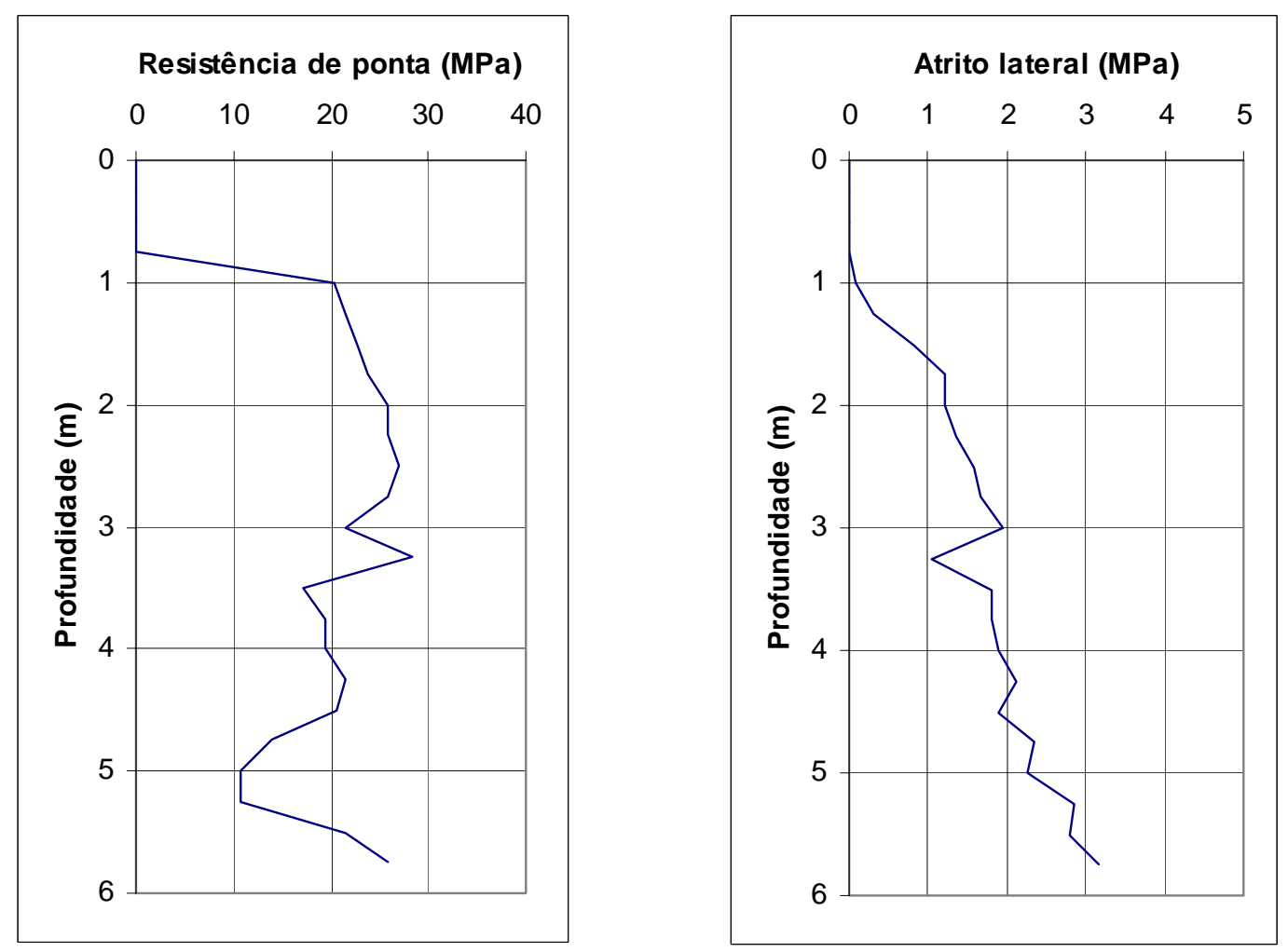

Figura 46. Ensaio de cone $\mathrm{n}^{\circ} 6 \mathrm{em}$ malha de estacas com espaçamento de $90 \mathrm{~cm}$. 

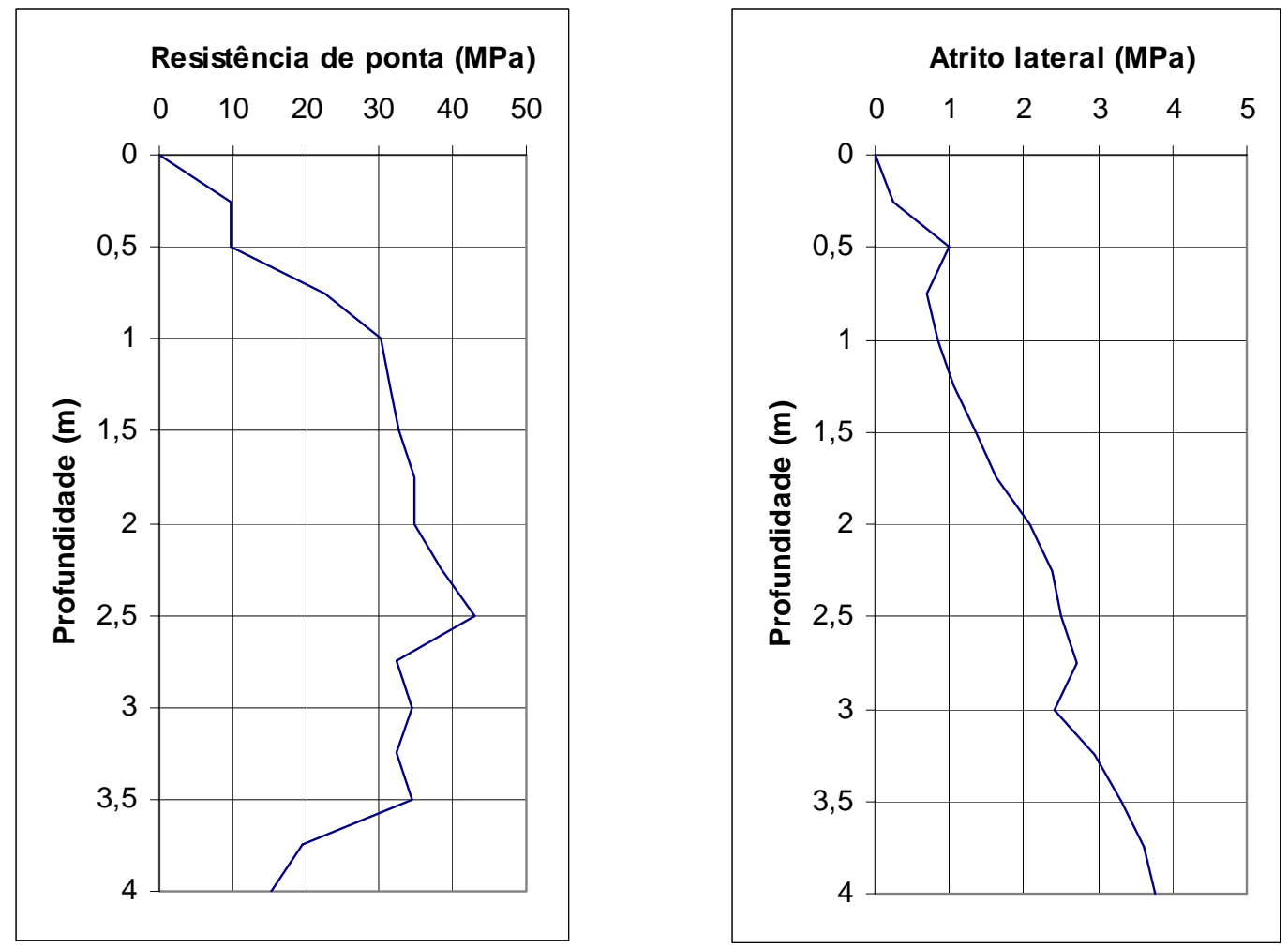

Figura 47. Ensaio de cone $\mathrm{n}^{\mathrm{o}} 7 \mathrm{em}$ malha de estacas com espaçamento de $80 \mathrm{~cm}$.
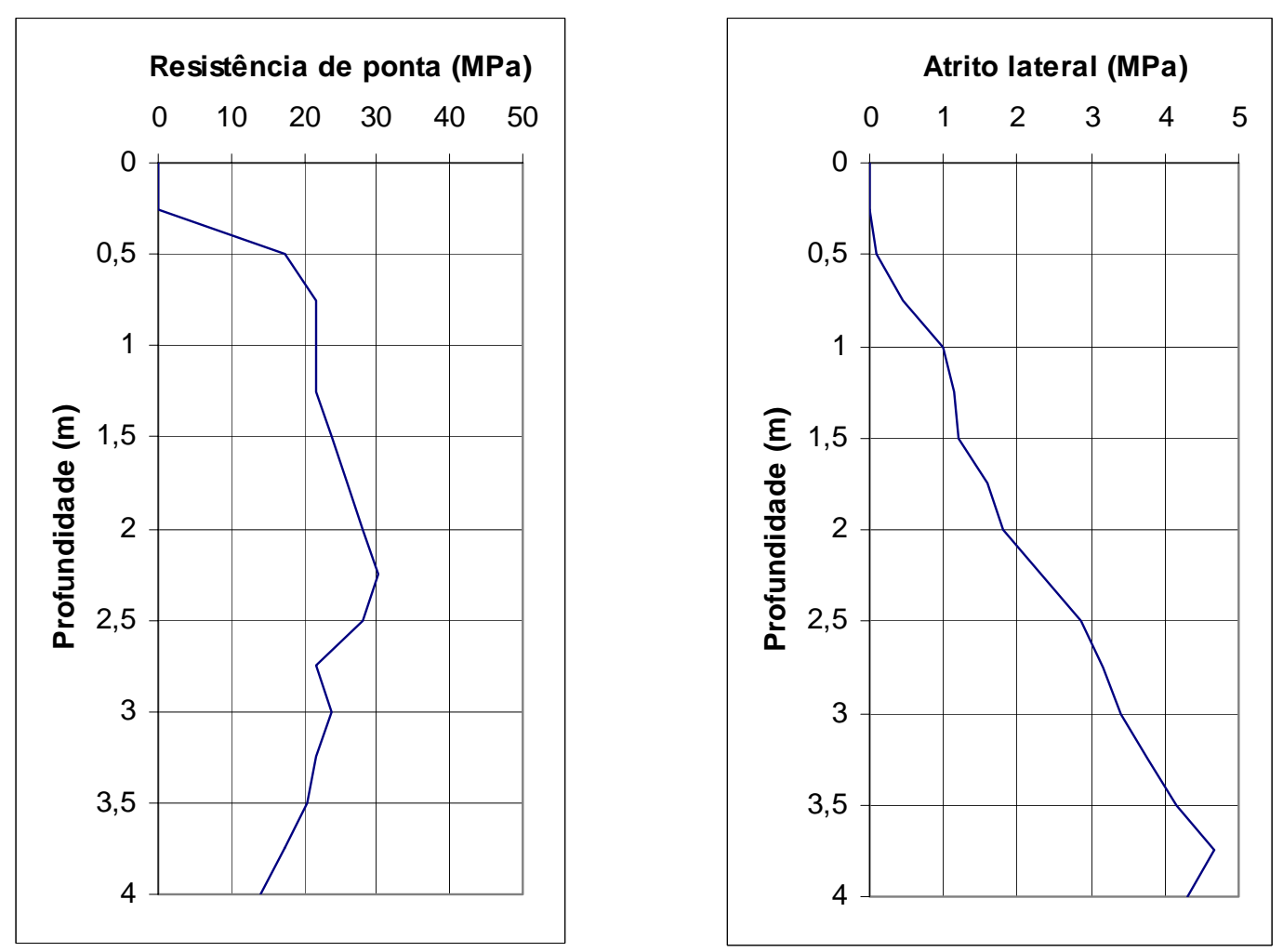

Figura 48. Ensaio de cone $\mathrm{n}^{\mathrm{o}} 8 \mathrm{em}$ malha de estacas com espaçamento de $80 \mathrm{~cm}$. 


\subsection{Prova de carga sobre placa}

A seguir são apresentados os gráficos tensão x recalque (Figuras 49 a 56), para o solo natural e compactado.

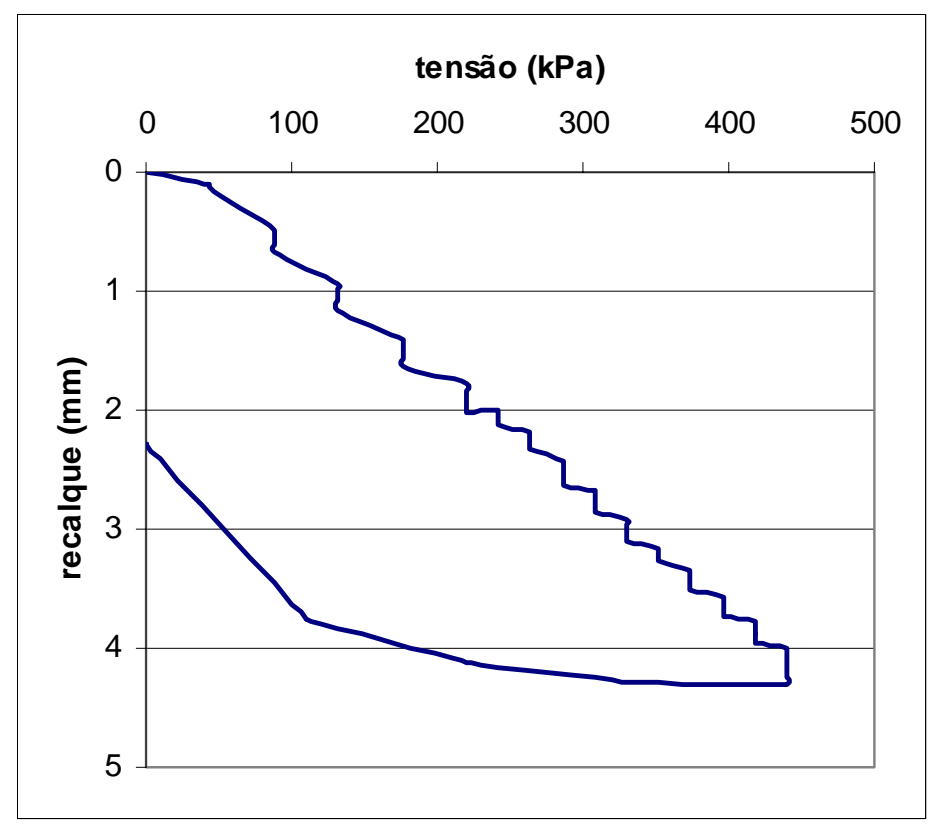

Figura 49. Prova de carga $\mathrm{n}^{\mathrm{o}} 1$ em solo natural.

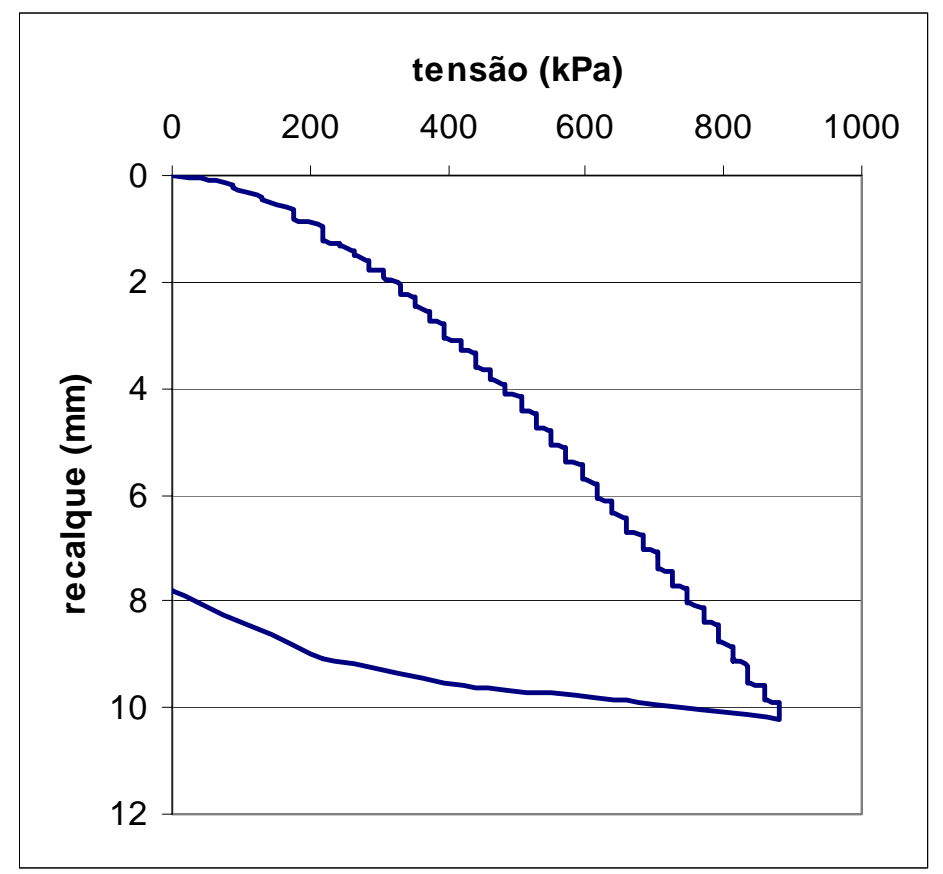

Figura 50. Prova de carga $\mathrm{n}^{\mathrm{o}} 2$ em solo natural. 


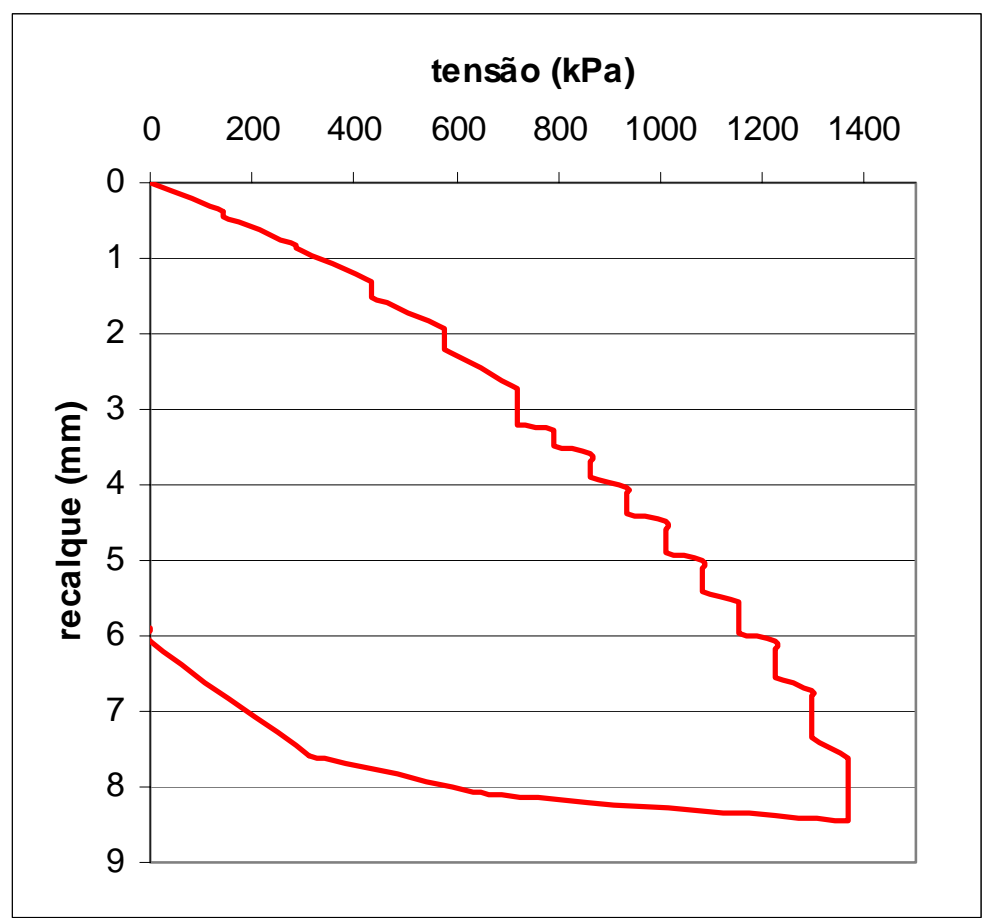

Figura 51. Prova de carga $\mathrm{n}^{\mathrm{o}} 3$ em solo compactado (malha de estacas com espaçamento de $100 \mathrm{~cm})$

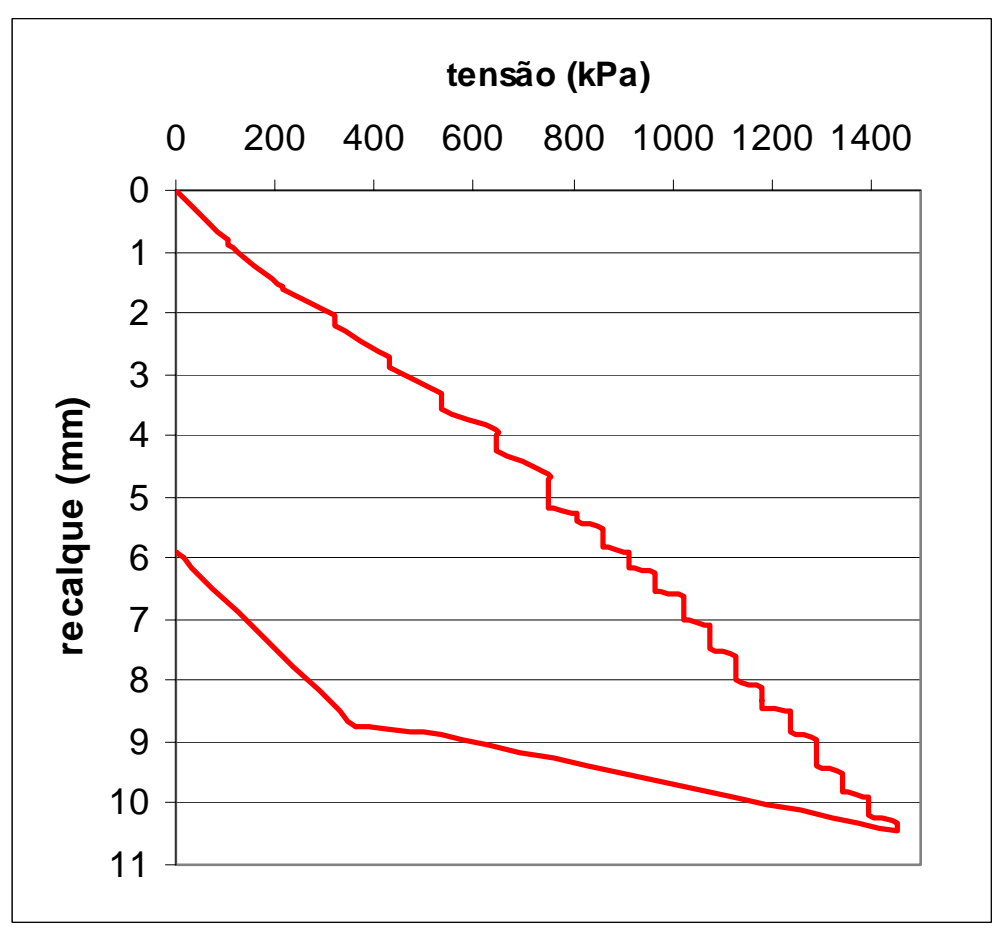

Figura 52. Prova de carga $\mathrm{n}^{\mathrm{o}} 4$ em solo compactado (malha de estacas com espaçamento de $100 \mathrm{~cm})$ 


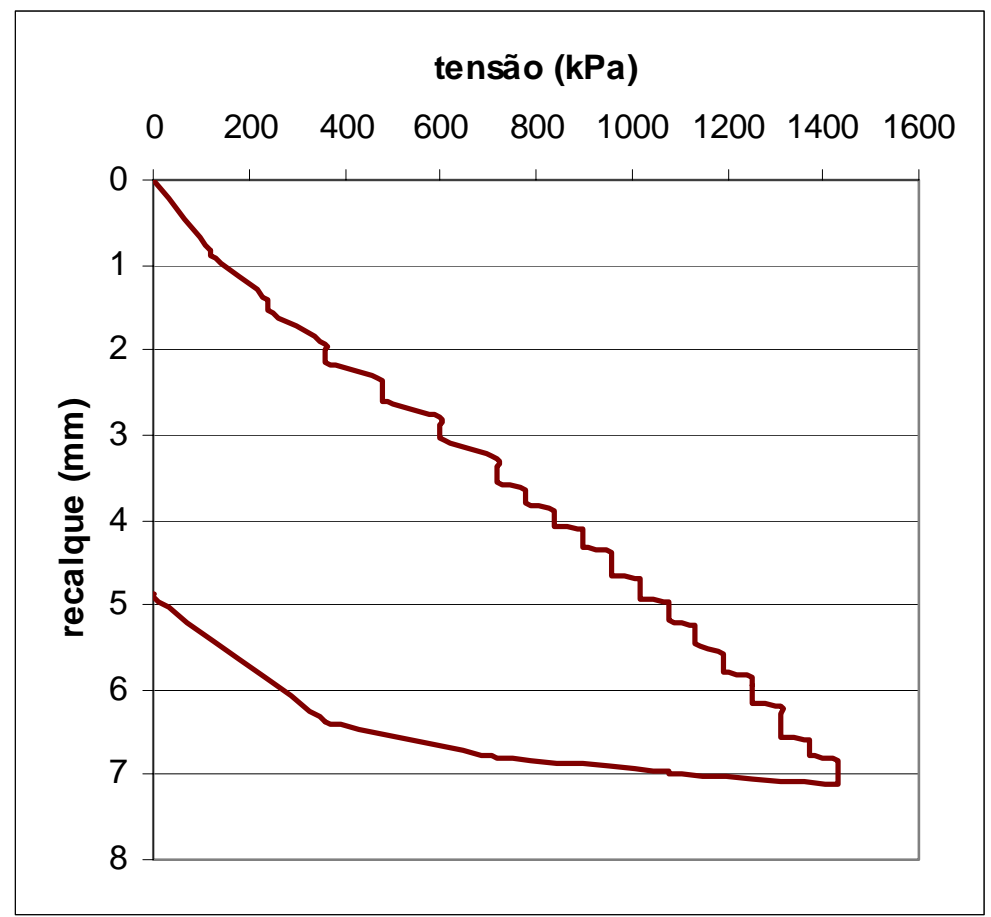

Figura 53. Prova de carga $\mathrm{n}^{\mathrm{o}} 5$ em solo compactado (malha de estacas com espaçamento de $90 \mathrm{~cm})$

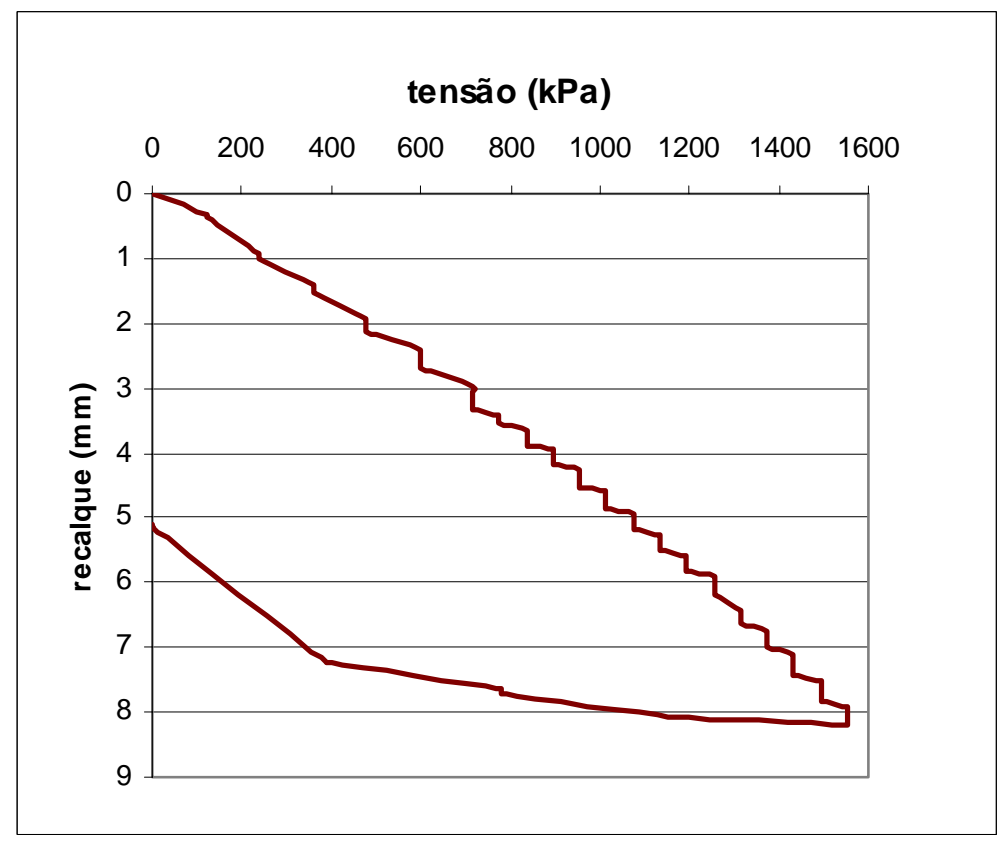

Figura 54. Prova de carga ${ }^{\circ} 6$ em solo compactado (malha de estacas com espaçamento de $90 \mathrm{~cm})$ 


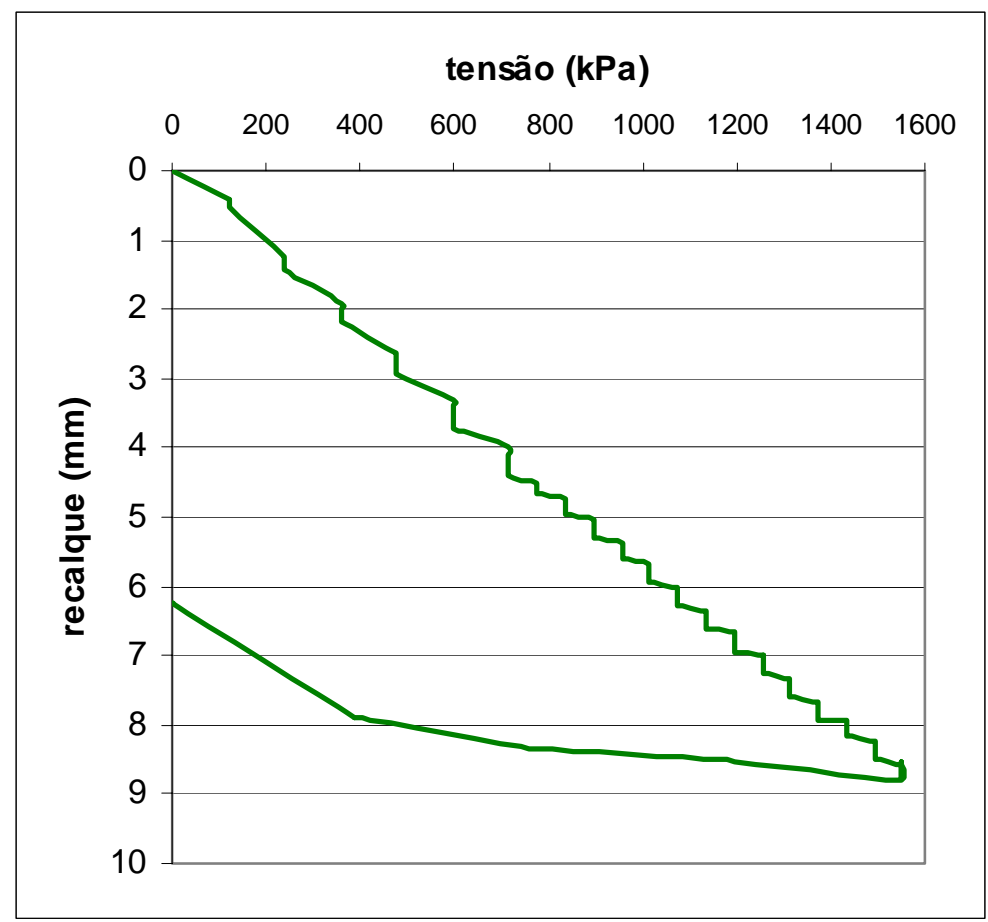

Figura 55. Prova de carga $\mathrm{n}^{\mathrm{o}} 7$ em solo compactado (malha de estacas com espaçamento de $80 \mathrm{~cm})$.

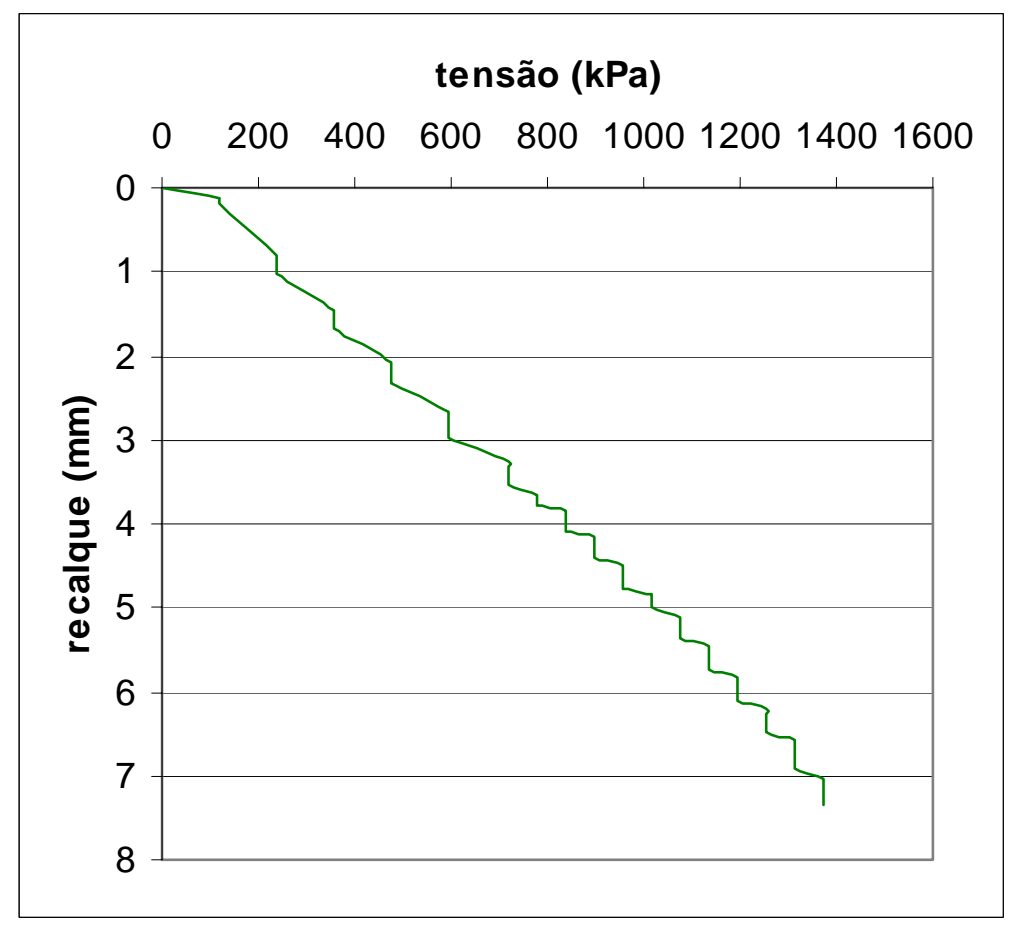

Figura 56. Prova de carga $\mathrm{n}^{\mathrm{o}} 8$ em solo compactado (malha de estacas com espaçamento de $80 \mathrm{~cm})$

Obs.: Não houve descarregamento, devido a problemas com a rótula. 


\subsection{Diagrama de cravação}

$\mathrm{Na}$ execução das estacas, foram determinados os números de golpes necessários para cravação do tubo de compactação a cada $50 \mathrm{~cm}$, obtendo-se o diagrama de cravação. A seguir, são apresentados os diagramas de cravação da primeira estaca, da média das estacas intermediárias e da última estaca para cada malha.

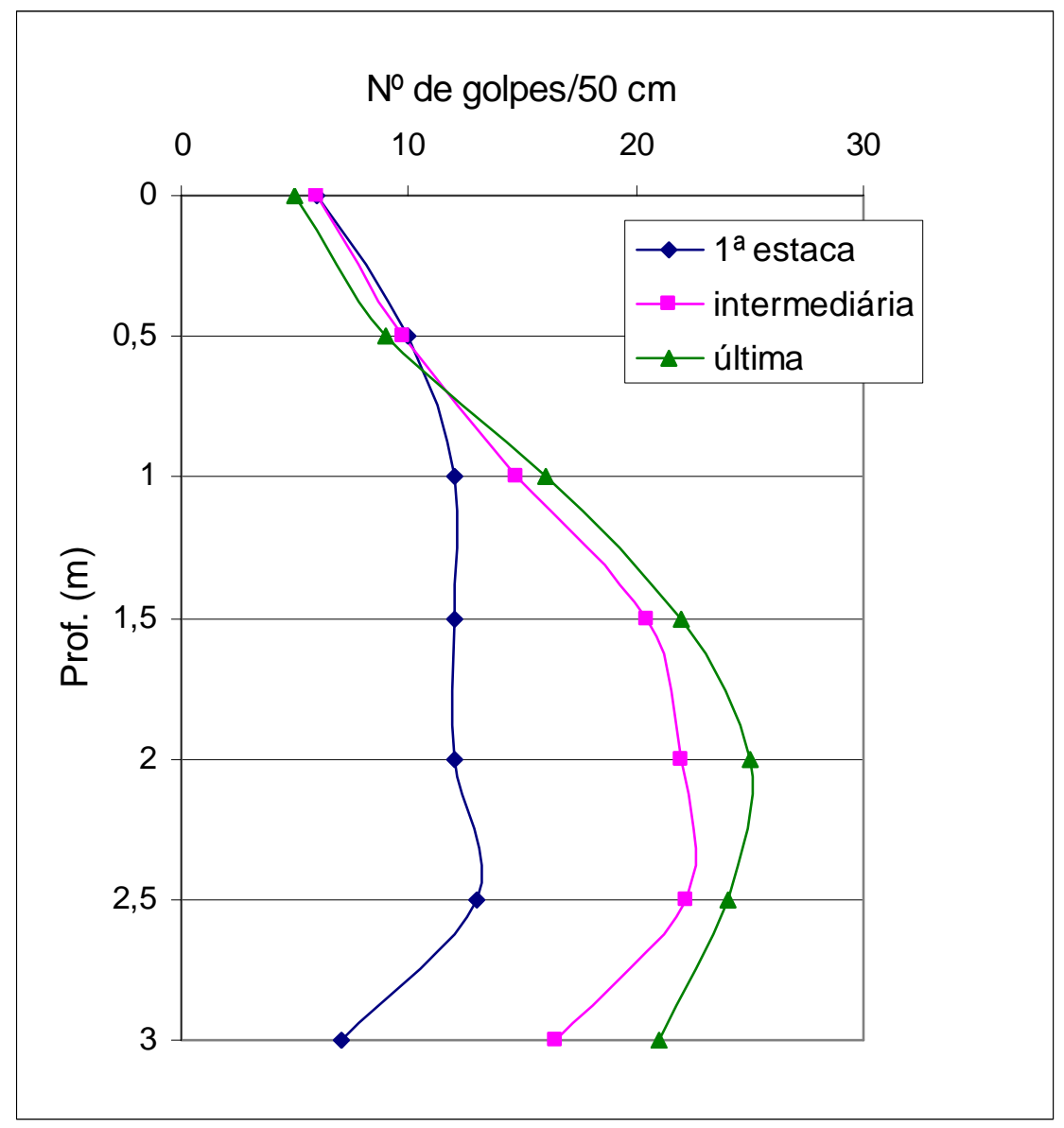

Figura 57. Diagrama de cravação (malha de $100 \mathrm{~cm}$ ). 


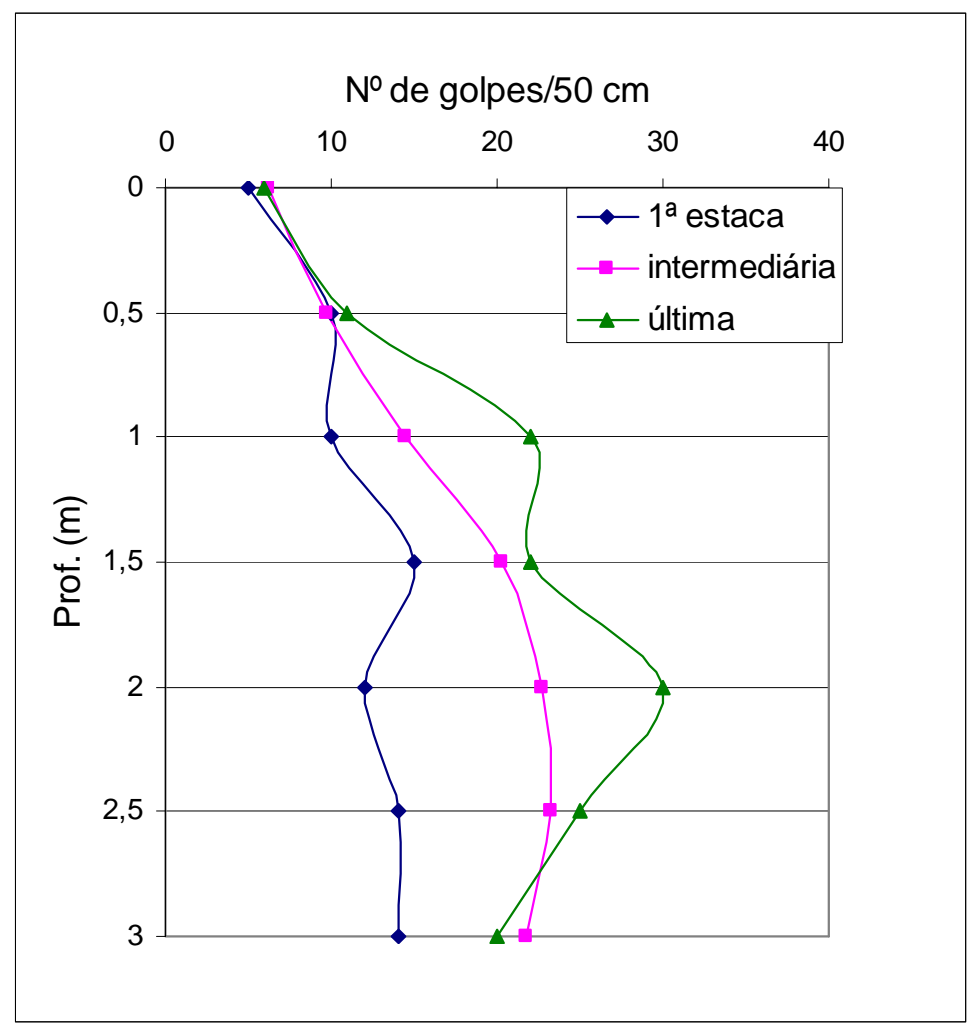

Figura 58. Diagrama de cravação (malha de $90 \mathrm{~cm}$ ).

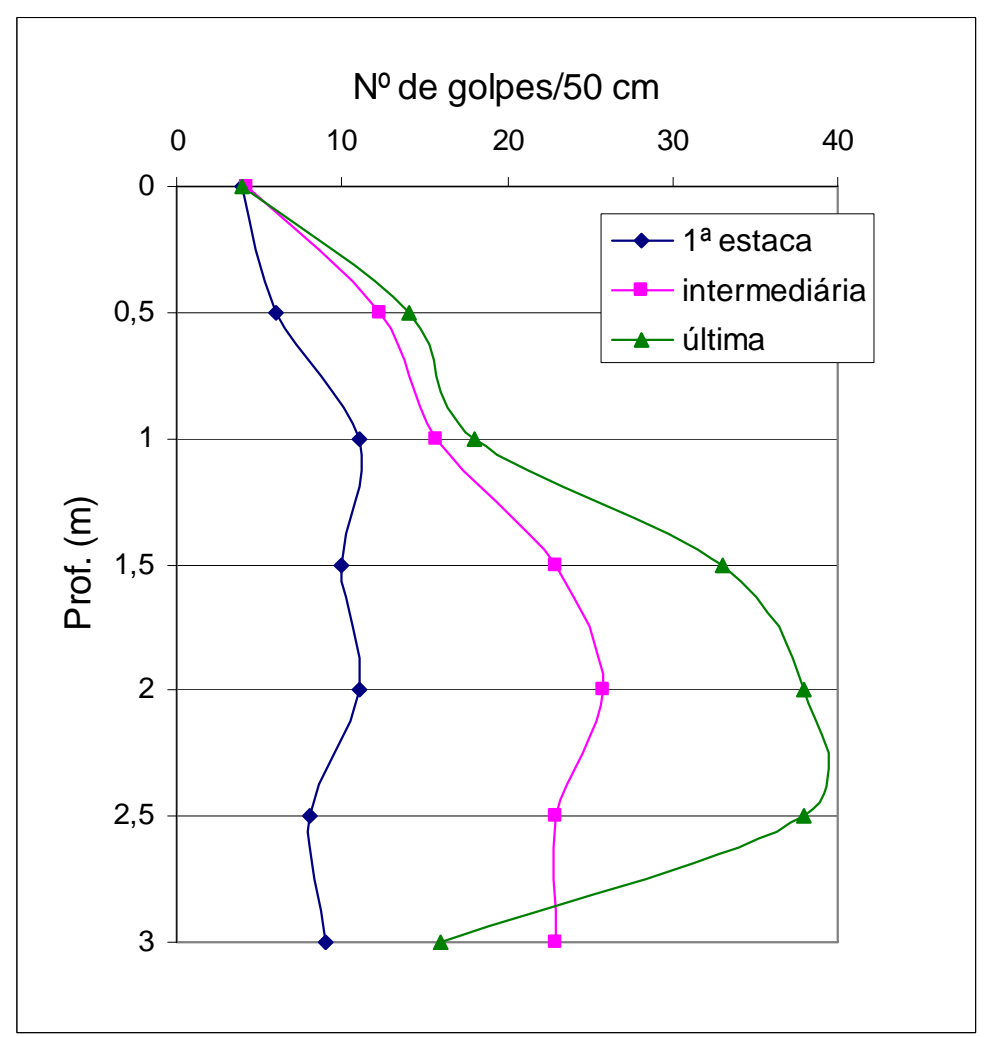

Figura 59. Diagrama de cravação (malha de $80 \mathrm{~cm}$ ). 


\section{CAPÍTULO 7 - ANÁLISE DOS RESULTADOS}

\subsection{Sondagem SPT}

Por meio de correlações entre o $\mathrm{N}_{\mathrm{SPT}}$ do solo natural e o $\mathrm{N}_{\mathrm{SPT}}$ do solo compactado, chegou-se a uma forma de previsão da capacidade de carga de fundações por sapata, instaladas em solo arenoso melhorado com estacas de compactação. Para tanto, foram analisados os valores médios do índice de resistência à penetração. A Figura 60 apresenta, em um mesmo boletim de sondagem, os valores do índice de resistência à penetração $\mathrm{N}_{\mathrm{SPT}}$ médios, obtidos em solo natural e nas malhas de estacas com espaçamento de 100, 90 e $80 \mathrm{~cm}$. 


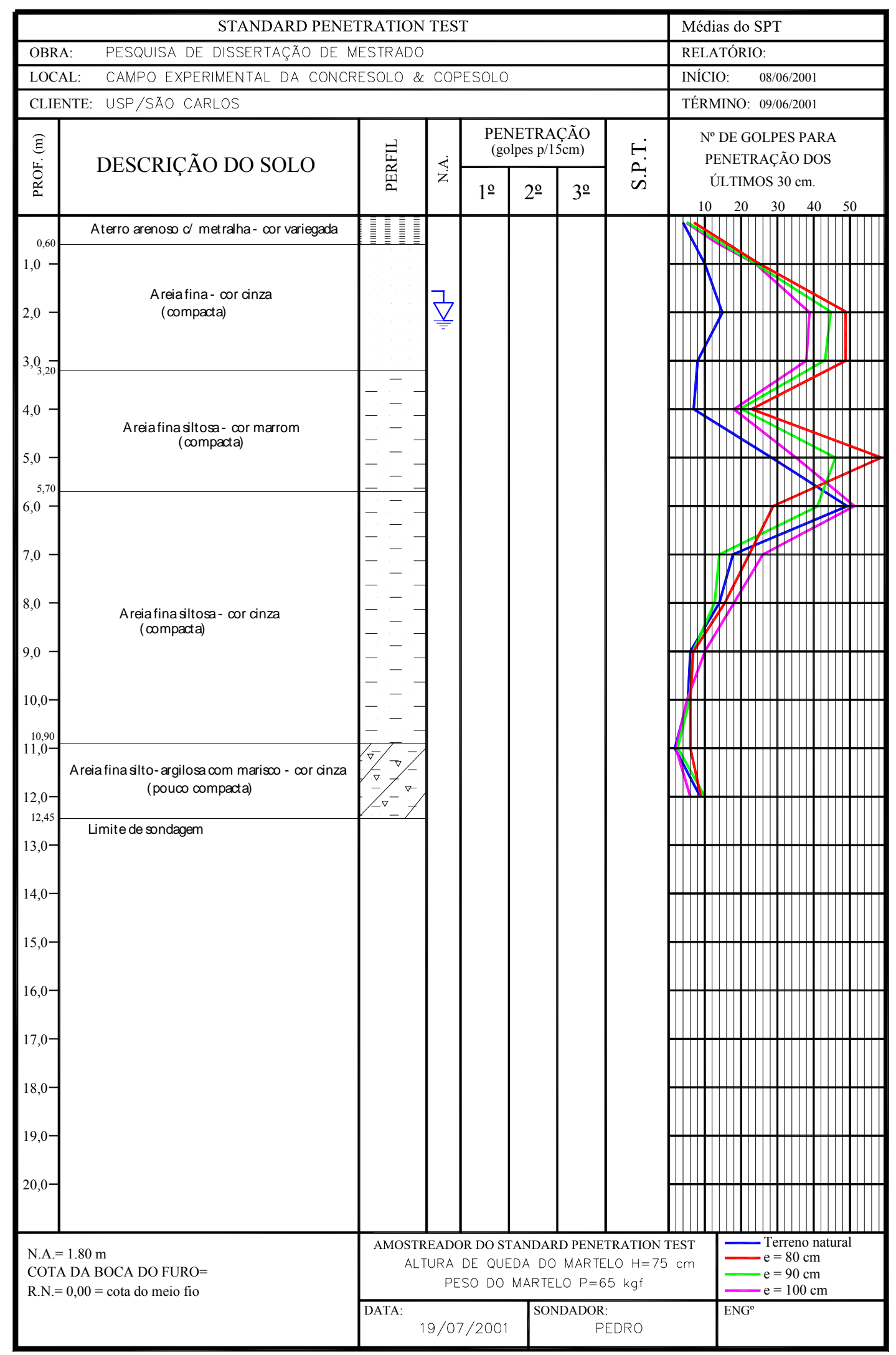

Figura 60 . Sondagem com $\mathrm{N}_{\mathrm{SPT}}$ médios para solo natural e compactado. 
Comparando-se os resultados das sondagens em solo natural e nas malhas de estacas, chegou-se às correlações entre os valores de $\mathrm{N}_{\mathrm{SPT}}$ antes e depois da compactação, nas diferentes malhas:

a) malha de estacas com espaçamento de $100 \mathrm{~cm}$.

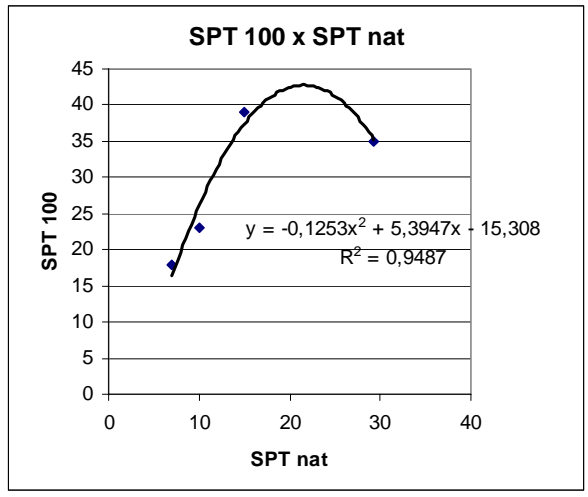

b) malha de estacas com espaçamento de $90 \mathrm{~cm}$.

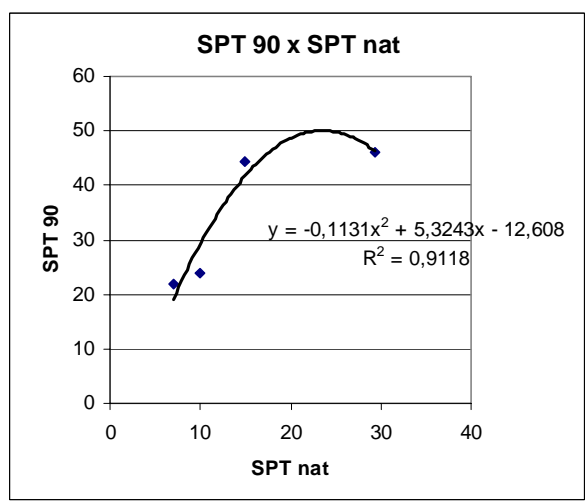

c) malha de estacas com espaçamento de $80 \mathrm{~cm}$.

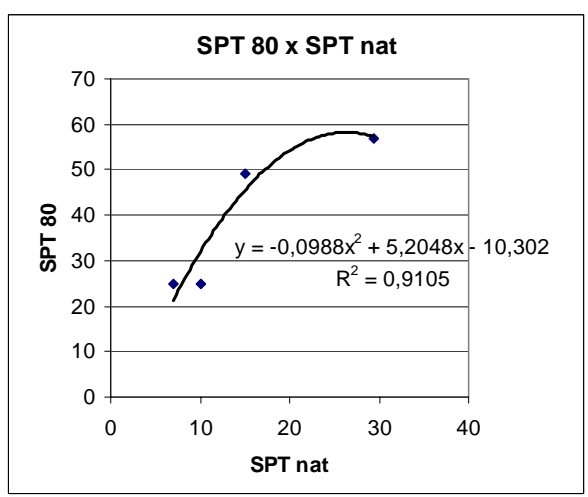


Os pontos usados nas correlações correspondem às profundidades de 1 a $5 \mathrm{~m}$, em que há efetiva compactação do solo. A função que melhor representa a relação entre $\mathrm{N}_{\mathrm{SPT}}$ do solo natural e compactado é a do segundo grau, que apresenta um bom coeficiente de determinação.

A partir das correlações entre $\mathrm{N}_{\mathrm{SPT}}$ do solo natural e compactado, determinou-se a tensão admissível para fundações por sapata em solo arenoso e compactado, mediante a fórmula de TEIXEIRA (1996), citada no Item 2.4.9.1 (página 34).

Em seguida, construiu-se o gráfico "teórico" com os valores da tensão admissível em função do $\mathrm{N}_{\mathrm{SPT}}$ do solo natural e compactado, para sapatas quadradas de lado B entre 1 e $3 \mathrm{~m}$. De forma análoga foram obtidos os gráficos "experimentais", a partir dos valores reais de $\mathrm{N}_{\mathrm{SPT}}$ antes e depois da compactação, isto é, sem o uso das correlações. As Figuras 61 a 70 apresentam os gráficos teóricos e experimentais. 


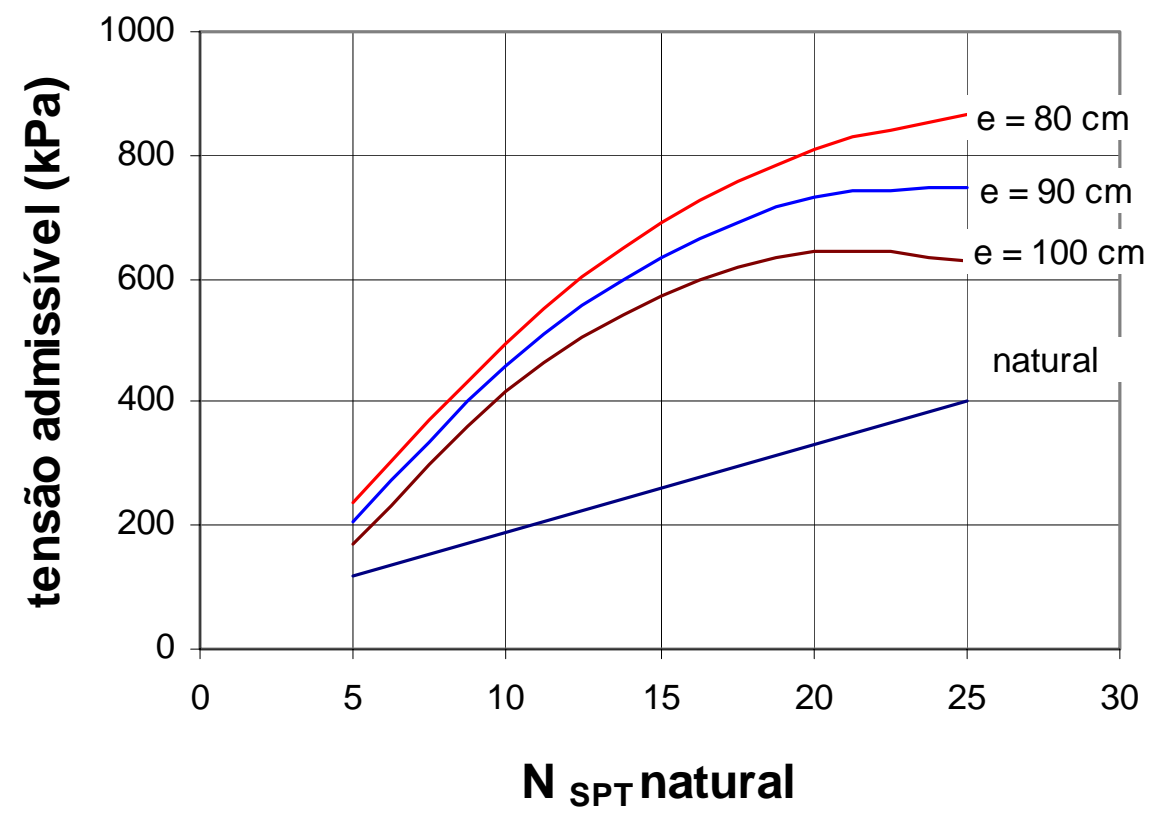

Figura 61. Gráfico teórico tensão admissível x $\mathrm{N}_{\mathrm{SPT}}$ natural para sapatas quadradas de lado $\mathrm{B}=1 \mathrm{~m}$.

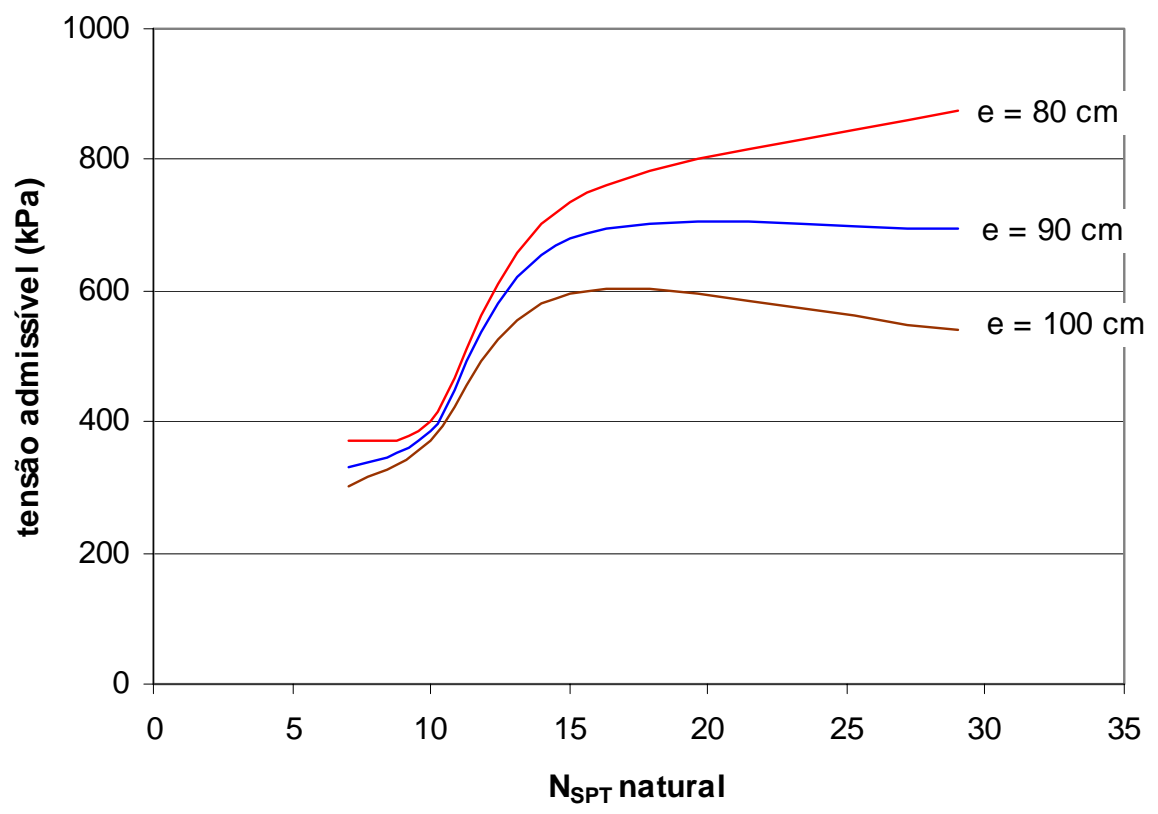

Figura 62. Gráfico experimental tensão admissível $x \mathrm{~N}_{\mathrm{SPT}}$ natural para sapatas quadradas de lado $\mathrm{B}=1 \mathrm{~m}$. 


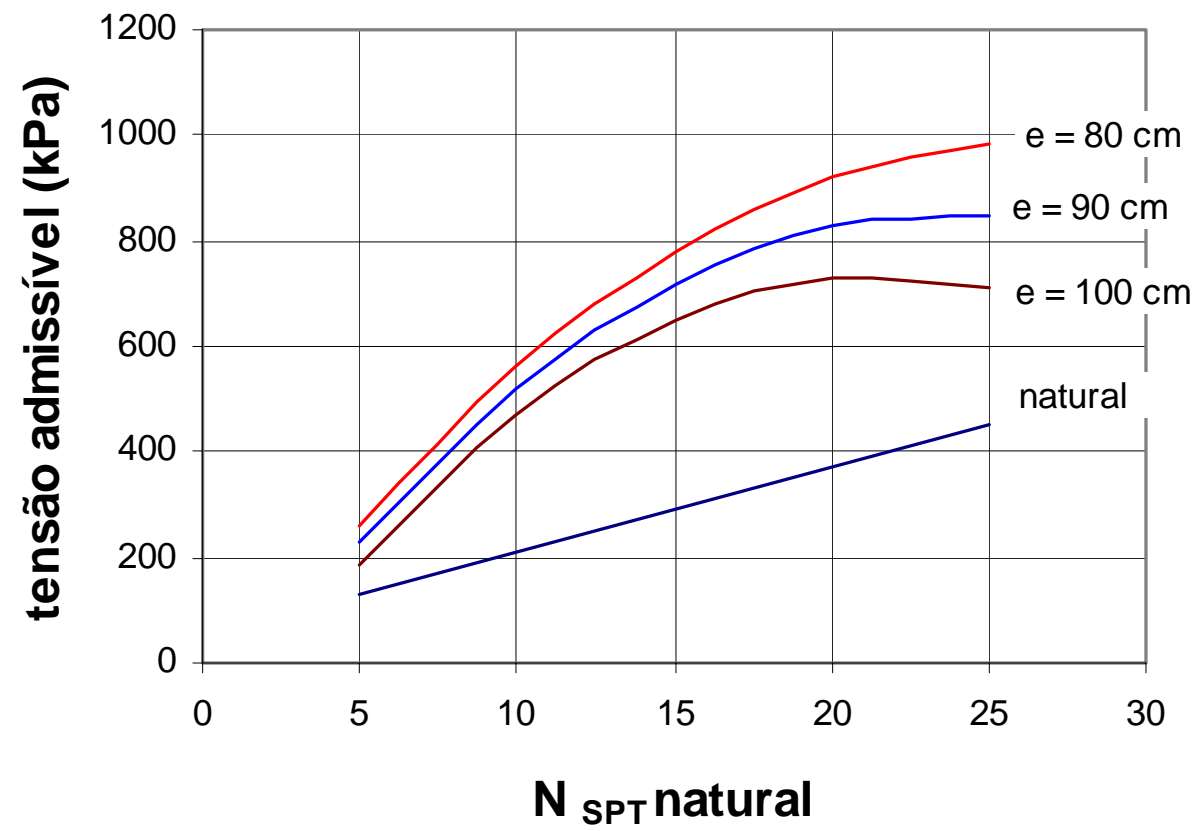

Figura 63. Gráfico teórico tensão admissível x $\mathrm{N}_{\mathrm{SPT}}$ natural para sapatas quadradas de lado $\mathrm{B}=1,5 \mathrm{~m}$.

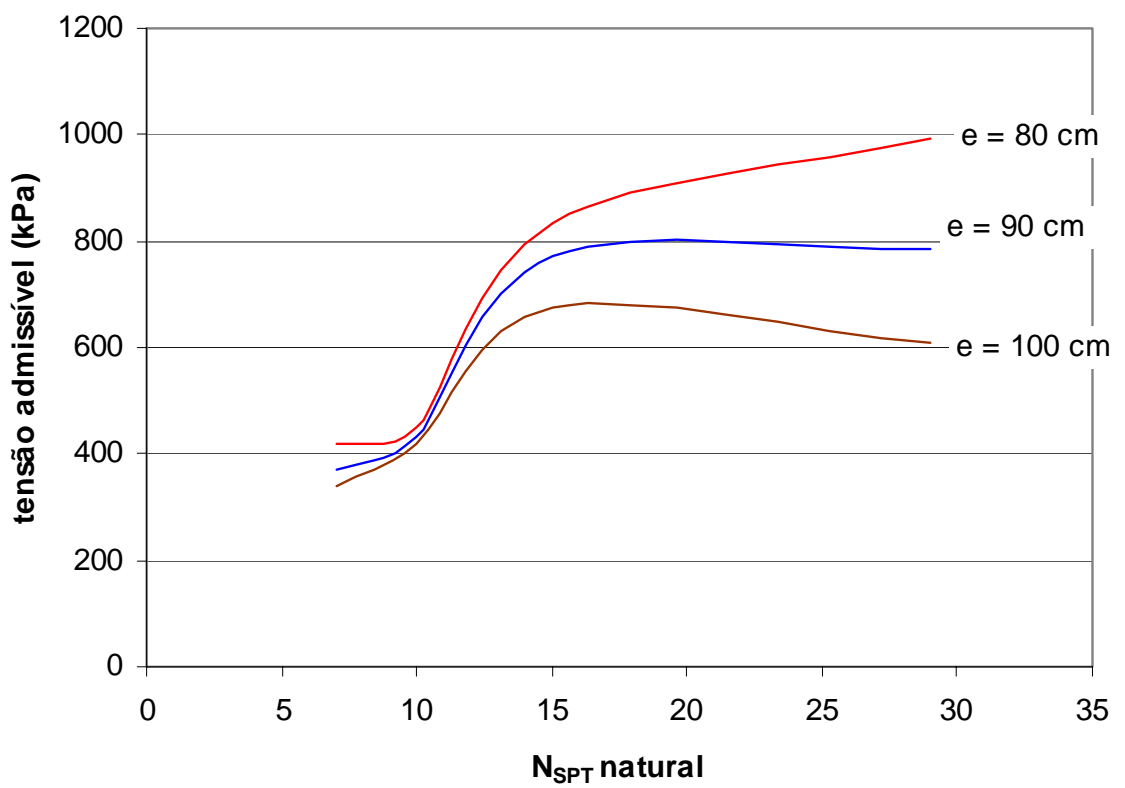

Figura 64. Gráfico experimental tensão admissível $x \mathrm{~N}_{\mathrm{SPT}}$ natural para sapatas quadradas de lado $\mathrm{B}=1,5 \mathrm{~m}$. 


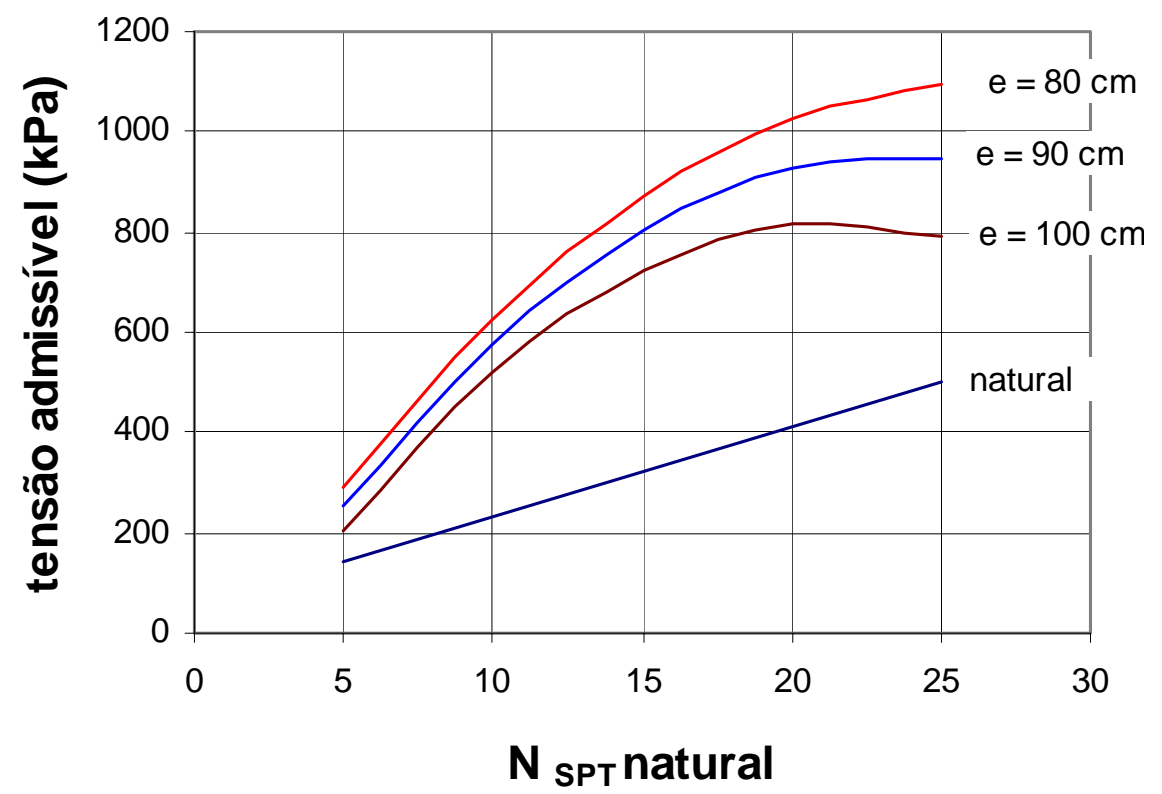

Figura 65. Gráfico teórico tensão admissível $\mathrm{x} \mathrm{N}_{\mathrm{SPT}}$ natural para sapatas quadradas de lado $\mathrm{B}=2 \mathrm{~m}$.

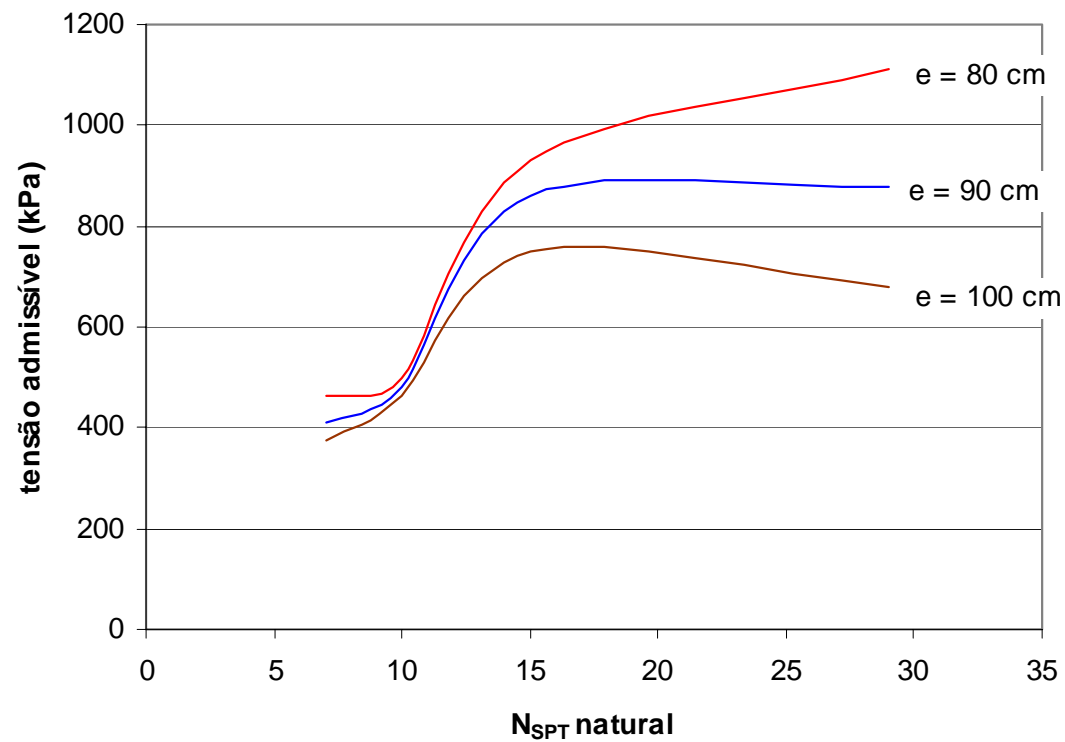

Figura 66. Gráfico experimental tensão admissível $\times \mathrm{N}_{\mathrm{SPT}}$ natural para sapatas quadradas de lado $\mathrm{B}=2 \mathrm{~m}$. 


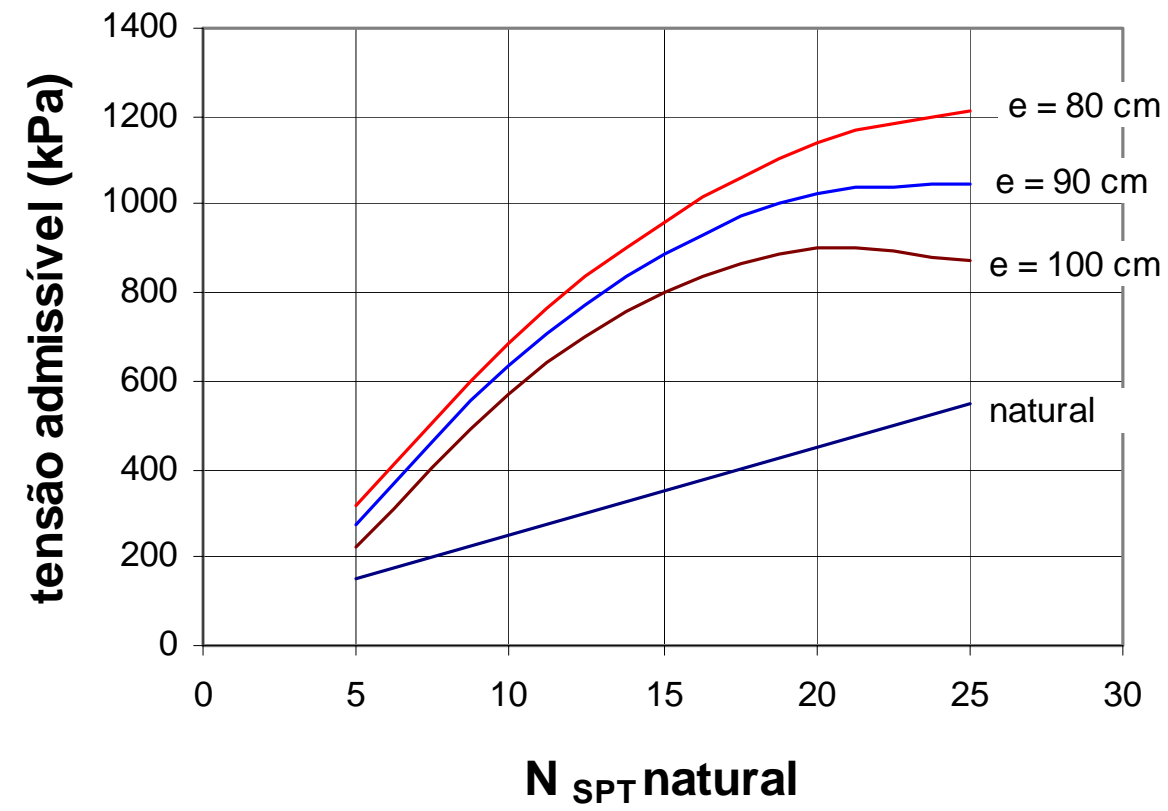

Figura 67. Gráfico teórico tensão admissível $x \mathrm{~N}_{\mathrm{SPT}}$ natural para sapatas quadradas de lado $\mathrm{B}=2,5 \mathrm{~m}$.

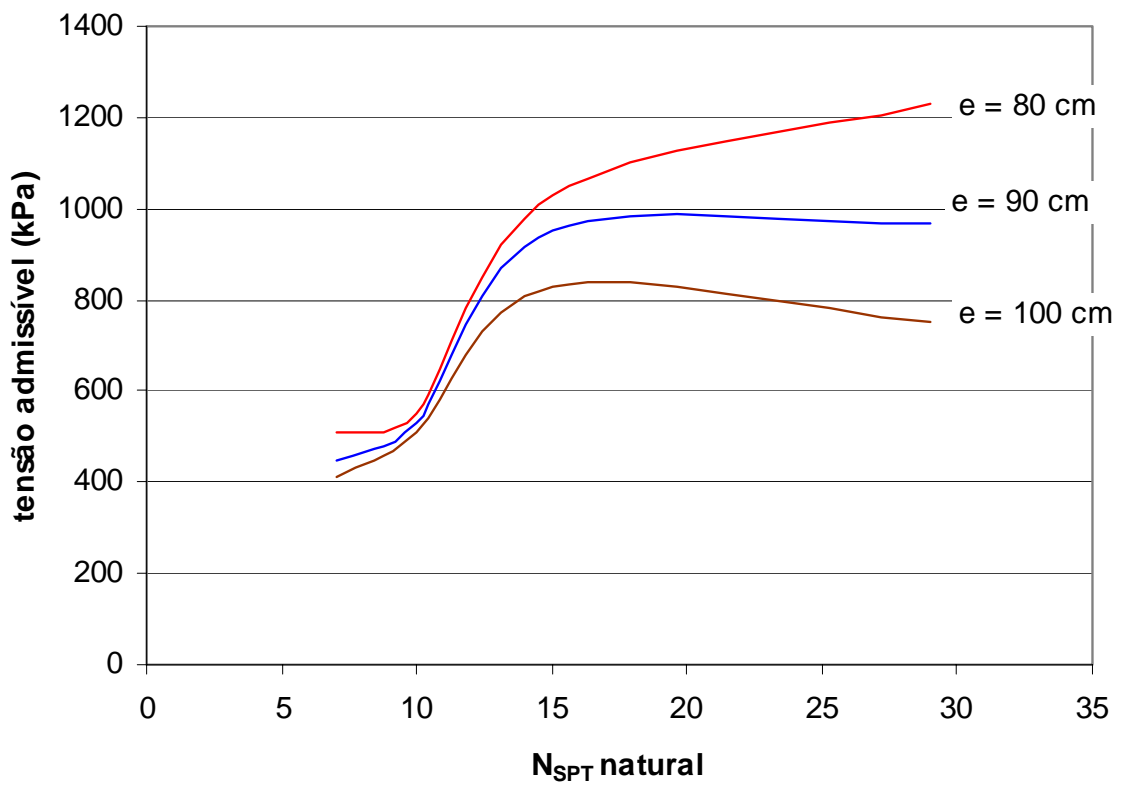

Figura 68. Gráfico experimental tensão admissível $\times \mathrm{N}_{\mathrm{SPT}}$ natural para sapatas quadradas de lado $\mathrm{B}=2,5 \mathrm{~m}$. 


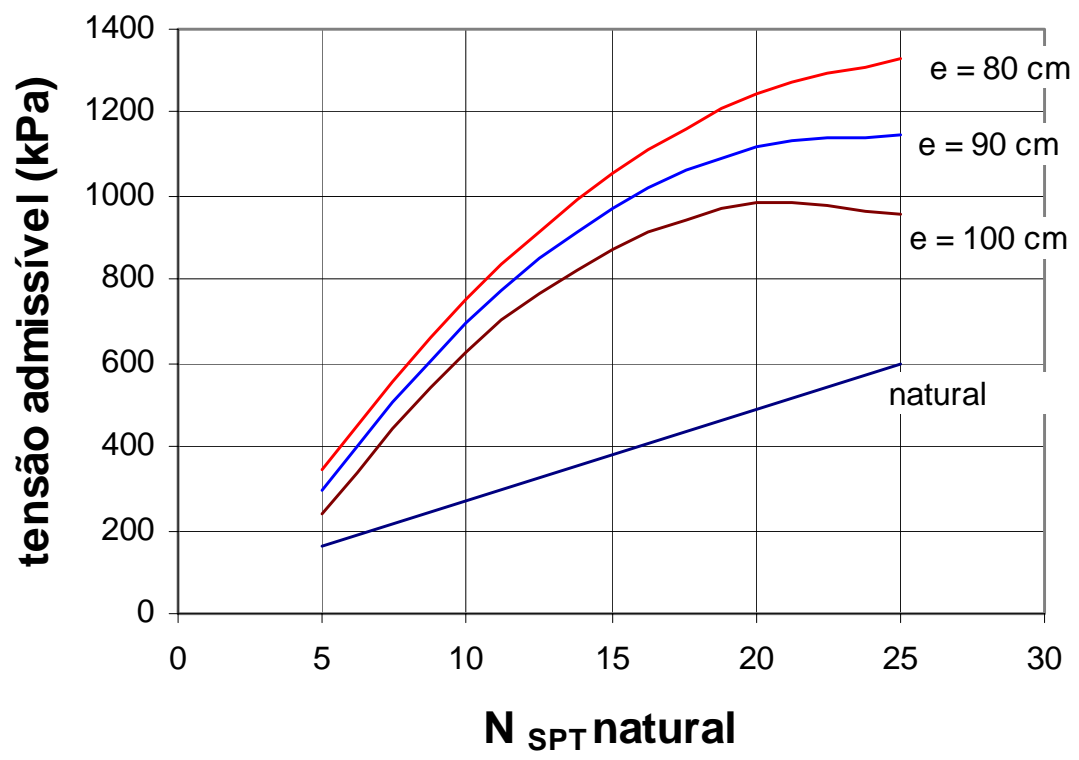

Figura 69. Gráfico teórico tensão admissível x $\mathrm{N}_{\mathrm{SPT}}$ natural para sapatas quadradas de lado $\mathrm{B}=3 \mathrm{~m}$.

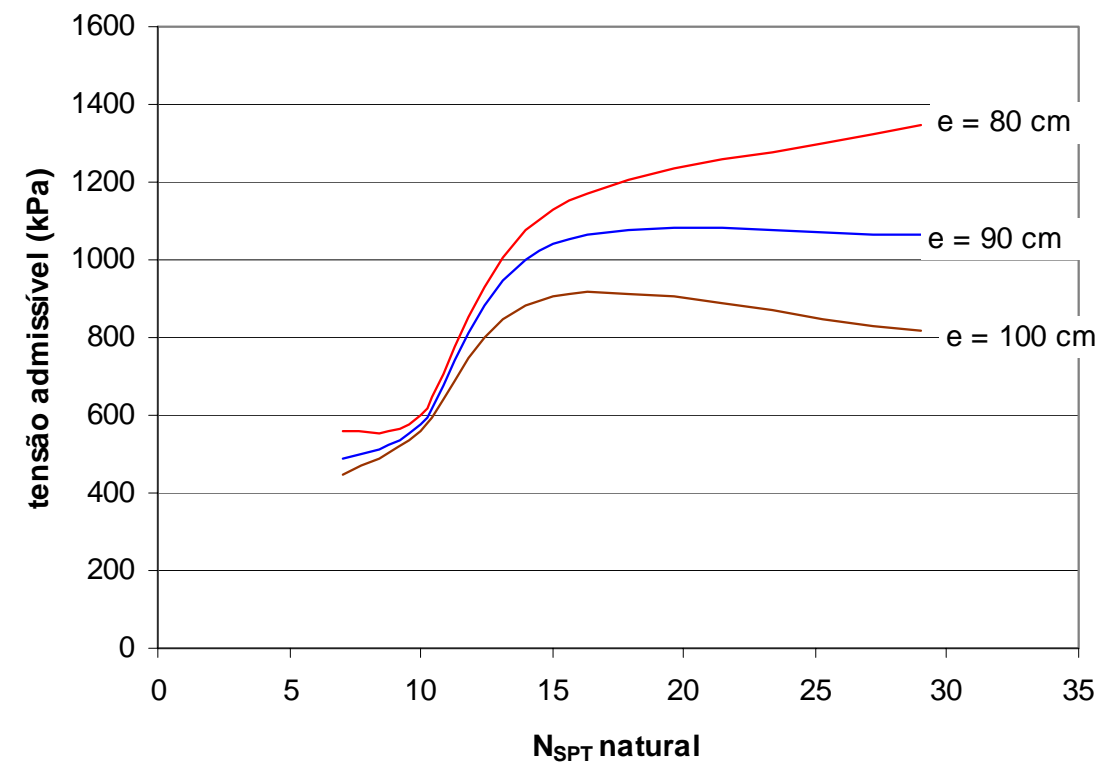

Figura 70. Gráfico experimental tensão admissível $\times \mathrm{N}_{\mathrm{SPT}}$ natural para sapatas quadradas de lado $\mathrm{B}=3 \mathrm{~m}$. 
As correlações entre o $\mathrm{N}_{\mathrm{SPT}}$ natural e compactado mostram um intervalo de $\mathrm{N}_{\mathrm{SPT}}$ natural, entre 5 e 10, em que a melhoria é mais eficaz, aumentando em até três vezes a resistência do solo. Para o intervalo de $\mathrm{N}_{\mathrm{SPT}}$ natural entre 15 e 20, a compactação produz valores absolutos máximos de $\mathrm{N}_{\mathrm{SPT}}$ de cerca de 50 (para a malha de $80 \mathrm{~cm}$ ). Além desses valores, os efeitos da compactação tendem a diminuir. Essa característica pode ser explicada pelo arranjo das partículas do solo no estado natural, ou seja, solos que apresentam valores de $\mathrm{N}_{\mathrm{SPT}}$ natural acima de 20 mostram maior dificuldade no rearranjo das partículas, diminuindo os efeitos da melhoria, pois o processo de compactação melhora as propriedades do solo por meio do deslocamento físico das partículas, reduzindo o volume de vazios do solo.

Observa-se que a melhoria é maior para os valores menores de $\mathrm{N}_{\mathrm{SPT}}$, fato também observado nas curvas teóricas $\sigma_{\mathrm{a}} \times \mathrm{N}_{\mathrm{SPT}}$, que apresentam melhorias mais eficientes para menores valores de $\mathrm{N}_{\mathrm{SPT}}$, ou seja, as curvas teóricas, oriundas da função linear $\sigma_{\mathrm{a}}=50+(10+4 \mathrm{~B}) \mathrm{N}_{\mathrm{SPT}}$, apresentam segmentos de reta com declividades cada vez menores. Isso se explica pelo fato da melhor correlação obtida entre $\mathrm{N}_{\mathrm{SPT}}$ do solo compactado e $\mathrm{N}_{\mathrm{SPT}}$ do solo natural ser uma função do segundo grau, cujo gráfico é do tipo parábola convexa.

Analisando-se os gráficos teóricos constata-se que as malhas de estacas com menor espaçamento proporcionaram maior ganho de resistência. A Tabela 4 mostra, para cada malha de estacas o aumento médio de resistência em relação ao solo natural.

Tabela 4. Aumento médio de resistência para cada malha de estacas.

\begin{tabular}{|c|c|}
\hline Espaçamento entre estacas & Aumento da resistência \\
\hline $100 \mathrm{~cm}$ & $57 \%$ \\
\hline $90 \mathrm{~cm}$ & $60 \%$ \\
\hline $80 \mathrm{~cm}$ & $63 \%$ \\
\hline
\end{tabular}


As tensões admissíveis obtidas têm segurança apenas em relação à ruptura, sendo necessário se fazerem os cálculos de tensão admissível em relação ao recalque. Para o local da pesquisa utilizou-se o método de Schmertmann (1970), adotando-se um recalque máximo de $30 \mathrm{~mm}$, $\gamma$ de $18 \mathrm{kN} / \mathrm{m}^{3}$ à profundidade de $1,5 \mathrm{~m}$, e o coeficiente de segurança de norma igual a 1,5. Não se considerou o efeito do aumento do recalque com o tempo $\left(\mathrm{C}_{2}=1\right)$. $\mathrm{O}$ módulo de deformabilidade foi estimado pela fórmula $\mathrm{E}=3 \mathrm{KN}$. $\mathrm{A}$ Figura 71 mostra o gráfico tensão admissível x lado B da sapata, obtido pelo método de Schmertmann para o solo natural e compactado.

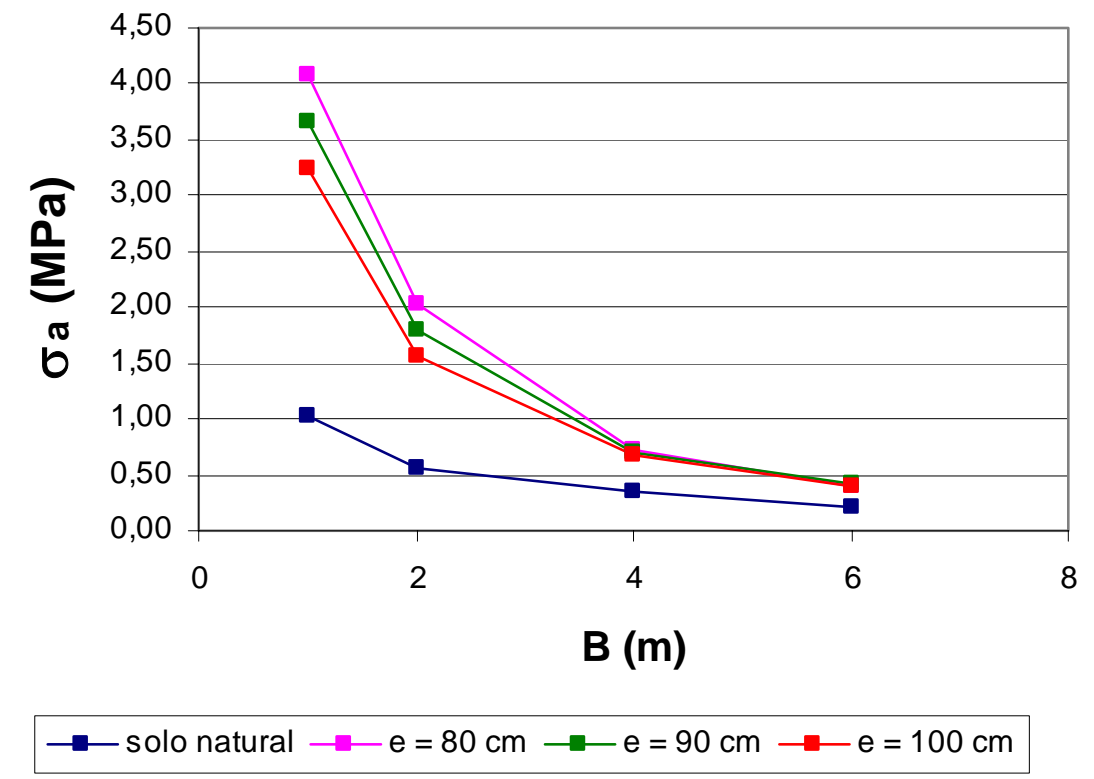

Figura 71. Gráfico tensão admissível x lado B da sapata.

O gráfico mostra que, para sapatas menores, o efeito da compactação é maior. Já para sapatas maiores, os efeitos da melhoria tendem a diminuir. Isso se explica, pelo fato das tensões exercidas por sapatas maiores atingirem profundidades que não sofrem os efeitos da compactação.

As Figuras 72 a 75 mostram os valores de tensão admissível, encontradas pelos critérios de recalque e ruptura, em função do lado B de uma sapata quadrada, para o solo natural e compactado. 


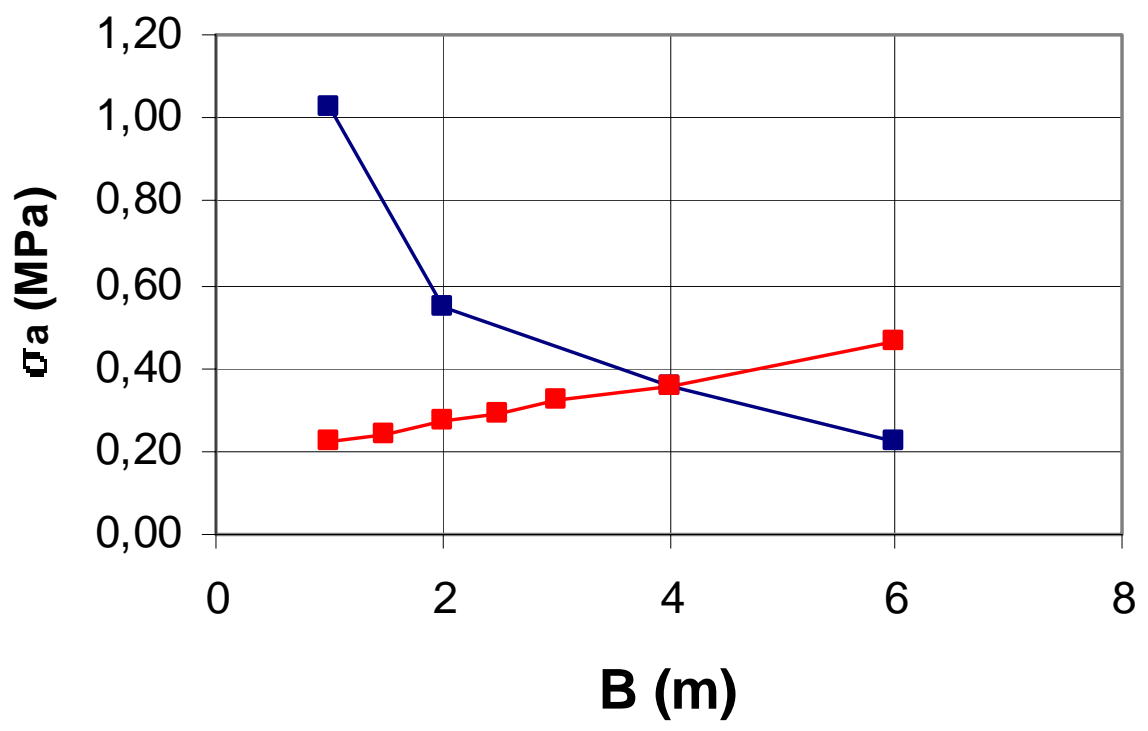

$\rightarrow$ recalque $\rightarrow-$ ruptura

Figura 72. Tensão admissível em solo natural.

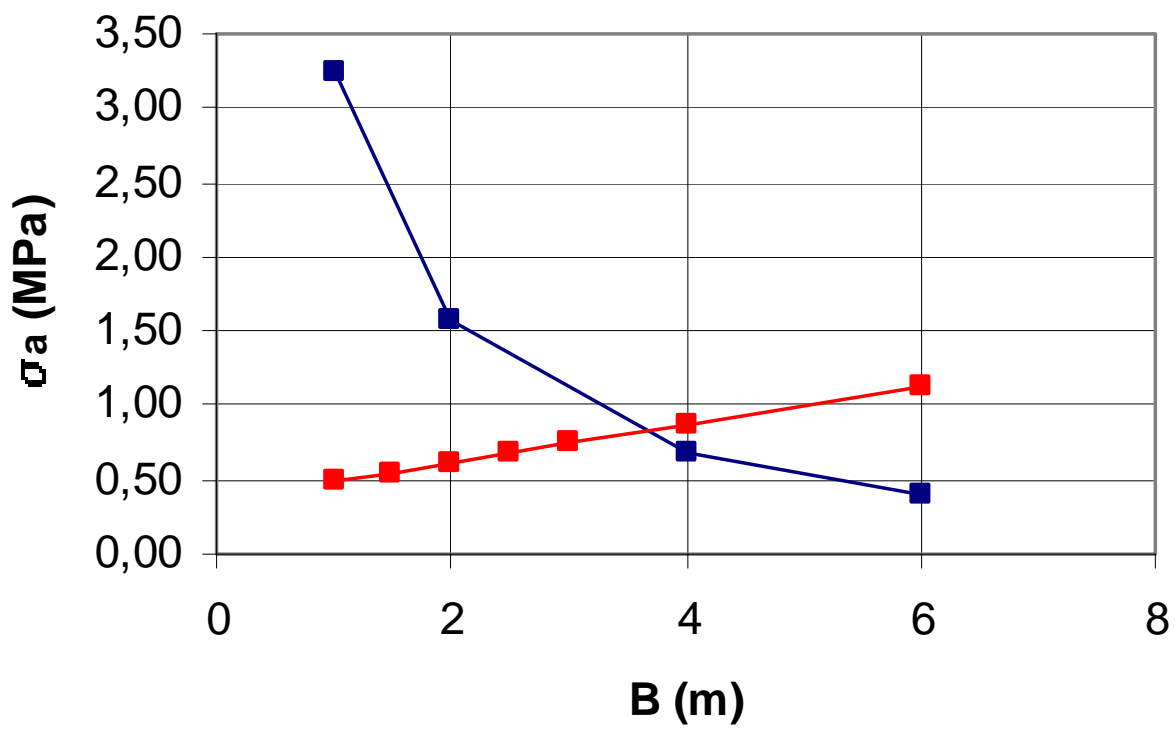

Figura 73. Tensão admissível em malha de estacas com espaçamento de $100 \mathrm{~cm}$. 


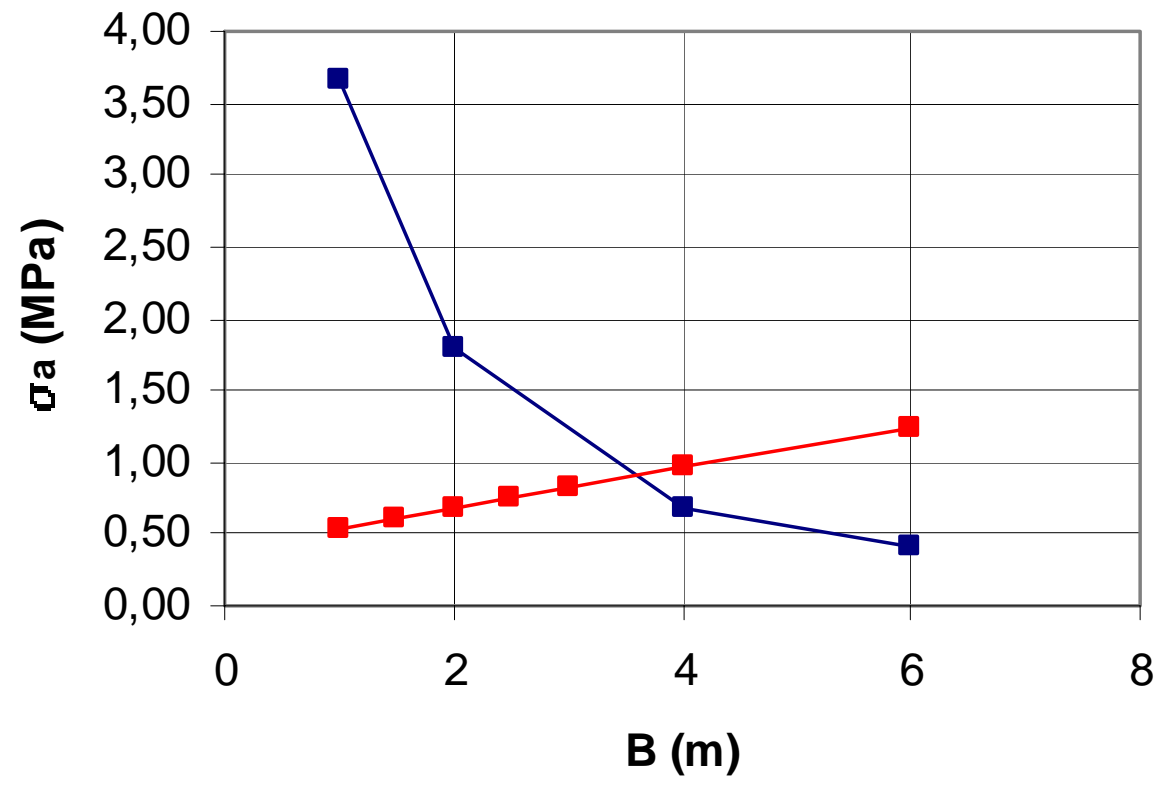

$\rightarrow$ recalque $\rightarrow$ ruptura

Figura 74. Tensão admissível em malha de estacas com espaçamento de $90 \mathrm{~cm}$.

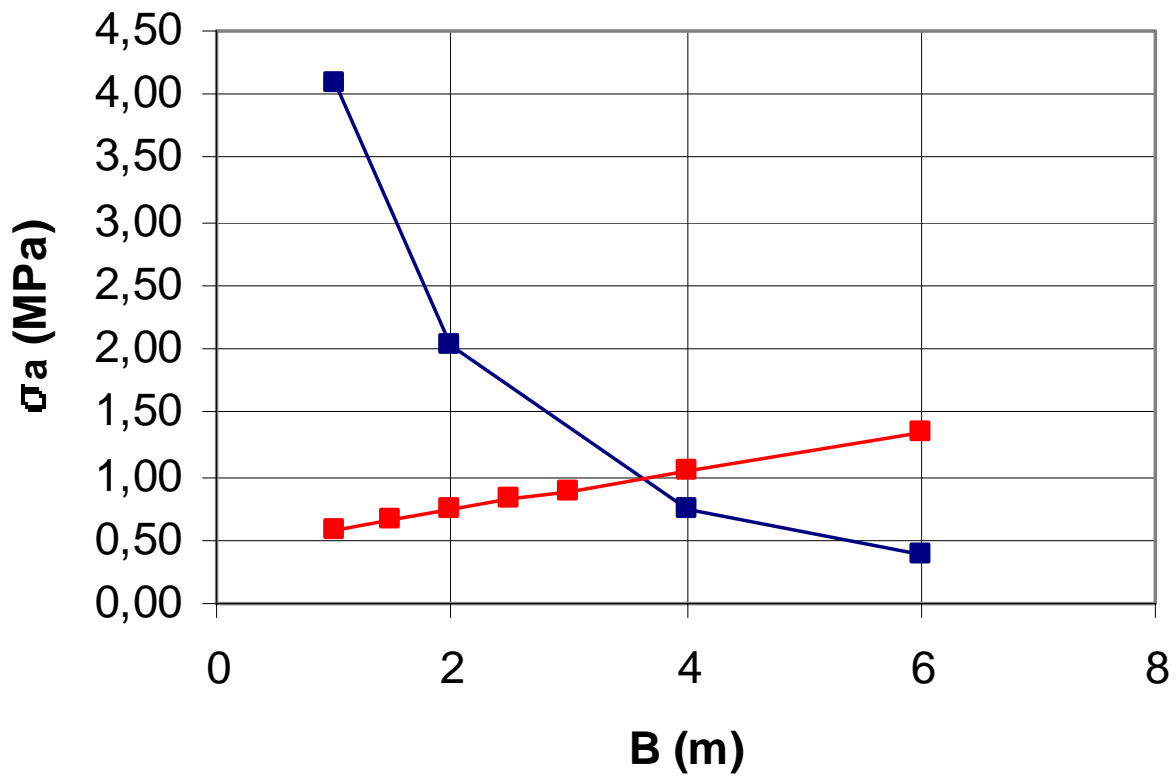

$\rightarrow$ recalque $\rightarrow$ ruptura

Figura 75. Tensão admissível em malha de estacas com espaçamento de $80 \mathrm{~cm}$ 
Os gráficos mostram que a tensão admissível é limitada pela resistência do solo para valores menores da largura da sapata e limitada pela deformabilidade do solo para valores maiores da largura da sapata. No solo natural, a tensão admissível aumenta de 0,2 $\mathrm{MPa}$, para $\mathrm{B}=1,0 \mathrm{~m}$, até cerca de $0,35 \mathrm{MPa}$ para $\mathrm{B}=4,0 \mathrm{~m}$, passando a diminuir para 0,2 $\mathrm{MPa}$, para $\mathrm{B}=6,0 \mathrm{~m}$. No solo compactado, a tensão admissível aumenta de cerca de 0,5 MPa, para $\mathrm{B}=1,0 \mathrm{~m}$, até cerca de 0,8 a $1,0 \mathrm{MPa}$, para $\mathrm{B}=3,5 \mathrm{~m}$, dependendo da malha, passando a diminuir para $0,5 \mathrm{MPa}$, para $\mathrm{B}=5,0 \mathrm{~m}$ e $0,4 \mathrm{MPa}$ para $\mathrm{B}=6,0 \mathrm{~m}$, independente da malha.

De forma conservadora, sem levar em conta o aumento da tensão admissível nos valores intermediários de $\mathrm{B}$, pode-se considerar os valores constantes de 0,2 $\mathrm{MPa}$ no solo natural e de 0,5 MPa no solo compactado, no intervalo de $\mathrm{B}=1$ a $5 \mathrm{~m}$.

A fim de se avaliar a redução dos recalques em solo compactado, construiu-se o gráfico recalque $\mathrm{x}$ lado $\mathrm{B}$ da sapata (Figura 76). Os recalques foram calculados pelo método de Schmertmann, para uma tensão admissível de $0,5 \mathrm{MPa}$ e B $\leq 5 \mathrm{~m}$.

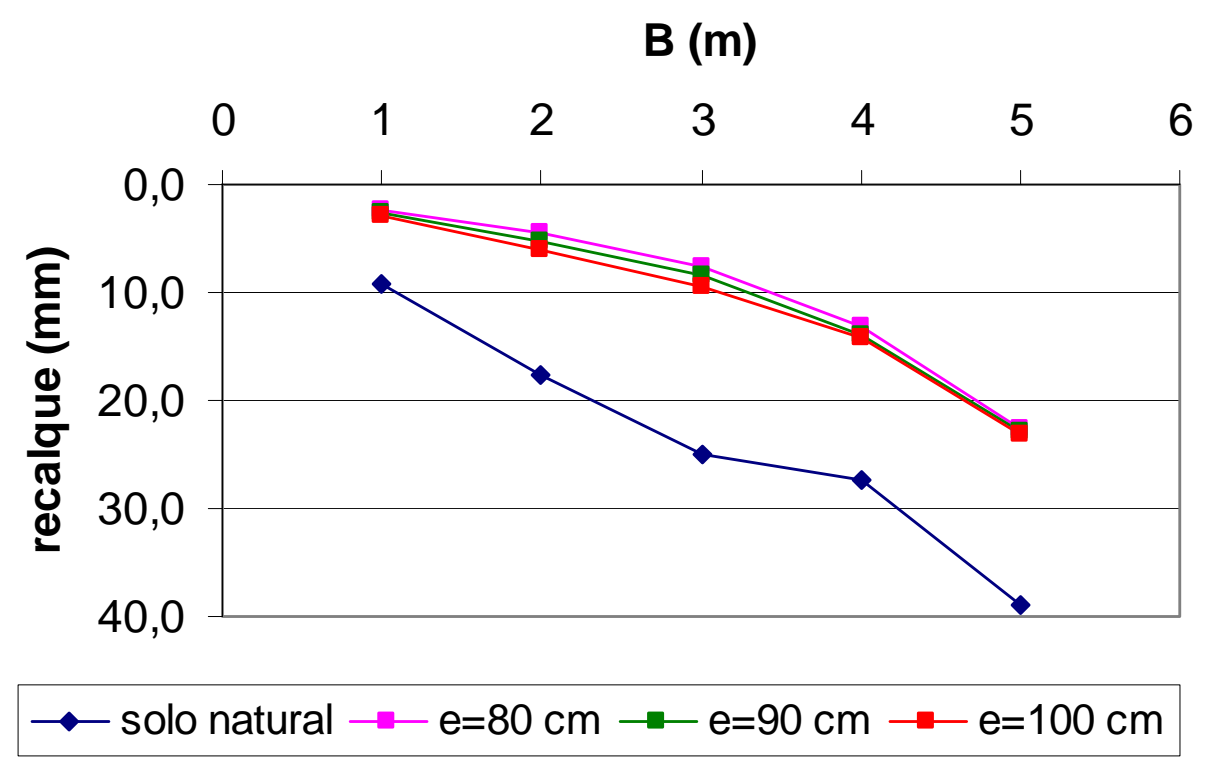

Figura 76. Gráfico recalques x lado B da sapata quadrada.

Há uma maior redução dos recalques nas sapatas menores. Para $\mathrm{B}=1,0 \mathrm{~m}$, a redução média no solo compactado foi de $72 \%$. Para $\mathrm{B}=5,0 \mathrm{~m}$, a redução média foi de 
41\%. A Figura 77 apresenta a redução dos recalques para cada malha de estacas, em função do lado B de uma sapata quadrada.

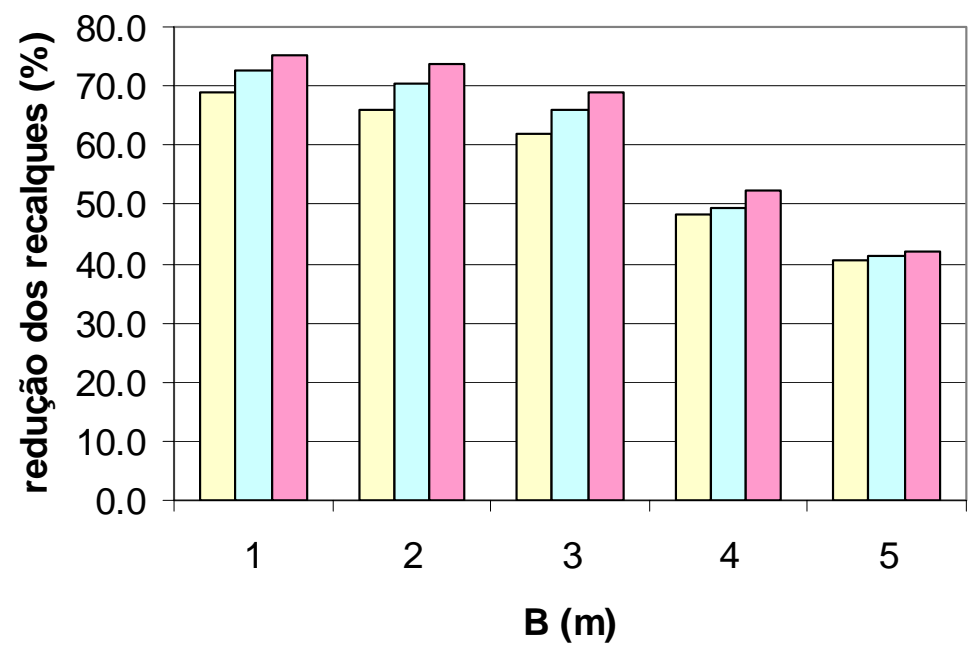

$$
\square \mathrm{e}=100 \mathrm{~cm} \square \mathrm{e}=90 \mathrm{~cm} \square \mathrm{e}=80 \mathrm{~cm}
$$

Figura 77. Redução dos recalques em solo compactado. 


\subsection{Ensaio de Cone}

Com os resultados do ensaio de cone, determinou-se a tensão admissível para o terreno natural e compactado pela regra empírica $\sigma_{\mathrm{a}}=\mathrm{q}_{\mathrm{c}} / 15(\mathrm{MPa})$, mencionada por TEIXEIRA \& GODOY (1996) para solos arenosos, em que $\mathrm{q}_{\mathrm{c}}$ é a resistência de ponta do cone, dada pela média dentro da profundidade de 1,5 B, sendo B a largura da sapata. Os valores médios de tensão admissível, obtidos para sapatas quadradas de largura B, variando de 1 a 3 m, em solo natural e compactado, são dados na Figura 78.

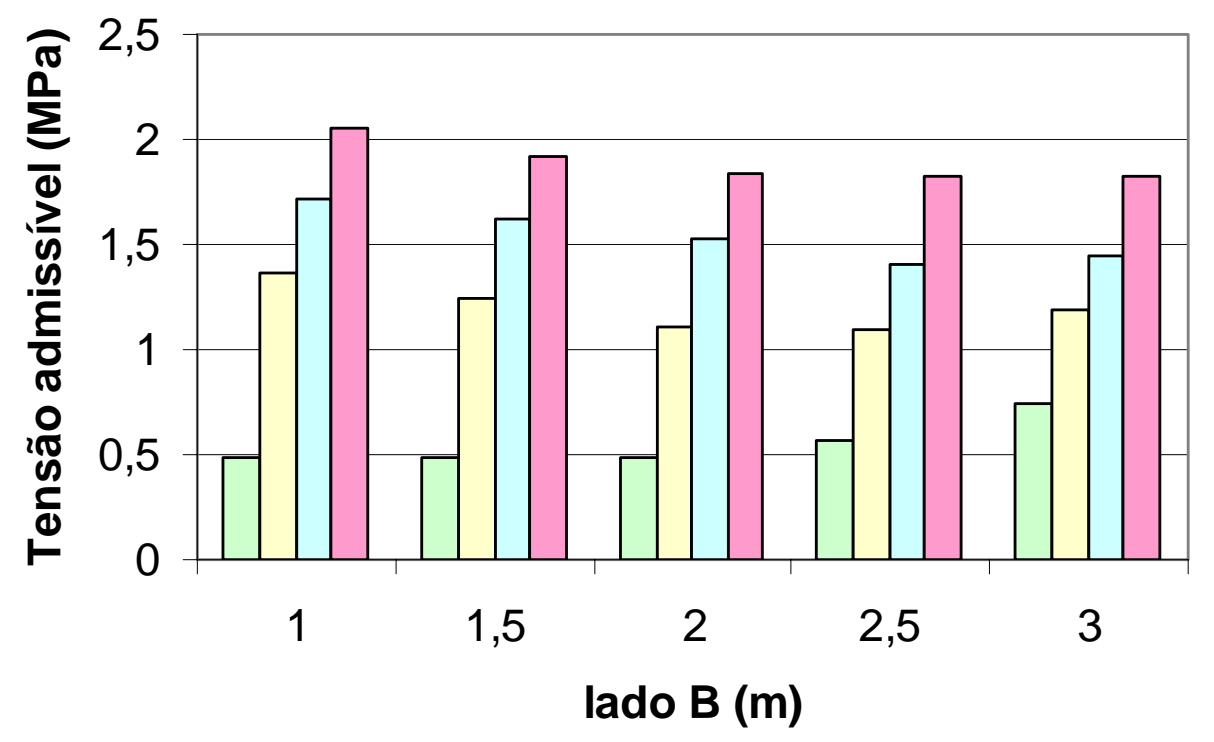

$\square$ solo natural $\square \mathrm{e}=100 \mathrm{~cm} \square \mathrm{e}=90 \mathrm{~cm} \square \mathrm{e}=80 \mathrm{~cm}$

Figura 78. Tensões admissíveis médias em solo natural e compactado.

Observa-se o aumento gradual da resistência do solo, à medida que o espaçamento entre estacas é diminuído. Para uma sapata quadrada de 1,0 m de largura, na malha de $80 \mathrm{~cm}$, o aumento chega até quatro vezes.

Comparando-se ao solo natural, a tensão admissível obtida com base em $\mathrm{q}_{\mathrm{c}}$, aumentou em média 52\%, 61\% e 69\%, para as malhas de estacas com espaçamento de $1,0 \mathrm{~m}, 0,90 \mathrm{~m}$ e $0,80 \mathrm{~m}$ respectivamente. 
Para a análise das tensões admissíveis em relação ao recalque máximo, adotado como $30 \mathrm{~mm}$, utilizou-se o método de Schmertmann (1970). Os cálculos foram feitos para $\gamma=18 \mathrm{kN} / \mathrm{m}^{3}$, na profundidade de $1,5 \mathrm{~m}$. Para o módulo de deformabilidade foi utilizada a relação $\mathrm{E}=3 \mathrm{q}_{\mathrm{c}}$. A Figura 79 mostra o gráfico tensão admissível x lado $\mathrm{B}$ da sapata, obtido pelo método de Schmertmann para o solo natural e compactado.

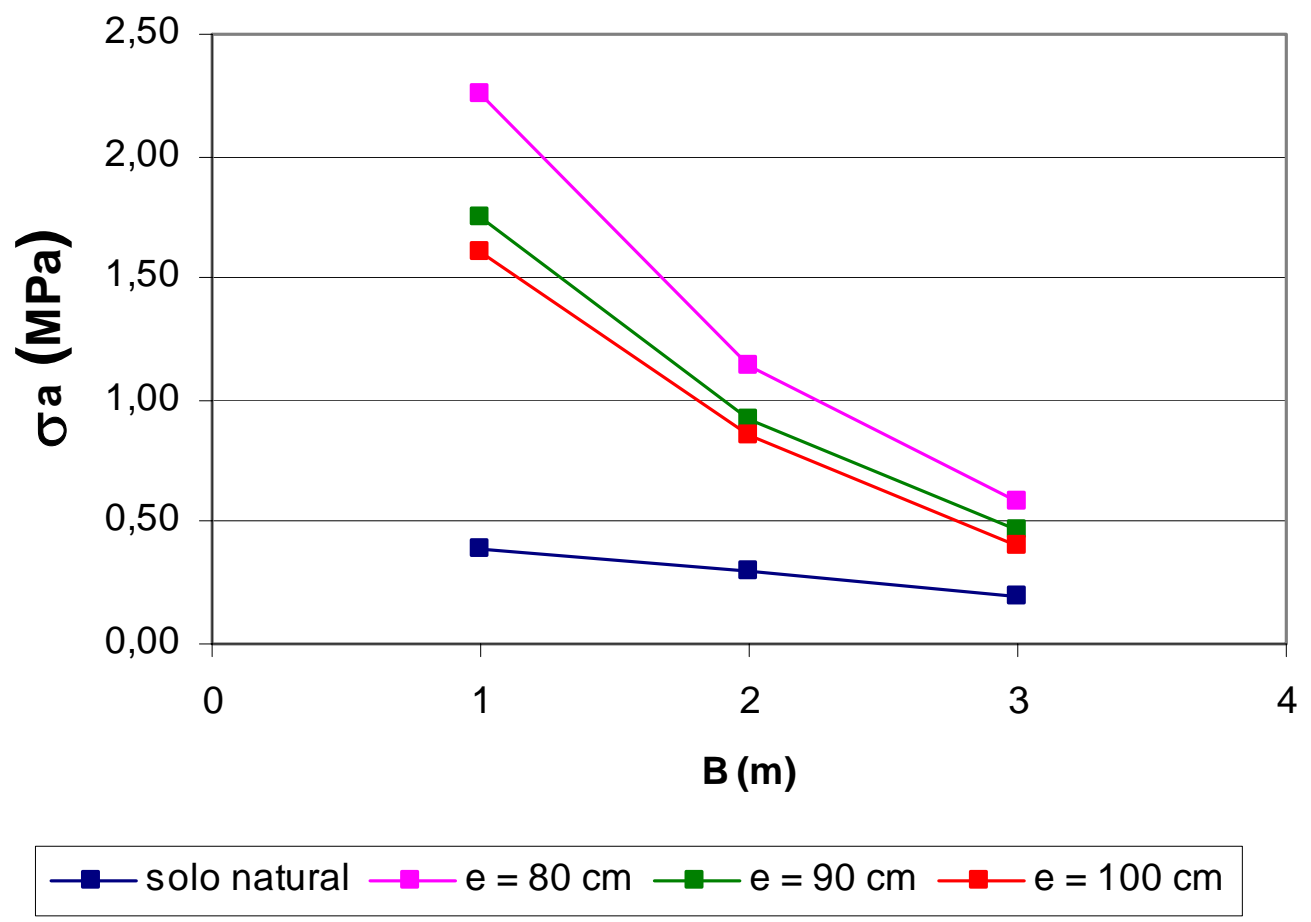

Figura 79. Gráfico tensão admissível x lado B da sapata.

As Figuras 80 a 83 mostram os valores de tensão admissível, encontrados pelos critérios de recalque e ruptura, em função do lado B de uma sapata quadrada, para o solo natural e compactado. 


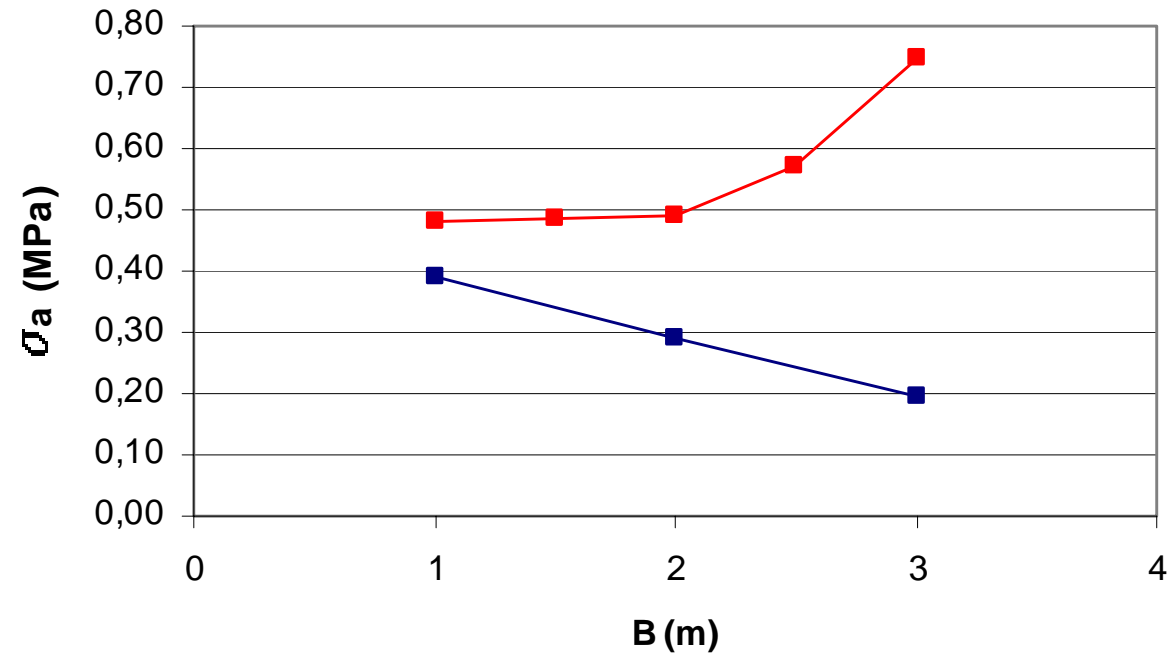

$\rightarrow$ recalque $\rightarrow$ ruptura

Figura 80. Tensão admissível em solo natural.

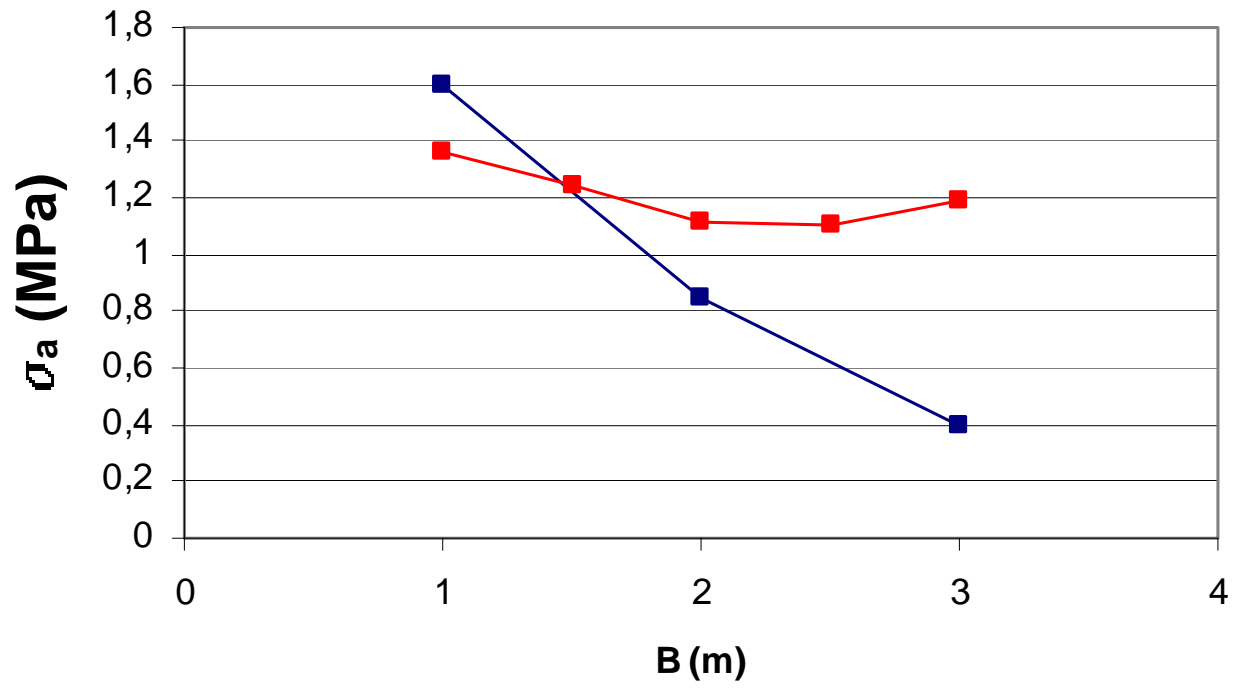

$\rightarrow$ recalque $\longrightarrow$ ruptura

Figura 81. Tensão admissível em malha de estacas com espaçamento de $100 \mathrm{~cm}$. 


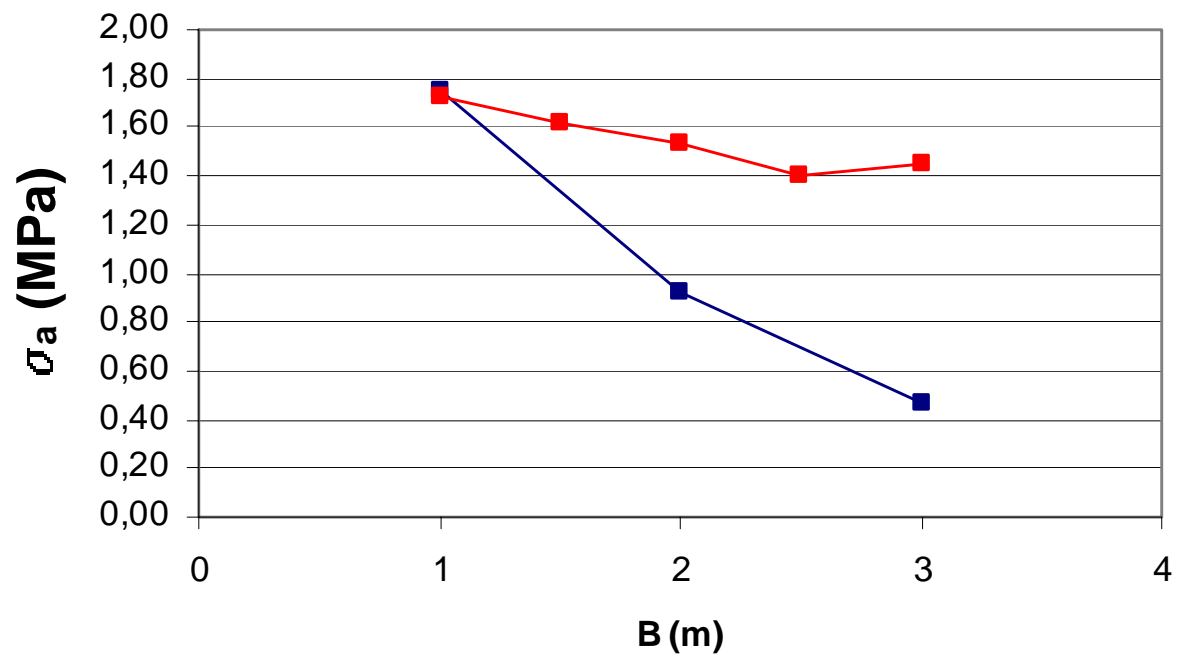

$\rightarrow$ recalque $\rightarrow$ ruptura

Figura 82. Tensão admissível em malha de estacas com espaçamento de $90 \mathrm{~cm}$.

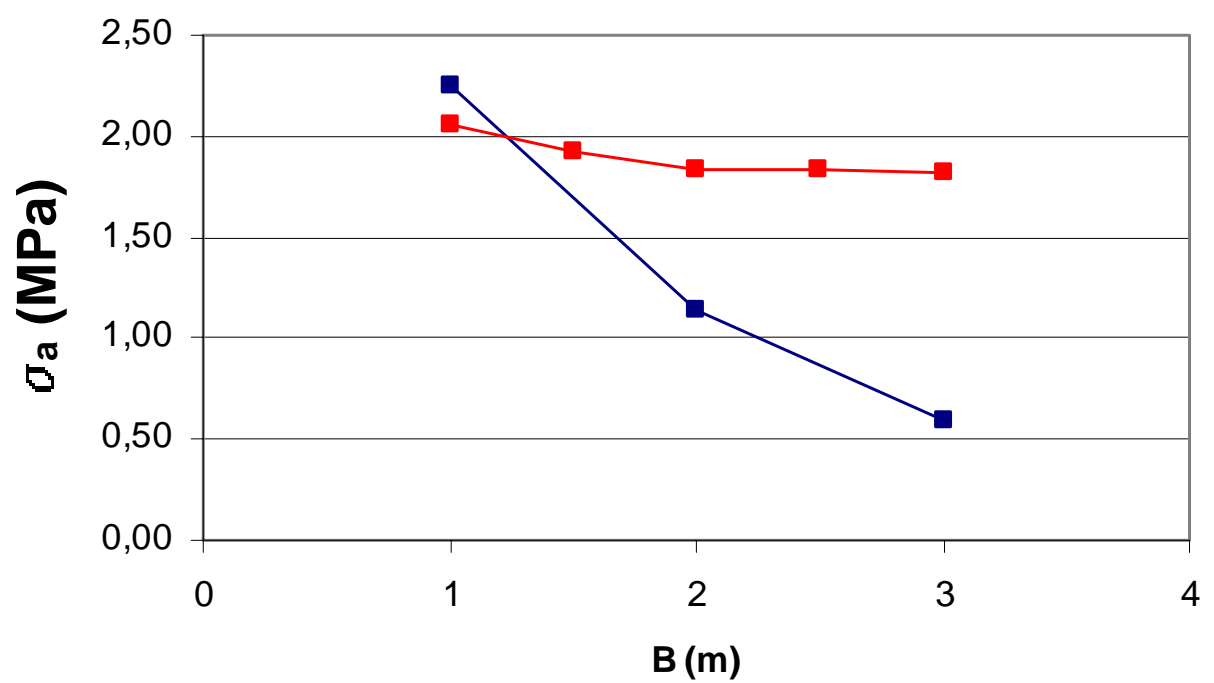

$\rightarrow$ recalque $\rightarrow$ ruptura

Figura 83. Tensão admissível em malha de estacas com espaçamento de $80 \mathrm{~cm}$. 
Os valores de tensão admissível, em relação à ruptura, estimadas pelo Cone estão bem acima dos obtidos pela Sondagem SPT. A correlação utilizada entre resistência de ponta e tensão admissível parece ser muito ousada.

As comparações entre as tensões admissíveis em relação à ruptura e ao recalque mostram que, para o solo natural, o critério de recalque é que limita o valor da tensão admissível. Seu valor varia de cerca de $0,4 \mathrm{MPa}$ para $\mathrm{B}=1,0 \mathrm{~m}$, até 0,2 $\mathrm{MPa}$ para $\mathrm{B}=3,0 \mathrm{~m}$. Para o solo compactado na malha de $100 \mathrm{~cm}$, a tensão admissível varia de cerca de 1,38 MPa para $\mathrm{B}=1,0 \mathrm{~m}$, até cerca de $1,25 \mathrm{MPa}$ para $\mathrm{B}=1,4 \mathrm{~m}$, passando a diminuir para $0,4 \mathrm{MPa}$ para $\mathrm{B}=3,0 \mathrm{~m}$. Da mesma forma que o solo natural, o solo compactado na malha de $90 \mathrm{~cm}$ também apresenta tensão admissível praticamente limitada pelo critério de recalque. Seu valor diminui de cerca de 1,75 MPa para $\mathrm{B}=1,0 \mathrm{~m}$, para cerca de $0,47 \mathrm{MPa}$ para $\mathrm{B}=3,0 \mathrm{~m}$. Para o solo compactado na malha de $80 \mathrm{~cm}$, a tensão admissível varia de 2,1 $\mathrm{MPa}$ para $\mathrm{B}=1,0 \mathrm{~m}$, para 2,0 $\mathrm{MPa}$ para $\mathrm{B}=1,25 \mathrm{~m}$, diminuindo até $0,6 \mathrm{MPa}$ para $\mathrm{B}=3,0 \mathrm{~m}$.

Analisando-se os critério de ruptura e recalque, para valores de B entre 1,0 e 3,0 m, as tensões admissíveis estimadas pelo Cone podem ser adotadas como 0,2 $\mathrm{MPa}$ para o solo natural, 0,4 MPa para solo compactado na malha de $100 \mathrm{~cm}, 0,47 \mathrm{MPa}$ para a malha de $90 \mathrm{~cm}$ e 0,6 MPa para o solo na malha de $80 \mathrm{~cm}$. 


\subsubsection{Correlação entre $q_{c}$ e $N_{S P T}$}

Por meio de correlações lineares pela origem, entre os valores médios da resistência de ponta $\left(\mathrm{q}_{\mathrm{c}}\right)$ e índice de resistência à penetração $\left(\mathrm{N}_{\mathrm{SPT}}\right)$, determinou-se o coeficiente $\mathrm{K}$ da camada de areia até $3 \mathrm{~m}$ de profundidade. As Figuras 84 a 87 mostram os gráficos $\mathrm{q}_{\mathrm{c}} \mathrm{x} \mathrm{N}_{\mathrm{SPT}}$ para o terreno natural e compactado.

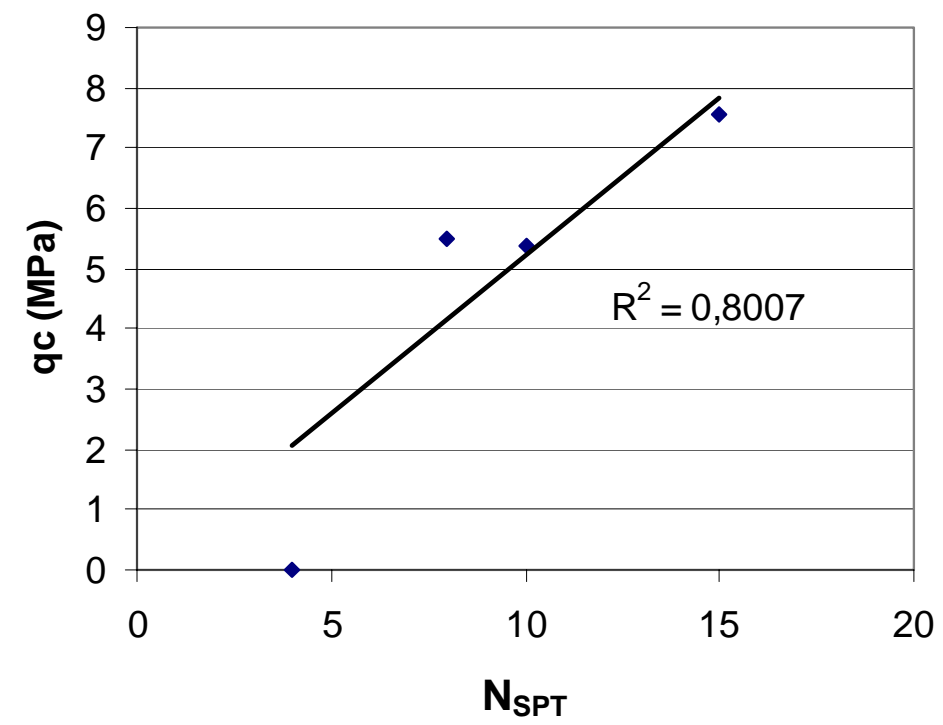

Figura 84. Gráfico $\mathrm{q}_{\mathrm{c}} \mathrm{x} \mathrm{N}_{\mathrm{SPT}}$ para o terreno natural.

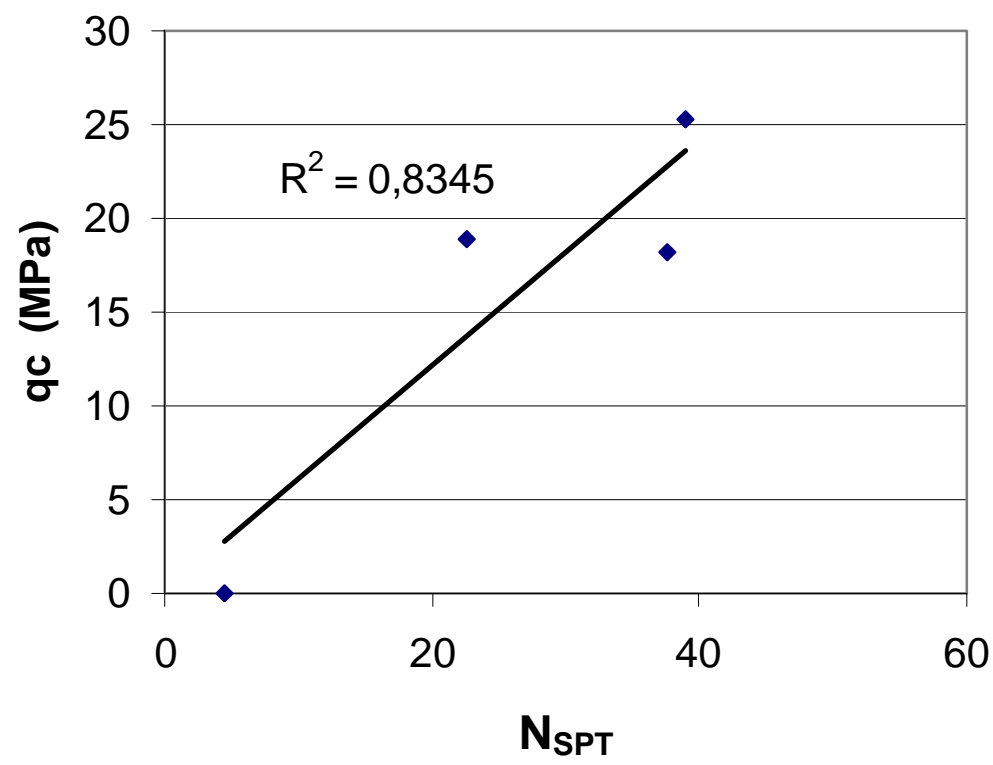

Figura 85. Gráfico $\mathrm{q}_{\mathrm{c}} \times \mathrm{N}_{\mathrm{SPT}}$ para malha de estacas com espaçamento de $100 \mathrm{~cm}$ 


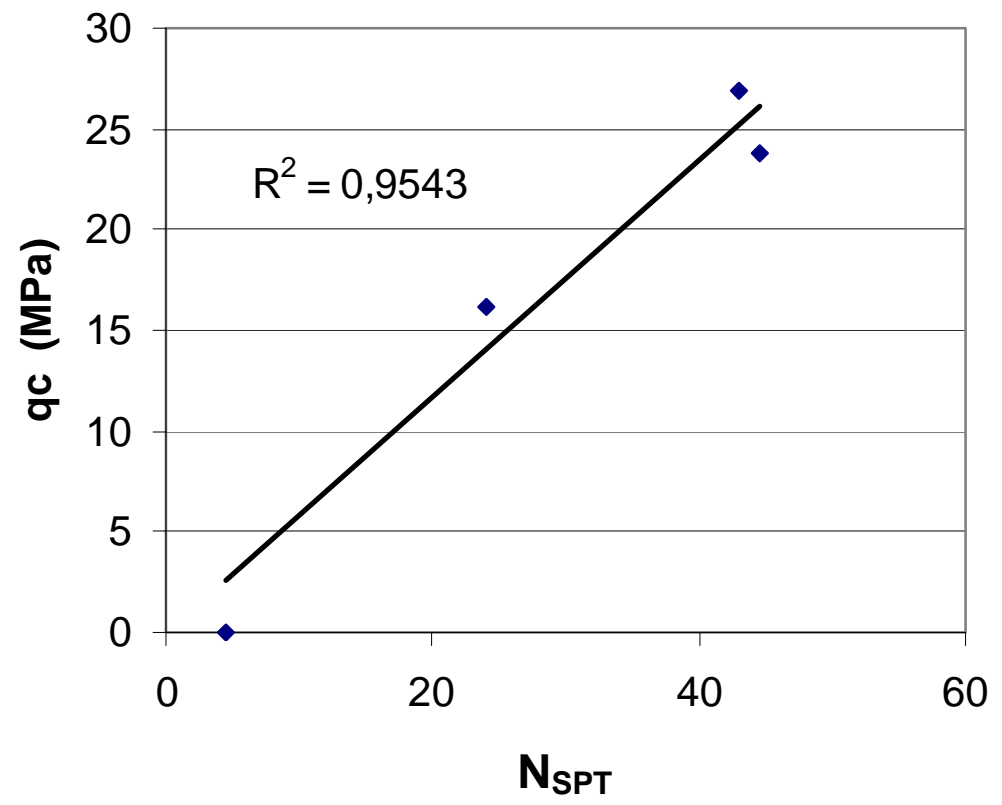

Figura 86. Gráfico $\mathrm{q}_{\mathrm{c}} \times \mathrm{N}_{\mathrm{SPT}}$ para malha de estacas com espaçamento de $90 \mathrm{~cm}$.

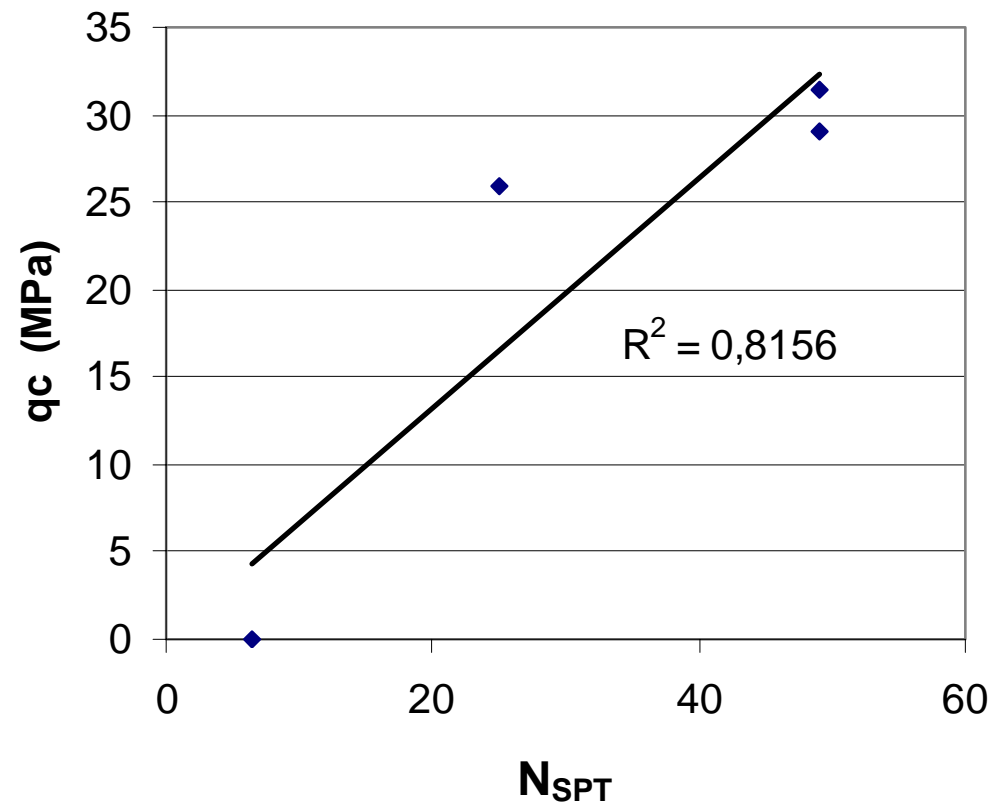

Figura 87. Gráfico $\mathrm{q}_{\mathrm{c}} \mathrm{x} \mathrm{N}_{\mathrm{SPT}}$ para malha de estacas com espaçamento de $80 \mathrm{~cm}$. 
A Tabela 5 mostra os valores de $\mathrm{K}$ para o terreno natural e compactado, demonstrando que praticamente não há influência da compactação do solo no valor de K. A variação encontrada pode ser atribuída provavelmente à qualidade das correlações.

Tabela 5. Valores de K

\begin{tabular}{c|c}
\hline Solo & $K(\mathrm{kPa})$ \\
\hline Natural & 500 \\
Compactado $(\mathrm{e}=100 \mathrm{~cm})$ & 600 \\
Compactado $(\mathrm{e}=90 \mathrm{~cm})$ & 600 \\
Compactado $(\mathrm{e}=80 \mathrm{~cm})$ & 650 \\
\hline
\end{tabular}

$\mathrm{O}$ coeficiente $\mathrm{K}$, obtido da relação entre $\mathrm{q}_{\mathrm{c}}$ e $\mathrm{N}_{\mathrm{SPT}}$, ficou perto de valores encontrados na literatura para areias, tendo uma média aproximada de $600 \mathrm{kPa}$. 


\subsubsection{Correlação entre $q_{c}$ e $f_{c}$}

Por meio de correlações entre os valores médios da resistência de ponta $\left(\mathrm{q}_{\mathrm{c}}\right)$ e atrito lateral $\left(\mathrm{f}_{\mathrm{c}}\right)$, determinou-se o coeficiente $\alpha$ da camada de areia até $3 \mathrm{~m}$ de profundidade. As Figuras 88 a 81 mostram os gráficos $\mathrm{f}_{\mathrm{c}} \times \mathrm{q}_{\mathrm{c}}$ para o terreno natural e compactado.

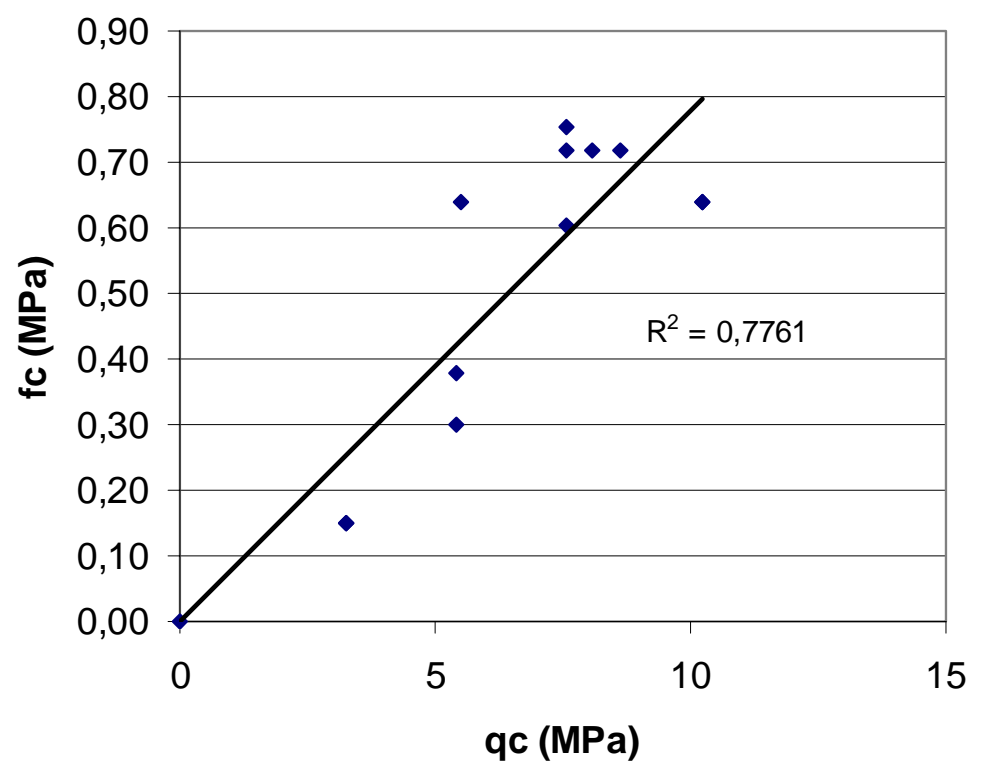

Figura 88. Gráfico $\mathrm{f}_{\mathrm{c}} \mathrm{x} \mathrm{q}_{\mathrm{c}}$ para o terreno natural.

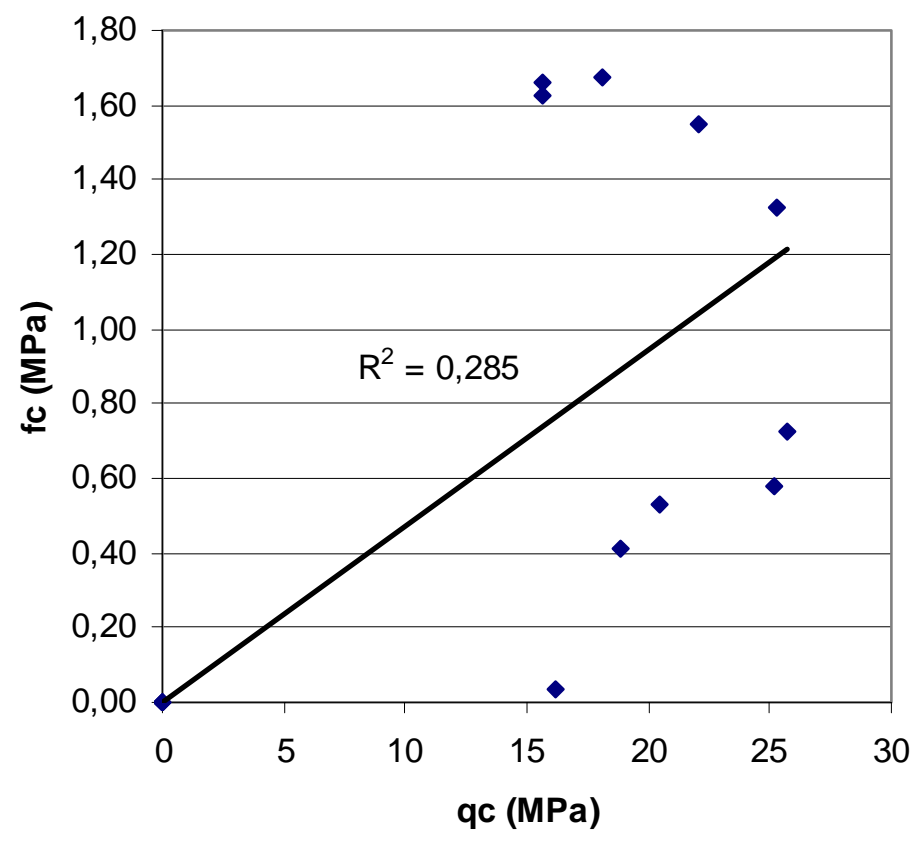

Figura 89. Gráfico $\mathrm{f}_{\mathrm{c}} \mathrm{x} \mathrm{q}_{\mathrm{c}}$ para malha de estacas com espaçamento de $100 \mathrm{~cm}$. 


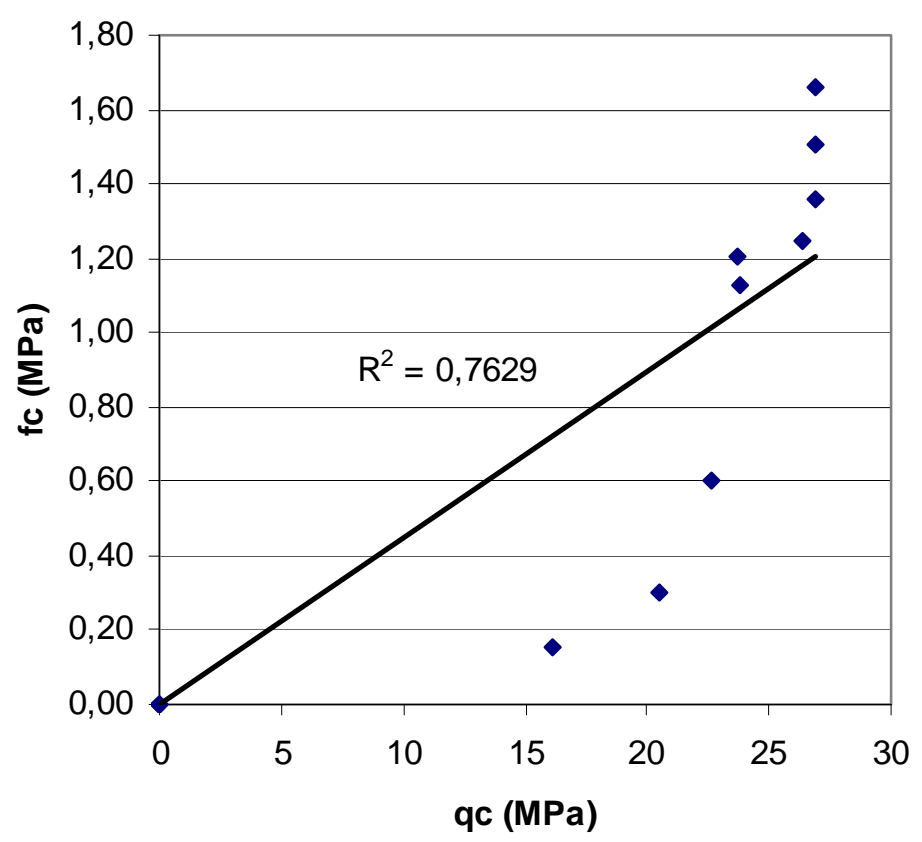

Figura 90. Gráfico $\mathrm{f}_{\mathrm{c}} \mathrm{x} \mathrm{q}_{\mathrm{c}}$ para malha de estacas com espaçamento de $90 \mathrm{~cm}$.

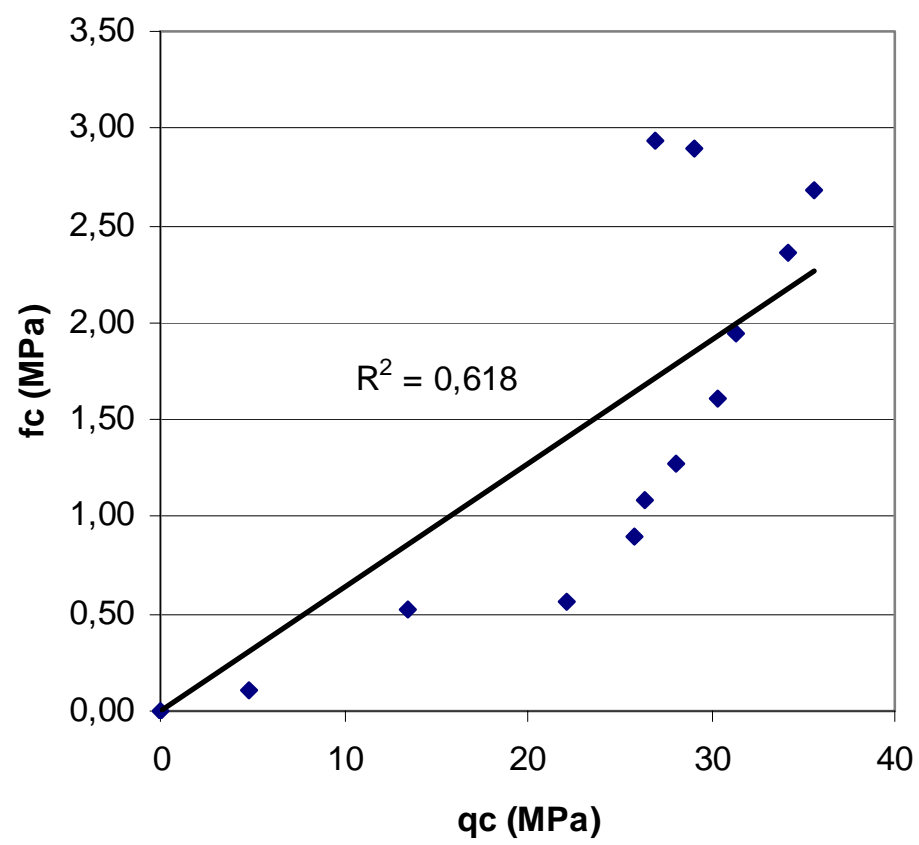

Figura 91. Gráfico $\mathrm{f}_{\mathrm{c}} \mathrm{x} \mathrm{q}_{\mathrm{c}}$ para malha de estacas com espaçamento de $80 \mathrm{~cm}$. 
Os gráficos mostram a inadequabilidade de se correlacionar $\mathrm{q}_{\mathrm{c}} \operatorname{com} \mathrm{f}_{\mathrm{c}}$ para o solo compactado.

A Tabela 6 mostra os valores de $\alpha$ obtidos para o terreno natural e compactado, com a ressalva que são precárias as correlações para o solo compactado.

Tabela 6. Valores de $\alpha$

\begin{tabular}{c|c}
\hline Solo & $\alpha(\%)$ \\
\hline Natural & 7,7 \\
Compactado $(\mathrm{e}=100 \mathrm{~cm})$ & 4,7 \\
Compactado $(\mathrm{e}=90 \mathrm{~cm})$ & 4,5 \\
Compactado $(\mathrm{e}=80 \mathrm{~cm})$ & 6,3 \\
\hline
\end{tabular}




\subsection{Provas de carga sobre placa}

A Figura 92 apresenta os gráficos tensão x recalque das provas de carga realizadas em terreno natural e compactado.

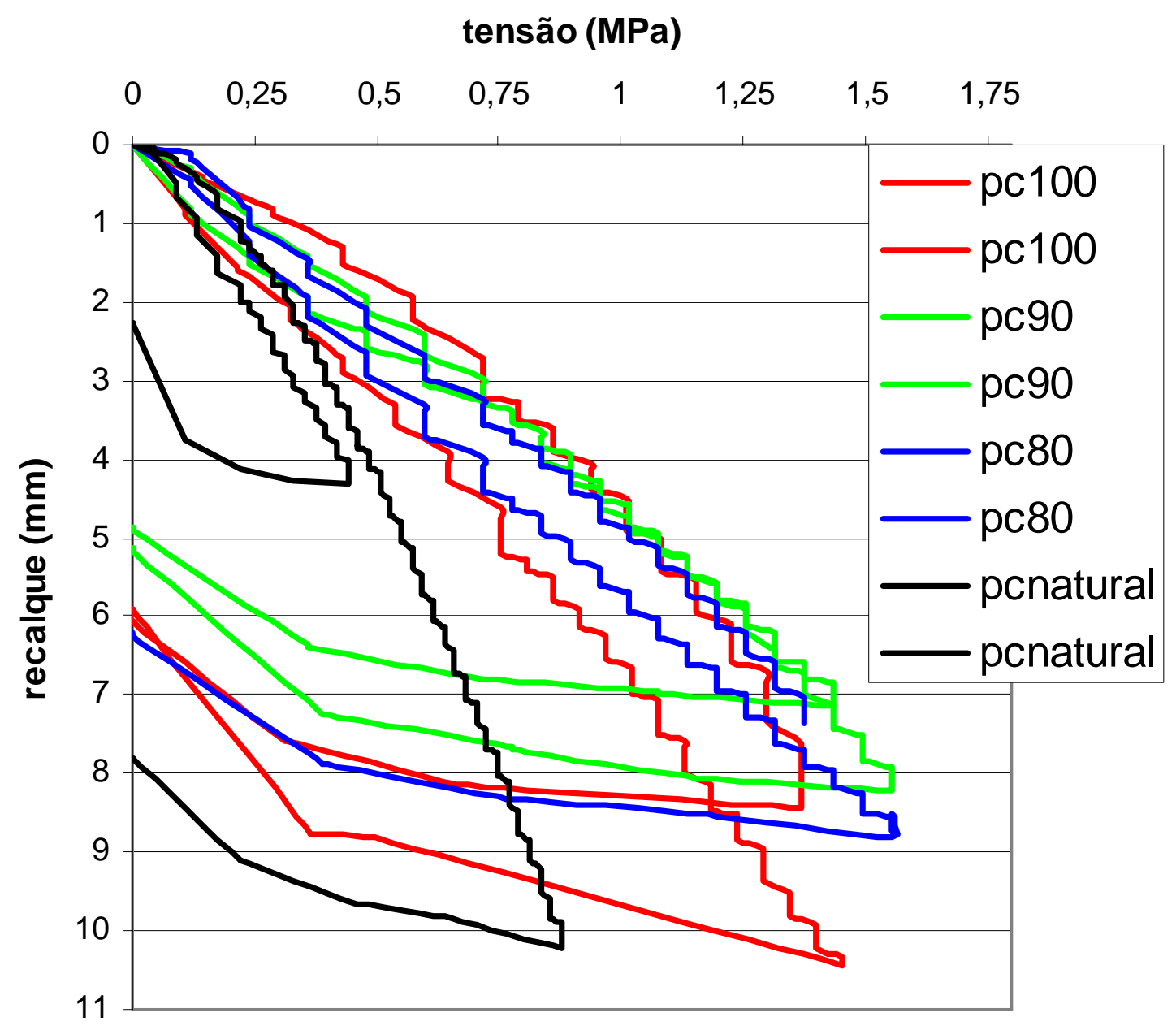

Figura 92. Gráficos tensão x recalque obtidos nas provas de carga.

Como a ruptura não ficou definida nas provas de carga, o critério escolhido, para a determinação da tensão admissível, é o da tensão correspondente a um recalque máximo, adotado como $30 \mathrm{~mm}$ para sapatas de lado B variando de 1 a $3 \mathrm{~m}$. Para a placa de $40 \mathrm{~cm}$, determinou-se um recalque máximo proporcional aos $30 \mathrm{~mm}$ das sapatas. A Tabela 7 mostra os valores equivalentes de recalques máximos para a placa de $40 \mathrm{~cm}$, relativos às sapatas de lado $B$ variando de 1 a $3 \mathrm{~m}$. 
Esse procedimento está baseado na hipótese de que não há efeito escala para sapatas em areia, de acordo com a constatação de BRIAUD \& GIBBENS (1999).

Tabela 7. Valores equivalentes de recalques para placa de $40 \mathrm{~cm}$

\begin{tabular}{c|cc}
\hline Lado B da sapata & $r_{\text {máx. }}($ sapata) & $r_{\text {equivalente }}($ placa de $40 \mathrm{~cm}$ ) \\
\hline $1,0 \mathrm{~m}$ & $30 \mathrm{~mm}$ & $12,0 \mathrm{~mm}$ \\
$1,5 \mathrm{~m}$ & $30 \mathrm{~mm}$ & $8,0 \mathrm{~mm}$ \\
$2,0 \mathrm{~m}$ & $30 \mathrm{~mm}$ & $6,0 \mathrm{~mm}$ \\
$2,5 \mathrm{~m}$ & $30 \mathrm{~mm}$ & $4,8 \mathrm{~mm}$ \\
$3,0 \mathrm{~m}$ & $30 \mathrm{~mm}$ & $4,0 \mathrm{~mm}$ \\
\hline
\end{tabular}

A Figura 93 mostra a tensão admissível em solo natural e compactado, em função do lado B da sapata quadrada, Observa-se que o aumento de resistência média para $\mathrm{B}=1,0 \mathrm{~m}$ é de $96 \%$. Já para a sapata quadrada de lado $\mathrm{B}=3,0 \mathrm{~m}$, o aumento médio da resistência é da ordem de $86 \%$.

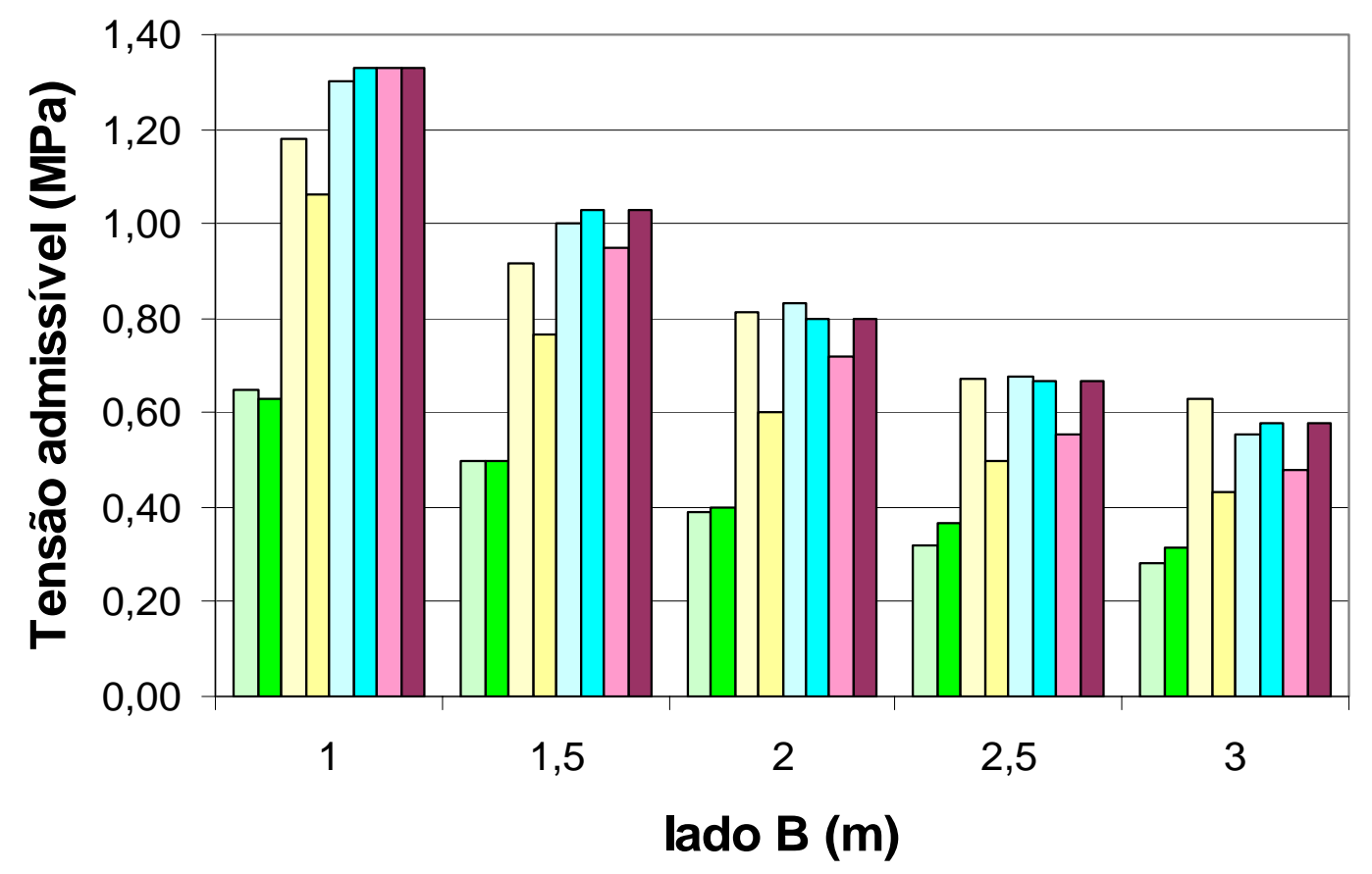

$\square$ PC1 solo natural $\square$ PC2 solo natural $\square$ PC3 e=100 $\square$ PC4 e=100 $\square$ PC5 e=90 $\square$ PC6 e=90 $\square$ PC7 e=80 $\square$ PC8 e=80

Figura 93. Tensão admissível em função do lado B para solo natural e compactado 
Novamente, constata-se que os valores de tensão admissível são muito elevados para sapatas menores. Para a sapata de lado $B=3,0 \mathrm{~m}$, em solo compactado, a tensão admissível é da ordem de 0,5 MPa.

\subsection{Diagrama de cravação das estacas}

O diagrama de cravação mostra o processo de aumento da resistência do solo, durante a execução das estacas. A última estaca executada em cada malha apresentou maior resistência para instalação.

Outra evidência apresentada pelo diagrama de cravação é o aumento da resistência do solo com a diminuição do espaçamento entre estacas. O gráfico na Figura 94, que retrata a cravação da última estaca de cada malha, mostra valores de maior resistência para a malha com espaçamento de $80 \mathrm{~cm}$. 


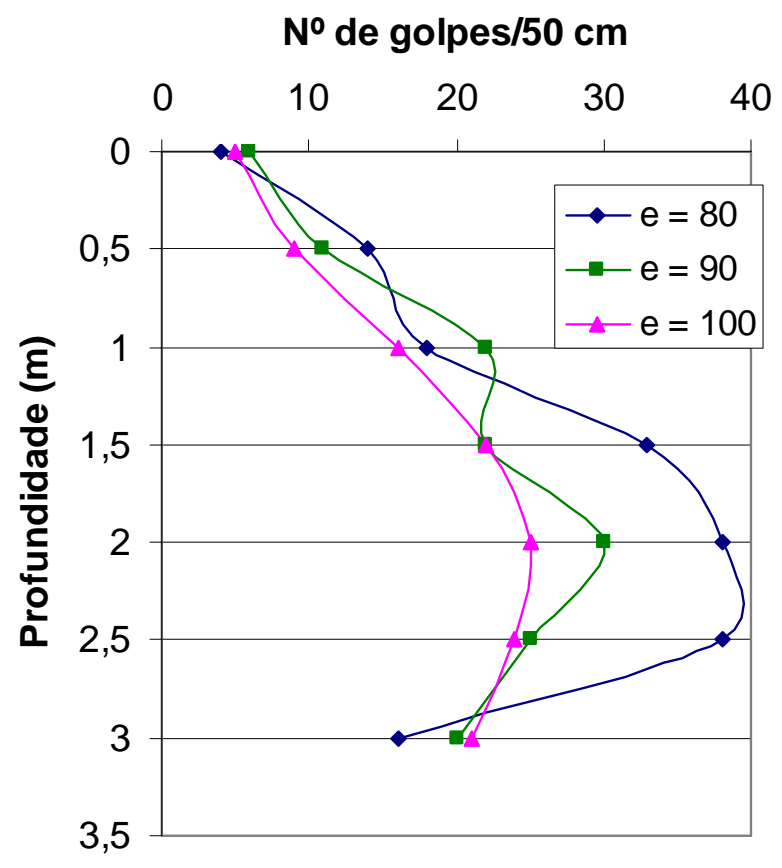

Figura 94. Diagrama de cravação comparativo entre as malhas para a última estaca.

Outra importância do diagrama de cravação é sua comparação com a Sondagem SPT, pois ambos apresentam uma mesma tendência de resistência do solo e o diagrama fornece esse perfil no momento da execução das estacas (Figuras 94 a 98).

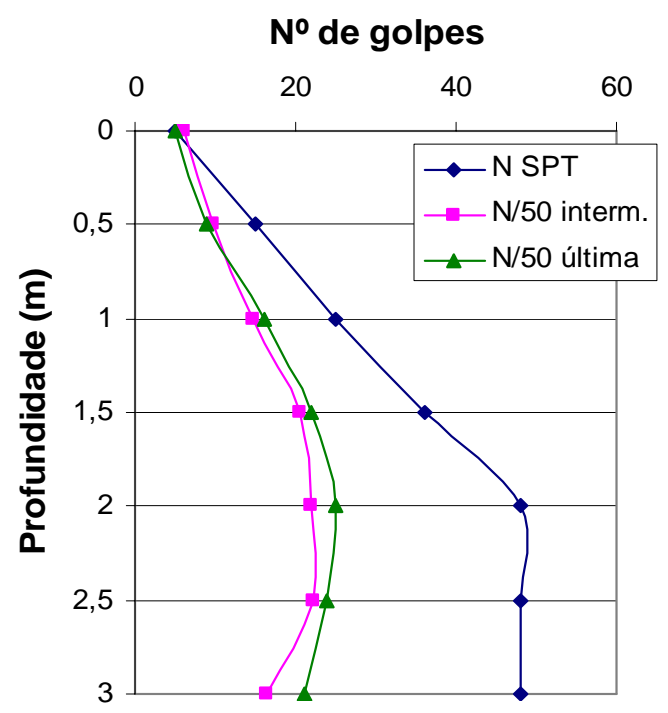

Figura 95. Diagrama de cravação comparado à sondagem na malha de $100 \mathrm{~cm}$ 


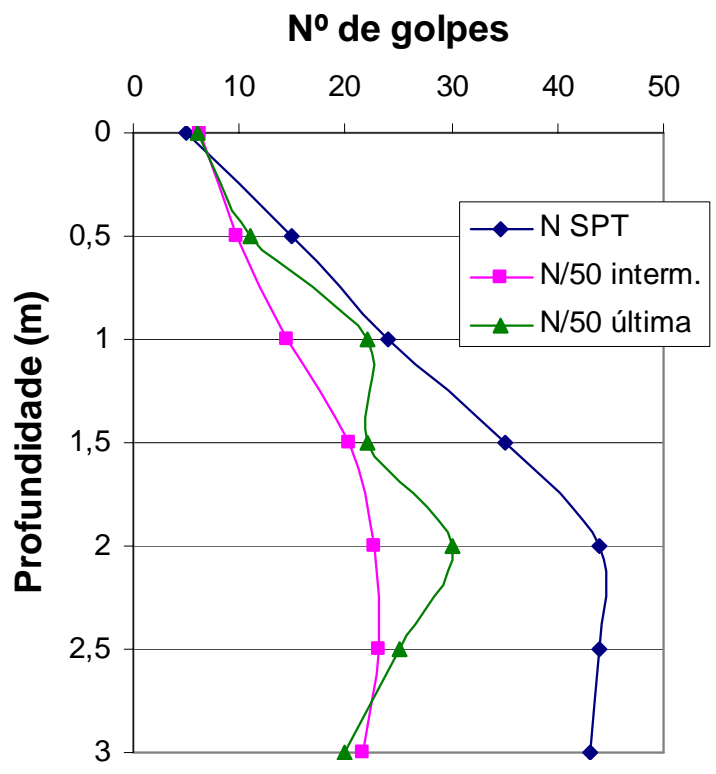

Figura 96. Diagrama de cravação comparado à sondagem na malha de $90 \mathrm{~cm}$.

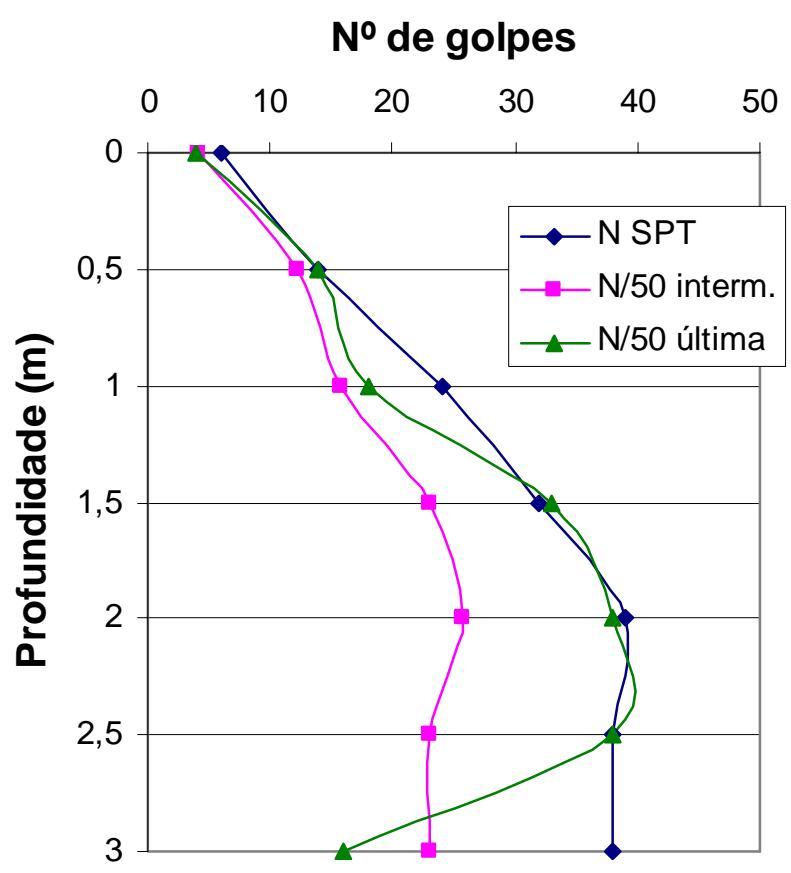

Figura 97. Diagrama de cravação comparado à sondagem na malha de $80 \mathrm{~cm}$. 


\section{CAPÍTULO 8 - CONCLUSÕES}

Os dados obtidos neste trabalho permitem a avaliação da melhoria do comportamento do solo compactado com estacas de areia e, conseqüentemente, o aumento da tensão admissível de fundações rasas.

Em qualquer das malhas de estacas utilizadas (espaçamento de 0,8 a 1,0 m entre estacas), a melhoria é mais eficiente no intervalo de $\mathrm{N}_{\mathrm{SPT}}$ entre 5 e 10; no qual após compactação, os valores de $\mathrm{N}_{\mathrm{SPT}}$ aumentam em até três vezes. Para o intervalo de $\mathrm{N}_{\mathrm{SPT}}$ natural entre 15 e 20, a compactação produz valores absolutos máximos de $\mathrm{N}_{\mathrm{SPT}}$ de até 50.

A tensão admissível, estimada com base nos valores de $\mathrm{N}_{\mathrm{SPT}}$, cresce linearmente com a largura da sapata. No caso de solo natural varia de cerca de 0,2 $\mathrm{MPa}$ para $\mathrm{B}=1,0 \mathrm{~m}$ até cerca de 0,5 MPa para $\mathrm{B}=6,0 \mathrm{~m}$. Com o benefício da compactação, a tensão admissível aumenta de cerca de $0,5 \mathrm{MPa}$ a $0,6 \mathrm{MPa}$ para $\mathrm{B}=1,0 \mathrm{~m}$ até $1,2 \mathrm{a}$ 1,3 $\mathrm{MPa}$ para $\mathrm{B}=6,0 \mathrm{~m}$, dependendo da malha.

Observou-se pequena influência do espaçamento entre estacas na tensão obtida com base no $\mathrm{N}_{\mathrm{SPT}}$; em comparação ao solo natural, a tensão admissível aumenta em média, de $57 \%$ a $63 \%$ quando a malha diminui de 1,0 para $0,80 \mathrm{~m}$, entre estacas.

Já a tensão admissível estimada pelo critério de recalques apresenta uma variação exponencialmente decrescente com a largura da sapata. No solo natural, a tensão admissível diminui de cerca de 1,0 MPa para $\mathrm{B}=1,0 \mathrm{~m}$ para cerca de 0,2 $\mathrm{MPa}$ para $\mathrm{B}=6,0 \mathrm{~m}$. No solo compactado, a tensão admissível diminui de cerca de 3,2 a 4,1 MPa para $\mathrm{B}=1,0 \mathrm{~m}$, dependendo da malha, até cerca de 0,4 MPa. 
Quando se consideram simultaneamente os dois critérios, a tensão admissível é limitada pela resistência do solo para valores menores da largura da sapata e limitada pela deformabilidade do solo para valores maiores da largura da sapata. No solo natural, a tensão admissível aumenta de cerca de 0,2 $\mathrm{MPa}$, para $\mathrm{B}=1,0 \mathrm{~m}$, até cerca de 0,35 $\mathrm{MPa}$ para $\mathrm{B}=4,0 \mathrm{~m}$, passando a diminuir para $0,2 \mathrm{MPa}$, para $\mathrm{B}=6,0 \mathrm{~m}$. No solo compactado, a tensão admissível aumenta de cerca de 0,5 $\mathrm{MPa}$, para $\mathrm{B}=1,0 \mathrm{~m}$, até cerca de 0,8 a 1,0 $\mathrm{MPa}$, para $\mathrm{B}=3,5 \mathrm{~m}$, dependendo da malha, passando a diminuir para $0,5 \mathrm{MPa}$, para $\mathrm{B}=5,0 \mathrm{~m}$ e 0,4 MPa para $\mathrm{B}=6,0 \mathrm{~m}$, independente da malha.

De forma conservadora, constatou-se que a melhoria do solo com estacas de compactação, elevou a tensão admissível do campo experimental de $0,2 \mathrm{MPa}$ para $0,5 \mathrm{MPa}$, no intervalo de $\mathrm{B}=1,0$ a 5,0 $\mathrm{m}$.

Os valores de tensão admissível, em relação à ruptura, obtidos pelo ensaio de cone estão bem acima dos obtidos pela sondagem SPT. A correlação utilizada entre resistência de ponta e pressão admissível parece ser muito ousada. Para o solo natural, a tensão admissível, com base no critério de ruptura, apresenta uma variação exponencial crescente com a largura da sapata. Seus valores são de cerca de 0,50 $\mathrm{MPa}$ para $\mathrm{B}=1,0$ $\mathrm{m}$, até cerca de $0,75 \mathrm{MPa}$ para $\mathrm{B}=3,0 \mathrm{~m}$. Para o solo compactado na malha de $100 \mathrm{~cm}$, a tensão varia de cerca de 1,4 MPa para $\mathrm{B}=1,0 \mathrm{~m}$, atinge $1,1 \mathrm{MPa}$ para $\mathrm{B}=2,0 \mathrm{~m}$, até 1,2 MPa para $\mathrm{B}=3,0 \mathrm{~m}$. Para a malha de $90 \mathrm{~cm}$ de espaçamento, a tensão varia de 1,7 $\mathrm{MPa}$ para $\mathrm{B}=1,0 \mathrm{~m}$, atinge $1,4 \mathrm{MPa}$ para $\mathrm{B}=2,5 \mathrm{~m}$, até cerca de $1,45 \mathrm{MPa}$ para $\mathrm{B}=$ 3,0 m. Na malha de $80 \mathrm{~cm}$, a tensão admissível varia de 2,05 $\mathrm{MPa}$ para $\mathrm{B}=1,0 \mathrm{~m}$, até $1,85 \mathrm{MPa}$ para $\mathrm{B}=2,0$ e 3,0 m.

Comparando-se ao solo natural, a tensão admissível obtida com base em $\mathrm{q}_{\mathrm{c}}$, aumentou, em média, de $52 \%$ a $69 \%$ quando a malha diminuiu de 1,0 para $0,80 \mathrm{~m}$, entre estacas, o que significa, neste caso, uma maior influência do espaçamento entre estacas na tensão admissível.

Já a tensão admissível estimada pelo critério de recalques apresenta, para o solo natural, uma variação linearmente decrescente com a largura da sapata. Seu valor diminui de cerca de 0,4 MPa para $\mathrm{B}=1,0 \mathrm{~m}$, para cerca de 0,2 $\mathrm{MPa}$ para $\mathrm{B}=3,0 \mathrm{~m}$. No solo compactado a tensão admissível apresenta uma variação exponencialmente decrescente com a largura da sapata. A tensão admissível diminui de cerca de 1,6 a 
2,2 $\mathrm{MPa}$ para $\mathrm{B}=1,0 \mathrm{~m}$, dependendo da malha, até cerca de 0,4 a 0,6 $\mathrm{MPa}$ para $\mathrm{B}=3,0 \mathrm{~m}$.

Analisando-se os critérios de recalque e ruptura, para determinação da tensão admissível com base nos valores de $\mathrm{q}_{\mathrm{c}}$, constata-se que para o solo natural e compactado na malha de $0,90 \mathrm{~m}$ a tensão admissível é limitada pelo critério de recalque. Para as malhas de estacas com espaçamento de 0,80 e 1,0 m, a tensão admissível é limitada pelo critério de ruptura para um B máximo de aproximadamente 1,3 m. Para valores maiores de B prevalece o critério de recalques como condicionante da tensão admissível da fundação.

Para valores de B entre 1,0 e 3,0 m, as tensões admissíveis estimadas pelo cone podem ser adotadas como 0,2 MPa para o solo natural, 0,4 MPa para solo compactado na malha de $1,0 \mathrm{~m}, 0,45 \mathrm{MPa}$ para a malha de $0,90 \mathrm{~m}$ e 0,6 MPa para o solo na malha de $0,80 \mathrm{~cm}$.

Pelos resultados das provas de carga em placa (diâmetro de $40 \mathrm{~cm}$ ), constataramse valores de tensão admissível muito elevados para sapatas menores. Para a sapata de lado $\mathrm{B}=1,0 \mathrm{~m}$, em solo compactado nas malhas de 0,80 e $0,90 \mathrm{~m}$, a tensão admissível é da ordem de 1,3 MPa. Na malha de 1,0 m, a tensão admissível para $\mathrm{B}=1,0 \mathrm{~m}$ é cerca de 1,1 MPa. Já para $\mathrm{B}=3,0 \mathrm{~m}$, nas três malhas, a tensão admissível é da ordem de 0,5 MPa. Para o solo natural, a tensão admissível diminui de cerca de $0,6 \mathrm{MPa}$ para $\quad \mathrm{B}=$ $1,0 \mathrm{~m}$, para cerca de $0,3 \mathrm{MPa}$ para $\mathrm{B}=3,0 \mathrm{~m}$.

As provas de carga mostram que o aumento médio da tensão admissível, nas três malhas de estacas, varia entre $96 \%$ e $86 \%$ para B entre 1,0 e $3,0 \mathrm{~m}$.

Os métodos de cálculos de tensão admissível, considerando-se o critério de ruptura, apresentam valores bem elevados, após compactação do solo. Dessa forma, fazse necessário um estudo completo de recalques, visto que os efeitos da compactação são notados até aproximadamente 5,0 $\mathrm{m}$ de profundidade, para um tubo de revestimento de 3,5 m de comprimento.

Os recalques, estimados pelo método de Schmertmann, sofreram uma redução média, no solo compactado, de $72 \%$ para sapatas quadradas de lado $\mathrm{B}=1,0 \mathrm{~m}$. Para $\mathrm{B}=5,0 \mathrm{~m}$, a redução média foi de $41 \%$. 
As correlações entre $\mathrm{N}_{\mathrm{SPT}}$ e $\mathrm{q}_{\mathrm{c}}$, para o terreno natural e compactado, mostram que praticamente não há influência da compactação do solo no valor de $\mathrm{K}$, que é em torno de $600 \mathrm{kPa}$.

As correlações entre $q_{c}$ e $f_{c}$ mostraram-se inadequadas para o solo compactado, pois apresentam coeficiente de determinação muito baixos e valores de $\alpha$ discrepantes dos encontrados na literatura.

O diagrama de cravação mostra o incremento de resistência obtido pelo solo, à medida que mais estacas são executadas. A última estaca atinge resistências semelhantes às das primeiras estacas, antes de alcançar a profundidade prevista. 


\section{ANEXO I - Dados das provas de carga}

Prova de carga 1 em solo natural

\begin{tabular}{|c|c|c|}
\hline tempo (min) & tensão $\mathrm{kPa}$ & recalque $(\mathrm{mm})$ \\
\hline 0 & 0 & 0,000 \\
\hline 1 & 44 & 0,105 \\
\hline 2 & 44 & 0,110 \\
\hline 4 & 44 & 0,110 \\
\hline 8 & 44 & 0,110 \\
\hline 15 & 44 & 0,113 \\
\hline 30 & 44 & 0,125 \\
\hline 0 & 88 & 0,125 \\
\hline 1 & 88 & 0,480 \\
\hline 2 & 88 & 0,495 \\
\hline 4 & 88 & 0,505 \\
\hline 8 & 88 & 0,518 \\
\hline 15 & 88 & 0,523 \\
\hline 30 & 88 & 0,540 \\
\hline 60 & 88 & 0,563 \\
\hline 90 & 88 & 0,583 \\
\hline 120 & 88 & 0,588 \\
\hline 0 & 132 & 0,665 \\
\hline 1 & 132 & 0,935 \\
\hline 2 & 132 & 0,993 \\
\hline 4 & 132 & 1,015 \\
\hline 8 & 132 & 1,038 \\
\hline 15 & 132 & 1,050 \\
\hline 30 & 132 & 1,063 \\
\hline 0 & 176 & 1,170 \\
\hline 1 & 176 & 1,410 \\
\hline 2 & 176 & 1,450 \\
\hline 4 & 176 & 1,475 \\
\hline 8 & 176 & 1,485 \\
\hline 15 & 176 & 1,528 \\
\hline 30 & 176 & 1,545 \\
\hline 0 & 220 & 1,623 \\
\hline 1 & 220 & 1,768 \\
\hline 2 & 220 & 1,830 \\
\hline 4 & 220 & 1,853 \\
\hline 8 & 220 & 1,893 \\
\hline 15 & 220 & 1,935 \\
\hline 30 & 220 & 1,975 \\
\hline 60 & 220 & 2,015 \\
\hline
\end{tabular}

\begin{tabular}{|c|c|c|}
\hline tempo (min) & tensão $\mathrm{kPa}$ & recalque $(\mathrm{mm})$ \\
\hline 0 & 242 & 2,015 \\
\hline 1 & 242 & 1,998 \\
\hline 2 & 242 & 2,010 \\
\hline 3 & 242 & 2,013 \\
\hline 6 & 242 & 2,030 \\
\hline 9 & 242 & 2,050 \\
\hline 12 & 242 & 2,075 \\
\hline 15 & 242 & 2,105 \\
\hline 0 & 264 & 2,130 \\
\hline 1 & 264 & 2,175 \\
\hline 2 & 264 & 2,183 \\
\hline 3 & 264 & 2,185 \\
\hline 6 & 264 & 2,213 \\
\hline 9 & 264 & 2,240 \\
\hline 12 & 264 & 2,308 \\
\hline 15 & 264 & 2,325 \\
\hline 0 & 286 & 2,330 \\
\hline 1 & 286 & 2,420 \\
\hline 2 & 286 & 2,458 \\
\hline 3 & 286 & 2,490 \\
\hline 6 & 286 & 2,518 \\
\hline 9 & 286 & 2,550 \\
\hline 12 & 286 & 2,568 \\
\hline 15 & 286 & 2,590 \\
\hline 0 & 308 & 2,628 \\
\hline 1 & 308 & 2,668 \\
\hline 2 & 308 & 2,690 \\
\hline 3 & 308 & 2,708 \\
\hline 6 & 308 & 2,723 \\
\hline 9 & 308 & 2,748 \\
\hline 12 & 308 & 2,775 \\
\hline 15 & 308 & 2,808 \\
\hline 0 & 330 & 2,863 \\
\hline 1 & 330 & 2,920 \\
\hline 2 & 330 & 2,975 \\
\hline 3 & 330 & 2,988 \\
\hline 6 & 330 & 3,038 \\
\hline 9 & 330 & 3,058 \\
\hline 12 & 330 & 3,068 \\
\hline 15 & 330 & 3,085 \\
\hline
\end{tabular}




\begin{tabular}{|c|c|c|}
\hline tempo (min) & tensão kPa & recalque $(\mathrm{mm})$ \\
\hline 0 & 352 & 3,095 \\
\hline 1 & 352 & 3,510 \\
\hline 2 & 352 & 3,553 \\
\hline 3 & 352 & 3,558 \\
\hline 6 & 352 & 3,558 \\
\hline 9 & 352 & 3,583 \\
\hline 12 & 352 & 3,620 \\
\hline 15 & 352 & 3,620 \\
\hline 0 & 374 & 3,625 \\
\hline 1 & 374 & 3,700 \\
\hline 2 & 374 & 3,733 \\
\hline 3 & 374 & 3,780 \\
\hline 6 & 374 & 3,780 \\
\hline 9 & 374 & 3,798 \\
\hline 12 & 374 & 3,825 \\
\hline 15 & 374 & 3,838 \\
\hline 0 & 396 & 3,860 \\
\hline 1 & 396 & 3,920 \\
\hline 2 & 396 & 3,960 \\
\hline 3 & 396 & 3,973 \\
\hline 6 & 396 & 3,983 \\
\hline 9 & 396 & 4,023 \\
\hline 12 & 396 & 4,053 \\
\hline 15 & 396 & 4,070 \\
\hline 0 & 418 & 4,075 \\
\hline 1 & 418 & 4,133 \\
\hline 2 & 418 & 4,158 \\
\hline 3 & 418 & 4,188 \\
\hline 6 & 418 & 4,205 \\
\hline 9 & 418 & 4,233 \\
\hline 12 & 418 & 4,258 \\
\hline 15 & 418 & 4,293 \\
\hline 0 & 440 & 4,310 \\
\hline 1 & 440 & 4,360 \\
\hline 2 & 440 & 4,390 \\
\hline 3 & 440 & 4,423 \\
\hline 6 & 440 & 4,425 \\
\hline 9 & 440 & 4,483 \\
\hline 12 & 440 & 4,505 \\
\hline 15 & 440 & 4,565 \\
\hline
\end{tabular}

\begin{tabular}{|c|c|c|}
\hline tempo (min) & tensão kPa & recalque (mm) \\
\hline 0 & 330 & 4,655 \\
\hline 1 & 330 & 4,640 \\
\hline 2 & 330 & 4,635 \\
\hline 3 & 330 & 4,635 \\
\hline 6 & 330 & 4,635 \\
\hline 9 & 330 & 4,628 \\
\hline 12 & 330 & 4,628 \\
\hline 15 & 330 & 4,628 \\
\hline 0 & 220 & 4,628 \\
\hline 1 & 220 & 4,468 \\
\hline 2 & 220 & 4,468 \\
\hline 3 & 220 & 4,468 \\
\hline 6 & 220 & 4,465 \\
\hline 9 & 220 & 4,465 \\
\hline 12 & 220 & 4,463 \\
\hline 15 & 220 & 4,463 \\
\hline 0 & 110 & 4,463 \\
\hline 1 & 110 & 4,098 \\
\hline 2 & 110 & 4,098 \\
\hline 3 & 110 & 4,098 \\
\hline 6 & 110 & 4,098 \\
\hline 9 & 110 & 4,098 \\
\hline 12 & 110 & 4,098 \\
\hline 15 & 110 & 4,098 \\
\hline 0 & 0 & 4,098 \\
\hline 1 & 0 & 2,630 \\
\hline 2 & 0 & 2,630 \\
\hline 3 & 0 & 2,630 \\
\hline 6 & 0 & 2,630 \\
\hline 9 & 0 & 2,630 \\
\hline 12 & 0 & 2,630 \\
\hline 15 & 0 & 2,630 \\
\hline
\end{tabular}


Prova de carga 2 em solo natural

\begin{tabular}{|c|c|c|}
\hline tempo (min) & tensão kPa & recalque $(\mathrm{mm})$ \\
\hline 0 & 44 & 0,048 \\
\hline$\overline{1}$ & 44 & 0,053 \\
\hline 2 & 44 & 0,055 \\
\hline 4 & 44 & 0,058 \\
\hline 8 & 44 & 0,060 \\
\hline 15 & 44 & 0,060 \\
\hline 30 & 44 & 0,060 \\
\hline 0 & 88 & 0,203 \\
\hline 1 & 88 & 0,205 \\
\hline 2 & 88 & 0,205 \\
\hline 4 & 88 & 0,205 \\
\hline 8 & 88 & 0,210 \\
\hline 15 & 88 & 0,210 \\
\hline 30 & 88 & 0,210 \\
\hline 0 & 132 & 0,395 \\
\hline 1 & 132 & 0,405 \\
\hline 2 & 132 & 0,410 \\
\hline 4 & 132 & 0,420 \\
\hline 8 & 132 & 0,430 \\
\hline 15 & 132 & 0,453 \\
\hline 30 & 132 & 0,460 \\
\hline 0 & 176 & 0,643 \\
\hline 1 & 176 & 0,680 \\
\hline 2 & 176 & 0,698 \\
\hline 4 & 176 & 0,703 \\
\hline 8 & 176 & 0,725 \\
\hline 15 & 176 & 0,763 \\
\hline 30 & 176 & 0,800 \\
\hline 0 & 220 & 0,980 \\
\hline 1 & 220 & 1,028 \\
\hline 2 & 220 & 1,043 \\
\hline 4 & 220 & 1,075 \\
\hline 8 & 220 & 1,108 \\
\hline 15 & 220 & 1,140 \\
\hline 30 & 220 & 1,175 \\
\hline 60 & 220 & 1,203 \\
\hline 90 & 220 & 1,215 \\
\hline
\end{tabular}

\begin{tabular}{|c|c|c|}
\hline tempo (min) & tensão kPa & recalque $(\mathrm{mm})$ \\
\hline 0 & \begin{tabular}{|l|}
242 \\
\end{tabular} & 1,265 \\
\hline 1 & 242 & 1,283 \\
\hline 2 & 242 & 1,288 \\
\hline 3 & 242 & 1,300 \\
\hline 6 & 242 & 1,313 \\
\hline 9 & 242 & 1,325 \\
\hline 12 & 242 & 1,325 \\
\hline 15 & 242 & 1,338 \\
\hline 0 & 264 & 1,398 \\
\hline 1 & 264 & 1,423 \\
\hline 2 & 264 & 1,435 \\
\hline 3 & 264 & 1,458 \\
\hline 6 & 264 & 1,480 \\
\hline 9 & 264 & 1,490 \\
\hline 12 & 264 & 1,495 \\
\hline 15 & 264 & 1,523 \\
\hline 0 & 286 & 1,583 \\
\hline 1 & 286 & 1,635 \\
\hline 2 & 286 & 1,655 \\
\hline 3 & 286 & 1,683 \\
\hline 6 & 286 & 1,708 \\
\hline 9 & 286 & 1,738 \\
\hline 12 & 286 & 1,758 \\
\hline 15 & 286 & 1,768 \\
\hline 0 & 308 & 1,783 \\
\hline 1 & 308 & 1,818 \\
\hline 2 & 308 & 1,833 \\
\hline 3 & 308 & 1,850 \\
\hline 6 & 308 & 1,885 \\
\hline 9 & 308 & 1,913 \\
\hline 12 & 308 & 1,925 \\
\hline 15 & 308 & 1,938 \\
\hline 0 & 330 & 2,043 \\
\hline 1 & 330 & 2,100 \\
\hline 2 & 330 & 2,105 \\
\hline 3 & 330 & 2,138 \\
\hline 6 & 330 & 2,173 \\
\hline 9 & 330 & 2,200 \\
\hline 12 & 330 & 2,215 \\
\hline 15 & 330 & 2,258 \\
\hline
\end{tabular}




\begin{tabular}{|c|c|c|}
\hline tempo (min) & tensão kPa & recalque (mm) \\
\hline 0 & 352 & 2,298 \\
\hline 1 & 352 & 2,338 \\
\hline 2 & 352 & 2,363 \\
\hline 3 & 352 & 2,383 \\
\hline 6 & 352 & 2,413 \\
\hline 9 & 352 & 2,443 \\
\hline 12 & 352 & 2,465 \\
\hline 15 & 352 & 2,485 \\
\hline 0 & 374 & 2,535 \\
\hline 1 & 374 & 2,568 \\
\hline 2 & 374 & 2,603 \\
\hline 3 & 374 & 2,633 \\
\hline 6 & 374 & 2,668 \\
\hline 9 & 374 & 2,698 \\
\hline 12 & 374 & 2,728 \\
\hline 15 & 374 & 2,753 \\
\hline 0 & 396 & 2,788 \\
\hline 1 & 396 & 2,820 \\
\hline 2 & 396 & 2,858 \\
\hline 3 & 396 & 2,878 \\
\hline 6 & 396 & 2,935 \\
\hline 9 & 396 & 2,973 \\
\hline 12 & 396 & 3,008 \\
\hline 15 & 396 & 3,060 \\
\hline 0 & 418 & 3,085 \\
\hline 1 & 418 & 3,110 \\
\hline 2 & 418 & 3,140 \\
\hline 3 & 418 & 3,155 \\
\hline 6 & 418 & 3,195 \\
\hline 9 & 418 & 3,255 \\
\hline 12 & 418 & 3,285 \\
\hline 15 & 418 & 3,298 \\
\hline 0 & 440 & 3,343 \\
\hline 1 & 440 & 3,388 \\
\hline 2 & 440 & 3,400 \\
\hline 3 & 440 & 3,428 \\
\hline 6 & 440 & 3,485 \\
\hline 9 & 440 & 3,538 \\
\hline 12 & 440 & 3,550 \\
\hline 15 & 440 & 3,588 \\
\hline
\end{tabular}

\begin{tabular}{|c|c|c|}
\hline tempo (min) & tensão kPa & recalque (mm) \\
\hline 0 & 462 & 3,633 \\
\hline 1 & 462 & 3,663 \\
\hline 2 & 462 & 3,683 \\
\hline 3 & 462 & 3,710 \\
\hline 6 & 462 & 3,833 \\
\hline 9 & 462 & 3,828 \\
\hline 12 & 462 & 3,845 \\
\hline 15 & 462 & 3,855 \\
\hline 0 & 484 & 3,918 \\
\hline 1 & 484 & 3,943 \\
\hline 2 & 484 & 3,960 \\
\hline 3 & 484 & 3,998 \\
\hline 6 & 484 & 4,043 \\
\hline 9 & 484 & 4,058 \\
\hline 12 & 484 & 4,105 \\
\hline 15 & 484 & 4,118 \\
\hline 0 & 506 & 4,173 \\
\hline 1 & 506 & 4,205 \\
\hline 2 & 506 & 4,238 \\
\hline 3 & 506 & 4,263 \\
\hline 6 & 506 & 4,340 \\
\hline 9 & 506 & 4,385 \\
\hline 12 & 506 & 4,400 \\
\hline 15 & 506 & 4,423 \\
\hline 0 & 528 & 4,480 \\
\hline 1 & 528 & 4,500 \\
\hline 2 & 528 & 4,538 \\
\hline 3 & 528 & 4,560 \\
\hline 6 & 528 & 4,620 \\
\hline 9 & 528 & 4,670 \\
\hline 12 & 528 & 4,700 \\
\hline 15 & 528 & 4,723 \\
\hline 0 & 550 & 4,795 \\
\hline 1 & 550 & 4,843 \\
\hline 2 & 550 & 4,868 \\
\hline 3 & 550 & 4,900 \\
\hline 6 & 550 & 4,975 \\
\hline 9 & 550 & 5,008 \\
\hline 12 & 550 & 5,038 \\
\hline 15 & 550 & 5,055 \\
\hline
\end{tabular}




\begin{tabular}{|c|c|c|}
\hline tempo (min) & tensão kPa & recalque (mm) \\
\hline 0 & 572 & 5,130 \\
\hline 1 & 572 & 5,175 \\
\hline 2 & 572 & 5,195 \\
\hline 3 & 572 & 5,213 \\
\hline 6 & 572 & 5,290 \\
\hline 9 & 572 & 5,338 \\
\hline 12 & 572 & 5,368 \\
\hline 15 & 572 & 5,403 \\
\hline 0 & 594 & 5,450 \\
\hline 1 & 594 & 5,480 \\
\hline 2 & 594 & 5,505 \\
\hline 3 & 594 & 5,523 \\
\hline 6 & 594 & 5,598 \\
\hline 9 & 594 & 5,635 \\
\hline 12 & 594 & 5,680 \\
\hline 15 & 594 & 5,720 \\
\hline 0 & 616 & 5,808 \\
\hline 1 & 616 & 5,818 \\
\hline 2 & 616 & 5,840 \\
\hline 3 & 616 & 5,863 \\
\hline 6 & 616 & 5,930 \\
\hline 9 & 616 & 5,985 \\
\hline 12 & 616 & 6,025 \\
\hline 15 & 616 & 6,048 \\
\hline 0 & 638 & 6,118 \\
\hline 1 & 638 & 6,128 \\
\hline 2 & 638 & 6,145 \\
\hline 3 & 638 & 6,210 \\
\hline 6 & 638 & 6,278 \\
\hline 9 & 638 & 6,308 \\
\hline 12 & 638 & 6,343 \\
\hline 15 & 638 & 6,363 \\
\hline 0 & 660 & 6,425 \\
\hline 1 & 660 & 6,443 \\
\hline 2 & 660 & 6,488 \\
\hline 3 & 660 & 6,513 \\
\hline 6 & 660 & 6,573 \\
\hline 9 & 660 & 6,618 \\
\hline 12 & 660 & 6,673 \\
\hline 15 & 660 & 6,710 \\
\hline
\end{tabular}

\begin{tabular}{|c|c|c|}
\hline tempo (min) & tensão kPa & recalque (mm) \\
\hline 0 & 682 & 6,773 \\
\hline 1 & 682 & 6,803 \\
\hline 2 & 682 & 6,828 \\
\hline 3 & 682 & 6,858 \\
\hline 6 & 682 & 6,930 \\
\hline 9 & 682 & 6,973 \\
\hline 12 & 682 & 7,005 \\
\hline 15 & 682 & 7,045 \\
\hline 0 & 704 & 7,093 \\
\hline 1 & 704 & 7,113 \\
\hline 2 & 704 & 7,143 \\
\hline 3 & 704 & 7,163 \\
\hline 6 & 704 & 7,205 \\
\hline 9 & 704 & 7,295 \\
\hline 12 & 704 & 7,333 \\
\hline 15 & 704 & 7,370 \\
\hline 0 & 726 & 7,418 \\
\hline 1 & 726 & 7,440 \\
\hline 2 & 726 & 7,468 \\
\hline 3 & 726 & 7,493 \\
\hline 6 & 726 & 7,563 \\
\hline 9 & 726 & 7,605 \\
\hline 12 & 726 & 7,668 \\
\hline 15 & 726 & 7,700 \\
\hline 0 & 748 & 7,748 \\
\hline 1 & 748 & 7,795 \\
\hline 2 & 748 & 7,825 \\
\hline 3 & 748 & 7,855 \\
\hline 6 & 748 & 7,925 \\
\hline 9 & 748 & 7,970 \\
\hline 12 & 748 & 8,013 \\
\hline 15 & 748 & 8,043 \\
\hline 0 & 770 & 8,115 \\
\hline 1 & 770 & 8,143 \\
\hline 2 & 770 & 8,168 \\
\hline 3 & 770 & 8,190 \\
\hline 6 & 770 & 8,265 \\
\hline 9 & 770 & 8,310 \\
\hline 12 & 770 & 8,368 \\
\hline 15 & 770 & 8,408 \\
\hline
\end{tabular}




\begin{tabular}{|c|c|c|}
\hline tempo (min) & tensão kPa & recalque (mm) \\
\hline 0 & 792 & 8,455 \\
\hline 1 & 792 & 8,510 \\
\hline 2 & 792 & 8,553 \\
\hline 3 & 792 & 8,585 \\
\hline 6 & 792 & 8,643 \\
\hline 9 & 792 & 8,693 \\
\hline 12 & 792 & 8,750 \\
\hline 15 & 792 & 8,778 \\
\hline 0 & 814 & 8,835 \\
\hline 1 & 814 & 8,875 \\
\hline 2 & 814 & 8,900 \\
\hline 3 & 814 & 8,938 \\
\hline 6 & 814 & 9,025 \\
\hline 9 & 814 & 9,080 \\
\hline 12 & 814 & 9,110 \\
\hline 15 & 814 & 9,090 \\
\hline 0 & 836 & 9,218 \\
\hline 1 & 836 & 9,255 \\
\hline 2 & 836 & 9,295 \\
\hline 3 & 836 & 9,315 \\
\hline 6 & 836 & 9,398 \\
\hline 9 & 836 & 9,445 \\
\hline 12 & 836 & 9,495 \\
\hline 15 & 836 & 9,520 \\
\hline 0 & 858 & 9,570 \\
\hline 1 & 858 & 9,583 \\
\hline 2 & 858 & 9,605 \\
\hline 3 & 858 & 9,638 \\
\hline 6 & 858 & 9,728 \\
\hline 9 & 858 & 9,778 \\
\hline 12 & 858 & 9,820 \\
\hline 15 & 858 & 9,855 \\
\hline 0 & 880 & 9,890 \\
\hline 1 & 880 & 9,890 \\
\hline 2 & 880 & 9,933 \\
\hline 3 & 880 & 9,960 \\
\hline 6 & 880 & 10,018 \\
\hline 9 & 880 & 10,103 \\
\hline 12 & 880 & 10,160 \\
\hline 15 & 880 & 10,205 \\
\hline
\end{tabular}

\begin{tabular}{|c|c|c|}
\hline tempo $(\mathrm{min})$ & tensão $\mathrm{kPa}$ & recalque $(\mathrm{mm})$ \\
\hline 0 & 660 & 9,835 \\
\hline 5 & 660 & 9,835 \\
\hline 10 & 660 & 9,835 \\
\hline 15 & 660 & 9,835 \\
\hline 0 & 440 & 9,618 \\
\hline 5 & 440 & 9,613 \\
\hline 10 & 440 & 9,613 \\
\hline 15 & 440 & 9,613 \\
\hline 0 & 220 & 9,090 \\
\hline 5 & 220 & 9,088 \\
\hline 10 & 220 & 9,088 \\
\hline 15 & 220 & 9,088 \\
\hline 0 & 0 & 7,823 \\
\hline 5 & 0 & 7,800 \\
\hline 10 & 0 & 7,800 \\
\hline 15 & 0 & 7,800 \\
\hline
\end{tabular}


Prova de carga 3 em solo compactado (malha de estacas com espaçamento de $100 \mathrm{~cm}$ )

\begin{tabular}{|c|c|c|}
\hline tempo (min) & tensão kPa & recalque $(\mathrm{mm})$ \\
\hline 0 & 144 & 0,395 \\
\hline 1 & 144 & 0,395 \\
\hline 2 & 144 & 0,398 \\
\hline 4 & 144 & 0,398 \\
\hline 8 & 144 & 0,405 \\
\hline 15 & 144 & 0,435 \\
\hline 30 & 144 & 0,435 \\
\hline 0 & 288 & 0,833 \\
\hline 1 & 288 & 0,850 \\
\hline 2 & 288 & 0,865 \\
\hline 4 & 288 & 0,870 \\
\hline 8 & 288 & 0,870 \\
\hline 15 & 288 & 0,875 \\
\hline 30 & 288 & 0,875 \\
\hline 0 & 432 & 1,310 \\
\hline 1 & 432 & 1,350 \\
\hline 2 & 432 & 1,415 \\
\hline 4 & 432 & 1,450 \\
\hline 8 & 432 & 1,470 \\
\hline 15 & 432 & 1,498 \\
\hline 30 & 432 & 1,498 \\
\hline 60 & 432 & 1,508 \\
\hline 0 & 576 & 1,948 \\
\hline 1 & 576 & 2,008 \\
\hline 2 & 576 & 2,048 \\
\hline 4 & 576 & 2,078 \\
\hline 8 & 576 & 2,138 \\
\hline 15 & 576 & 2,178 \\
\hline 30 & 576 & 2,218 \\
\hline 0 & 720 & 2,708 \\
\hline 1 & 720 & 2,793 \\
\hline 2 & 720 & 2,850 \\
\hline 4 & 720 & 2,925 \\
\hline 8 & 720 & 2,980 \\
\hline 15 & 720 & 3,045 \\
\hline 30 & 720 & 3,110 \\
\hline 60 & 720 & 3,188 \\
\hline 90 & 720 & 3,215 \\
\hline
\end{tabular}

\begin{tabular}{|c|c|c|}
\hline tempo (min) & tensão kPa & recalque $(\mathrm{mm})$ \\
\hline 0 & 792 & 3,288 \\
\hline 1 & 792 & 3,335 \\
\hline 2 & 792 & 3,350 \\
\hline 3 & 792 & 3,368 \\
\hline 6 & 792 & 3,405 \\
\hline 9 & 792 & 3,433 \\
\hline 12 & 792 & 3,473 \\
\hline 15 & 792 & 3,493 \\
\hline 0 & 864 & 3,600 \\
\hline 1 & 864 & 3,698 \\
\hline 2 & 864 & 3,775 \\
\hline 3 & 864 & 3,800 \\
\hline 6 & 864 & 3,825 \\
\hline 9 & 864 & 3,880 \\
\hline 12 & 864 & 3,898 \\
\hline 15 & 864 & 3,913 \\
\hline 0 & 936 & 4,045 \\
\hline 1 & 936 & 4,145 \\
\hline 2 & 936 & 4,178 \\
\hline 3 & 936 & 4,203 \\
\hline 6 & 936 & 4,268 \\
\hline 9 & 936 & 4,318 \\
\hline 12 & 936 & 4,355 \\
\hline 15 & 936 & 4,380 \\
\hline 0 & 1008 & 4,493 \\
\hline 1 & 1008 & 4,593 \\
\hline 2 & 1008 & 4,668 \\
\hline 3 & 1008 & 4,683 \\
\hline 6 & 1008 & 4,775 \\
\hline 9 & 1008 & 4,828 \\
\hline 12 & 1008 & 4,885 \\
\hline 15 & 1008 & 4,913 \\
\hline 0 & 1080 & 5,013 \\
\hline 1 & 1080 & 5,098 \\
\hline 2 & 1080 & 5,150 \\
\hline 3 & 1080 & 5,190 \\
\hline 6 & 1080 & 5,268 \\
\hline 9 & 1080 & 5,338 \\
\hline 12 & 1080 & 5,383 \\
\hline 15 & 1080 & 5,418 \\
\hline
\end{tabular}




\begin{tabular}{|c|c|c|}
\hline tempo (min) & tensão kPa & recalque (mm) \\
\hline 0 & 1152 & 5,545 \\
\hline 1 & 1152 & 5,608 \\
\hline 2 & 1152 & 5,678 \\
\hline 3 & 1152 & 5,730 \\
\hline 6 & 1152 & 5,820 \\
\hline 9 & 1152 & 5,888 \\
\hline 12 & 1152 & 5,935 \\
\hline 15 & 1152 & 5,963 \\
\hline 0 & 1224 & 6,085 \\
\hline 1 & 1224 & 6,180 \\
\hline 2 & 1224 & 6,258 \\
\hline 3 & 1224 & 6,308 \\
\hline 6 & 1224 & 6,405 \\
\hline 9 & 1224 & 6,470 \\
\hline 12 & 1224 & 6,533 \\
\hline 15 & 1224 & 6,563 \\
\hline 0 & 1296 & 6,708 \\
\hline 1 & 1296 & 6,840 \\
\hline 2 & 1296 & 6,920 \\
\hline 3 & 1296 & 7,003 \\
\hline 6 & 1296 & 7,155 \\
\hline 9 & 1296 & 7,225 \\
\hline 12 & 1296 & 7,255 \\
\hline 15 & 1296 & 7,333 \\
\hline 0 & 1368 & 7,608 \\
\hline 1 & 1368 & 7,608 \\
\hline 2 & 1368 & 7,788 \\
\hline 3 & 1368 & 7,825 \\
\hline 6 & 1368 & 8,073 \\
\hline 9 & 1368 & 8,265 \\
\hline 12 & 1368 & 8,370 \\
\hline 15 & 1368 & 8,435 \\
\hline 0 & 666 & 8,120 \\
\hline 5 & 666 & 8,120 \\
\hline 10 & 666 & 8,120 \\
\hline 15 & 666 & 8,120 \\
\hline 0 & 313 & 7,578 \\
\hline 5 & 313 & 7,578 \\
\hline 10 & 313 & 7,578 \\
\hline 15 & 313 & 7,573 \\
\hline 0 & 0 & 6,073 \\
\hline 5 & 0 & 6,073 \\
\hline 10 & 0 & 6,073 \\
\hline 15 & 0 & 5,913 \\
\hline
\end{tabular}


Prova de carga 4 em solo compactado (malha de estacas com espaçamento de $100 \mathrm{~cm}$ )

\begin{tabular}{|c|c|c|}
\hline tempo (min) & tensão kPa & recalque (mm) \\
\hline 0 & 107 & 0,805 \\
\hline 1 & 107 & 0,843 \\
\hline 2 & 107 & 0,878 \\
\hline 4 & 107 & 0,880 \\
\hline 8 & 107 & 0,900 \\
\hline 15 & 107 & 0,903 \\
\hline 30 & 107 & 0,903 \\
\hline 0 & 215 & 1,560 \\
\hline 1 & 215 & 1,573 \\
\hline 2 & 215 & 1,583 \\
\hline 4 & 215 & 1,585 \\
\hline 8 & 215 & 1,590 \\
\hline 15 & 215 & 1,600 \\
\hline 30 & 215 & 1,600 \\
\hline 0 & 322 & 2,035 \\
\hline 1 & 322 & 2,085 \\
\hline 2 & 322 & 2,113 \\
\hline 4 & 322 & 2,148 \\
\hline 8 & 322 & 2,155 \\
\hline 15 & 322 & 2,215 \\
\hline 30 & 322 & 2,218 \\
\hline 0 & 430 & 2,700 \\
\hline 1 & 430 & 2,760 \\
\hline 2 & 430 & 2,785 \\
\hline 4 & 430 & 2,808 \\
\hline 8 & 430 & 2,843 \\
\hline 15 & 430 & 2,888 \\
\hline 30 & 430 & 2,908 \\
\hline 0 & 537 & 3,293 \\
\hline 1 & 537 & 3,350 \\
\hline 2 & 537 & 3,408 \\
\hline 4 & 537 & 3,440 \\
\hline 8 & 537 & 3,508 \\
\hline 15 & 537 & 3,540 \\
\hline 30 & 537 & 3,565 \\
\hline
\end{tabular}

\begin{tabular}{|c|c|c|}
\hline tempo (min) & tensão kPa & recalque $(\mathrm{mm})$ \\
\hline 0 & 645 & 3,920 \\
\hline 1 & 645 & 4,040 \\
\hline 2 & 645 & 4,085 \\
\hline 4 & 645 & 4,133 \\
\hline 8 & 645 & 4,185 \\
\hline 15 & 645 & 4,245 \\
\hline 30 & 645 & 4,265 \\
\hline 0 & 752 & 4,615 \\
\hline 1 & 752 & 4,760 \\
\hline 2 & 752 & 4,803 \\
\hline 4 & 752 & 4,863 \\
\hline 8 & 752 & 4,925 \\
\hline 15 & 752 & 4,985 \\
\hline 30 & 752 & 5,063 \\
\hline 60 & 752 & 5,145 \\
\hline 90 & 752 & 5,185 \\
\hline 0 & 806 & 5,270 \\
\hline 1 & 806 & 5,298 \\
\hline 2 & 806 & 5,310 \\
\hline 3 & 806 & 5,323 \\
\hline 6 & 806 & 5,350 \\
\hline 9 & 806 & 5,385 \\
\hline 12 & 806 & 5,398 \\
\hline 15 & 806 & 5,415 \\
\hline 0 & 860 & 5,513 \\
\hline 1 & 860 & 5,568 \\
\hline 2 & 860 & 5,613 \\
\hline 3 & 860 & 5,638 \\
\hline 6 & 860 & 5,745 \\
\hline 9 & 860 & 5,768 \\
\hline 12 & 860 & 5,795 \\
\hline 15 & 860 & 5,805 \\
\hline 0 & 914 & 5,915 \\
\hline 1 & 914 & 5,953 \\
\hline 2 & 914 & 5,953 \\
\hline 3 & 914 & 5,983 \\
\hline 6 & 914 & 6,033 \\
\hline 9 & 914 & 6,080 \\
\hline 12 & 914 & 6,110 \\
\hline 15 & 914 & 6,143 \\
\hline
\end{tabular}




\begin{tabular}{|c|c|c|}
\hline tempo (min) & tensão kPa & recalque (mm) \\
\hline 0 & 967 & 6,245 \\
\hline 1 & 967 & 6,320 \\
\hline 2 & 967 & 6,398 \\
\hline 3 & 967 & 6,423 \\
\hline 6 & 967 & 6,470 \\
\hline 9 & 967 & 6,498 \\
\hline 12 & 967 & 6,525 \\
\hline 15 & 967 & 6,548 \\
\hline 0 & 1021 & 6,645 \\
\hline 1 & 1021 & 6,720 \\
\hline 2 & 1021 & 6,788 \\
\hline 3 & 1021 & 6,798 \\
\hline 6 & 1021 & 6,853 \\
\hline 9 & 1021 & 6,925 \\
\hline 12 & 1021 & 6,960 \\
\hline 15 & 1021 & 6,993 \\
\hline 0 & 1075 & 7,073 \\
\hline 1 & 1075 & 7,148 \\
\hline 2 & 1075 & 7,243 \\
\hline 3 & 1075 & 7,243 \\
\hline 6 & 1075 & 7,340 \\
\hline 9 & 1075 & 7,413 \\
\hline 12 & 1075 & 7,463 \\
\hline 15 & 1075 & 7,493 \\
\hline 0 & 1129 & 7,595 \\
\hline 1 & 1129 & 7,700 \\
\hline 2 & 1129 & 7,735 \\
\hline 3 & 1129 & 7,765 \\
\hline 6 & 1129 & 7,858 \\
\hline 9 & 1129 & 7,915 \\
\hline 12 & 1129 & 7,950 \\
\hline 15 & 1129 & 7,995 \\
\hline 0 & 1182 & 8,130 \\
\hline 1 & 1182 & 8,130 \\
\hline 2 & 1182 & 8,130 \\
\hline 3 & 1182 & 8,188 \\
\hline 6 & 1182 & 8,278 \\
\hline 9 & 1182 & 8,318 \\
\hline 12 & 1182 & 8,400 \\
\hline 15 & 1182 & 8,468 \\
\hline 0 & 1236 & 8,505 \\
\hline 1 & 1236 & 8,530 \\
\hline 2 & 1236 & 8,610 \\
\hline 3 & 1236 & 8,693 \\
\hline 6 & 1236 & 8,735 \\
\hline 9 & 1236 & 8,795 \\
\hline 12 & 1236 & 8,833 \\
\hline 15 & 1236 & 8,850 \\
\hline
\end{tabular}

\begin{tabular}{|c|c|c|}
\hline tempo (min) & tensão kPa & recalque (mm) \\
\hline 0 & 1290 & 8,953 \\
\hline 1 & 1290 & 8,995 \\
\hline 2 & 1290 & 9,048 \\
\hline 3 & 1290 & 9,108 \\
\hline 6 & 1290 & 9,203 \\
\hline 9 & 1290 & 9,253 \\
\hline 12 & 1290 & 9,298 \\
\hline 15 & 1290 & 9,375 \\
\hline 0 & 1344 & 9,515 \\
\hline 1 & 1344 & 9,603 \\
\hline 2 & 1344 & 9,623 \\
\hline 3 & 1344 & 9,660 \\
\hline 6 & 1344 & 9,718 \\
\hline 9 & 1344 & 9,768 \\
\hline 12 & 1344 & 9,800 \\
\hline 15 & 1344 & 9,825 \\
\hline 0 & 1397 & 9,913 \\
\hline 1 & 1397 & 9,940 \\
\hline 2 & 1397 & 9,968 \\
\hline 3 & 1397 & 10,018 \\
\hline 6 & 1397 & 10,090 \\
\hline 9 & 1397 & 10,120 \\
\hline 12 & 1397 & 10,153 \\
\hline 15 & 1397 & 10,208 \\
\hline 0 & 1451 & 10,313 \\
\hline 1 & 1451 & 10,355 \\
\hline 2 & 1451 & 10,433 \\
\hline 3 & 1451 & 10,487 \\
\hline 6 & 1451 & 10,547 \\
\hline 9 & 1451 & 10,607 \\
\hline 12 & 1451 & 10,667 \\
\hline 15 & 1451 & 10,727 \\
\hline 0 & 497 & 8,820 \\
\hline 5 & 497 & 8,820 \\
\hline 10 & 497 & 8,820 \\
\hline 15 & 497 & 8,820 \\
\hline 0 & 362 & 8,763 \\
\hline 5 & 362 & 8,763 \\
\hline 10 & 362 & 8,763 \\
\hline 15 & 362 & 8,763 \\
\hline 0 & 0 & 5,898 \\
\hline 5 & 0 & 5,898 \\
\hline 10 & 0 & 5,898 \\
\hline 15 & 0 & 5,898 \\
\hline
\end{tabular}


Prova de carga 5 em solo compactado (malha de estacas com espaçamento de $90 \mathrm{~cm}$ )

\begin{tabular}{|c|c|c|}
\hline tempo (min) & tensão kPa & recalque $(\mathrm{mm})$ \\
\hline 0 & 119 & 0,827 \\
\hline 1 & 119 & 0,830 \\
\hline 2 & 119 & 0,830 \\
\hline 4 & 119 & 0,830 \\
\hline 8 & 119 & 0,830 \\
\hline 15 & 119 & 0,860 \\
\hline 30 & 119 & 0,887 \\
\hline 0 & 239 & 1,403 \\
\hline 1 & 239 & 1,453 \\
\hline 2 & 239 & 1,467 \\
\hline 4 & 239 & 1,483 \\
\hline 8 & 239 & 1,507 \\
\hline 15 & 239 & 1,523 \\
\hline 30 & 239 & 1,523 \\
\hline 0 & 358 & 1,930 \\
\hline 1 & 358 & 2,017 \\
\hline 2 & 358 & 2,023 \\
\hline 4 & 358 & 2,033 \\
\hline 8 & 358 & 2,070 \\
\hline 15 & 358 & 2,143 \\
\hline 30 & 358 & 2,143 \\
\hline 0 & 478 & 2,370 \\
\hline 1 & 478 & 2,433 \\
\hline 2 & 478 & 2,460 \\
\hline 4 & 478 & 2,483 \\
\hline 8 & 478 & 2,547 \\
\hline 15 & 478 & 2,620 \\
\hline 30 & 478 & 2,600 \\
\hline 0 & 597 & 2,780 \\
\hline 1 & 597 & 2,903 \\
\hline 2 & 597 & 2,910 \\
\hline 4 & 597 & 2,927 \\
\hline 8 & 597 & 2,987 \\
\hline 15 & 597 & 3,027 \\
\hline 30 & 597 & 3,043 \\
\hline 0 & 717 & 3,283 \\
\hline 1 & 717 & 3,390 \\
\hline 2 & 717 & 3,420 \\
\hline 4 & 717 & 3,450 \\
\hline 8 & 717 & 3,483 \\
\hline 15 & 717 & 3,533 \\
\hline 30 & 717 & 3,567 \\
\hline
\end{tabular}

\begin{tabular}{|c|c|c|}
\hline tempo (min) & tensão kPa & recalque $(\mathrm{mm})$ \\
\hline 0 & 776 & 3,647 \\
\hline 1 & 776 & 3,680 \\
\hline 2 & 776 & 3,717 \\
\hline 3 & 776 & 3,730 \\
\hline 6 & 776 & 3,750 \\
\hline 9 & 776 & 3,787 \\
\hline 12 & 776 & 3,787 \\
\hline 15 & 776 & 3,790 \\
\hline 0 & 836 & 3,883 \\
\hline 1 & 836 & 3,900 \\
\hline 2 & 836 & 3,950 \\
\hline 3 & 836 & 3,983 \\
\hline 6 & 836 & 4,020 \\
\hline 9 & 836 & 4,033 \\
\hline 12 & 836 & 4,057 \\
\hline 15 & 836 & 4,063 \\
\hline 0 & 896 & 4,117 \\
\hline 1 & 896 & 4,173 \\
\hline 2 & 896 & 4,193 \\
\hline 3 & 896 & 4,217 \\
\hline 6 & 896 & 4,240 \\
\hline 9 & 896 & 4,290 \\
\hline 12 & 896 & 4,303 \\
\hline 15 & 896 & 4,317 \\
\hline 0 & 955 & 4,373 \\
\hline 1 & 955 & 4,443 \\
\hline 2 & 955 & 4,447 \\
\hline 3 & 955 & 4,487 \\
\hline 6 & 955 & 4,540 \\
\hline 9 & 955 & 4,647 \\
\hline 12 & 955 & 4,647 \\
\hline 15 & 955 & 4,647 \\
\hline 0 & 1015 & 4,703 \\
\hline 1 & 1015 & 4,740 \\
\hline 2 & 1015 & 4,777 \\
\hline 3 & 1015 & 4,790 \\
\hline 6 & 1015 & 4,863 \\
\hline 9 & 1015 & 4,877 \\
\hline 12 & 1015 & 4,920 \\
\hline 15 & 1015 & 4,927 \\
\hline
\end{tabular}




\begin{tabular}{|c|c|c|}
\hline tempo (min) & tensão kPa & recalque (mm) \\
\hline 0 & 1075 & 4,973 \\
\hline 1 & 1075 & 5,037 \\
\hline 2 & 1075 & 5,060 \\
\hline 3 & 1075 & 5,090 \\
\hline 6 & 1075 & 5,110 \\
\hline 9 & 1075 & 5,117 \\
\hline 12 & 1075 & 5,123 \\
\hline 15 & 1075 & 5,190 \\
\hline 0 & 1135 & 5,233 \\
\hline 1 & 1135 & 5,247 \\
\hline 2 & 1135 & 5,317 \\
\hline 3 & 1135 & 5,327 \\
\hline 6 & 1135 & 5,387 \\
\hline 9 & 1135 & 5,427 \\
\hline 12 & 1135 & 5,467 \\
\hline 15 & 1135 & 5,467 \\
\hline 0 & 1194 & 5,563 \\
\hline 1 & 1194 & 5,620 \\
\hline 2 & 1194 & 5,657 \\
\hline 3 & 1194 & 5,693 \\
\hline 6 & 1194 & 5,717 \\
\hline 9 & 1194 & 5,750 \\
\hline 12 & 1194 & 5,777 \\
\hline 15 & 1194 & 5,797 \\
\hline 0 & 1254 & 5,850 \\
\hline 1 & 1254 & 5,917 \\
\hline 2 & 1254 & 5,940 \\
\hline 3 & 1254 & 5,987 \\
\hline 6 & 1254 & 6,050 \\
\hline 9 & 1254 & 6,107 \\
\hline 12 & 1254 & 6,150 \\
\hline 15 & 1254 & 6,150 \\
\hline 0 & 1314 & 6,207 \\
\hline 1 & 1314 & 6,273 \\
\hline 2 & 1314 & 6,300 \\
\hline 3 & 1314 & 6,340 \\
\hline 6 & 1314 & 6,437 \\
\hline 9 & 1314 & 6,533 \\
\hline 12 & 1314 & 6,533 \\
\hline 15 & 1314 & 6,567 \\
\hline
\end{tabular}

\begin{tabular}{|c|c|c|}
\hline tempo (min) & tensão kPa & recalque (mm) \\
\hline 0 & 1373 & 6,583 \\
\hline 1 & 1373 & 6,620 \\
\hline 2 & 1373 & 6,640 \\
\hline 3 & 1373 & 6,670 \\
\hline 6 & 1373 & 6,750 \\
\hline 9 & 1373 & 6,760 \\
\hline 12 & 1373 & 6,770 \\
\hline 15 & 1373 & 6,783 \\
\hline 0 & 1433 & 6,850 \\
\hline 1 & 1433 & 6,897 \\
\hline 2 & 1433 & 6,910 \\
\hline 3 & 1433 & 6,970 \\
\hline 6 & 1433 & 6,997 \\
\hline 9 & 1433 & 7,063 \\
\hline 12 & 1433 & 7,093 \\
\hline 15 & 1433 & 7,117 \\
\hline 0 & 1075 & 6,980 \\
\hline 5 & 1075 & 6,963 \\
\hline 10 & 1075 & 6,963 \\
\hline 15 & 1075 & 6,963 \\
\hline 0 & 717 & 6,817 \\
\hline 5 & 717 & 6,790 \\
\hline 10 & 717 & 6,790 \\
\hline 15 & 717 & 6,790 \\
\hline 0 & 358 & 6,383 \\
\hline 5 & 358 & 6,363 \\
\hline 10 & 358 & 6,363 \\
\hline 15 & 358 & 6,363 \\
\hline 0 & 0 & 4,907 \\
\hline 5 & 0 & 4,870 \\
\hline 10 & 0 & 4,870 \\
\hline 15 & 0 & 4,870 \\
\hline
\end{tabular}


Prova de carga 6 em solo compactado (malha de estacas com espaçamento de $90 \mathrm{~cm}$ )

\begin{tabular}{|c|c|c|}
\hline tempo (min) & tensão kPa & recalque $(\mathrm{mm})$ \\
\hline 0 & 119 & 0,307 \\
\hline 1 & 119 & 0,310 \\
\hline 2 & 119 & 0,310 \\
\hline 4 & 119 & 0,337 \\
\hline 8 & 119 & 0,343 \\
\hline 15 & 119 & 0,350 \\
\hline 30 & 119 & 0,353 \\
\hline 0 & 239 & 0,907 \\
\hline 1 & 239 & 0,933 \\
\hline 2 & 239 & 0,963 \\
\hline 4 & 239 & 0,963 \\
\hline 8 & 239 & 1,000 \\
\hline 15 & 239 & 1,000 \\
\hline 30 & 239 & 1,000 \\
\hline 0 & 358 & 1,417 \\
\hline 1 & 358 & 1,460 \\
\hline 2 & 358 & 1,460 \\
\hline 4 & 358 & 1,503 \\
\hline 8 & 358 & 1,507 \\
\hline 15 & 358 & 1,513 \\
\hline 30 & 358 & 1,523 \\
\hline 0 & 478 & 1,943 \\
\hline 1 & 478 & 2,020 \\
\hline 2 & 478 & 2,023 \\
\hline 4 & 478 & 2,070 \\
\hline 8 & 478 & 2,077 \\
\hline 15 & 478 & 2,083 \\
\hline 30 & 478 & 2,110 \\
\hline 0 & 597 & 2,407 \\
\hline 1 & 597 & 2,500 \\
\hline 2 & 597 & 2,530 \\
\hline 4 & 597 & 2,563 \\
\hline 8 & 597 & 2,643 \\
\hline 15 & 597 & 2,657 \\
\hline 30 & 597 & 2,677 \\
\hline 0 & 717 & 2,980 \\
\hline 1 & 717 & 3,087 \\
\hline 2 & 717 & 3,103 \\
\hline 4 & 717 & 3,133 \\
\hline 8 & 717 & 3,263 \\
\hline 15 & 717 & 3,310 \\
\hline 30 & 717 & 3,323 \\
\hline
\end{tabular}

\begin{tabular}{|c|c|c|}
\hline tempo (min) & tensão kPa & recalque $(\mathrm{mm})$ \\
\hline 0 & 776 & 3,397 \\
\hline 1 & 776 & 3,453 \\
\hline 2 & 776 & 3,463 \\
\hline 3 & 776 & 3,490 \\
\hline 6 & 776 & 3,520 \\
\hline 9 & 776 & 3,533 \\
\hline 12 & 776 & 3,547 \\
\hline 15 & 776 & 3,547 \\
\hline 0 & 836 & 3,653 \\
\hline 1 & 836 & 3,747 \\
\hline 2 & 836 & 3,763 \\
\hline 3 & 836 & 3,767 \\
\hline 6 & 836 & 3,797 \\
\hline 9 & 836 & 3,840 \\
\hline 12 & 836 & 3,870 \\
\hline 15 & 836 & 3,880 \\
\hline 0 & 896 & 3,937 \\
\hline 1 & 896 & 4,027 \\
\hline 2 & 896 & 4,043 \\
\hline 3 & 896 & 4,050 \\
\hline 6 & 896 & 4,140 \\
\hline 9 & 896 & 4,150 \\
\hline 12 & 896 & 4,153 \\
\hline 15 & 896 & 4,197 \\
\hline 0 & 955 & 4,277 \\
\hline 1 & 955 & 4,320 \\
\hline 2 & 955 & 4,350 \\
\hline 3 & 955 & 4,397 \\
\hline 6 & 955 & 4,427 \\
\hline 9 & 955 & 4,473 \\
\hline 12 & 955 & 4,523 \\
\hline 15 & 955 & 4,523 \\
\hline 0 & 1015 & 4,583 \\
\hline 1 & 1015 & 4,650 \\
\hline 2 & 1015 & 4,663 \\
\hline 3 & 1015 & 4,763 \\
\hline 6 & 1015 & 4,783 \\
\hline 9 & 1015 & 4,827 \\
\hline 12 & 1015 & 4,837 \\
\hline 15 & 1015 & 4,853 \\
\hline
\end{tabular}




\begin{tabular}{|c|c|c|}
\hline tempo (min) & tensão kPa & recalque $(\mathrm{mm})$ \\
\hline 0 & 1075 & \begin{tabular}{|l|}
4,927 \\
\end{tabular} \\
\hline 1 & 1075 & 5,007 \\
\hline 2 & 1075 & 5,020 \\
\hline 3 & 1075 & 5,047 \\
\hline 6 & 1075 & 5,087 \\
\hline 9 & 1075 & 5,133 \\
\hline 12 & 1075 & 5,163 \\
\hline 15 & 1075 & 5,173 \\
\hline 0 & 1135 & 5,250 \\
\hline 1 & 1135 & $\overline{5,303}$ \\
\hline 2 & 1135 & 5,310 \\
\hline 3 & 1135 & 5,337 \\
\hline 6 & 1135 & 5,393 \\
\hline 9 & 1135 & 5,457 \\
\hline 12 & 1135 & 5,490 \\
\hline 15 & 1135 & 5,493 \\
\hline 0 & 1194 & 5,567 \\
\hline 1 & 1194 & 5,613 \\
\hline 2 & 1194 & 5,637 \\
\hline 3 & 1194 & 5,690 \\
\hline 6 & 1194 & 5,723 \\
\hline 9 & 1194 & 5,783 \\
\hline 12 & 1194 & 5,823 \\
\hline 15 & 1194 & 5,840 \\
\hline 0 & 1254 & 5,897 \\
\hline 1 & 1254 & 5,987 \\
\hline 2 & 1254 & 6,030 \\
\hline 3 & 1254 & 6,050 \\
\hline 6 & 1254 & 6,080 \\
\hline 9 & 1254 & 6,153 \\
\hline 12 & 1254 & 6,183 \\
\hline 15 & 1254 & 6,193 \\
\hline 0 & 1314 & 6,440 \\
\hline 1 & 1314 & 6,440 \\
\hline 2 & 1314 & 6,440 \\
\hline 3 & 1314 & 6,477 \\
\hline 6 & 1314 & 6,527 \\
\hline 9 & 1314 & 6,587 \\
\hline 12 & 1314 & 6,620 \\
\hline 15 & 1314 & 6,637 \\
\hline
\end{tabular}

\begin{tabular}{|c|c|c|}
\hline tempo (min) & tensão kPa & recalque $(\mathrm{mm})$ \\
\hline 0 & 1373 & 6,733 \\
\hline 1 & 1373 & 6,793 \\
\hline 2 & 1373 & 6,813 \\
\hline 3 & 1373 & 6,870 \\
\hline 6 & 1373 & 6,903 \\
\hline 9 & 1373 & 6,953 \\
\hline 12 & 1373 & 6,977 \\
\hline 15 & 1373 & 6,983 \\
\hline 0 & 1433 & 7,123 \\
\hline 1 & 1433 & 7,147 \\
\hline 2 & 1433 & 7,183 \\
\hline 3 & 1433 & 7,217 \\
\hline 6 & 1433 & 7,280 \\
\hline 9 & 1433 & 7,340 \\
\hline 12 & 1433 & 7,410 \\
\hline 15 & 1433 & 7,427 \\
\hline 0 & 1493 & 7,513 \\
\hline 1 & 1493 & 7,560 \\
\hline 2 & 1493 & 7,567 \\
\hline 3 & 1493 & 7,587 \\
\hline 6 & 1493 & 7,707 \\
\hline 9 & 1493 & 7,743 \\
\hline 12 & 1493 & 7,813 \\
\hline 15 & 1493 & 7,827 \\
\hline 0 & 1553 & 7,930 \\
\hline 1 & 1553 & 7,930 \\
\hline 2 & 1553 & 7,970 \\
\hline 3 & 1553 & 7,990 \\
\hline 6 & 1553 & 8,097 \\
\hline 9 & 1553 & 8,163 \\
\hline 12 & 1553 & 8,210 \\
\hline 15 & 1553 & 8,213 \\
\hline 0 & 1164 & 8,063 \\
\hline 5 & 1164 & 8,063 \\
\hline 10 & 1164 & 8,063 \\
\hline 15 & 1164 & 8,063 \\
\hline 0 & 779 & 7,703 \\
\hline 5 & 779 & 7,650 \\
\hline 10 & 779 & 7,650 \\
\hline 15 & 779 & 7,650 \\
\hline 0 & 388 & 7,233 \\
\hline 5 & 388 & 7,233 \\
\hline 10 & 388 & 7,233 \\
\hline 15 & 388 & 7,233 \\
\hline 0 & 0 & 5,160 \\
\hline 5 & 0 & 5,160 \\
\hline 10 & 0 & 5,123 \\
\hline 15 & 0 & 5,117 \\
\hline
\end{tabular}


Prova de carga 7 em solo compactado (malha de estacas com espaçamento de $80 \mathrm{~cm}$ )

\begin{tabular}{|c|c|c|}
\hline tempo (min) & tensão kPa & recalque $(\mathrm{mm})$ \\
\hline 0 & 119 & 0,428 \\
\hline 1 & 119 & 0,458 \\
\hline 2 & 119 & 0,475 \\
\hline 4 & 119 & 0,488 \\
\hline 8 & 119 & 0,510 \\
\hline 15 & 119 & 0,518 \\
\hline 30 & 119 & 0,518 \\
\hline 0 & 239 & 1,235 \\
\hline 1 & 239 & 1,318 \\
\hline 2 & 239 & 1,325 \\
\hline 4 & 239 & 1,340 \\
\hline 8 & 239 & 1,358 \\
\hline 15 & 239 & 1,398 \\
\hline 30 & 239 & 1,425 \\
\hline 0 & 358 & 1,923 \\
\hline 1 & 358 & 2,025 \\
\hline 2 & 358 & 2,063 \\
\hline 4 & 358 & 2,110 \\
\hline 8 & 358 & 2,138 \\
\hline 15 & 358 & 2,168 \\
\hline 30 & 358 & 2,185 \\
\hline 0 & 478 & 2,625 \\
\hline 1 & 478 & 2,680 \\
\hline 2 & 478 & 2,735 \\
\hline 4 & 478 & 2,815 \\
\hline 8 & 478 & 2,860 \\
\hline 15 & 478 & 2,900 \\
\hline 30 & 478 & 2,933 \\
\hline 0 & 597 & 3,293 \\
\hline 1 & 597 & 3,428 \\
\hline 2 & 597 & 3,475 \\
\hline 4 & 597 & 3,513 \\
\hline 8 & 597 & 3,560 \\
\hline 15 & 597 & 3,608 \\
\hline 30 & 597 & 3,683 \\
\hline 60 & 597 & 3,708 \\
\hline 0 & 717 & 3,970 \\
\hline 1 & 717 & 4,123 \\
\hline 2 & 717 & 4,158 \\
\hline 4 & 717 & 4,198 \\
\hline 8 & 717 & 4,245 \\
\hline 15 & 717 & 4,298 \\
\hline 30 & 717 & 4,375 \\
\hline 60 & 717 & 4,410 \\
\hline
\end{tabular}

\begin{tabular}{|c|c|c|}
\hline tempo (min) & tensão kPa & recalque (mm) \\
\hline 0 & 776 & 4,498 \\
\hline 1 & 776 & 4,523 \\
\hline 2 & 776 & 4,550 \\
\hline 3 & 776 & 4,560 \\
\hline 6 & 776 & 4,600 \\
\hline 9 & 776 & 4,618 \\
\hline 12 & 776 & 4,633 \\
\hline 15 & 776 & 4,650 \\
\hline 0 & 836 & 4,738 \\
\hline 1 & 836 & 4,795 \\
\hline 2 & 836 & 4,820 \\
\hline 3 & 836 & 4,858 \\
\hline 6 & 836 & 4,890 \\
\hline 9 & 836 & 4,925 \\
\hline 12 & 836 & 4,945 \\
\hline 15 & 836 & 4,958 \\
\hline 0 & 896 & 5,040 \\
\hline 1 & 896 & 5,113 \\
\hline 2 & 896 & 5,135 \\
\hline 3 & 896 & 5,173 \\
\hline 6 & 896 & 5,203 \\
\hline 9 & 896 & 5,245 \\
\hline 12 & 896 & 5,280 \\
\hline 15 & 896 & 5,285 \\
\hline 0 & 955 & 5,388 \\
\hline 1 & 955 & 5,433 \\
\hline 2 & 955 & 5,465 \\
\hline 3 & 955 & 5,490 \\
\hline 6 & 955 & 5,538 \\
\hline 9 & 955 & 5,605 \\
\hline 12 & 955 & 5,598 \\
\hline 15 & 955 & 5,620 \\
\hline 0 & 1015 & 5,690 \\
\hline 1 & 1015 & 5,738 \\
\hline 2 & 1015 & 5,775 \\
\hline 3 & 1015 & 5,800 \\
\hline 6 & 1015 & 5,853 \\
\hline 9 & 1015 & 5,893 \\
\hline 12 & 1015 & 5,918 \\
\hline 15 & 1015 & 5,958 \\
\hline
\end{tabular}




\begin{tabular}{|c|c|c|}
\hline tempo (min) & tensão kPa & recalque (mm) \\
\hline 0 & 1075 & 6,025 \\
\hline 1 & 1075 & 6,055 \\
\hline 2 & 1075 & 6,110 \\
\hline 3 & 1075 & 6,128 \\
\hline 6 & 1075 & 6,190 \\
\hline 9 & 1075 & 6,220 \\
\hline 12 & 1075 & 6,260 \\
\hline 15 & 1075 & 6,280 \\
\hline 0 & 1135 & 6,345 \\
\hline 1 & 1135 & 6,388 \\
\hline 2 & 1135 & 6,438 \\
\hline 3 & 1135 & 6,488 \\
\hline 6 & 1135 & 6,525 \\
\hline 9 & 1135 & 6,568 \\
\hline 12 & 1135 & 6,595 \\
\hline 15 & 1135 & 6,605 \\
\hline 0 & 1194 & 6,668 \\
\hline 1 & 1194 & 6,728 \\
\hline 2 & 1194 & 6,768 \\
\hline 3 & 1194 & 6,795 \\
\hline 6 & 1194 & 6,838 \\
\hline 9 & 1194 & 6,890 \\
\hline 12 & 1194 & 6,908 \\
\hline 15 & 1194 & 6,938 \\
\hline 0 & 1254 & 6,993 \\
\hline 1 & 1254 & 7,043 \\
\hline 2 & 1254 & 7,073 \\
\hline 3 & 1254 & 7,110 \\
\hline 6 & 1254 & 7,160 \\
\hline 9 & 1254 & 7,223 \\
\hline 12 & 1254 & 7,250 \\
\hline 15 & 1254 & 7,270 \\
\hline 0 & 1314 & 7,328 \\
\hline 1 & 1314 & 7,378 \\
\hline 2 & 1314 & 7,415 \\
\hline 3 & 1314 & 7,455 \\
\hline 6 & 1314 & 7,503 \\
\hline 9 & 1314 & 7,543 \\
\hline 12 & 1314 & 7,575 \\
\hline 15 & 1314 & 7,605 \\
\hline
\end{tabular}

\begin{tabular}{|c|c|c|}
\hline tempo (min) & tensão $\mathrm{kPa}$ & recalque $(\mathrm{mm})$ \\
\hline 0 & 1373 & 7,685 \\
\hline 1 & 1373 & 7,710 \\
\hline 2 & 1373 & 7,730 \\
\hline 3 & 1373 & 7,765 \\
\hline 6 & 1373 & 7,823 \\
\hline 9 & 1373 & 7,870 \\
\hline 12 & 1373 & 7,913 \\
\hline 15 & 1373 & 7,920 \\
\hline 0 & 1433 & 7,945 \\
\hline 1 & 1433 & 7,975 \\
\hline 2 & 1433 & 7,975 \\
\hline 3 & 1433 & 8,005 \\
\hline 6 & 1433 & 8,093 \\
\hline 9 & 1433 & 8,115 \\
\hline 12 & 1433 & 8,143 \\
\hline 15 & 1433 & 8,168 \\
\hline 0 & 1493 & 8,235 \\
\hline 1 & 1493 & 8,255 \\
\hline 2 & 1493 & 8,285 \\
\hline 3 & 1493 & 8,318 \\
\hline 6 & 1493 & 8,388 \\
\hline$\overline{9}$ & 1493 & 8,438 \\
\hline 12 & 1493 & 8,470 \\
\hline 15 & 1493 & 8,498 \\
\hline 0 & 1553 & 8,560 \\
\hline 1 & 1553 & 8,585 \\
\hline 2 & 1553 & 8,610 \\
\hline 3 & 1553 & 8,638 \\
\hline 6 & 1553 & 8,713 \\
\hline 9 & 1553 & 8,745 \\
\hline 12 & 1553 & 8,523 \\
\hline 15 & 1553 & 8,800 \\
\hline 0 & 1164 & 8,515 \\
\hline 5 & 1164 & 8,515 \\
\hline 10 & 1164 & 8,515 \\
\hline 15 & 1164 & 8,515 \\
\hline 0 & 776 & 8,333 \\
\hline 5 & 776 & 8,333 \\
\hline 10 & 776 & 8,333 \\
\hline 15 & 776 & 8,328 \\
\hline 0 & 388 & 7,895 \\
\hline 5 & 388 & 7,895 \\
\hline 10 & 388 & 7,895 \\
\hline 15 & 388 & 7,885 \\
\hline 0 & 0 & 6,253 \\
\hline 5 & 0 & 6,253 \\
\hline 10 & 0 & 6,253 \\
\hline 15 & 0 & 6,223 \\
\hline
\end{tabular}


Prova de carga 8 em solo compactado (malha de estacas com espaçamento de $80 \mathrm{~cm}$ )

\begin{tabular}{|c|c|c|}
\hline tempo (min) & tensão kPa & recalque $(\mathrm{mm})$ \\
\hline 0 & 119 & 0,100 \\
\hline 1 & 119 & 0,110 \\
\hline 2 & 119 & 0,110 \\
\hline 4 & 119 & 0,160 \\
\hline 8 & 119 & 0,170 \\
\hline 15 & 119 & 0,170 \\
\hline 30 & 119 & 0,180 \\
\hline 0 & 239 & 1,050 \\
\hline 1 & 239 & 1,050 \\
\hline 2 & 239 & 1,050 \\
\hline 4 & 239 & 1,150 \\
\hline 8 & 239 & 1,190 \\
\hline 15 & 239 & 1,240 \\
\hline 30 & 239 & 1,390 \\
\hline 0 & 358 & 1,950 \\
\hline 1 & 358 & 2,110 \\
\hline 2 & 358 & 2,130 \\
\hline 4 & 358 & 2,200 \\
\hline 8 & 358 & 2,240 \\
\hline 15 & 358 & 2,250 \\
\hline 30 & 358 & 2,250 \\
\hline 0 & 478 & 2,850 \\
\hline 1 & 478 & 2,950 \\
\hline 2 & 478 & 2,970 \\
\hline 4 & 478 & 3,040 \\
\hline 8 & 478 & 3,050 \\
\hline 15 & 478 & 3,150 \\
\hline 30 & 478 & 3,150 \\
\hline 0 & 597 & 3,660 \\
\hline 1 & 597 & 3,790 \\
\hline 2 & 597 & 3,850 \\
\hline 4 & 597 & 3,890 \\
\hline 8 & 597 & 3,940 \\
\hline 15 & 597 & 3,970 \\
\hline 30 & 597 & 4,050 \\
\hline 60 & 597 & 4,090 \\
\hline 0 & 717 & 4,560 \\
\hline 1 & 717 & 4,710 \\
\hline 2 & 717 & 4,720 \\
\hline 4 & 717 & 4,760 \\
\hline 8 & 717 & 4,820 \\
\hline 15 & 717 & 4,860 \\
\hline 30 & 717 & 4,950 \\
\hline 60 & 717 & 5,000 \\
\hline
\end{tabular}

\begin{tabular}{|c|c|c|}
\hline tempo (min) & tensão kPa & recalque (mm) \\
\hline 0 & 776 & 5,130 \\
\hline 1 & 776 & 5,180 \\
\hline 2 & 776 & 5,190 \\
\hline 3 & 776 & 5,210 \\
\hline 6 & 776 & 5,260 \\
\hline 9 & 776 & 5,260 \\
\hline 12 & 776 & 5,300 \\
\hline 15 & 776 & 5,310 \\
\hline 0 & 836 & 5,440 \\
\hline 1 & 836 & 5,520 \\
\hline 2 & 836 & 5,550 \\
\hline 3 & 836 & 5,550 \\
\hline 6 & 836 & 5,630 \\
\hline 9 & 836 & 5,640 \\
\hline 12 & 836 & 5,720 \\
\hline 15 & 836 & 5,740 \\
\hline 0 & 896 & 5,860 \\
\hline 1 & 896 & 5,930 \\
\hline 2 & 896 & 5,960 \\
\hline 3 & 896 & 5,970 \\
\hline 6 & 896 & 6,050 \\
\hline 9 & 896 & 6,110 \\
\hline 12 & 896 & 6,120 \\
\hline 15 & 896 & 6,120 \\
\hline 0 & 955 & 6,240 \\
\hline 1 & 955 & 6,360 \\
\hline 2 & 955 & 6,410 \\
\hline 3 & 955 & 6,450 \\
\hline 6 & 955 & 6,560 \\
\hline 9 & 955 & 6,560 \\
\hline 12 & 955 & 6,590 \\
\hline 15 & 955 & 6,620 \\
\hline 0 & 1015 & 6,750 \\
\hline 1 & 1015 & 6,750 \\
\hline 2 & 1015 & 6,790 \\
\hline 3 & 1015 & 7,060 \\
\hline 6 & 1015 & 7,070 \\
\hline 9 & 1015 & 7,080 \\
\hline 12 & 1015 & 7,100 \\
\hline 15 & 1015 & 7,100 \\
\hline
\end{tabular}




\begin{tabular}{|c|c|c|}
\hline tempo (min) & tensão kPa & recalque (mm) \\
\hline 0 & 1075 & 7,260 \\
\hline 1 & 1075 & 7,340 \\
\hline 2 & 1075 & 7,360 \\
\hline 3 & 1075 & 7,420 \\
\hline 6 & 1075 & 7,450 \\
\hline 9 & 1075 & 7,510 \\
\hline 12 & 1075 & 7,550 \\
\hline 15 & 1075 & 7,570 \\
\hline 0 & 1135 & 7,720 \\
\hline 1 & 1135 & 7,800 \\
\hline 2 & 1135 & 7,840 \\
\hline 3 & 1135 & 7,890 \\
\hline 6 & 1135 & 7,970 \\
\hline 9 & 1135 & 8,020 \\
\hline 12 & 1135 & 8,030 \\
\hline 15 & 1135 & 8,080 \\
\hline 0 & 1194 & 8,220 \\
\hline 1 & 1194 & 8,280 \\
\hline 2 & 1194 & 8,360 \\
\hline 3 & 1194 & 8,400 \\
\hline 6 & 1194 & 8,500 \\
\hline 9 & 1194 & 8,550 \\
\hline 12 & 1194 & 8,620 \\
\hline 15 & 1194 & 8,630 \\
\hline 0 & 1254 & 8,790 \\
\hline 1 & 1254 & 8,920 \\
\hline 2 & 1254 & 8,970 \\
\hline 3 & 1254 & 9,020 \\
\hline 6 & 1254 & 9,100 \\
\hline 9 & 1254 & 9,190 \\
\hline 12 & 1254 & 9,250 \\
\hline 15 & 1254 & 9,300 \\
\hline 0 & 1314 & 9,520 \\
\hline 1 & 1314 & 9,520 \\
\hline 2 & 1314 & 9,760 \\
\hline 3 & 1314 & 9,870 \\
\hline 6 & 1314 & 9,870 \\
\hline 9 & 1314 & 9,880 \\
\hline 12 & 1314 & 9,940 \\
\hline 15 & 1314 & 9,970 \\
\hline 0 & 1373 & 10,280 \\
\hline 1 & 1373 & 10,280 \\
\hline 2 & 1373 & 10,450 \\
\hline 3 & 1373 & 10,570 \\
\hline 6 & 1373 & 10,700 \\
\hline 9 & 1373 & 11,030 \\
\hline
\end{tabular}




\section{REFERÊNCIAS}

ABELEV, M. Y. (1975). Compacting loess soils in the USSR. Geotechnique, vol. 25, n. 1, p. 79-82.

ALVES, A. M. L.; LOPES, F. R.; ARAGÃO, C. J. G. (2000). Proposta de método de projeto de fundações superficiais em solos granulares melhorados por estacas de compactação. In: $4^{\circ}$ SEMINÁRIO DE ENGENHARIA DE FUNDAÇÕES ESPECIAIS E GEOTECNIA, São Paulo, vol. 2, p. 102-112.

AOKI, N. \& CINTRA, J. C. A. (2002). Notas de aula. EESC-USP/São Carlos.

ASSOCIAÇÃO BRASILEIRA DE NORMAS TÉCNICAS (1996) . NBR 6122 Projeto e execução de fundações profundas. Rio de Janeiro, ABNT.

ASSOCIAÇÃO BRASILEIRA DE NORMAS TÉCNICAS (2001). NBR 6484 - Solo Sondagens de simples reconhecimento com SPT. Rio de Janeiro, ABNT

ASSOCIAÇÃO BRASILEIRA DE NORMAS TÉCNICAS (1996). NBR 6489 -Prova de carga direta sobre terreno de fundação, procedimento. Rio de Janeiro, ABNT

ASSOCIAÇÃO BRASILEIRA DE NORMAS TÉCNICAS (1991). MB 3406 - Solo, ensaio de penetração de cone in-situ (CPT). Rio de Janeiro, ABNT

ATKINSON, M. F. (1993). Structural foundations manual, for low-rise buildings. E \& FN SPON.

BELL, F. G. (1993). Engineering treatment of soils. Londres, E \& FN SPON.

BERGADO, D. T. et al. (1994). Improvement techniques of soft ground in subsiding and lowland environment. Roterdã, A. A. Balkema. 
BESANCON, G.; PERTUSIER, E. (1985). Soil improvement by deep vibration. In: BALASUBRAMANIAM, A. S. et al. Recent developments in ground improvement techniques. Roterdã, A. A. Balkema. Cap. 3, p. 31-38.

BOUASSIDA, M.; HADHRI, T. (1995). Extreme load of soils reiforced by columns: the case of an isolated column. Soils and Foundations, vol. 35, n. 1, p. 21-35.

BRIAUD, J. L.; GIBBENS, R. (1999). Behaviour of five large spread footings on sand. Journal of Geotechnical Geoenvironmental Engineering, ASCE, 125 (9): 787 796.

CINTRA, J. C. A. (1998). Fundações em solos colapsíveis. São Carlos, EESC.

CINTRA, J. C. A.; AOKI, N. (1999). Carga admissível em fundações profundas. São Carlos, EESC.

CONCIANI, W; BEZERRA, R. L; MEDEIROS, J. L. G. (1999). Características de Deformação de uma Areia de Praia Obtidas por Pressiômetro. Solos e Rochas, v.22, n.3, p. 207-214.

DATYE, K. R. (1985). Settlement and bearing capacity of foundation system with stone columns. Recent developments in ground improvement techniques. Roterdã, A. A. Balkema. Cap. 8, p. 85-103.

DATYE, K. R.; NAGARAJU, S. S. (1981). Design aproach and field control for stone columns, In: TENTH INTERNATIONAL CONFERENCE ON SOIL MECHANICS AND FOUNDATION ENGINEERING, Stockholm, Sweden, vol. 3, pp. 637-640.

FELLENIUS, B. H. (1975). The load of piles and new proof testing procedure. Journal of the Geothechnical Engineering Division, ASCE, v. 101, GT9, p. 855-869.

GIBBS, H.J.; HOLTZ, W. G. (1957). Research on determining the density of sands by spoon penetration testing. In: FOURTH INTERNATIONAL CONFERENCE ON SOIL MECHANICS AND FOUNDATION ENGINEERING, London, England, vol. 1, pp. 35-39. 
GLOVER, J. C. (1985). Sand compaction and stone columns by the vibroflotation process. In: BALASUBRAMANIAM, A. S. et al. Recent developments in ground improvement techniques. Roterdã, A. A. Balkema. Cap. 1, p. 3-15.

GOUGHNOUR, R. R. (1988). Discussion of "Settlement analysis of skirted granular piles”. Journal of Geotechnical Engineering, ASCE, vol. 114, n. 6, p. 727-728, jun./ paper by RAO, B. G.; RANJAN, G. (1985). Settlement analysis of skirted granular piles. Journal of Geotechnical Engineering, ASCE, vol. 111, n. 11, p. 1264-1283, nov.

GUSMÃO FILHO, J. A. (1982). Prática de fundações nas capitais nordestinas. In: VII CONGRESSO BRASILEIRO DE MECÂNICA DOS SOLOS E ENGENHARIA DE FUNDAÇÕES , Anais. Olinda, v.7, p.189-206.

GUSMÃO FILHO, J. A. (1998). Fundações: do conhecimento geológico à prática da engenharia. Recife, Editora Universitária, UFPE.

GUSMÃO, A. D. (2000a). Interação solo-estrutura em um edifício com fundação em terreno melhorado. In: SIMPÓSIO INTERAÇÃO ESTRUTURA-SOLO EM EDIFÍCIOS. São Carlos, 2000. (CD ROM). São Paulo, USP.

GUSMÃO, A. D. (2000b). Medições de recalque de um prédio em Recife. In: SIMPÓSIO INTERAÇÃO ESTRUTURA-SOLO EM EDIFÍCIOS. São Carlos, 2000. (CD ROM). São Paulo, USP.

HARDER, L. F.; HAMMOND, W. D.; ROSS, P. S. (1984). Vibroflotation compaction at thermalito afterbay. Journal of Geotechnical Engineering, ASCE, vol. 110, n. 1, p. 57-70, jan.

HUGHES, J. M. O.; WITHERS, H. J. (1974). Reiforcing of soft coesive soil with stone columns. Ground Engineering, vol. 7, p. 42-49.

MADHAV, M. R.; VITKAR, P. P. (1978). Strip footing on weak clay stabilized with a granular trench or pile. Canadian Geotechnical Journal, vol. 15, p. 605-609. 
MITCHELL, J. K. (1968). In-place treatment of foundations soils. In: SPECIALTY CONFERENCE ON PLACEMENT AND IMPROVEMENT OF SOIL TO SUPPORT STRUCTURES, USA, ASCE. Proceedings, p. 93-130.

MITCHELL, J. K. (1970). In-place treatment of foundation soils. Journal of the Soil Mechanics and Foundations Division, ASCE, vol. 96, n. SM1, p. 73-110, jan.

$\mathrm{MOH}$, Z. C. et al. Compaction sand piles for soil improvement. In: TENTH INTERNATIONAL CONFERENCE ON SOIL MECHANICS AND FOUNDATION ENGINEERING, Stockholm, Sweden, vol. 3, 1981, pp. 749752.

MONTEIRO, P. F. F. (1996). Estacas Executadas com Compactação do solo em Profundidade. In: Seminário De Engenharia de Fundações Especiais e Geotecnia III, Anais. São Paulo.

MOSELEY, M. P.; PRIEBE, H. J. (1993). Vibro techniques. In: MOSELEY, M. P., ed. Ground improvement. Glasgow, Chapman \& Hall. Cap. 1, p. 1-19.

SABHAHIT, N.; BASUDHAR, P. K.; MADHAV, M. (1997). Generalized stability analysis of embankments on granular piles. Soils and Foundations, vol. 37, n. 4, p. 13-22.

SCHMERTMANN, J. H. (1970) - Static cone to compute static settlement over sand Journal of the Soil Mechanics and Foundations Engineering - ASCE - Vol. 96 - SM.3 - pg. 1011-1043.

SCHNAID, F. (2000). Ensaios de campo e suas aplicações à engenharia de fundações. São Paulo, Oficina de Textos.

SHAHU, J. T.; MADHAV, M. R.; HAYASHI, S. (1975). Analysis of granular pile-mat system for soils with stiff crust. Geotechnique, vol. 25, n. 1, p. 1-16.

SKEMPTON, A. W. (1951). The bearing capacity of clays, proceedings, Building Research Congress, p. 180-189. 
SKEMPTON, A. W. (1986). Standard Penetration Test procedures and the effects in sands of overburden pressure, relative density, particle size, ageing and overconsolidation, in: Geotechnique, vol. 36, n. 3, p. 425-447.

SLOCOMBE, B. C. (1993). Dynamic compaction. In: MOSELEY, M. P., ed. Ground improvement. Glasgow, Chapman \& Hall. Cap. 2, p. 20-39.

SLOCOMBE, B. C.; BELL, A. L. (1985). Discussion of "Vibroflotation compaction at thermalito afterbay". Journal of Geotechnical Engineering, ASCE, vol. 111, n. 8, p. 1035-1036, ago./ paper by HARDER, L. F.; HAMMOND, W. D.; ROSS, P. S. (1984). Vibroflotation compaction at thermalito afterbay. Journal of Geotechnical Engineering, ASCE, vol. 110, n. 1, p. 57-70, jan.

SOARES, V. B. (2000). Histórico da fundações do Condomínio Residencial Torino, com vinte pavimentos, em João Pessoa - PB. In: Seminário De Engenharia de Fundações Especiais e Geotecnia IV, Anais. São Paulo, v.2, p.451-462.

TEIXEIRA, A. H. (1966). Correlação entre a capacidade de carga das argilas e resistência à penetração. In: III CONCRESSO BRASILEIRO DE MECÂNICA DOS SOLOS. Anais. Belo Horizonte, vol. 1, p.55 a 69.

TEIXEIRA, A. H. (1996). Projeto e execução de fundações. In: Seminário De Engenharia de Fundações Especiais e Geotecnia III, Anais. São Paulo, v.1, p.33-50.

TEIXEIRA, A. H.; GODOY, N. S. (1996). Análise, projeto e execução de fundações rasas. In: HACHICH, W. et al., ed. Fundações, teoria e prática. São Paulo, PINI. Cap. 7, p. 227-264.

TERZAGHI, K. and PECK, R. B. (1948). Soil mechanics in engineering practice. $2^{\text {nd }}$ edition, John Wiley \& Sons, New York.

THORBURN, S. (1975). Building structures supported by stabilized ground. Geotechnique, vol. 25, n. 1, p. 83-94.

U.S. DEPARTMENT OF TRANSPORTATION (1978). Guidelines for cone penetration test, performance and design. Washington, D.C. Jul. 
VAN IMPE, W. F. (1989). Soil improvement techniques and their evolution. Roterdã, A. A. Balkema.

VARGAS, M. (1955). Foundation of structures on over-consolidated clay layers in São Paulo. Geotechnique, 5 (3): 253 - 266.

WALLAYS, M. (1985). Deep compaction by casing drive. In: BALASUBRAMANIAM, A. S. et al. Recent developments in ground improvement techniques. Roterdã, A. A. Balkema. Cap. 4, p. 39-52. 
APÊNDICE I - Planta de locação do campo experimental.

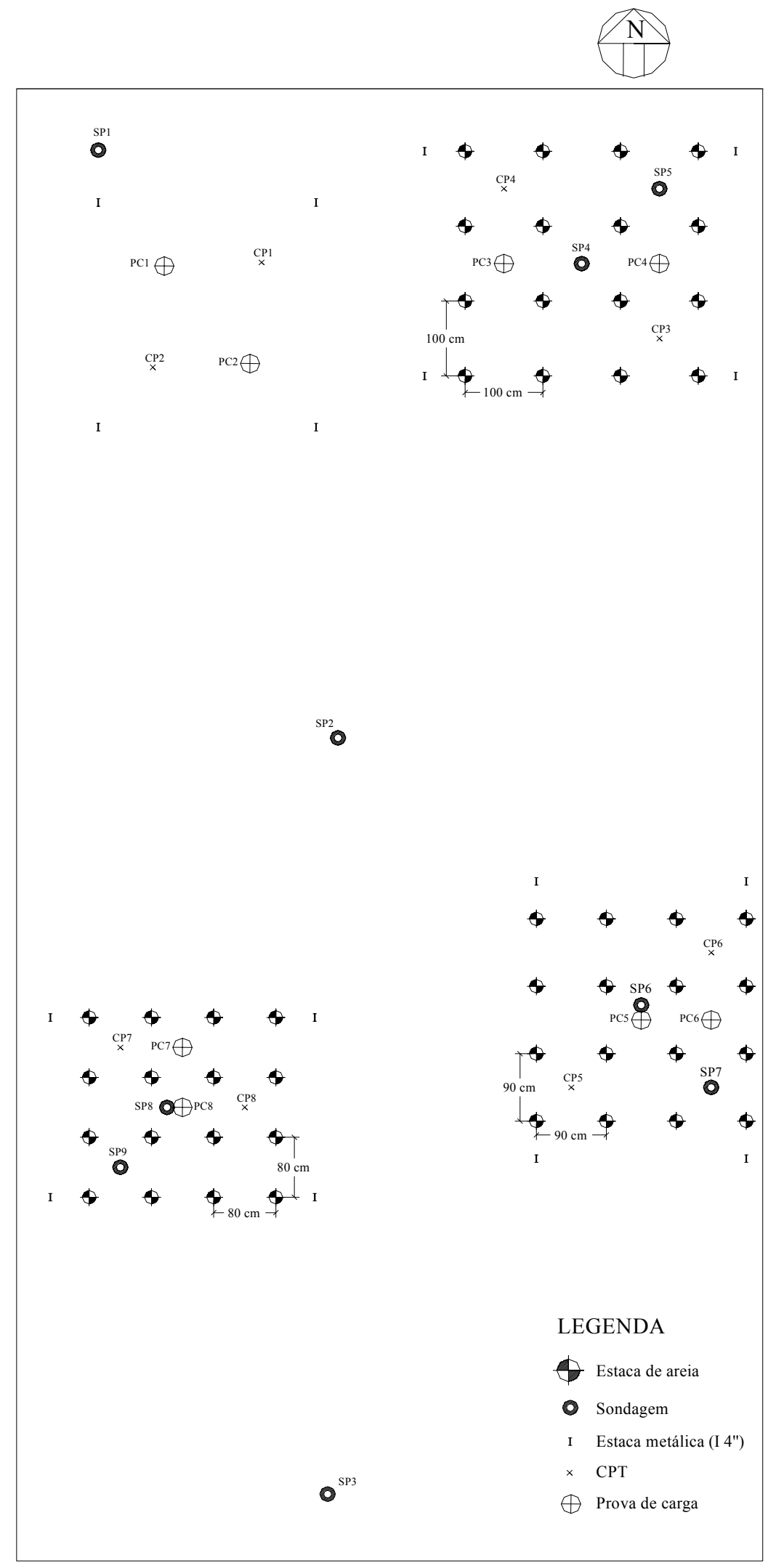

SEM ESCALA 